April 2004 • NREL/SR-560-34780

\title{
Aggregation of Distributed Generation Assets in New York State: Appendix
}

Electrotek Concepts Inc.

Arlington, Virginia

New York State Energy Research and Development Authority

Albany, New York
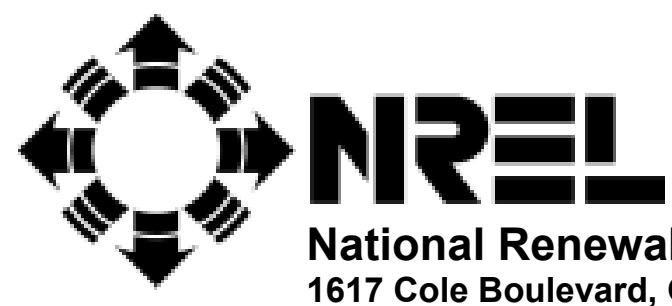

National Renewable Energy Laboratory 1617 Cole Boulevard, Golden, Colorado 80401-3393 303-275-3000 • www.nrel.gov

Operated for the U.S. Department of Energy Office of Energy Efficiency and Renewable Energy by Midwest Research Institute • Battelle 


April $2004 \quad$ NREL/SR-560-34780

Aggregation of Distributed
Generation Assets in New York
State: Appendix

Electrotek Concepts Inc.

Arlington, Virginia

New York State Energy Research and Development Authority Albany, New York

NREL Technical Monitor: H. Thomas

Prepared under Subcontract No. AAD-1-30605-08

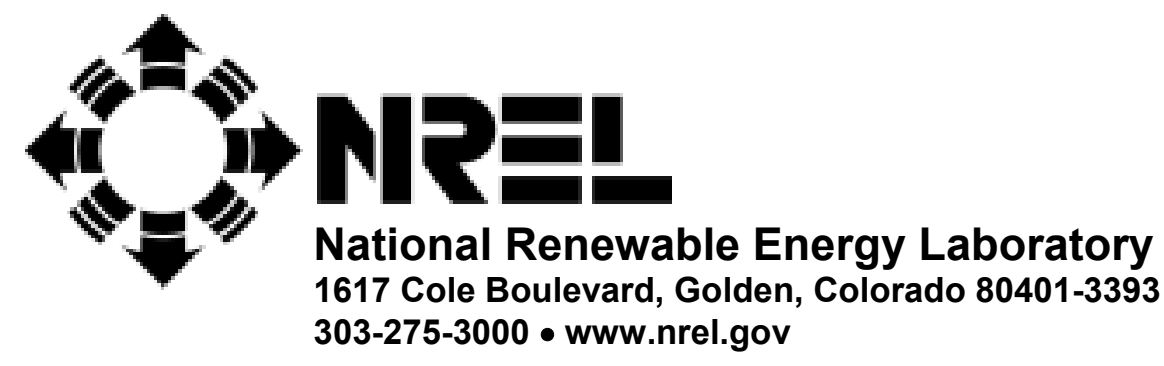

Operated for the U.S. Department of Energy

Office of Energy Efficiency and Renewable Energy

by Midwest Research Institute • Battelle

Contract No. DE-AC36-99-GO10337 


\section{NOTICE}

This report was prepared as an account of work sponsored by an agency of the United States government. Neither the United States government nor any agency thereof, nor any of their employees, makes any warranty, express or implied, or assumes any legal liability or responsibility for the accuracy, completeness, or usefulness of any information, apparatus, product, or process disclosed, or represents that its use would not infringe privately owned rights. Reference herein to any specific commercial product, process, or service by trade name, trademark, manufacturer, or otherwise does not necessarily constitute or imply its endorsement, recommendation, or favoring by the United States government or any agency thereof. The views and opinions of authors expressed herein do not necessarily state or reflect those of the United States government or any agency thereof.

Available electronically at http://www.osti.gov/bridge

Available for a processing fee to U.S. Department of Energy and its contractors, in paper, from:

U.S. Department of Energy

Office of Scientific and Technical Information

P.O. Box 62

Oak Ridge, TN 37831-0062

phone: 865.576.8401

fax: 865.576.5728

email: mailto:reports@adonis.osti.gov

Available for sale to the public, in paper, from:

U.S. Department of Commerce

National Technical Information Service

5285 Port Royal Road

Springfield, VA 22161

phone: 800.553 .6847

fax: 703.605.6900

email: orders@ntis.fedworld.gov

online ordering: http://www.ntis.gov/ordering.htm 
The full report of "Aggregation of Distributed Generation Assets in New York State" has been published in two parts. These are available at http://www.nrel.gov/publications under the following titles:

- “Aggregation of Distributed Generation Assets in New York State," NREL/SR-56034779

- "Aggregation of Distributed Generation Assets in New York State: Appendix," NREL/SR-560-34780. 


\section{Acknowledgments}

Electrotek Concepts would like to acknowledge the strong support, assistance, coordination, and cooperation of a number of individuals and organizations. The acknowledgment of particularly noteworthy contributions is due to:

- Jim Foster of the New York State Energy Research and Development Authority for his continued support and assistance in helping this project come to fruition

- Holly Thomas of the National Renewable Energy Laboratory for her support and assistance in many facets of this project

- John Charlton of the New York Independent System Operator for his time, attention, and assistance in helping formulate technical and institutional solutions

- Dave Lawrence of the New York Independent System Operator for his multifaceted roles in helping bring demand-side reduction programs into existence and particularly for his strong and effective leadership of the New York Independent System Operator Price Responsive Load Working Group. 


\section{Table of Contents}

Task 6: Field Testing of Aggregated Backup Generator Control System.................Task 6: i

Task 7: Survey of Backup Generation in New York State.......................................Task 7: i

Task 8: Design of Distributed Generation Aggregation System for Commercial

Demonstration ....................................................................................... 
Task 6: Field Testing of Aggregated Backup Generator Control System

Task 6 


\section{Acronyms}

$\begin{array}{ll}\text { DA } & \text { day-ahead } \\ \text { DAM } & \text { day-ahead market } \\ \text { DADRP } & \begin{array}{l}\text { Day-Ahead Demand Response Program } \\ \text { distributed generation }\end{array} \\ \text { DG } & \text { Generating Availability Data System } \\ \text { GADS } & \text { Installed Capacity } \\ \text { ICAP } & \text { Inter Control Center Communications Protocol } \\ \text { ICCP } & \text { Long Island Power Authority } \\ \text { LIPA } & \text { locational-based marginal price } \\ \text { LBMP } & \text { New York Independent System Operator } \\ \text { NYISO } & \text { Open Access Same-Time Information System } \\ \text { OASIS } & \text { system resource } \\ \text { SR } & \text { unforced capacity } \\ \text { UCAP } & \end{array}$

Task 6 


\section{Table of Contents}

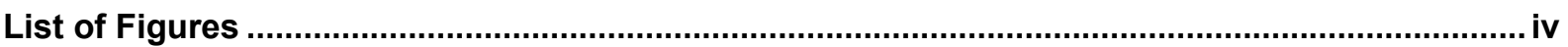

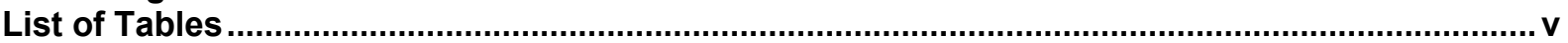

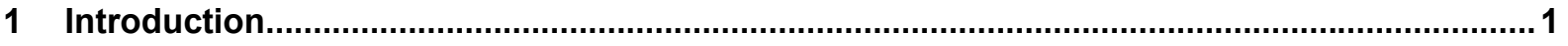

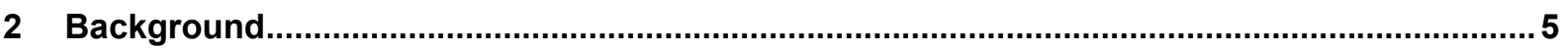

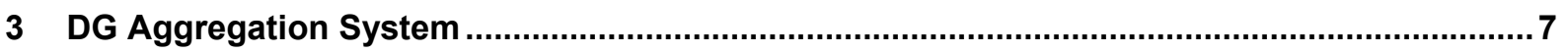

3.1 Data Collection and Management Center ....................................................... 8

3.2 Aggregation and Dispatch Center ..................................................................... 8

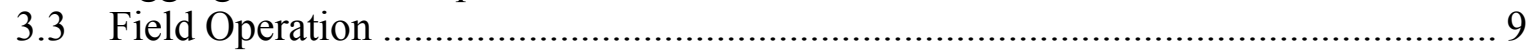

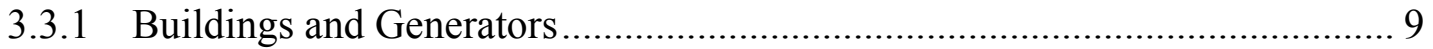

3.3.2 On-Site Equipment Installation and Testing ....................................... 10

4 Development of Procedures and Supporting Tools ....................................................... 11

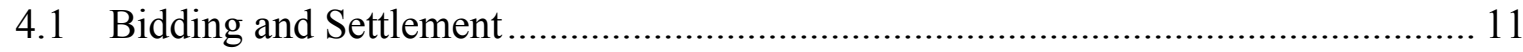

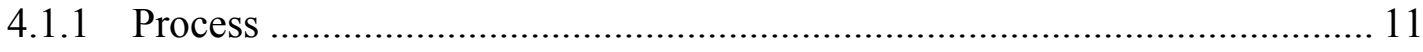

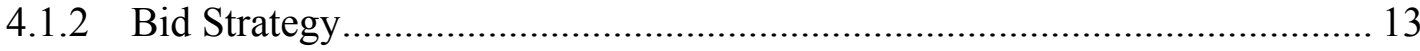

4.1.3 Bidding Procedure.................................................................................. 14

4.1.4 Settlement....................................................................................... 16

4.2 Bidding and Optimization Tools ....................................................................... 17

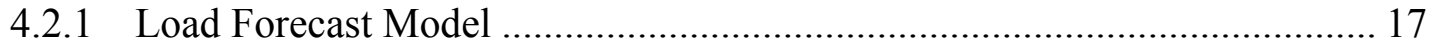

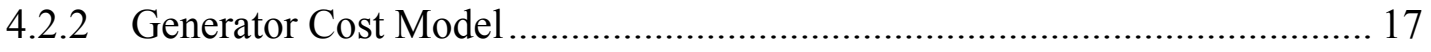

4.2.3 Dispatch Schedule Model ............................................................... 18

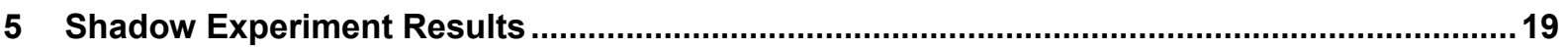

5.1 Bill Calculation - Market Mechanics .................................................................... 19

5.2 Shadow Experiment Load Data.......................................................................... 20

5.3 Shadow Experiment Bid and Price Data ...................................................... 22

5.4 Shadow Experiment Cost and Revenue Data..................................................... 23 


\section{List of Figures}

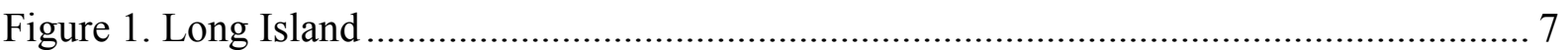

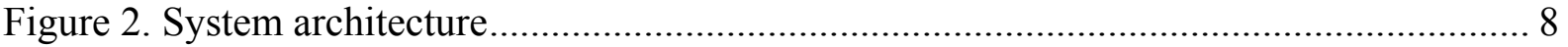

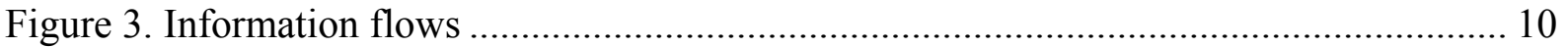

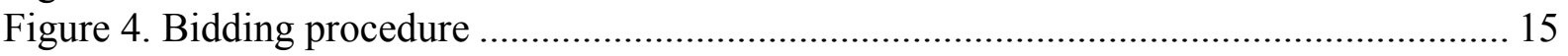

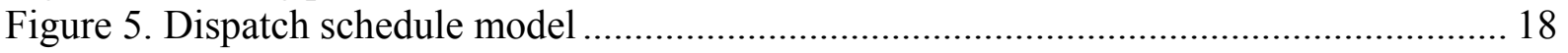




\section{List of Tables}

Table 1. Emergency Generators at 10 Long Island Buildings ............................................ 2

Table 2. Building Load and Installed Backup Generator Capacity ...................................... 3

Table 3. Monthly Energy Consumption (MWh) ............................................................ 21

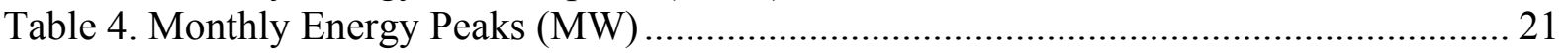

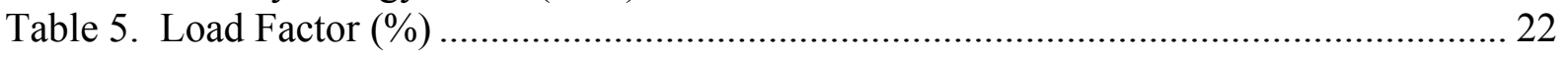

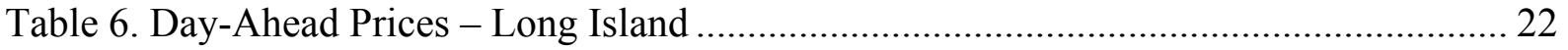

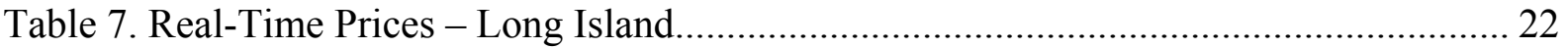

Table 8. Average Hourly Bid Prices (\$/MWh) ..................................................................... 23

Table 9. Hours of Operation .............................................................................................. 23

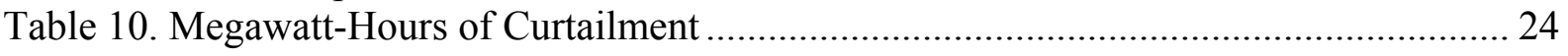

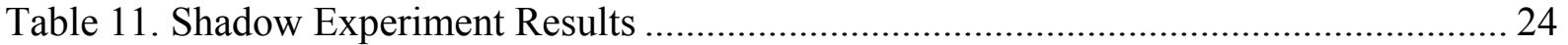




\section{Introduction}

This report presents the results of Task 6, "Field Testing of Aggregated Backup Generator Control System," of the Department of Energy/National Renewable Energy Laboratory project "Aggregated Dispatch of Distributed Generation." This project is a multiyear effort to demonstrate the feasibility of aggregating distributed demand-side resources and offering these resources in wholesale power markets.

Task 6 was designed to conduct field-testing of the distributed generation (DG) aggregation system. Under this task, Electrotek integrated, aggregated, and controlled several DG units within Long Island Power Authority (LIPA) service territory. To carry out this task, it was necessary to develop a DG aggregation system with the ability to monitor and dispatch DG units and to aggregate these units into a single transaction unit. This task is the critical element needed to confirm the technical validity of the concept that multiple DG units can be aggregated and dispatched to supply services in a competitive market environment.

The specific objectives of this task were to:

- Identify a distribution planning area within LIPA territory and evaluate it in terms of specific requirements of reliability and economic viability

- Identify several participant-owners of backup generators within the selected territory and recruit them for participation in the experiment

- Develop and implement an aggregation system with the ability to monitor and dispatch generators

- Conduct a field test of the developed DG aggregation system.

To fulfill these objectives, the following steps were taken:

- The New York Independent System Operator (NYISO) approved Electrotek as its first system resource (SR). SR is a NYISO designation for an aggregated collection of DG units, which are normally not tracked by the NYISO because of their small individual capacities. An SR is treated as a single central generator, given a point identification number, and modeled and scheduled as a single generator by the NYISO. This allows the SR to participate in the DAM.

- A set of operating procedures was developed. These procedures are necessary for participation in the energy market. They describe coordination with the NYISO, dispatch of generators, and financial settlements.

- A control system was designed and implemented. This control system consists of a data collection and monitoring center, an aggregation and dispatch center, and a field operation - which includes data acquisition and transmitting equipment installed on backup generators-aggregated into the SR.

- A field test was planned and executed during the May-September period of 2002. 
The selected sites are identified in Table 1. Table 2 contains information about the buildings' electric load and installed backup capacity. The identification of participants is withheld because of the proprietary nature of the information.

Table 1. Emergency Generators at 10 Long Island Buildings

\begin{tabular}{ccccc}
\hline $\begin{array}{c}\text { Building } \\
\text { Address }\end{array}$ & $\begin{array}{l}\text { Generator } \\
\text { Type and Amount }\end{array}$ & $\begin{array}{l}\text { Engine Size } \\
(\mathbf{k W})\end{array}$ & $\begin{array}{l}\text { Engine } \\
\text { Manufacturer }\end{array}$ & Fuel \\
\cline { 2 - 5 } 1 & 2 combustion & 750 & Solar & Diesel \\
& turbines & & Detroit Diesel & Diesel \\
2 & 2 diesels & 750 & Solar & Kerosene \\
3 & 1 combustion turbine & 750 & Detroit Diesel & Diesel \\
4 & 1 diesel & 1000 & Solar & \\
5 & 1 combustion turbine & 200 & Caterpillar & Diesel \\
6 & 1 diesel & 1000 & Onan & Kerosene \\
7 & 1 combustion turbine & 435 & Solar & Kerosene \\
8 & 1 combustion turbine & 200 & Solar & Kerosene \\
9 & 1 combustion turbine & 200 & Solar & Kerosene \\
10 & 1 combustion turbine & 750 & & \\
\hline & & & &
\end{tabular}


Table 2. Building Load and Installed Backup Generator Capacity

\begin{tabular}{|c|c|c|c|c|}
\hline Building & $\begin{array}{l}\text { Maximum } \\
\text { Building } \\
\text { Load } \\
(\mathrm{kW})\end{array}$ & $\begin{array}{l}\text { Load } \\
\text { Transferable to } \\
\text { Backup } \\
\text { Generator (kW) }\end{array}$ & $\begin{array}{l}\text { Installed Backup } \\
\text { Generator } \\
\text { Capacity } \\
\text { (kW) }\end{array}$ & Comments \\
\hline 1 & 800 & 800 & 1500 & $\begin{array}{l}\text { Both turbines can be synchronized and } \\
\text { work for one bus. }\end{array}$ \\
\hline 2 & 880 & 880 & 1500 & $\begin{array}{l}\text { The entire building load is transferred to } \\
\text { the backup generators automatically. }\end{array}$ \\
\hline 3 & 500 & 500 & 750 & $\begin{array}{l}\text { Central office load ( } 250-300 \mathrm{~kW}) \text { is } \\
\text { transferred to the backup generators } \\
\text { automatically. A/C and lighting should } \\
\text { be transferred manually. }\end{array}$ \\
\hline 4 & 500 & 500 & 1000 & $\begin{array}{l}\text { The entire building load is transferred to } \\
\text { the backup generators automatically. }\end{array}$ \\
\hline 5 & 100 & 100 & 200 & $\begin{array}{l}\text { The entire building load is transferred to } \\
\text { the backup generators automatically. }\end{array}$ \\
\hline 6 & 500 & 500 & 1000 & $\begin{array}{l}\text { The entire building load is transferred to } \\
\text { the backup generators automatically. }\end{array}$ \\
\hline 7 & 230 & 230 & 435 & $\begin{array}{l}\text { Central office load (120-130 kW) is } \\
\text { transferred to the backup generators } \\
\text { automatically. } A / C \text { and lighting should } \\
\text { be transferred manually. }\end{array}$ \\
\hline 8 & 100 & 100 & 200 & $\begin{array}{l}\text { The entire building load is transferred to } \\
\text { the backup generators automatically. }\end{array}$ \\
\hline 9 & 100 & 100 & 200 & $\begin{array}{l}\text { The entire building load is transferred to } \\
\text { the backup generators automatically. }\end{array}$ \\
\hline 10 & 500 & 500 & 750 & $\begin{array}{l}\text { The entire building load is transferred to } \\
\text { the backup generators automatically. }\end{array}$ \\
\hline
\end{tabular}

In addition, it should be noted that Task 6 was executed in parallel with Task 8, "Design of Commercial Demonstration," of the project. Task 8 is focused on the physical design of the aggregation system, including control rooms, field equipment, and communication systems for the commercial demonstration. Therefore, a detailed description of the physical design of the Data Collection and Management Center and Aggregation and Dispatch Center as well as of the software, computer tools, and procedures for data collection and management are provided in the Task 8 final report. The Task 6 report contains only brief descriptions of equipment and procedures necessary for understanding of operations and results of the current effort. 
This rest of this report is divided into five sections:

- Background, which details the project development

- DG aggregation system design, which describes the control center used for the aggregation system components and the installation and testing of monitoring equipment

- Procedures and tools, which details the conduct of the project as well as the software developed for bid preparation and execution

- Economic analysis, which presents the economic evaluation of the project

- Results and conclusions. 


\section{Background}

With serious capacity deficiencies in New York's bulk power system, the NYISO offered demand-side resources the opportunity to participate in wholesale power markets through two programs. The first of these is the Day-Ahead Demand Response Program; the second is the Emergency Demand Response Program. These two programs allow load curtailment or local (behind-the-fence) generation to participate in wholesale power markets to provide the NYISO with load relief on a day-ahead basis (Day-Ahead Demand Response Program) or during system emergencies (Emergency Demand Response Program). With New York State Energy Research and Development Authority support, these programs have proved successful in providing demand-side resources for load relief to the NYISO during high load periods and averaged $420 \mathrm{MW}$ of load reduction over the first three event calls. ${ }^{1}$

In an effort extending beyond the NYISO demand-side programs, Electrotek proposed to aggregate distributed demand-side resources and offer these resources in New York DA energy markets. The original scope of this initiative was to aggregate four sites on Long Island and register them as a single SR unit.

An SR is a capacity resource that can be sold and dispatched in NYISO markets. An SR is treated as a generator in NYISO markets whose capacity, when sold in the NYISO Installed Capacity (ICAP) Market, is obligated to participate in NYISO Day-Ahead, Real-Time, or Ancillary Services markets.

As such, this SR unit, coupled with Electrotek's aggregation control center, would behave like a generator in NYISO markets, to be bid and dispatched just like a generator. Under such an arrangement, the SR, once sold in ICAP markets, bids on a daily basis in the NYISO energy markets and is subject to all ICAP market requirements, including testing, metering, communications, reporting, and performance procedures. This approach was later broadened to include 10 sites on Long Island aggregated into a single SR in the NYISO DAM.

In the development of this concept, Electrotek worked closely with the NYISO to ensure compliance with all pertinent NYISO requirements and solicit recommendations regarding system implementation. The NYISO was supportive and cooperative in this process.

As a result, the NYISO accepted a proposed reporting protocol for the SR. This protocol was based on the installation of a KYZ terminal and pulse initiator at each site's billing meter by the transmission operator. ${ }^{2}$ The pulses would then be aggregated and provided to the transmission operator and the NYISO by Electrotek Control Center in formats to be specified by each of the recipients. Such an approach was cost-effective, reliable, and verifiable. The NYISO extended its acceptance of the proposed protocol along with an interim arrangement to allow for quick implementation of the SR.

\footnotetext{
1 "NYISO Price Responsive Load Program Evaluation," Neenan Associates, Jan. 8, 2002.

${ }^{2}$ A detailed description of the data acquisition and transmission system is provided in Section 3 of this report.
} 
This protocol, however, was not accepted by the LIPA, which sought recovery from Electrotek for expenses incurred related to the implementation of its existing metering and reporting protocols and other unspecified additional costs. The imposition of these costs doomed the schedule and economic viability of the proposed project.

With this development, technical implementation was not possible. However, to test the viability of the market transactions of such an arrangement, a shadow market operation was developed. This shadow market operation became a simulation of the market transactions of the proposed SR. The specific structure and mechanisms of the shadow experiment are detailed in Section 4 of this report, but, in brief, a number of transactional arrangements were evaluated. These included selling the SR capacity in the ICAP Market or deploying for selfservice, and bidding, selling, and dispatching in the DAM.

The 10 sites selected for participation in the SR unit are located on Long Island and are facilities with local generation. These facilities and their capacities are detailed in Section 3 of this report.

Each of the sites has behind-the-fence generation and sufficient capacity to serve site load. The capacity values listed in Table 1 and Table 2 for these locations are based on their NYISO unforced capacity rating (UCAP), which is a reliability- and performance-adjusted value. This UCAP value is determined on a monthly basis by the NYISO and is the capacity that can be sold in each month's capacity and energy markets.

A final background note is that the original proposal for the control center included automated generator dispatch. The 10 project sites were all one-client facilities, and client operating procedures did not allow for the remote dispatch of generation. Thus, a dispatch procedure adjustment was made to accommodate operating standards. In the revised dispatch procedure, only two of the company's area managers were contacted automatically via pager and e-mail when dispatch was scheduled. These managers were able to start all generators within their areas remotely. Such an approach, called "semi-automatic dispatch," was successfully demonstrated multiple times in the Emergency Demand Response Program in the summers of 2001 and 2002. 


\section{DG Aggregation System}

Ten client facilities were recruited for participation in the SR experiment. All these facilities are located on Long Island (Figure 1). To combine these generators into a single dispatchable resource, a DG aggregation system was developed and built by Electrotek.

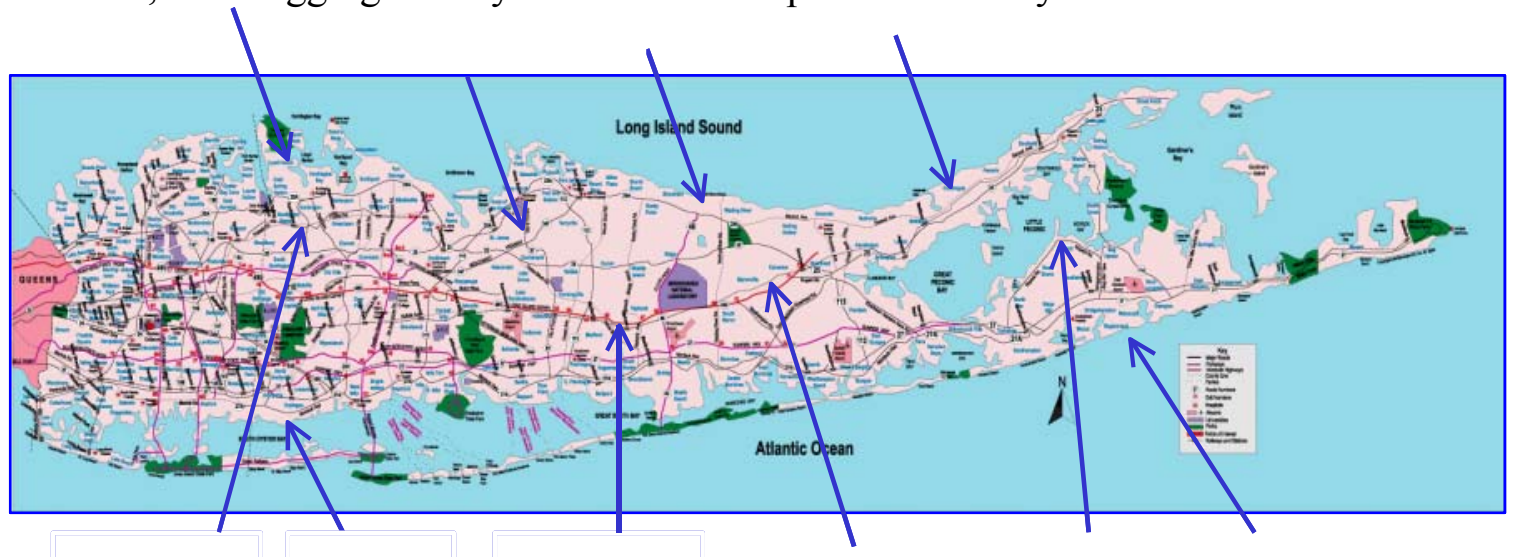

Figure 1. Long Island

The development, design, and construction of the DG aggregation system are the subjects of Task 8 of this project and are described the final report for Task 8 . Only a brief description of the entire aggregation system, necessary for understanding of core subjects of the current report, is presented here.

The DG aggregation system architecture is composed of two essential elements: the physical/logical design of the entire system and its components (Figure 2) and the information flow among all system components and between the system and outside counterparts such as clients and energy markets (Figure 3).

On the physical side, the system comprises three major entities: Field Operation, which includes participating buildings/generators on Long Island; Data Collection and Management Center, located in Knoxville, Tennessee; and Aggregation and Dispatch Center, located in Edison, New Jersey. Each entity includes several operation modules with specific duties that are interconnected via the Internet and other communication media. 


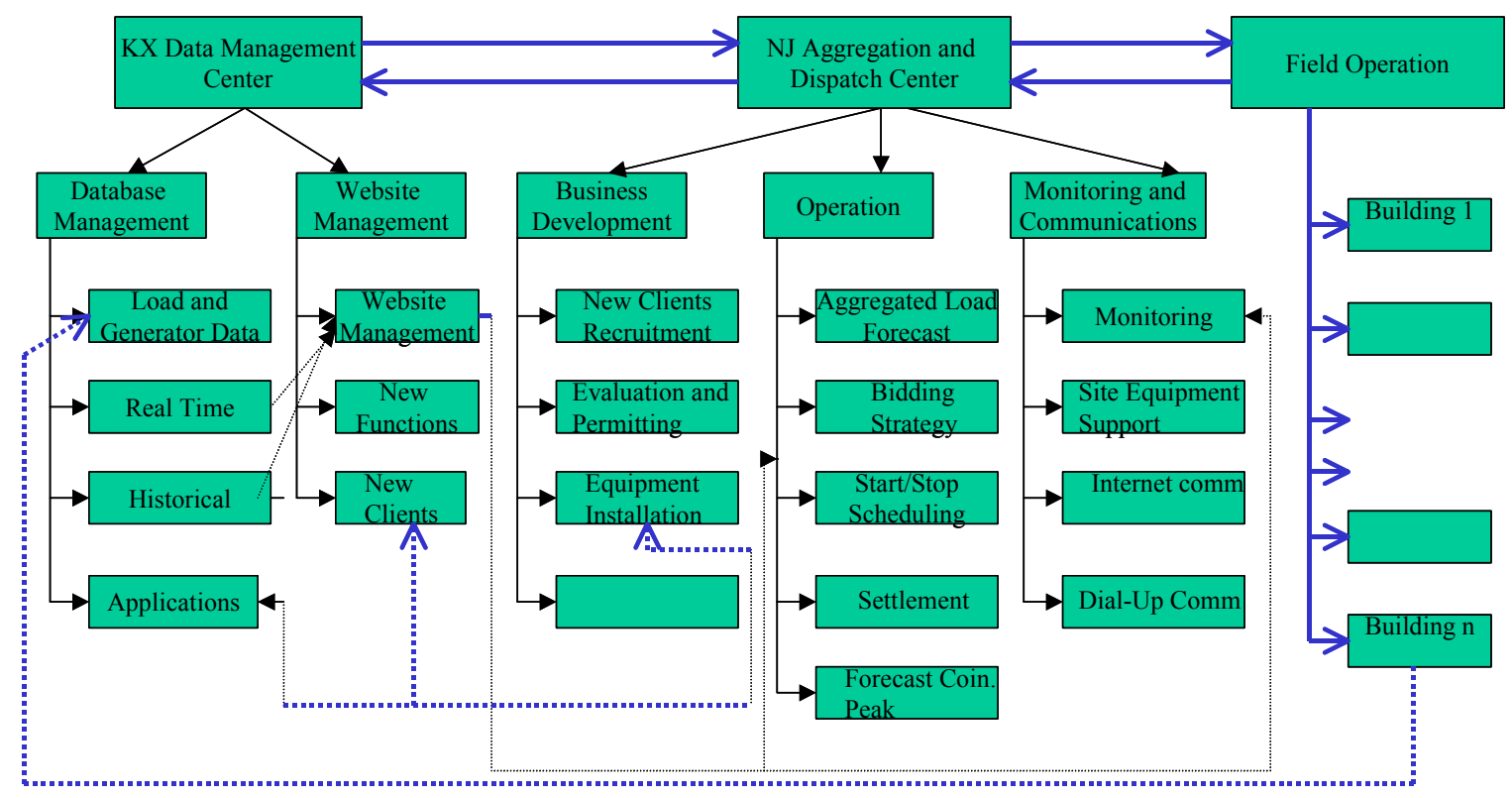

Figure 2. System architecture

\subsection{Data Collection and Management Center}

The Data Collection and Management Center is located at the Electrotek Concepts Inc. office in Knoxville, Tennessee. Servers and workstations are the foundation of the data collection and management system of the DG operation. The storage capacity of the Dranetz-BMI InfoNode 5500 located at the generation site is limited and is not designed for long-term data storage. The Data Collection and Management Center houses the system responsible for downloading the data from onsite InfoNodes, organizing data into a database, and storing and manipulating these data.

\subsection{Aggregation and Dispatch Center}

The Aggregation and Dispatch Center is the central point of operation of the DG aggregation system. It will be built in Edison, New Jersey, and will include three divisions: Operations, Business Development, and Monitoring and Communication.

- Operations is responsible for operation strategy, bidding preparation and execution, dispatching and monitoring of generators, and settlement and accounting procedures.

- Business Development is responsible for recruiting new clients, economic and technical site evaluation, permitting, and field equipment installation and start-up.

- Monitoring and Communication is responsible for the support and maintenance of field monitoring equipment and all communication channels (Internet, dial-up, pagers, etc.).

The physical design of the Aggregation and Dispatch Center has been developed, and construction and start-up is planned for 2003. 


\subsection{Field Operation}

To aggregate generators into a single system, information was collected about facility and equipment electrical loads, schedules, and electrical system designs. Based on this information, a design for monitoring equipment was developed for each facility.

\subsubsection{Buildings and Generators}

All 10 buildings are typical telephone communication facilities. The electrical load in these buildings is usually composed of essential loads, which include all telephone equipment and auxiliary equipment necessary to provide reliable operation of telephones, and non-essential loads, which include all other electrical equipment, such as elevators, fans, and airconditioning units.

The main requirement for a power supply system serving telephone communication facilities is availability. To provide necessary redundancy, these facilities are equipped with huge banks of batteries and emergency generators. Emergency generators in such facilities usually cover essential loads, which are transferred to an emergency bus automatically when commercial power is cut. A brief interruption of power supply occurs during the switchover from commercial power to emergency generators as the emergency generators start up. During this transition period, the essential load is covered by batteries. In most buildings, nonessential load is also covered by emergency generators, with automatic or manual transfer to the emergency bus. First priority in this case is the air-conditioning equipment because sufficient cooling is vital for the reliability of telephone equipment. Air-conditioning load represents a significant part of the building load in summer.

As shown in Table 2, in all selected facilities, the installed capacity of emergency generators exceeds building load by $50 \%$ to $100 \%$. In all but two buildings, the building load (essential and non-essential) is automatically transferred to emergency generators.

To avoid any effect of load curtailment on facility reliability, a method of procedure for curtailment activities was developed by Electrotek and approved by client officials. This method of procedure stipulates the following order of operations:

1. Emergency generators are started on idle.

2. Generators are synchronized with the commercial grid.

3. The building load, designed for automated switching, is switched from the commercial bus to the emergency bus.

4. The rest of the non-essential building load not designed for automated switching is manually switched to the emergency bus.

The shutdown of emergency generators and transfer back to commercial power should be performed in the opposite order. 


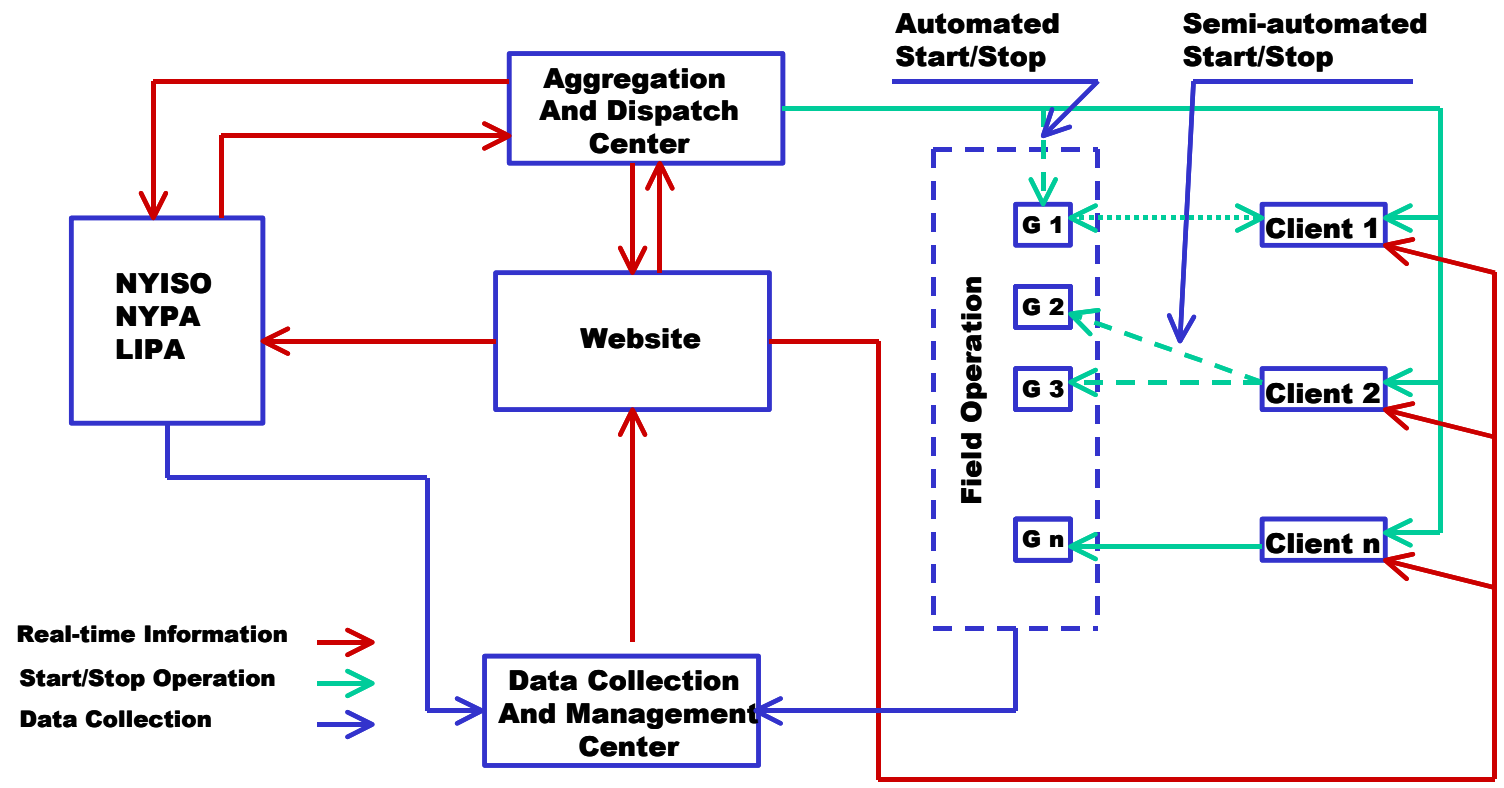

Figure 3. Information flows

\subsubsection{On-Site Equipment Installation and Testing}

On-site monitoring equipment was installed during the period of May to July of 2002. The installed equipment was started and tested by Electrotek's field technicians.

During the tests, emergency generators were started, and the entire building load was transferred to the emergency bus. There were no problems with the load switching or building power equipment operation during transition. A curtailment operation initiated this way did not have any effect on power supply system reliability.

Power monitoring instruments were tested by comparing the total building load measured by the utility meter when the backup generators were not operating with the sum of energy generated by backup generators and energy taken from the commercial grid by the building. Data storage capacity and the ability of InfoNodes to communicate with the Data Collection Management Center and transfer collected information were also tested. The collection of data from several facilities was started at the beginning of June, and by mid-August all facilities were included in the DG aggregation system. 


\section{Development of Procedures and Supporting Tools}

\subsection{Bidding and Settlement}

Essential to the cost-effective bidding and dispatch of aggregated units in the DAM is the ability to calculate the running costs of each of the sites and bid these sites in a manner consistent with NYISO procedures. When bidding the SR as a single generator in the NYISO day-ahead (DA) energy market, the site-specific performance of the loads and the generation parameters must be considered.

The 10 sites were aggregated into an equivalent single generator. This aggregation was done in accordance with NYISO rules, which require a minimum threshold of $1 \mathrm{MW}$ for any resource block bid in the DAM. This single unit was bid and dispatched in three blocks, each of which was at least $1 \mathrm{MW}$.

The bidding process was conducted through a rigorous analytical approach that involved forecasting hourly site loads and using these loads - as well as hourly temperature and humidity forecasts - to develop site-specific hourly running costs. These site-specific hourly running costs were then used in an optimization model to determine how the three blocks could be configured to minimize the total running cost to serve the load. These running costs were then used to develop hourly bid prices for each block in the DA energy market.

In this section, the technical requirements and the process of developing the bid costs are detailed. This process is based on NYISO rules and procedures and individual site loads and running costs. The tools developed and the steps of creating the hourly bid prices by block will also be described.

\subsubsection{Process}

The NYISO has extensive requirements and procedures that market participants must follow in the DAM. For the DAM, seven NYISO manuals detail the requirements, regulations, and procedures. All of these are available on the NYISO Web site. They are:

- NYISO Open Access Transmission Tariff

- NYISO Day Ahead Scheduling Manual

- NYISO Control Center Requirements Manual

- NYISO Market Information System

- NYISO Market Participation Users Guide

- NYISO Installed Capacity Manual

- NYISO Accounting \& Billing Manual.

The process consists of both technical requirements for market participation of the SR and the market rules, each of which are described below. 


\subsubsection{Technical Requirements}

The technical requirements for an SR participating in the NYISO DAM are the same as those for a generator. The essence of the technical requirements relates to the metering and communications systems that can be used. As detailed in the background of this report, although the metering and communications systems proposed by Electrotek were accepted by the NYISO, they were not accepted by LIPA.

Although all functional requirements were satisfied by the proposed systems, LIPA would not accept them. These requirements are detailed in the NYISO Control Center Requirements Manual (revised Sept. 24, 1999).

The NYISO require communication of real-time information of the site load to the transmission operator (LIPA) using one of three communications protocols. This physical connection must be a frame relay channel using one of three protocols:

- NYISO/Bisync as defined in New York Power Pool Communications Standards \& Message Specifications (issued August 1992 and revised April 1996)

- X.25/IDEC (Inter-Utility Data Exchange Consortium) as described in Data Communications Capability Network Interface Control Document (July 31, 1992)

- IEC 870-6-503 as defined in TASE.2 Services and Protocol (version 1996-08), also known as ICCP (Inter Control Center Communications Protocol).

The metering requirements dictate that the system must meet ANSI C12 standards and be capable of providing both instantaneous and stored energy readings. Meter systems must also be able to provide 1-hour interval values for purposes of settlement.

There are also requirements for voice communications and market information system interface. These mandate private telephone lines and Internet access, which is used for the NYISO OASIS (Open Access Same-Time Information System). The OASIS interface uses hypertext transfer protocol and is accessed by certified users with any Web browser.

\subsubsection{Market Rules}

NYISO market participants transact in the DAM in accordance with rules detailed in three NYISO manuals. These manuals are:

- NYISO Market Participants Users Guide (revised June 1, 2001)

- NYISO Installed Capacity Manual (Stage 2, revised August 30, 2002)

- NYISO Day-Ahead Scheduling Manual (revised Sept. 2, 1999). 
Market participants in the DAM are actually active in two markets. The first of these is the ICAP Market, in which the market participant sells its capacity either bilaterally or in the ICAP monthly or strip (6-month) auction. Once a market participant sells ICAP, it is committed to selling energy or ancillary services in the DAM or real-time markets. The capacity value of the bid ICAP is adjusted by NYISO based on the capacity actually delivered. This adjusted value, known as UCAP, is calculated and reported to each resource on a monthly basis by NYISO.

In the energy and AS markets, the market participant must submit daily offers for each hour in the day. These offers, due by 5 a.m. for the next day, are for all capacity sold in the ICAP Market (the UCAP) at the hourly price. For any single generator, or SR, the capacity can be sold in up to five blocks. Each block, however, must be at least $1 \mathrm{MW}$ of capacity. For Electrotek's SR, the total capacity of $4 \mathrm{MW}$ was bid in three blocks (two 1.5-MW blocks and a 1-MW block). Before one can bid in the DAM, it must obtain a digital certificate from the NYISO to enable full access to the OASIS and Bid/Post System. These digital certificates are machine-dependent.

\subsubsection{Bid Strategy}

The bid strategy used to develop hourly prices for each block of the SR capacity takes explicit consideration of the hourly running costs of each of the 10 sites. The strategy uses a series of analytical tools to develop least-cost hourly bid prices for each of the three blocks. The basic strategy is to calculate the hourly running costs of each of the 10 sites and aggregate these sites such that the total generating cost for all blocks is minimized. The bid price for each block is based on the weighted running cost (fuel, labor, variable operations and maintenance, and start-up) _ adjusted for margin and additional manpower deployment costs — of each of the generators in each block. Because the primary business of the sites is not generation, any time the sites run, there is an additional manpower cost. The block bid prices are based on the weighted average running costs of each of the three blocks.

This strategy begins with an hourly load forecast for each site every day. The load forecast tool is a linear regression model based on actual loads and hourly temperature and humidity. The load forecast model uses forecasted hourly temperature and humidity. Once the hourly load forecasts are developed, each site's hourly running costs for on-site generation is calculated, again using forecasted hourly temperature and humidity and the forecasted loads.

The bid strategy is to maximize the hours the SR is dispatched. This is achieved with an optimization model that minimizes the weighted average running cost by combining the 10 sites into the three bidding blocks. By minimizing the running costs, the probability of having the hourly bids accepted in the NYISO DAM is maximized. It should be noted that the running costs of the on-site generation is high, and they are not dispatched often. 


\subsubsection{Bidding Procedure}

As shown in Figure 4, the DAM bidding procedure consists of a series of steps that must be undertaken in order each day. These steps include developing the bid costs and preliminary operating schedules, submitting the bids to the NYISO, and if the bids are accepted, forwarding the dispatch schedules to the sites.

The first step is to obtain an hourly temperature and humidity forecast for Long Island. The 10 sites of the SR are distributed uniformly throughout Long Island. Two National Weather Service field offices are also located on Long Island. These are located at Brookhaven National Laboratory in Upton and in Bohemia. An examination of the historical temperature and humidity data at these two stations found little variance. Given the significant computational effect of using multiple temperature forecasts and the minor temperature differences between these locations, only one temperature/humidity forecast was used. The location selected for the temperature and humidity forecast was Central Islip, located in the center of Long Island. The hourly temperature and humidity forecast was obtained over the Internet at http://www.weather.com./

The next step is to forecast hourly loads and calculate running costs by site. This is done with the load forecast regression model to calculate each site's hourly load and a spreadsheet model to calculate each site's hourly running cost. The hourly running costs use both the forecasted loads and the hourly forecasted temperatures. The running costs are based on unit availability, unit fuel, operations and maintenance costs, and start-up costs. The unit operating cost (fuel plus operations and maintenance) is calculated based on site load and temperature for each hour. Because that these units are not expected to operate more than 6 hours a day, start-up cost is a significant factor in determining the least-cost dispatch.

The third step is to develop the least-cost block schedule. The block schedule is the selection of sites for each block. This is accomplished with an optimization model that selects the resource configuration that minimizes the weighted average running cost between the hours of 12 p.m. and 6 p.m. - the only hours that the SR would operate. A more detailed discussion of least-cost schedule development is provided in Section 4.2. 


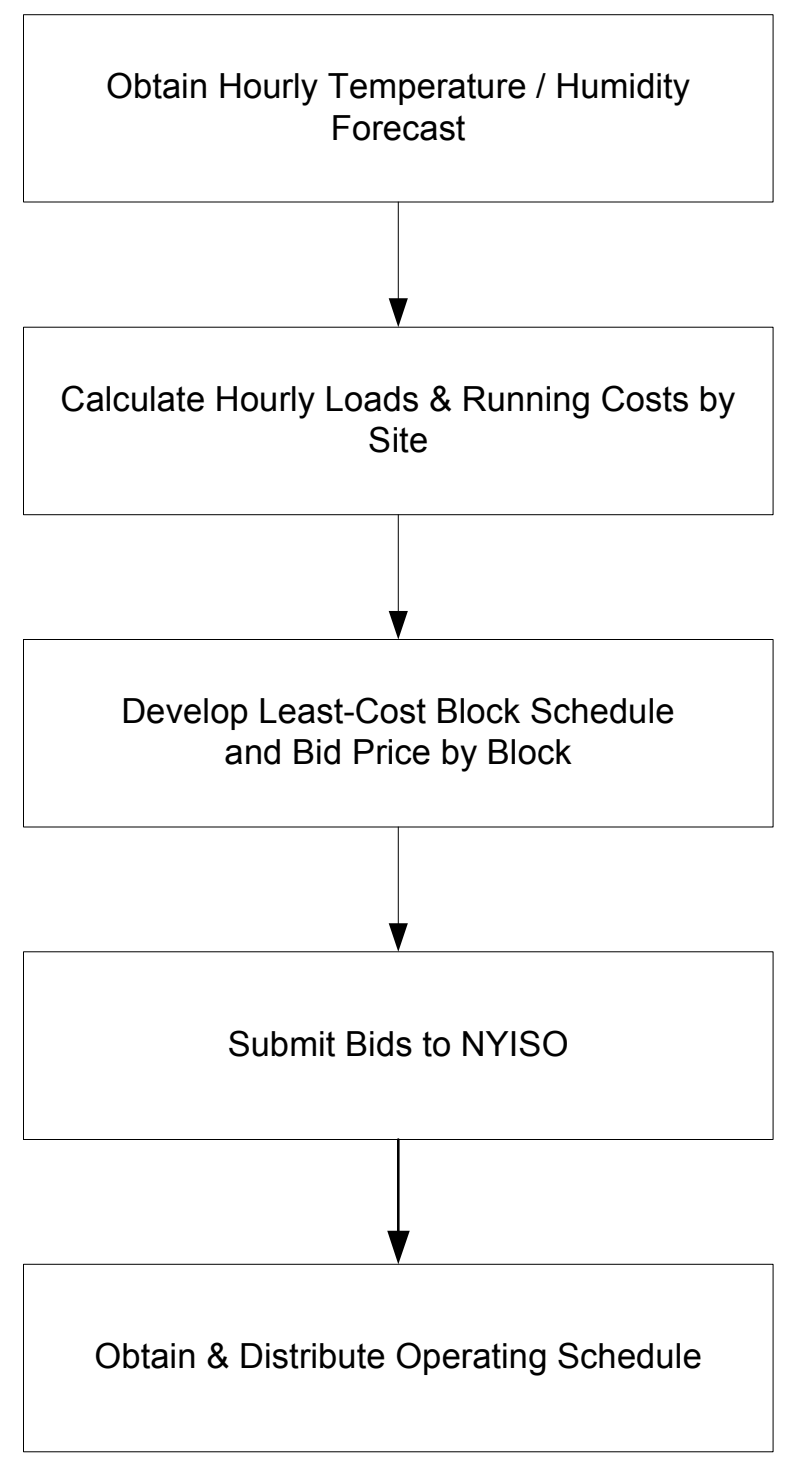

Figure 4. Bidding procedure

After the block schedule determined, the block bid price is calculated. During off-peak hours (between $6 \mathrm{p} . \mathrm{m}$. and $8 \mathrm{a} . \mathrm{m}$.), the manpower cost is high because it is necessary to dispatch personnel to the locations. Hence, in all cases, off-peak bid prices are higher than peak bid prices. 
After each block's hourly bid prices are calculated, they are bid into the NYISO DAM. This is done through the NYISO OASIS. The procedure requires that bids be submitted to the NYISO by 5 a.m. for the next day. The NYISO then evaluates all submitted bids and determines and posts the market-clearing price by 11 for the next day. Successful bidders are notified of their dispatch schedule. Any hourly bids equal to or below the hourly marketclearing price are accepted and obligated to run for those hours.

Finally, in the event any blocks are called to operate (their bids are accepted), a notification procedure is invoked. This procedure is executed out of Electrotek's Control Center. All of the sites have designated contacts with special e-mail accounts and pagers. Once the NYISO notifies Electrotek that a block is scheduled, Electrotek notifies the sites by both e-mail and pager. Each site's operating schedule is forwarded to the designated personnel, and these individuals acknowledge receipt of the schedule. All of the sites are notified by noon the day before the scheduled dispatch.

\subsubsection{Settlement}

The settlement process for NYISO transactions is conducted in accordance with rules and procedures defined by the NYISO. The schedule and procedures for settlement are detailed in the NYISO Accounting and Billing Manual. For a generator or SR selling energy to the NYISO, the basic requirement is to provide interval (hourly) meter data for the total generation.

For Electrotek's SR, the generation is metered at each site with revenue-certified interval meters and aggregated at the Control Center. In accordance with NYISO procedures, for months when energy is sold to the NYISO, Electrotek is obligated to provide performance data pertaining to unit operation. These data are provided in a format developed by the North American Electric Reliability Council known as the Generating Availability Data System (GADS).

Three types of data are reported in GADS:

- Event data

- Performance data

- Design data.

Event data are those data provided when a unit's operating status or capability changes. Events generally fall into four categories: outages, deratings, shutdowns, and non-curtailing events. Performance data are information about the unit's operation during a calendar month. These data are used to calculate unit performance, reliability, and availability. Design data provide information about equipment design and operating characteristics.

The NYISO requires that GADS data be reported by the 20th day of each month for the previous month. These data are used for settlement of energy sold and to develop the capacity ratings of resources, which is conducted in the ICAP Market. 
In the settlement process, the NYISO reimburses any supplier from whom energy is purchased for each hour of dispatch at that hour's locational-based marginal price (LBMP). For Electrotek, the LBMP is for NYISO Zone K (Long Island). In addition, the supplier is reimbursed for start-up costs and any specified minimum run time, which is the hours a unit must run after it is started. Electrotek's SR has a 2-hour minimum run time.

\subsection{Bidding and Optimization Tools}

The entire process for DA bidding relies on three sets of analysis developed by Electrotek. The first tool is a load-forecasting model that calculates hourly building load based on temperature and humidity forecasts. The second model calculates hourly generator running cost based on forecasted temperature, humidity, and load. The third is a linear programming model developed by Electrotek. The linear programming model uses numbers calculated in the first model and returns an optimal dispatch schedule to the spreadsheet.

The performance characteristics of these generators are dependent on site load and temperature. As temperature increases, the loads increase because of increased cooling requirements. As the loads increase, the performance of these units tends to improve. However, as temperature increases, the performance of turbines suffers. This combination of factors makes the estimation of generator performance more challenging.

The portfolio of tools developed by Electrotek explicitly addresses these issues. Each of these tools and their sequence of execution is described in sections 4.2.1 through 4.2.3.

\subsubsection{Load Forecast Model}

To determine the loads of the 10 sites in the SR experiment, Electrotek developed a loadforecast model for each location. This tool is a linear regression model that uses the forecast of hourly temperature and humidity to estimate hourly loads for each site.

The regression model was developed by Electrotek to provide a reasonable hourly load forecast for each of the 10 locations and then to use this forecast along with other data to estimate generation costs. The regression equations were created using one year of historical hourly temperature and humidity data as well as hourly load data for each location.

The regression equations were specifically targeted to those hours when the SR would be operating: 8:00 a.m. to $6 \mathrm{p} . \mathrm{m}$. It is during this period that most variation in load, temperature, and humidity occurs. Hence, the regression equations were tuned to this period to capture load variation more directly attributable to the temperature and humidity index.

\subsubsection{Generator Cost Model}

The generator cost model is used to calculate the cost of operating the generators at each site by hour, i.e., the running cost. This running cost is the variable cost of generation, i.e., fuel and variable operations and maintenance costs. The generator cost model calculates the generator load as a percentage of generator capacity based on the load forecast model for each location. Two adjustment factors are then calculated. Taken together, these adjustment factors provide an improved basis for calculating the running costs of the generators. 
The first adjustment factor is the load adjustment, which accounts for generator performance changes observed at various levels of output. The performance of generators changes based on the output levels of the generators. The relationship between output level and efficiency is the basis of the heat-rate curve, which correlates electrical output and fuel consumption levels.

The second adjustment factor reflects the relationship between the generator output and the ambient temperature. The load on gas turbines is especially sensitive to ambient temperatures. As ambient temperature rises, the output of the gas turbine decreases.

Using the hourly generator performance data described above along with the operations and maintenance costs of each unit and the fuel cost, the generator cost model calculates the hourly variable cost of operating each generator. These hourly running costs are then used to develop the hourly bid costs in the dispatch schedule model described below.

\subsubsection{Dispatch Schedule Model}

Once the hourly running cost of each site is calculated, it is necessary to determine how to combine the sites into three blocks to bid their capacity (or curtailment) in the NYISO DAM. Because each site's load and running cost vary by hour, determining how to combine them in the most efficient (i.e., least-cost) way becomes a daunting task. There are 10 locations and 24 hourly costs to be combined into three bidding blocks. For each day, 720 potential combinations (10 sites $\times 24$ hours $\times$ three blocks) need to be evaluated.

To streamline the evaluation process of dispatch schedules, Electrotek developed an optimization model that calculates the least-cost combination of resources to increase the likelihood of having the DAM bids accepted. A flowchart of the model is presented in Figure 5.

\section{Dispatch Schedule Model}

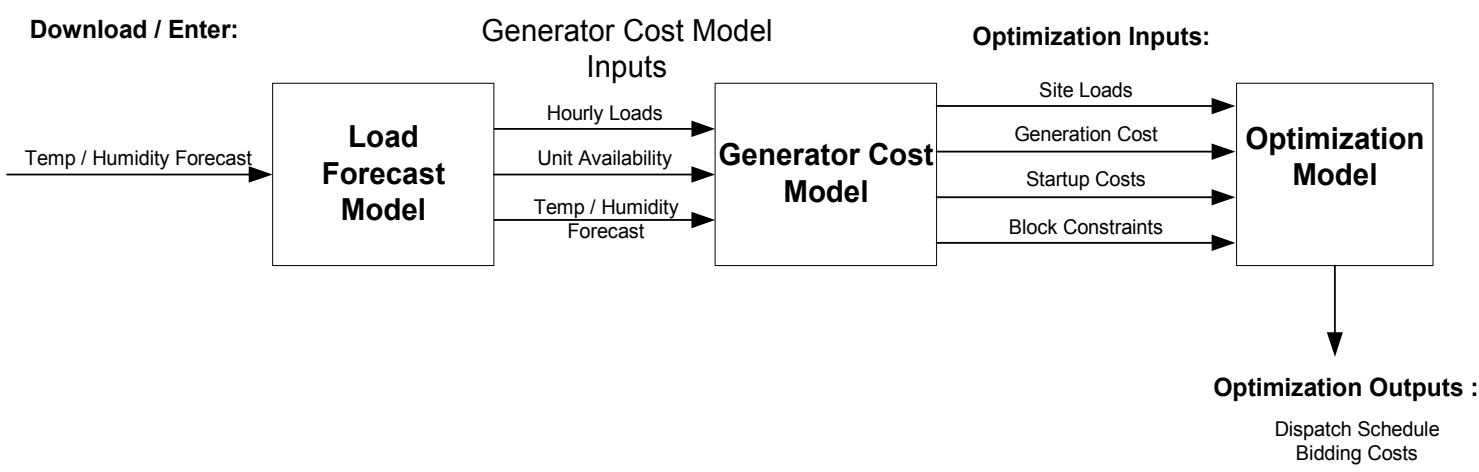

Figure 5. Dispatch schedule model 


\section{$5 \quad$ Shadow Experiment Results}

Using actual hourly load data for the 10 participating sites, NYISO DA prices for Long Island, NYISO real-time prices for Long Island, NYISO settlement procedures, and estimated LIPA delivery charges, Electrotek calculated the costs and revenues associated with being a direct customer bidding a price-capped load in the NYISO DAM. In this section, the mechanics of the calculations of the cost of electricity to the 10 sites is described. Next, the data, costs, and revenues of the aggregated resource under this approach are presented. This is followed by a discussion of the results.

\subsection{Bill Calculation - Market Mechanics}

The calculation of the cost of providing the 10 aggregated sites with power under a pricecapped load bid as a direct customer consists of several components. These are:

- The DA hourly price of electricity in the NYISO market for Zone K (Long Island)

- The cost of running the generators at each of the sites for those hours when these sites successfully bid their curtailment in the DAM

- The LIPA delivery charge for the energy purchased from the NYISO and delivered over LIPA's distribution system

- The LIPA delivery charge for the energy curtailed through self-generation

- The real-time hourly price of electricity in the NYISO market for Zone K

- The revenue realized by the sale of load curtailments in the NYISO DAM.

The NYISO DA energy price is the hourly LBMP of electricity for Zone K. These hourly market-clearing prices are determined every day for each hour of the next day in the DA auction. For a direct customer purchasing electricity, these hourly prices are the cost of procuring this energy in the NYISO DAM. Thus, for any hour when the LBMP is less than or equal to the bid price, that hour's electricity consumption is purchased from NYISO.

For those hours when the LBMP is greater than the block bid price, the sites in that block do not purchase energy from the NYISO but provide self-service. In this case, the cost of electricity supply is the hourly load of that block multiplied by that block's cost of selfgeneration - the running cost.

For any customer taking distribution service in the LIPA service territory, there is an obligation to pay LIPA a delivery charge for energy used at the customer's site. This applies to energy actually delivered by LIPA as well as energy supplied through self-generation. Thus, each of the sites must pay LIPA this distribution charge for all energy consumed, whether self-generated or purchased from LIPA. 
Under New York Department of Public Service regulations, all investor-owned utilities are required to post their delivery charge under their tariffs. However, as a public authority, LIPA is not under the NYDPS purview and, hence, does not post a delivery charge. Attempts to obtain a value for the distribution system service charge were not successful. This is apparently a negotiated value. For purposes of this report, three distribution service charge values were used to represent low, medium, and high values. These values are representative of the distribution service charges used by the New York state investor-owned utilities for customers the sizes of the individual sites.

The real-time hourly electricity price is used to reconcile the energy contracted for and the energy bought or sold. Variances between the amount contracted for (either for purchase or sale) and the amount used or delivered are settled at the hourly real-time rate by the NYISO. This reconciliation is part of the NYISO settlement process.

The final component of the shadow experiment is the revenue associated with the sale of the load curtailment of the aggregated sites. Under this component, each block of the aggregated site sells its load curtailment to the NYISO when the DAM price exceeds the block bid price. The DA price is for the specific hour for Long Island (Zone K).

\subsection{Shadow Experiment Load Data}

Although the basis of all transactions under the shadow experiment is hourly loads and prices, there are data that offer insight into the characteristics of each site and the aggregated entity. The data reviewed in this section include energy, demand, and DA and real-time price data for July through October 2002. These data will be presented and reviewed to offer some perspective on the performance of the shadow experiment.

The monthly energy consumption and peak demand data of the 10 sites show some interesting behavior. The monthly energy consumption and monthly peaks, Table A-3 and Table A-4, show some of the variances among the sites. The smaller sites $(2,5$, and 8$)$ have demand slightly more than $100 \mathrm{~kW}$, and the largest sight has a peak demand more than $1.2 \mathrm{MW}$. 
Table 3. Monthly Energy Consumption (MWh)

\begin{tabular}{cccccc}
\hline \multicolumn{7}{c}{ Energy Consumption } \\
Site & July & Aug. & Sept. & Oct. & Total \\
\cline { 2 - 6 } & 572 & 577 & 533 & 529 & 2,211 \\
1 & 88 & 87 & 80 & 71 & 326 \\
2 & 836 & 840 & 763 & 702 & 3,140 \\
3 & 303 & 296 & 273 & 260 & 1,131 \\
4 & 78 & 78 & 67 & 66 & 289 \\
5 & 323 & 310 & 286 & 274 & 1,193 \\
6 & 316 & 319 & 290 & 256 & 1,181 \\
7 & 61 & 64 & 62 & 63 & 249 \\
8 & 180 & 166 & 148 & 143 & 639 \\
9 & 387 & 375 & 341 & 320 & 1,422 \\
10 & & & & & \\
& 3,144 & 3,111 & 2,844 & 2,683 & 11,781 \\
Total & & & & & \\
\hline
\end{tabular}

Table 4. Monthly Energy Peaks (MW)

\begin{tabular}{ccccc}
\hline Site & July & Aug. & Sept. & Oct. \\
\cline { 2 - 5 } & & & & \\
1 & 881 & 887 & 830 & 838 \\
2 & 136 & 136 & 126 & 121 \\
3 & 1,445 & 1,427 & 1,283 & 1,280 \\
4 & 504 & 493 & 476 & 440 \\
5 & 117 & 119 & 123 & 109 \\
6 & 547 & 501 & 457 & 454 \\
7 & 512 & 521 & 490 & 461 \\
8 & 112 & 104 & 104 & 101 \\
9 & 292 & 274 & 240 & 240 \\
10 & 613 & 591 & 560 & 516 \\
& & & & \\
Coincident Peak & $\mathbf{4 , 9 8 6}$ & $\mathbf{4 , 9 6 2}$ & $\mathbf{4 , 6 2 5}$ & $\mathbf{4 , 4 7 0}$ \\
& & & & \\
\hline
\end{tabular}

Table A-5 provides the monthly load factors for each of the sites. All of these locations have a fairly high load factor, averaging more than $80 \%$ for each month. The lowest monthly load factor was $73 \%$ for Site 8 in July; the highest was $89.2 \%$ for Site 1 in September. An examination of the hourly load data shows that all of these sites are in operation 24 hours a day 7 days a week. 
Table 5. Load Factor (\%)

\begin{tabular}{ccccc}
\hline Sites & July & Aug. & Sept. & Oct. \\
\cline { 2 - 5 } 1 & 87.2 & 87.4 & 89.2 & 84.9 \\
2 & 86.5 & 86.5 & 88.3 & 79.0 \\
3 & 77.8 & 79.1 & 82.6 & 73.7 \\
4 & 80.7 & 80.6 & 79.6 & 79.4 \\
5 & 88.8 & 87.9 & 75.7 & 81.5 \\
6 & 79.5 & 83.1 & 87.0 & 81.2 \\
7 & 83.1 & 82.2 & 82.1 & 74.5 \\
8 & 73.0 & 83.2 & 82.0 & 83.3 \\
9 & 83.0 & 81.8 & 85.9 & 80.3 \\
10 & 84.9 & 85.2 & 84.6 & 83.2 \\
Total & & & & \\
& & & & \\
\end{tabular}

\subsection{Shadow Experiment Bid and Price Data}

The DA and real-time price data for July through October are summarized in Table 6 and Table 7. The DA prices were significantly higher in July and August than in September and October. Maximum prices were 7.7 times higher than the average price in July, 8.8 times higher in August, and only 3 to 4 times higher in September and October. The real-time prices exhibited greater volatility, with the ratio of maximum price to average price equal to 14.8 in July, 5.5 in August, 14.4 in September, and 4.3 in October.

The minimum prices in the real-time market were consistently lower than in the DAM. Maximum prices, with the exception of August, were higher in the real-time market than in the DAM. With the exception of July, the average prices tended to be fairly close. In July, however, real-time prices averaged roughly \$10/MWh more.

Table 6. Day-Ahead Prices - Long Island

\begin{tabular}{cccc}
\hline Month & Min & Max & Avg \\
\cline { 2 - 4 } July & 21.68 & 498.06 & 64.36 \\
Aug. & 21.10 & 599.75 & 67.95 \\
Sept. & 21.19 & 198.46 & 50.18 \\
Oct. & 19.05 & 148.46 & 47.91
\end{tabular}

Table 7. Real-Time Prices - Long Island

\begin{tabular}{cccc}
\hline Month & Min & Max & Avg \\
\cline { 2 - 4 } Jul & 4.97 & 1109.05 & 74.79 \\
Aug & 13.59 & 365.86 & 66.08 \\
Sep & 1.98 & 756.90 & 52.58 \\
Oct & 11.90 & 207.83 & 48.31 \\
& & & \\
\hline
\end{tabular}


A summary of the bid price data for each of the three blocks is presented in Table 8. Although it should be noted that the sites of each block changed daily, the bid prices were fairly uniform. For each month, the lowest bid price was around $\$ 230 / \mathrm{MWh}$, and the highest bid price was about $\$ 250 / \mathrm{MWh}$.

Table 8. Average Hourly Bid Prices (\$/MWh)

\begin{tabular}{lcccc}
\hline \multicolumn{1}{c}{ Block } & Jul & Aug & Sep & Oct \\
\cline { 2 - 5 } Block A & 230.93 & 252.86 & 252.71 & 246.59 \\
Block B & 246.20 & 228.47 & 234.68 & 231.08 \\
Block C & 248.50 & 247.11 & 263.95 & 244.02 \\
\hline
\end{tabular}

\subsection{Shadow Experiment Cost and Revenue Data}

In the structure of the shadow experiment, four types of costs are realized. These are the DA energy costs resulting from the purchase of energy in the NYISO DAM, the generator running costs that result from the operation of the on-site generators during those periods when energy is not purchased in the DAM; the energy delivery charge paid to LIPA; and the cost of realtime reconciliation when curtailment is sold in the DAM but not fully delivered.

On the revenue side, there are two sources. The first is the revenue associated with the sale of curtailments in the DAM. For those hours when the bid price of a block, or set of buildings, is equal to or less than the DA clearing price, the buildings in that block self-generate and sell their load curtailment. The second revenue source is the reconciliation in the real-time market of over-performance. On those occasions when all blocks of curtailment capacity are sold in the DAM and the curtailment delivered exceeds the amount sold, there is a reconciliation based on the excess energy for each hour times the real-time hourly price.

Several other points should be noted regarding the shadow experiment. Among these is the frequency with which the generators were "run" in the DAM. Table 9 presents the hours of "operation" by block for each month. As shown in the table, the generators did not run many hours. In the months of September and October, there was no on-site generation for the DAM.

Table 9. Hours of Operation

\begin{tabular}{lcccc}
\hline \multicolumn{1}{c}{ Block } & July & Aug. & Sept. & Oct. \\
\cline { 2 - 5 } Block A & 6 & 16 & 0 & 0 \\
Block B & 5 & 19 & 0 & 0 \\
Block C & 10 & 18 & 0 & 0 \\
& & & & \\
\hline
\end{tabular}

The energy curtailment sold in the DAM reflected the limited number of operating hours. Table 10 shows the curtailment energy sold by block and month for the shadow experiment. In July, curtailment was sold on 5 days; in August, it was sold on 6 days. The days were July 2, 3, 16, 18, and 23 and August 2, 5, and 13 through 16. On 6 days all three blocks were sold in the DAM. These were July 2, August 2, and August 13 through 16. 
Table 10. Megawatt-Hours of Curtailment

\begin{tabular}{lcccc}
\hline \multicolumn{1}{c}{ Block } & July & Aug. & Sept. & Oct. \\
\cline { 2 - 5 } Block A & 12 & 23 & 0 & 0 \\
Block B & 5 & 27.6 & 0 & 0 \\
Block C & 10 & 18.1 & 0 & 0 \\
& & & & \\
\hline
\end{tabular}

Table 11 presents the costs and revenues of the shadow experiment. Three delivery charge unit costs were used: $\$ 40 / \mathrm{MWh}, \$ 55 / \mathrm{MWh}$, and $\$ 70 / \mathrm{MWh}$. These delivery charges have a significant effect on the total cost of the shadow experiment. Over the 4-month period considered, the low delivery charge totaled more than $\$ 470,000$, and the high delivery charge totaled nearly $\$ 825,000$. The delivery charge accounted for $43 \%$ of the total cost in the $\$ 40 / \mathrm{MWh}$ case and $53 \%$ in the $\$ 70 / \mathrm{MWh}$ case. Clearly, this is a significant impediment to favorable financial performance.

Table 11. Shadow Experiment Results

\begin{tabular}{lccccc}
\hline & July & Aug. & Sept. & Oct. & Total \\
\cline { 2 - 6 } & \multicolumn{5}{c}{} \\
Total Energy (MWh) & 3,144 & 3,111 & 2,844 & 2,683 & 11,781 \\
Total DA Energy Cost $(\$)$ & 172,130 & 174,343 & 144,506 & 142,600 & 633,580 \\
Total DA Revenue (\$) & 9,661 & 26,317 & 0 & 0 & 35,978 \\
Real-Time Reconciliation (\$) & 979 & -147 & 0 & 0 & 832 \\
Total Energy Cost (\$) & 161,490 & 148,173 & 144,506 & 142,600 & 596,770 \\
Average Energy Cost (\$/MWh) & 51.37 & 47.63 & 50.81 & 53.15 & 50.65 \\
& & & & & \\
\hline
\end{tabular}

Over the 4-month period, the total average cost of energy was $\$ 50.65 / \mathrm{MWh}$. However, when the effect of the LIPA delivery charge is considered, this changes dramatically. Using low, medium, and high estimates based on the delivery charges of other utilities in New York State, the effect is significant. In the best case, with a $\$ 40 / \mathrm{MWh}$ delivery charge, the total average delivered cost is almost twice the energy cost, $\$ 90.65 / \mathrm{MWh}$. In the medium and high delivery charge scenarios, $\$ 55 / \mathrm{MWh}$ and $\$ 70 / \mathrm{MWh}$, the total cost becomes prohibitive.

A review of the Huntington site's LIPA billing history was conducted. The period reviewed was from July 18 to Oct. 16. During this period, the average cost of electricity was $\$ 117.46 / \mathrm{MWh}$. Although this does not consider all of the sites, it does suggest that the cost of participating as a direct customer may be slightly lower than the cost of continuing service from LIPA. 
In summary, the following conclusions can be drawn from the shadow experiment:

- The cost of energy from the NYISO DAM is quite favorable. For the 4-month evaluation period, the average cost of DA energy to serve the aggregated site was $\$ 50.65 / \mathrm{MWh}$.

- The additional burden imposed by the LIPA delivery charge makes the prospects for this model considerably less favorable. Using the most favorable (lowest) delivery charge of $\$ 40 / \mathrm{MWh}$ doubles the cost.

- When the total cost and revenues are considered, the average energy cost for the aggregated sites over the 4-month evaluation period is $\$ 90.65 / \mathrm{MWh}$ with the low delivery charge, $\$ 105.65$ for the medium delivery charge, and $\$ 120.65$ for the high delivery charge. These costs are not significantly different from the LIPA retail rates.

The shadow experiment demonstrated that the SR concept on Long Island, while technically possible, is not an economically viable business model. Electrotek believes that an alternative business model would be more cost-effective. In the new business model, the 10 aggregated sites would participate as a direct customer in the NYISO DAM, where the energy for the aggregated site load would be purchased based on the bid cost of the aggregated site. In this approach, the daily price capped load bids would be submitted to the NYISO DAM. It is Electrotek's belief that with proper management under such an arrangement, the ICAP requirements can be significantly reduced or eliminated, thus making this business model more feasible. 
Task 7: Survey of Backup Generation in New York State 


\section{Acronyms}

$\begin{array}{ll}\text { DEC } & \begin{array}{l}\text { Department of Environmental Conservation } \\ \text { distributed generation }\end{array} \\ \text { DG } & \text { demonstrated maximum net capability } \\ \text { DMNC } & \text { Emergency Demand Response Program } \\ \text { EDRP } & \text { Installed Capacity } \\ \text { ICAP } & \text { Long Island Power Authority } \\ \text { LIPA } & \text { meter data service provider } \\ \text { MDSP } & \text { New York Control Area } \\ \text { NYCA } & \text { New York Independent System Operator } \\ \text { NYISO } & \text { New } \\ \text { NYSRC } & \text { New York State Reliability Council } \\ \text { SCR } & \text { Special Case Resources } \\ \text { SCUC } & \text { security constrained unit commitment } \\ \text { SIC } & \text { standard industrial classification } \\ \text { UCAP } & \text { Unforced Capacity }\end{array}$




\section{Executive Summary}

In New York State, the confluence of utility industry restructuring, increasing capacity requirements, and advancing technologies are raising the potential of distributed generation (DG), particularly in the New York City and Long Island areas.

In a 3-year project jointly funded by the New York State Energy Research and Development Authority (NYSERDA) and the National Renewable Energy Laboratory of the U.S. Department of Energy, Electrotek Concepts is demonstrating the technical and economic feasibility of aggregated DG in New York State. The project will demonstrate a system that enables DG units to participate in regional competitive markets like large central-station power plants.

The project will develop system architecture to enable DG to participate in New York energy markets, and it will address and quantify key technical and economic issues. Current activities include (1) testing the concept via a pilot project on Long Island (Task 6), (2) evaluating DG capacity available in New York State and recruiting DG units (Task 7), and (3) designing the DG aggregation system structure and developing its elements (Task 8). These activities will culminate, in Option Year Two, in a 30-MW commercial demonstration.

This report addresses two objectives of Task 7 of the project:

- Identify and recruit new participants with a total of $30 \mathrm{MW}$ of DG capacity for the commercial demonstration

- Provide an assessment of the potential for DG in New York State.

\section{Recruitment of $30 \mathrm{MW}$ of Distributed Generation Capacity for the Demonstration Project}

Participation in New York Independent System Operator (NYISO) markets requires DG to be (a) equipped with monitoring equipment that can provide data for generator dispatch and settlement with NYISO and (b) in compliance with all New York State Department of Environmental Conservation (DEC) regulations and permitting requirements. Therefore, to recruit new buildings for the commercial DG program, it is necessary to consider the minimum configuration of monitoring equipment to be installed and to know the status of the environmental permitting of the buildings.

In Task 6, 10 buildings with a total curtailable capacity of $4.5 \mathrm{MW}$ were recruited for the pilot project. These buildings were equipped with monitoring equipment, including electricity meters on emergency generators and commercial service entrances and gateway devices to collect information transfer it to the Electrotek Data Collection and Management Center. The only instrument required by the NYISO for participation in power markets is an interval-type electricity meter at the service entrance that is installed and maintained by a certified meter data service provider (MDSP), which is usually the load serving entity (utility). Only data collected by such meters are recognized by the NYISO for settlements. The installation of other monitoring equipment is advantageous but not necessary for participation in NYISO markets. 
Thirty-eight buildings with a total installed capacity of $55.69 \mathrm{MW}$ were selected for participation in the commercial operation. This installed capacity will provide about $30 \mathrm{MW}$ of curtailable load, represented by three groups of buildings.

The first group consists of buildings that participated in the pilot project. These buildings were already fully equipped with monitoring equipment for the pilot. The second group includes buildings previously used by Electrotek in the NYISO Emergency Demand Response Program (EDRP). These buildings have some monitoring equipment, usually electric meters at emergency generators. The third group does not have any monitoring equipment except for interval meters operated by the utility. To support the operation of backup generators in buildings from the second and the third groups with forecasting and historical data analysis capabilities, building load and emergency generator output data will be modeled using interval meter data obtained from the MDSP or utility.

\section{Survey of Backup Generation in New York State}

To evaluate the potential for DG capacity in New York State, Electrotek formulated and conducted an analysis that consisted of two steps.

First, the total installed DG capacity of New York State was determined using a database inventory of emergency backup generators developed by Power Systems Research of Eagan, Minnesota. Analysis showed there is more than 3,582 MW of installed DG capacity across the state. Most of this capacity-2,896 MW, or $80 \%$-is from reciprocating engines. The balance is from turbines. There were 10,542 generators of at least $100 \mathrm{~kW}$ capacity in the database. Turbines account for only 460 of these. Across the state, the average capacity of a reciprocating engine was $285 \mathrm{~kW}$, and the average turbine was more than $1.5 \mathrm{MW}$.

Second, the share of the installed capacity that could technically participate in NYISO markets was determined by evaluating the New York State energy markets. Only two markets were identified as potentially valuable for DG participation: (1) the EDRP and Special Case Resources (SCR) and (2) the Energy and Ancillary Services markets. It was also determined that reciprocating engines can participate in only the EDRP and SCR market, but turbines can participate in both markets. Because participation in the Energy and Ancillary Services markets is more profitable, it was assumed that turbines would participate in this market only.

As a result, it was determined that the technical market potential for DG in New York State consists of about 1,869 MW in the EDRP and SCR markets (reciprocating engines) and 468 MW in the Energy and Ancillary Services markets (turbines). This brings the total technical DG potential in New York State to 2,338 MW. This potential represents approximately $65 \%$ of the 3,582 MW of total DG capacity. 


\section{Table of Contents}

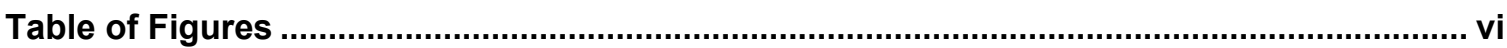

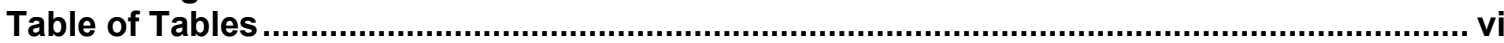

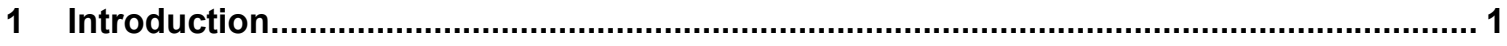

2 Recruitment for Demonstration Project......................................................................... 3

2.1 Monitoring Equipment Duties and Configuration ....................................... 3

2.2 Buildings for the 30-MW Commercial Distributed Generation Aggregation

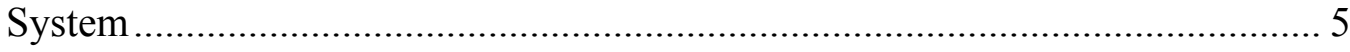

2.3 Utility Service Entrance Load Data ............................................................. 7

3 Survey of Backup Generation in New York State ...................................................... 10

3.1 New York Independent System Operator Markets ...................................... 10

3.1.1 Installed Capacity Market ........................................................... 10

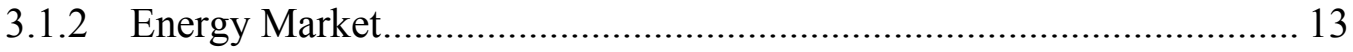

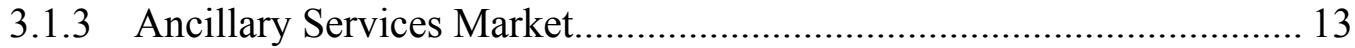

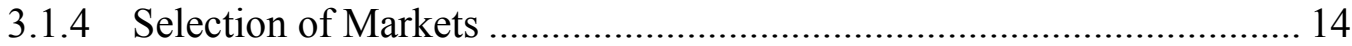

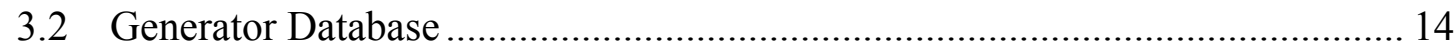

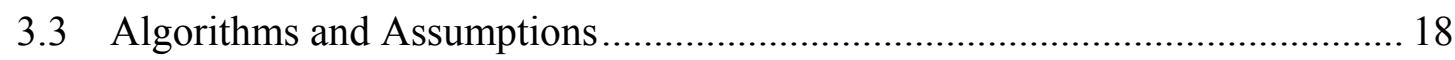

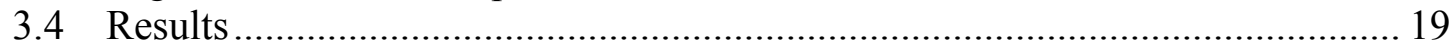

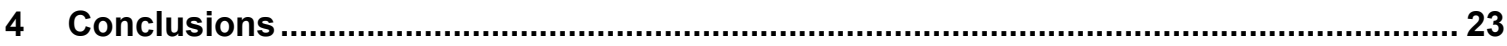

4.1 Recruitment for Demonstration Project ...................................................... 23

4.2 Survey of Backup Generation in New York State ......................................... 24

Appendix A: Distributed Generation Database.............................................................. A-1 Appendix B: Standard Industrial Classification Code and Curtailment Ratios.................... B-1 


\section{Table of Figures}

Figure 1. Processing of utility interval load data.............................................. 8

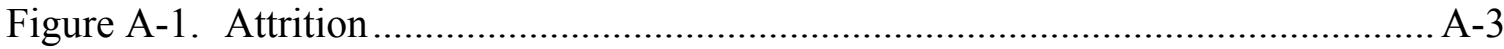

\section{Table of Tables}

Table 1. Buildings Equipped With Meters on Generators and Commercial Service

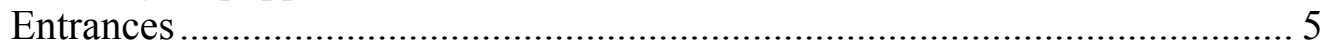

Table 2. Buildings Equipped With Meters on Generators (All) and on Commercial Service Entrance (Some) ...................................................................... 6

Table 3. Buildings With No Metering Equipment ................................................... 7

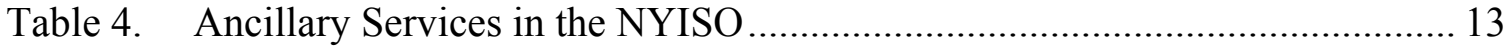

Table 5. New York State DG Resources - Installed Capacity................................... 16

Table 6. New York State DG Resources - Number of Generators............................. 17 


\section{Introduction}

For this task, Electrotek will assess the potential for distributed generation (DG) in New York State and the $30 \mathrm{MW}$ of generation recruited for participation in the commercial demonstration. DG holds promise and opportunity for the bulk power system and DG owners. However, the specific roles of DG depend on the type of generating asset, its location, and the fuel used. Electrotek relied on Power Systems Research of Eagan, Minnesota, to develop and provide a list of DG resources in the state. Using this listing, Electrotek formulated and conducted an analysis of the potential for DG in New York.

To evaluate the potential for DG capacity in New York, Electrotek first considered the markets in which these resources would participate. The opportunities for DG in New York wholesale power markets are driven by a number of factors. These include the restructuring of the electric utility industry, decreasing capacity reserves, and advancements in DG technologies. In New York State, the restructuring of the power industry has resulted in competitive markets for generation procurement, distribution services provided by regulated monopolies, and transmission services provided by the New York Independent System Operator (NYISO) using transmission capacity owned by regulated utilities. In New York wholesale power markets, DG has been aggressively pursued. The deployment of DG for load curtailment has been successfully used in New York with the Emergency Demand Response Program (EDRP) and the Day-Ahead Demand Response Program. The EDRP market was critical in maintaining system reliability in the summers of 2001 and 2002 and has been recognized as one of the most effective curtailment programs in the country.

The capacity situation in New York, and particularly in New York City, is acute and jeopardizes the reliability of the bulk power system. A report published by the NYISO noted that New York State needs an additional 7,100 MW of capacity by 2005. Because of transmission capacity constraints in New York City, 2,000 to 3,000 MW of this capacity must be located there.

Although there are many emergency and backup generators in New York, many of these are diesel fuel-fired internal combustion and turbine units. This means much of the available emergency reserve potential has high emission levels. Compounding that fact, these resources are most likely to be called during peak load periods characterized by high temperatures and humidity, which exacerbates an already severe pollution problem.

Under this contract, Electrotek has developed an aggregation and dispatch system for DG that is well suited for the institutional and regulatory environment of New York State. This system can be used for nearly all qualified generating assets in any number of NYISO programs and markets. With this system, DG units can participate in the Installed Capacity (ICAP), Energy, and Ancillary Services markets. This flexibility makes the aggregation system a key component of bringing DG to the marketplace and helping mitigate reserve shortfalls in New York State's bulk power system. 
This report consists of two sections. The first section describes the commercial demonstration of the aggregation of DG resources. Thirty megawatts were recruited for this demonstration. In the second section, a survey of backup generation in New York State is presented. This survey starts with descriptions of the markets that DG resources might be able to enter. This is followed by a description and summary of the DG database used in this analysis. Then the objectives and methodology of the analysis will be detailed. Finally, the results of the analysis will be presented. 


\section{Recruitment for Demonstration Project}

In Task 6, 10 buildings with a total curtailable capacity of $4.5 \mathrm{MW}$ were recruited for participation in the pilot project. These buildings are located in Long Island. These buildings were equipped with full sets of monitoring equipment, including:

- Electricity meters on emergency generators

- A KYZ demarcation box on the utility electricity meter, installed on the commercial service entrance and equipped with a module to convert pulses from the electric meter into kilowatt-hours

- A gateway device (InfoNode 5500) for collection of information from generators and the commercial entrance and transfer of this information to the Electrotek Data Collection and Management Center.

This configuration permits Electrotek to constantly monitor total building load and load on the emergency generators when they are operated. The average cost of the full set of equipment, including installation, for a facility with one emergency generator was $\$ 9,000$ to $\$ 11,000$. Each additional emergency generator cost about $\$ 1,500$. Such expenses incurred for participation in the EDRP or other peak-shaving or economic programs could be prohibitive.

Meanwhile, over 2 years, Electrotek recruited a number of generators for participation in several NYISO and utility curtailment programs. Some of these buildings already had monitoring equipment installed. If included in the commercial aggregation system, these generators could bring the total capacity to $15-16 \mathrm{MW}$. This means an additional 9-10 MW of new capacity should be identified and recruited for participation in the commercial DG system, as required by Task 7 .

Participation in NYISO markets requires that generators be in compliance with all New York State Department of Environmental Conservation (DEC) regulations and permitting requirements. Therefore, to achieve $30 \mathrm{MW}$ of capacity, it was necessary to consider:

- How buildings with installed monitoring equipment of different configurations could be incorporated into the existing DG aggregation system

- The minimum configuration of monitoring equipment necessary in newly selected buildings to enable them to be included in the existing DG aggregation system

- The status of the environmental permitting for the selected facilities.

\subsection{Monitoring Equipment Duties and Configuration}

The significant experience gained in Task 6 provided insights into the flow of operating information gathered by the monitoring and communications systems. 
First, for the purposes of settlements, the NYISO recognizes only energy metering data collected by certified metering instruments. Thus, Electrotek was obligated to obtain these data from a meter data service provider (MDSP) or utility. Electrotek contracted with the utilities to obtain interval data at the end of each month. The data are 15-minute interval load data from Con Ed and 15-minute pulse data from the Long Island Power Authority (LIPA). The utilities email the data to the DG Dispatch and Monitoring Center. The data are received mid-month for the previous month.

All data collected by Electrotek through its on-site monitoring equipment are stored and presented on the aggregation Web site. These data are used for information and operation/decision-making purposes only.

- Building electric load data collected at the service entrance with a GE meter installed by Electrotek or by the utility service meter through the KYZ demarcation box. These data are used for the building load forecast algorithm, which is necessary for the operation of several additional programs, such as the bidding and peak-hunting tools.

Usually, this information is stored in the InfoNode 5500 on-site and transferred to the Data Collection and Management Center once a day. If this information is available, the building load forecast algorithm (building electric load versus ambient temperature and humidity) is updated daily. In general, this relationship is relatively stable during short periods of time and, if necessary, can be updated with acceptable accuracy once in a one-week to one-month period. This means that buildings not equipped for continuous monitoring can be modeled on the basis of monthly information interval data received from the utilities.

- Data on emergency generator output provides DG operators, generator owners, and clients with near real-time (10-min lag) generator output information during curtailment and information for historical performance presentations. In buildings not so equipped, generator load can be calculated as the difference between the building load before/after curtailments and the building load during curtailment, though this is not real-time information.

- InfoNode 5500 computers, installed on-site, can also be used for remote start/stop of emergency generators. Unfortunately, a major client and owner of almost all the generators aggregated for this project does not permit remote operation of its generators by any third party. In these facilities, Electrotek is using a "semi-remote" technique in which Electrotek's dispatcher notifies the client's area managers about dispatch requirements and schedules via phone, pager and e-mail. The area managers then start or stop their generators remotely from their computers. Under this routine, Electrotek informs only three or four people instead of calling each generator site. 
Based on experience with these facilities, Electrotek believes the installation of monitoring equipment is advantageous but not necessary. This is because these facilities are curtailable loads, not generators in the NYISO markets, and as such do not need the more stringent metering and communication systems required for generators. Electrotek believes each case should be evaluated separately, and appropriate decisions about metering and communications configurations should be tailored to customer requirements.

\subsection{Buildings for the 30-MW Commercial Distributed Generation Aggregation System}

Thirty-eight buildings in New York City, Long Island, and Westchester County were selected and recruited for the commercial aggregated DG system. Total installed capacity is $55.69 \mathrm{MW}$ with $31.75 \mathrm{~kW}$ of curtailable load. All these buildings were registered with the NYISO for curtailment operations in the summer of 2003. All have environmental permits.

These buildings were differentiated by the presence and configuration of DG monitoring equipment, as presented in the following tables. The identification of participants is withheld because of the proprietary nature of the information provided.

Table 1 lists buildings equipped with the full set of monitoring equipment, including electricity meters on generators and monitoring of the building commercial service entrance. These are the seven buildings on Long Island that participated in the DG aggregation pilot experiment. This group also includes a building in Manhattan - one of this client's largest buildings in New York State. In this building, all four generators are equipped with electric meters, as are commercial service entrances. Information from these buildings is automatically collected at Electrotek's Data Collection and Management Center as described in the Task 6 and Task 8 reports.

Table 1. Buildings Equipped With Meters on Generators and Commercial Service Entrances

\begin{tabular}{cccc}
\hline & & $\begin{array}{c}\text { Curtailable } \\
\text { Load } \\
\text { Resource }\end{array}$ & $\begin{array}{c}\text { Generator } \\
\text { Capacity } \\
\text { (MW) }\end{array}$ \\
\cline { 2 - 4 } 1 & $\mathrm{~K}$ & 0.589 & 0.750 \\
2 & $\mathrm{~K}$ & 0.493 & 1.000 \\
3 & $\mathrm{~K}$ & 0.601 & 1.500 \\
4 & $\mathrm{~K}$ & 0.274 & 0.435 \\
5 & $\mathrm{~K}$ & 0.862 & 1.500 \\
6 & $\mathrm{~K}$ & 0.502 & 0.750 \\
7 & $\mathrm{~K}$ & 0.506 & 1.000 \\
8 & $\mathrm{~J}$ & 5.428 & 10.000 \\
& & & \\
Total & & $\mathbf{9 . 2 5 5}$ & $\mathbf{1 6 . 9 3 5}$ \\
& & & \\
\hline
\end{tabular}


Table 2 lists buildings that already were or are involved in the EDRP. These buildings are equipped with electric meters on each emergency generator and connected to the InfoNode 5500 for storage and transfer of information to the Electrotek center. Information about building load, necessary for the Web site and for forecasting models and tools, will be based on monthly interval load data provided by the utilities. For these buildings, a generator load during curtailment will be shown using "real time" data from the on-site generator load meters. A building load between curtailment operations will be calculated using forecasting building load versus ambient temperature and humidity.

Table 2. Buildings Equipped With Meters on Generators (All) and on Commercial Service Entrance (Some)

\begin{tabular}{|c|c|c|c|}
\hline Resource & Zone & $\begin{array}{l}\text { Curtailable } \\
\text { Load } \\
\text { (MW) }\end{array}$ & $\begin{array}{l}\text { Generator } \\
\text { Capacity } \\
\text { (MW) }\end{array}$ \\
\hline 9 & I & 2.251 & 3.750 \\
\hline 10 & $J$ & 0.537 & 0.850 \\
\hline 11 & $\mathrm{~J}$ & 1.397 & 4.000 \\
\hline 12 & $\mathrm{~J}$ & 0.798 & 2.250 \\
\hline 13 & $J$ & 1.252 & 1.500 \\
\hline 14 & $\mathrm{~J}$ & 2.228 & 5.000 \\
\hline 15 & I & 0.426 & 0.435 \\
\hline 16 & I & 0.337 & 0.350 \\
\hline 17 & $\mathrm{~J}$ & 0.617 & 0.970 \\
\hline 18 & $J$ & 0.392 & 0.400 \\
\hline 19 & $\mathrm{~J}$ & 0.847 & 1.000 \\
\hline 20 & $\mathrm{~J}$ & 1.562 & 2.000 \\
\hline Total & & 12.644 & 22.505 \\
\hline
\end{tabular}

Table 3 lists newly recruited buildings without any on-site monitoring equipment. For most of these buildings, the installed capacity of emergency generators is bigger than the entire building load, which is automatically transferred to the emergency generators during curtailment. For these facilities, a building load between curtailment events and building/generator load during curtailment will be calculated using a building load forecast model, based initially on the data (electric load and weather information) for the last year, and updated every following month on the basis of the NYISO monthly report. 
Table 3. Buildings With No Metering Equipment

\begin{tabular}{|c|c|c|c|c|}
\hline & Resource & Zone & $\begin{array}{c}\text { Curtailable } \\
\text { Load } \\
\text { (MW) }\end{array}$ & $\begin{array}{c}\text { Generator } \\
\text { Capacity } \\
\text { (MW) }\end{array}$ \\
\hline & 21 & $\mathrm{~J}$ & 0.273 & 0.400 \\
\hline & 22 & $\mathrm{~K}$ & 0.565 & 1.000 \\
\hline & 23 & $\mathrm{~K}$ & 0.394 & 0.600 \\
\hline & 24 & $\mathrm{~K}$ & 0.963 & 1.000 \\
\hline & 25 & 1 & 0.324 & 2.000 \\
\hline & 26 & $\mathrm{~K}$ & 3.035 & 5.000 \\
\hline & 27 & $\mathrm{~K}$ & 0.250 & 0.300 \\
\hline & 28 & $\mathrm{~K}$ & 0.873 & 1.000 \\
\hline & 29 & $\mathrm{~K}$ & 0.479 & 0.500 \\
\hline & 30 & $\mathrm{~K}$ & 0.294 & 1.200 \\
\hline & 31 & $\mathrm{~K}$ & 0.453 & 0.500 \\
\hline & 32 & $\mathrm{~K}$ & 0.327 & 0.350 \\
\hline & 33 & $\mathrm{~K}$ & 0.340 & 0.500 \\
\hline & 34 & $\mathrm{~K}$ & 0.271 & 0.350 \\
\hline & 35 & $\mathrm{~K}$ & 0.333 & 0.500 \\
\hline & 36 & $\mathrm{~J}$ & 0.274 & 0.350 \\
\hline & 37 & $\mathrm{~J}$ & 0.404 & 0.700 \\
\hline Total & & & 9.852 & 16.250 \\
\hline
\end{tabular}

All necessary building load models will be developed in preparation for the operation of the commercial DG aggregation system during the execution of Task 9.

\subsection{Utility Service Entrance Load Data}

The utility service entrance load data are critical for the operation of the aggregated DG system. The data formats received and their conversion into the Electrotek DG system are also important. A technique for downloading and converting data is described below.

Utilities provide Electrotek with load data once a month. Currently, Electrotek is receiving load data from Con Ed and LIPA. The utilities e-mail the file to the DG Dispatch Center. These are received mid-month for the previous month's data. The files from the utilities are in different formats, but both provide interval load data. Electrotek has developed a program that will extract the interval load data from these files and insert it into the PQView database. 
The steps for processing the interval load data supplied by the utilities are:

- The utility e-mails the file to the Dispatch Center.

- The dispatch center runs the file provided through a program that parses the data and transfers it to a comma-separated file, CSV, with data formatted as shown below.

Date, Time, Interval Load (kWh)

- The Utility Data Handler processes the CSV files and the data inserted into the PQView database.

These steps are illustrated in Figure 1.

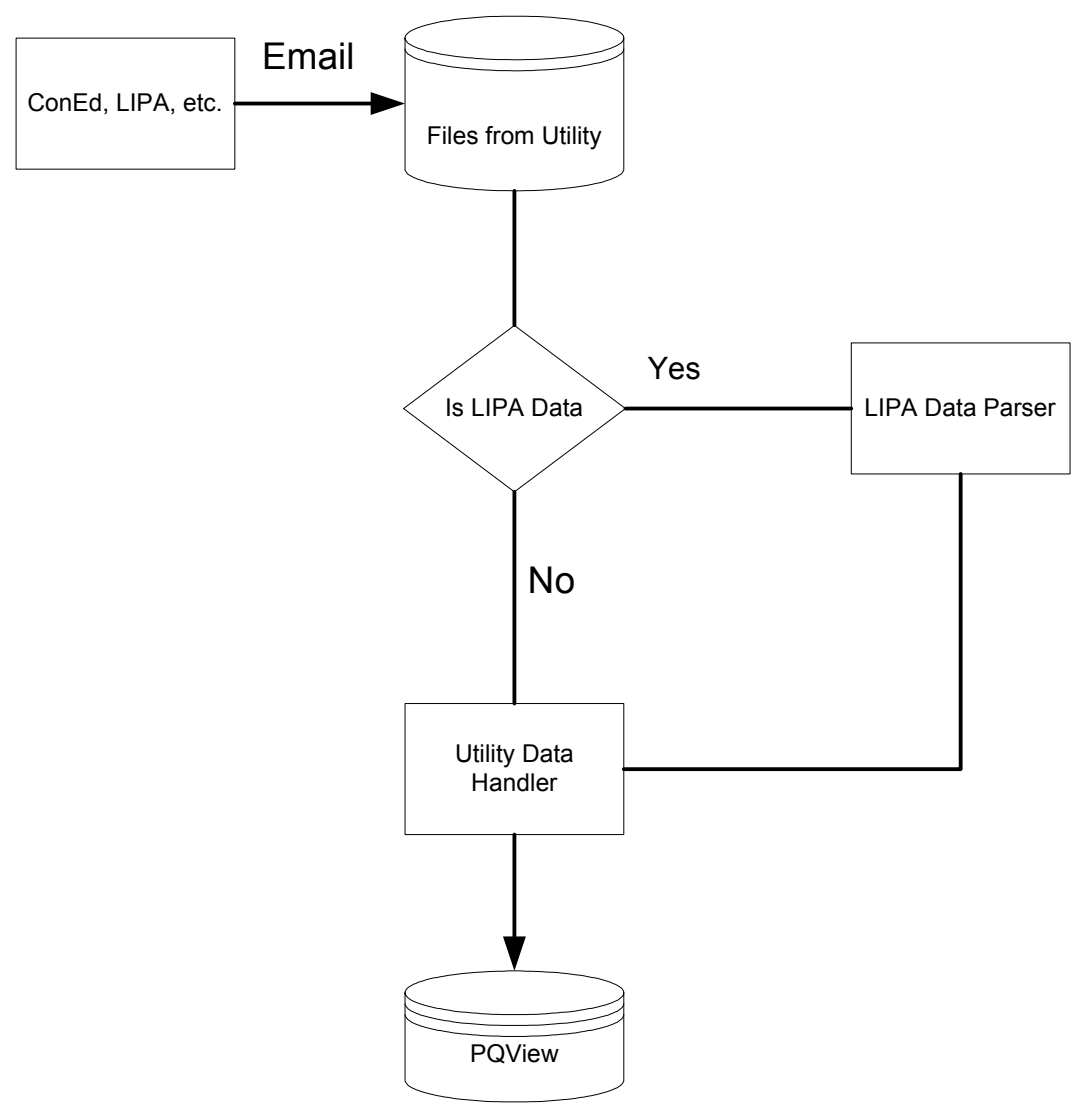

Figure 1. Processing of utility interval load data

Once the interval load data are stored in the PQView database, viewing the data will be virtually the same as viewing data downloaded from the monitoring equipment. 
The PQView database is the database in which all the data downloaded from buildings with monitoring equipment is stored. The single point of access for users is the Web site application, AggregationWeb. AggregationWeb provides users views of the data in PQView.

The only disadvantage of using the utility data is the time delay. For buildings that have installed monitoring equipment, the interval load data for any day will be available the next day. In addition, AggregationWeb can communicate to the installed monitoring equipment through a live data interface, thus providing live data views for generator output data and interval load data. For buildings without installed monitoring equipment, the live data views will not be available.

Servers for downloading monthly reports and converting them into formats in the aggregation Web site and for data collection, storage, and management utilities in the DG Data Collection and Management Center will be developed during Task 9. 


\section{Survey of Backup Generation in New York State}

To evaluate the potential for DG capacity in New York State, it is necessary to determine not only the installed DG capacity but also:

- What load is served by the installed capacity (especially if generators will be used for peak-shaving activities without interconnection with the grid)

- What economic incentives will drive the use of these generators

- What environmental implications will influence the operation of the DG.

These considerations are detailed in the following sections.

\subsection{New York Independent System Operator Markets}

There are four markets in the NYISO in which DG can participate. These are the ICAP, Energy, and Ancillary Services markets and the EDRP. These markets are administered by the NYISO in accordance with rules detailed in the OATT and numerous NYISO manuals. In this section, each of the major markets-ICAP, Energy, and Ancillary Services - will be detailed. Each of these markets will also be broken down into component markets.

\subsubsection{Installed Capacity Market}

The NYISO ICAP market is the market for capacity administered by the NYISO. This market has two 6-month planning cycles, or capability periods. The Winter Capability Period runs from November through April; the Summer Capability Period runs from May through October. Each capability period has a series of six monthly capacity auctions, a six-month strip auction, and, if necessary, monthly deficiency auctions.

The planning and procurement process for the NYISO ICAP market begins with the New York State Reliability Council (NYSRC). The NYSRC is a non-profit entity responsible for developing, maintaining, and updating the reliability rules for the NYISO and all parties engaged in electric transmission, ancillary services, and energy and power transactions on the New York State power system.

The NYSRC determines the New York Control Area (NYCA) reserve margin on an annual basis. Next, the NYISO determines the ICAP requirement for the NYCA in accordance with the reliability rules and standards of the NYSRC and the Northeast Power Coordinating Council. The NYISO then converts the NYCA installed capacity requirement into a NYCA unforced capacity (UCAP) requirement. The UCAP value is obtained by multiplying the ICAP requirement by one minus the average forced outage rate for all resources in the NYCA. 
After estimating the NYCA UCAP requirement, the NYISO determines the locational ICAP requirement for each of the 11 NYISO zones in New York State. Locational ICAP is generating capacity physically located within a specific zone, i.e., local (zonal) generating capacity. This locational ICAP requirement is based on the load and local generating capacity within each zone as well as the available transmission capacity to each zone. Thus, transmission-constrained areas will tend to have higher locational ICAP requirements as a percentage of total zonal load. This is the case in two NYISO zones: Zone J (New York City) and Zone K (Long Island).

ICAP resources face a number of requirements. First, any ICAP resource must be in full compliance with New York DEC registration and emissions regulations. This means these resources must register with DEC either a state facilities permit, a Title V registration, or an air facilities registration. Each of these classifications places a cap on total emissions for the facility. All ICAP resources sold in the NYCA either bilaterally or in NYISO markets must be certified on a monthly basis with NYISO. This certification process registers all transactions with the NYISO and provides a basis for determining whether these ICAP resources have satisfied their transaction obligations. In addition, for most ICAP resources, maintenance scheduling and outage reports must be filed with the NYISO. This ensures that all certified capacity not in service because of maintenance or outage is reported as unavailable to the NYISO. Finally, there are operating data reporting requirements for all resources.

There are six types of ICAP resources in the NYISO. These are:

- Generators and system resources

- Energy limited resources

- Interruptible load resources

- Municipally owned generation

- Special case resources

- Intermittent power resources

Each of these is described in the following sections.

\subsubsection{Generators and System Resources}

Generators are interconnected units that can inject power into the grid. A generator must have at least $1 \mathrm{MW}$ of capacity to be certified in the NYISO ICAP market. All generators participating in NYISO markets must undergo a demonstrated maximum net capability (DMNC) test to verify their certified capacity value. DMNC tests typically determine a unit's sustained maximum net output averaged over 4 hours. Generators must also provide the NYISO with planned maintenance schedules, which may be voluntarily rescheduled at the NYISO's request.

A system resource is a portfolio of UCAP provided by multiple sites or units in a single NYISO zone and owned by or controlled by a single entity. A system resource is offered in whole or in part to the NYISO, and like generators must have a minimum capacity of $1 \mathrm{MW}$. A system resource must also undergo a DMNC test and must be able to operate in Day-Ahead or RealTime energy markets. An example of a system resource is a set of small DG located within a single NYISO zone and aggregated to satisfy the $1 \mathrm{MW}$ minimum capacity threshold. 


\subsubsection{Energy Limited Resources}

Energy limited resources are those capacity resources that - because of design considerations, environmental restrictions, cyclical requirements, or other non-economic reasons-are unable to operate continuously on a daily basis but are able to operate for at least 4 consecutive hours each day. Typically, such resources include storage units (e.g., pumped storage or compressed air energy storage) and units whose operation is restricted by emission limits.

\subsubsection{Interruptible Load Resources}

An interruptible load resource is a load that is obligated, under a contract, to be interrupted when required by the ISO. Interruptible loads must demonstrate through a DMNC test that they are capable of the contract reduction in consumption in response to the NYISO request. Like generators and system resources, interruptible load resources that sell capacity in the ICAP market are then obligated to offer their load in either the Day-Ahead or Real-Time energy markets.

\subsubsection{Municipally Owned Generation}

A municipal utility that owns generation in excess of its ICAP requirement may qualify that excess capacity as UCAP in the ICAP market. To do so, the municipal utility must provide the NYISO with the physical operating parameters of the generation and operate the excess generation capacity in accordance with NYISO ICAP market rules. However, for generation that was in service or under construction as of Dec. 31, 1999, exemptions for bidding, scheduling, and notification requirements may be sought.

\subsubsection{Special Case Resources}

Special case resources (SCR) are loads capable of being interrupted upon demand and DG, rated $100 \mathrm{~kW}$ or more, that are not visible to NYISO's market information system. The UCAP of an SCR corresponds to its pledged load reduction adjusted by historical performance factors and increased by the transmission district loss factor (to account for transmission losses that would be incurred serving the SCR site load). SCR are required to demonstrate their capability once in each capability period with a 1-hour test.

Because of their smaller size and the fact that few of the DG units in New York are interconnected, these units would only be eligible for the ICAP market as SCR. This allows these units to receive a capacity payment based on the load they curtail and obligates them to curtail when called.

The UCAP of SCR may be sold in the ICAP market or in bilateral transactions. If sold, SCR must provide their energy or curtailment for a minimum 4-hour block when called. SCR are only dispatched when system reserve margins are deficient. These resources are not required to bid in Energy and Ancillary Service markets.

\subsubsection{Intermittent Power Resources}

Intermittent power resources are capacity resources that rely on the wind or solar energy for generation. These resources are dependent on sources that cannot be readily scheduled for production, and their capacity value may vary based on the availability of the driver (i.e., the wind or sun). 
Such resources are considered irregular capacity, though they may qualify as ICAP suppliers without having to comply with the daily bidding and scheduling requirements of other suppliers. To qualify as ICAP suppliers, intermittent power resources must comply with the standard notification requirements. In addition, to calculate the UCAP for an intermittent power resource, the historical capacity factor will be adjusted to remove the effects of outages.

\subsubsection{Energy Market}

The NYISO has two Energy markets: the Day-Ahead and Real-Time markets. Market participants - excluding SCR, qualified intermittent power resources, and qualified municipally owned generators - must offer their UCAP in either the Energy or Ancillary Services markets to satisfy the requirements of the ICAP market, detailed above.

The NYISO Day-Ahead Market relies on the security constrained unit commitment (SCUC) program to schedule resources and determine locational based marginal prices, which are hourly zonal electricity prices. The SCUC evaluates load forecasts and the price and availability of resource bids to prepare a generation schedule for the next day. The SCUC is an optimization model that minimizes the total production cost of energy while satisfying reliability and generator performance constraints (e.g., ramp rates and minimum run time).

The Real-Time (RT) Energy market balances the scheduled day-ahead dispatch, which is based on forecasted loads, with actual loads. In New York State, the RT market accounts for roughly $5 \%$ of the total energy of the system. It serves as a balancing market.

\subsubsection{Ancillary Services Market}

Ancillary services are those services necessary to support the transmission of energy from generators to loads. In the NYISO, there are six ancillary services. Of these, three are marketbased; the others are provided by the NYISO and paid for through embedded costs. The NYISO coordinates the provision of all ancillary services and directly arranges for the supply of all ancillary services that are not self-supplied. Some ancillary services must be provided by the NYISO; others may be self-supplied. Table 4 summarizes the ancillary services in the NYISO.

Table 4. Ancillary Services in the NYISO

\begin{tabular}{lcll}
\hline \multicolumn{1}{c}{ Ancillary Service } & $\begin{array}{c}\text { Location } \\
\text { Based }\end{array}$ & \multicolumn{1}{c}{ Provider } & Pricing \\
\cline { 2 - 4 } $\begin{array}{l}\text { Scheduling, System Control, and } \\
\text { Dispatch }\end{array}$ & No & NYISO & Embedded \\
$\begin{array}{l}\text { Voltage Support } \\
\text { Regulation and Frequency Response }\end{array}$ & Yes & NYISO & Embedded \\
Energy Imbalance & No & NYISO or self-supply & Market-based \\
Operating Reserves & Yes & NYISO or self-supply & Market-based \\
Black Start & Yes & NYISO & Embedded \\
& & & \\
\hline
\end{tabular}


Because the DG resources considered here are not interconnected with the grid, the only ancillary services they are able to provide is operating reserves. Operating reserve service provides backup generation in the event major generating resources trip offline because of a power system contingency or equipment failure. Most of the reserves must be available from units within the NYCA and specific regions, as required by the NYSRC.

Three types of reserves are sold in the NYISO ancillary services market. These are:

- 10-min spinning reserves

Operating reserves provided by generators and interruptible/dispatchable load resources within the NYCA that are already synchronized to the NYS power system and can respond to instructions to change output level within $10 \mathrm{~min}$.

- 10-min non-synchronized reserves Operating reserves provided by generators that can be started, synchronized, and loaded within $10 \mathrm{~min}$. These reserves are carried on quick-start units, such as gas turbines.

- 30-min spinning reserves

30-min spinning reserve provided by generators and interruptible/dispatchable load resources located within the NYCA and that are already synchronized to the NYS power system.

Curtailable loads can participate in any of the reserve markets. Like other resources, they must be registered and certified in the ICAP market before participating in the ancillary services market.

\subsubsection{Selection of Markets}

A number of conclusions about the NYISO markets should be restated. First, diesel generation can participate only in the NYISO EDRP or in the ICAP market as an SCR. The emission levels associated with diesels preclude their participation in Energy or Ancillary Services markets. Furthermore, the new DG rules being promulgated by DEC are likely to explicitly exclude their operation in the Energy and Ancillary Services markets. In addition, turbines in this analysis are considered only in the Energy and Ancillary Services markets. Although they can and do participate in EDRP and ICAP markets as SCR, they are not considered in those markets because the financial incentives for participation in Energy and Ancillary Services markets are much greater.

\subsection{Generator Database}

The analysis for this report is based on a database inventory of emergency backup generators provided by Power Systems Research Corp. of Eagan, Minnesota. The database lists each generator's county, capacity, type, fuel, and vintage as well as the type of business in which the owner of the generator is engaged. A description of the database is provided in Appendix A.

A review of the database found some omissions. These exclusions were generators known to Electrotek but not in the database provided by Power Systems Research. Although these 
omissions cannot be dismissed, Electrotek does not believe they warrant a diminution of the value of the data. Although the database cannot be considered all-inclusive, it is the most comprehensive accounting of DG in New York State Electrotek was able to find.

The original database listed DG resources of all sizes, including units as small as $10 \mathrm{~kW}$. For this study, units less than $100 \mathrm{~kW}$ were excluded because $100 \mathrm{~kW}$ is the minimum size for participation in NYISO programs, EDRP, and SCR.

Table 5 shows the total generating capacity of DG units with a capacity of $100 \mathrm{~kW}$ or more by generator type and county. There are more than 3,582 MW of capacity across the state. Most of this capacity-2,896 MW, or $80 \%$ - is from reciprocating engines, with the balance from turbines. Table 6 shows the number of generators by type and county. There were 10,542 generators of at least $100 \mathrm{~kW}$ of capacity listed in the database. Of these, most were reciprocating engines; turbines accounted for only 460 . Across the state, the average capacity of a reciprocating engine was $285 \mathrm{~kW}$, and the average turbine was more than $1.5 \mathrm{MW}$.

Another interesting point is that there were nine counties with a DG capacity of more than 100 MW. These counties were Dutchess, Erie, Kings, Monroe, Nassau, New York, Queens, Suffolk, and Westchester. Of these, Erie County had the most capacity: 124 MW. Most of these counties are in the New York City and Long Island areas, which are the areas in most need of capacity. 
Table 5. New York State DG Resources - Installed Capacity

\begin{tabular}{|c|c|c|c|c|c|c|c|c|c|c|c|}
\hline \multicolumn{12}{|c|}{ New York State DG Resources - MW } \\
\hline County & Recip & Turbine & Total & County & Recip & Turbine & Total & County & Recip & Turbine & Total \\
\hline Albany & 50.2 & 16.3 & 66.5 & Herkimer & 29.7 & 8.7 & 38.4 & Richmond & 42.9 & 12.1 & 55.0 \\
\hline Allegany & 29.5 & 4.9 & 34.3 & Jefferson & 31.6 & 9.6 & 41.2 & Rockland & 55.2 & 9.2 & 64.3 \\
\hline Bronx & 76.9 & 18.1 & 95.0 & Kings & 83.5 & 21.2 & 104.7 & Saratoga & 39.4 & 6.8 & 46.2 \\
\hline Broome & 52.3 & 11.1 & 63.4 & Lewis & 35.3 & 8.6 & 43.9 & Schenectady & 59.6 & 15.5 & 75.0 \\
\hline Cattaraugus & 70.9 & 18.4 & 89.3 & Livingston & 41.4 & 8.9 & 50.3 & Schoharie & 30.0 & 4.8 & 34.8 \\
\hline Cayuga & 36.7 & 8.5 & 45.3 & Madison & 38.0 & 9.7 & 47.8 & Schuyler & 21.6 & 7.3 & 28.9 \\
\hline Chautauqua & 73.4 & 24.9 & 98.3 & Monroe & 84.4 & 24.2 & 108.6 & Seneca & 19.7 & 8.0 & 27.7 \\
\hline Chemung & 37.7 & 4.7 & 42.4 & Montgomery & 35.5 & 5.0 & 40.5 & St. Lawrence & 49.0 & 13.6 & 62.7 \\
\hline Chenango & 34.5 & 7.0 & 41.5 & Nassau & 89.2 & 22.1 & 111.3 & Steuben & 27.9 & 14.7 & 42.6 \\
\hline Clinton & 33.1 & 9.0 & 42.1 & New York & 87.9 & 21.3 & 109.2 & Suffolk & 89.7 & 28.0 & 117.7 \\
\hline Columbia & 31.4 & 4.4 & 35.8 & Niagara & 69.2 & 15.2 & 84.4 & Sullivan & 56.8 & 13.1 & 69.9 \\
\hline Cortland & 35.3 & 6.0 & 41.3 & Oneida & 56.8 & 14.5 & 71.2 & Tioga & 29.5 & 2.5 & 32.0 \\
\hline Delaware & 35.1 & 7.1 & 42.2 & Onondaga & 77.6 & 20.4 & 98.0 & Tompkins & 31.2 & 10.5 & 41.7 \\
\hline Dutchess & 85.2 & 23.1 & 108.3 & Ontario & 41.5 & 5.9 & 47.4 & Ulster & 37.6 & 12.8 & 50.4 \\
\hline Erie & 90.4 & 33.5 & 124.0 & Orange & 62.4 & 13.6 & 76.0 & Warren & 35.8 & 6.0 & 41.8 \\
\hline Essex & 34.3 & 8.3 & 42.5 & Orleans & 32.9 & 3.0 & 35.9 & Washington & 20.3 & 6.2 & 26.5 \\
\hline Franklin & 34.6 & 9.4 & 43.9 & Oswego & 39.4 & 6.8 & 46.2 & Wayne & 24.8 & 5.5 & 30.3 \\
\hline Fulton & 30.6 & 9.4 & 40.0 & Otsego & 35.3 & 7.5 & 42.7 & Westchester & 89.0 & 27.1 & 116.1 \\
\hline Genesee & 31.7 & 7.1 & 38.8 & Putnam & 32.1 & 6.0 & 38.1 & Wyoming & 25.9 & 6.4 & 32.4 \\
\hline Greene & 22.0 & 4.9 & 26.9 & Queens & 85.9 & 24.2 & 110.1 & Yates & 6.1 & 0.0 & 6.1 \\
\hline Hamilton & 22.2 & 4.9 & 27.1 & Rensselaer & 40.2 & 5.7 & 45.9 & Total & $2,869.8$ & 712.9 & $3,582.7$ \\
\hline
\end{tabular}

Task 7 
Table 6. New York State DG Resources - Number of Generators

\begin{tabular}{|c|c|c|c|c|c|c|c|c|c|c|c|}
\hline \multicolumn{12}{|c|}{ New York State DG Resources - Generators } \\
\hline County & Recip & Turbine & Total & County & Recip & Turbine & Total & County & Recip & Turbine & Total \\
\hline Albany & 160 & 11 & 171 & Herkimer & 107 & 5 & 112 & Richmond & 151 & 7 & 158 \\
\hline Allegany & 110 & 3 & 113 & Jefferson & 115 & 6 & 121 & Rockland & 199 & 7 & 206 \\
\hline Bronx & 271 & 12 & 283 & Kings & 293 & 15 & 308 & Saratoga & 140 & 5 & 145 \\
\hline Broome & 185 & 8 & 193 & Lewis & 121 & 5 & 126 & Schenectady & 204 & 10 & 214 \\
\hline Cattaraugus & 245 & 14 & 259 & Livingston & 146 & 6 & 152 & Schoharie & 107 & 3 & 110 \\
\hline Cayuga & 131 & 6 & 137 & Madison & 135 & 5 & 140 & Schuyler & 72 & 5 & 77 \\
\hline Chautauqua & 253 & 16 & 269 & Monroe & 299 & 15 & 314 & Seneca & 64 & 6 & 70 \\
\hline Chemung & 135 & 3 & 138 & Montgomery & 125 & 4 & 129 & St. Lawrence & 179 & 8 & 187 \\
\hline Chenango & 122 & 5 & 127 & Nassau & 315 & 14 & 329 & Steuben & 96 & 7 & 103 \\
\hline Clinton & 117 & 5 & 122 & New York & 309 & 14 & 323 & Suffolk & 316 & 15 & 331 \\
\hline Columbia & 111 & 4 & 115 & Niagara & 245 & 9 & 254 & Sullivan & 200 & 10 & 210 \\
\hline Cortland & 132 & 4 & 136 & Oneida & 201 & 9 & 210 & Tioga & 108 & 2 & 110 \\
\hline Delaware & 123 & 5 & 128 & Onondaga & 277 & 14 & 291 & Tompkins & 110 & 7 & 117 \\
\hline Dutchess & 288 & 14 & 302 & Ontario & 145 & 5 & 150 & Ulster & 128 & 8 & 136 \\
\hline Erie & 318 & 16 & 334 & Orange & 220 & 10 & 230 & Warren & 129 & 4 & 133 \\
\hline Essex & 122 & 6 & 128 & Orleans & 116 & 2 & 118 & Washington & 78 & 4 & 82 \\
\hline Franklin & 120 & 6 & 126 & Oswego & 141 & 4 & 145 & Wayne & 89 & 4 & 93 \\
\hline Fulton & 104 & 6 & 110 & Otsego & 119 & 6 & 125 & Westchester & 311 & 17 & 328 \\
\hline Genesee & 113 & 5 & 118 & Putnam & 114 & 3 & 117 & Wyoming & 91 & 5 & 96 \\
\hline Greene & 83 & 3 & 86 & Queens & 299 & 14 & 313 & Yates & 13 & 0 & 13 \\
\hline Hamilton & 70 & 4 & 74 & Rensselaer & 142 & 5 & 147 & Total & 10,082 & 460 & 10,542 \\
\hline
\end{tabular}




\subsection{Algorithms and Assumptions}

To estimate the generating capacity available in New York for participation in NYISO markets, several factors must be considered. First, reciprocating engine generators are not eligible for participation in Energy or Ancillary Services markets. In addition, the DEC is promulgating new rules for DG in New York. Although final rules have not yet been drafted, it is clear that the allowable emission levels for DG will be very stringent and preclude the possibility of diesel-fired generation without external pollution control. Thus, reciprocating engine generators will only be eligible to participate in the NYISO EDRP and the ICAP Market as SCR - and only after they have been registered with DEC.

Turbine generators can participate in Energy and Ancillary Services markets if they satisfy all DEC and local permitting requirements. For DEC, this would most likely require a state facilities permit, which would cap NOX emissions at 12.5 tons per year. Larger facilities would require a Title $\mathrm{V}$ permit, though the turbines included in this study - the largest of which is $2.6 \mathrm{MW}$ - would not warrant such. In this analysis, the turbine generators are considered only for the Energy and Ancillary Services markets because these offer the greatest financial incentives for participation.

Finally, because the generator data are provided by standard industrial classification (SIC) code, it is necessary to consider these resources by industry-specific characteristics. Different industries have different requirements for backup generation. For example, certain facilitiessuch as financial institutions, telecommunication centers, and data processing centers - need redundancy of back-up generation. The criticality of their loads might mean that a facility with a 1-MW load could have $2 \mathrm{MW}$ of backup generation to provide protection against an outage of the backup generator. Other industrial sectors have less critical loads and typically do not have redundant backup generation. In fact, they may not have their entire load served by the backup generator.

To account for these sector anomalies, a curtailment ratio was developed for each two-digit SIC classification. This ratio is the generating capacity that would actually curtail load during dispatch. These ratios were estimated based on Electrotek's experience with a wide range of clients with DG resources. Although principally based on professional judgment, it represents a reasonable first-order estimate of the actual curtailment that could be realized by each generator in a sector. Appendix B lists the two-digit SIC codes and their curtailment ratios.

To estimate the technical potential for DG, total DG capacity was summed by sector and then multiplied by the curtailment ratio. It should be noted that there are two distinct classifications for capacity. The first is for reciprocating engines. These generators would only participate in the NYISO EDRP or in the NYISO ICAP Market as SCR. The second classification is for turbines, which could be eligible for participation in the Energy and Ancillary Services markets. 


\subsection{Results}

The technical potential for DG in New York is the capacity that is technically capable of participating in NYISO markets. Two market categories have been evaluated: (1) EDRP and SCR and (2) Energy and Ancillary Services markets. Because the database provided generator data by generator type (turbine and reciprocating engine) and SIC code, it is possible to develop the technical market potential by market category and SIC code. Table 7 shows the technical market potential for curtailment in New York by SIC code and for the entire state.

Table 7. Technical Market Potential by Sector

\begin{tabular}{|c|c|c|c|c|}
\hline $\begin{array}{l}\text { SIC } \\
\text { Code }\end{array}$ & Description & $\begin{array}{c}\text { EDRP/SCR } \\
\text { Capacity } \\
\text { (MW) }\end{array}$ & $\begin{array}{c}\text { Energyl } \\
\text { Ancillary } \\
\text { Services } \\
\text { Capacity } \\
\text { (MW) }\end{array}$ & $\begin{array}{l}\text { Total } \\
\text { (MW) }\end{array}$ \\
\hline 01 & Agricultural Production Crops & 2.4 & 0.0 & 2.4 \\
\hline 07 & Agricultural Services & 2.9 & 1.2 & 4.1 \\
\hline 08 & Forestry & 0.1 & 0.0 & 0.1 \\
\hline 09 & Fishing, Hunting, and Trapping & 0.1 & 0.0 & 0.1 \\
\hline 13 & Oil and Gas Extraction & 0.7 & 0.0 & 0.7 \\
\hline 15 & $\begin{array}{l}\text { Building Construction General Contractors and } \\
\text { Operative Builders }\end{array}$ & 20.5 & 1.5 & 22.0 \\
\hline 16 & $\begin{array}{l}\text { Heavy Construction Other Than Building } \\
\text { Construction Contractors }\end{array}$ & 3.5 & 0.0 & 3.5 \\
\hline 17 & Construction Special Trade Contractors & 15.1 & 2.9 & 18.0 \\
\hline 20 & Food and Kindred Products & 17.3 & 18.7 & 35.9 \\
\hline 21 & Tobacco Products & 0.5 & 0.0 & 0.5 \\
\hline 22 & Textile Mill Products & 13.3 & 3.0 & 16.2 \\
\hline 23 & $\begin{array}{l}\text { Apparel and Other Finished Products Made From } \\
\text { Fabrics and Similar Materials }\end{array}$ & 45.1 & 5.4 & 50.5 \\
\hline 24 & Lumber and Wood Products Except Furniture & 0.6 & 0.0 & 0.6 \\
\hline 25 & Furniture and Fixtures & 4.2 & 0.0 & 4.2 \\
\hline 26 & Paper and Allied Products & 9.6 & 9.5 & 19.2 \\
\hline 27 & Printing, Publishing, and Allied Industries & 55.7 & 19.6 & 75.3 \\
\hline 28 & Chemicals and Allied Products & 6.2 & 1.2 & 7.4 \\
\hline 29 & Petroleum Refining and Related Industries & 0.2 & 0.0 & 0.2 \\
\hline 30 & Rubber and Miscellaneous Plastics Products & 5.5 & 0.5 & 6.0 \\
\hline 31 & Leather and Leather Products & 1.4 & 0.0 & 1.4 \\
\hline 32 & Stone, Clay, Glass, and Concrete Products & 1.8 & 0.0 & 1.8 \\
\hline 33 & Primary Metal Industries & 2.9 & 0.0 & 2.9 \\
\hline
\end{tabular}




\begin{tabular}{|c|c|c|c|c|}
\hline $\begin{array}{l}\text { SIC } \\
\text { Code }\end{array}$ & Description & $\begin{array}{c}\text { EDRP/SCR } \\
\text { Capacity } \\
\text { (MW) }\end{array}$ & $\begin{array}{c}\text { Energyl } \\
\text { Ancillary } \\
\text { Services } \\
\text { Capacity } \\
\text { (MW) }\end{array}$ & $\begin{array}{l}\text { Total } \\
\text { (MW) }\end{array}$ \\
\hline 34 & $\begin{array}{l}\text { Fabricated Metal Products Except Machinery and } \\
\text { Transportation Equipment }\end{array}$ & 17.0 & 8.2 & 25.2 \\
\hline 35 & $\begin{array}{l}\text { Industrial and Commercial Machinery and } \\
\text { Computer Equipment }\end{array}$ & 4.9 & 1.1 & 6.1 \\
\hline 36 & $\begin{array}{l}\text { Electronic and Other Electrical Equipment and } \\
\text { Components Except Computer Equipment }\end{array}$ & 16.9 & 0.0 & 16.9 \\
\hline 37 & Transportation Equipment & 4.4 & 2.2 & 6.6 \\
\hline 38 & $\begin{array}{l}\text { Measuring, Analyzing, and Controlling } \\
\text { Instruments; Photographic, Medical, and Optical } \\
\text { Goods; Watches and Clocks }\end{array}$ & 11.1 & 3.4 & 14.5 \\
\hline 39 & Miscellaneous Manufacturing Industries & 21.6 & 0.8 & 22.4 \\
\hline 40 & Railroad Transportation & 1.0 & 0.0 & 1.0 \\
\hline 41 & $\begin{array}{l}\text { Local and Suburban Transit and Interurban } \\
\text { Highway Passenger Transportation }\end{array}$ & 37.3 & 5.6 & 42.9 \\
\hline 42 & Motor Freight Transportation and Warehousing & 18.4 & 4.6 & 23.0 \\
\hline 43 & United States Postal Service & 6.3 & 0.0 & 6.3 \\
\hline 44 & Water Transportation & 0.4 & 2.0 & 2.4 \\
\hline 45 & Transportation by Air & 7.7 & 0.0 & 7.7 \\
\hline 47 & Transportation Services & 10.0 & 0.0 & 10.0 \\
\hline 48 & Communications & 19.7 & 4.2 & 23.9 \\
\hline 49 & Electric, Gas, and Sanitary Services & 3.0 & 1.3 & 4.3 \\
\hline 50 & Wholesale Trade- Durable Goods & 79.0 & 17.5 & 96.4 \\
\hline 51 & Wholesale Trade - Non-Durable Goods & 26.4 & 10.9 & 37.3 \\
\hline 52 & $\begin{array}{l}\text { Building Materials, Hardware, Garden Supply, } \\
\text { and Mobile Home Dealers }\end{array}$ & 6.0 & 4.9 & 10.9 \\
\hline 53 & General Merchandise Stores & 17.0 & 8.2 & 25.2 \\
\hline 54 & Food Stores & 25.6 & 4.0 & 29.6 \\
\hline 55 & $\begin{array}{l}\text { Automotive Dealers and Gasoline Service } \\
\text { Stations }\end{array}$ & 16.2 & 1.1 & 17.3 \\
\hline 56 & Apparel and Accessory Stores & 30.2 & 2.4 & 32.6 \\
\hline 57 & $\begin{array}{l}\text { Home Furniture, Furnishings, and Equipment } \\
\text { Stores }\end{array}$ & 29.9 & 5.5 & 35.4 \\
\hline 58 & Eating and Drinking Places & 66.3 & 10.6 & 76.9 \\
\hline 59 & Miscellaneous Retail & 29.2 & 8.5 & 37.7 \\
\hline 60 & Depository Institutions & 18.2 & 16.9 & 35.1 \\
\hline 61 & Non-Depository Credit Institutions & 5.8 & 1.7 & 7.5 \\
\hline
\end{tabular}




\begin{tabular}{|c|c|c|c|c|}
\hline $\begin{array}{l}\text { SIC } \\
\text { Code }\end{array}$ & Description & $\begin{array}{c}\text { EDRP/SCR } \\
\text { Capacity } \\
\text { (MW) }\end{array}$ & $\begin{array}{c}\text { Energyl } \\
\text { Ancillary } \\
\text { Services } \\
\text { Capacity } \\
\text { (MW) }\end{array}$ & $\begin{array}{l}\text { Total } \\
\text { (MW) }\end{array}$ \\
\hline 62 & $\begin{array}{l}\text { Security and Commodity Brokers, Dealers, } \\
\text { Exchanges, and Services }\end{array}$ & 40.9 & 7.1 & 48.0 \\
\hline 63 & Insurance Carriers & 4.4 & 0.0 & 4.4 \\
\hline 64 & Insurance Agents, Brokers, and Service & 32.2 & 6.8 & 38.9 \\
\hline 65 & Real Estate & 21.6 & 4.7 & 26.3 \\
\hline 67 & Holding and Other Investment Offices & 6.9 & 0.7 & 7.6 \\
\hline 70 & $\begin{array}{l}\text { Hotels, Rooming Houses, Camps, and Other } \\
\text { Lodging Places }\end{array}$ & 22.4 & 3.3 & 25.7 \\
\hline 72 & Personal Services & 12.7 & 5.0 & 17.7 \\
\hline 73 & Business Services & 104.8 & 21.1 & 125.9 \\
\hline 75 & Automotive Repair, Services, and Parking & 3.5 & 1.0 & 4.5 \\
\hline 76 & Miscellaneous Repair Services & 0.9 & 0.0 & 0.9 \\
\hline 78 & Motion Pictures & 6.8 & 2.6 & 9.4 \\
\hline 79 & Amusement and Recreation Services & 25.9 & 4.9 & 30.7 \\
\hline 80 & Health Services & 175.3 & 57.0 & 232.3 \\
\hline 81 & Legal Services & 70.3 & 37.4 & 107.7 \\
\hline 82 & Educational Services & 322.9 & 75.6 & 398.5 \\
\hline 83 & Social Services & 62.3 & 14.8 & 77.1 \\
\hline 84 & $\begin{array}{l}\text { Museums, Art Galleries, and Botanical and } \\
\text { Zoological Gardens }\end{array}$ & 3.3 & 5.1 & 8.4 \\
\hline 86 & Membership Organizations & 21.6 & 7.9 & 29.5 \\
\hline 87 & $\begin{array}{l}\text { Engineering, Accounting, Research, } \\
\text { Management, and Related Services }\end{array}$ & 56.3 & 10.7 & 67.0 \\
\hline 89 & Actuaries & 1.1 & 0.0 & 1.1 \\
\hline 91 & Executive, Legislative, and General Government & 12.2 & 2.8 & 15.0 \\
\hline 92 & Justice, Public Order, and Safety & 38.8 & 2.4 & 41.2 \\
\hline 93 & Public Finance, Taxation and Monetary Policy & 0.5 & 0.0 & 0.5 \\
\hline 94 & Administration of Human Resource Programs & 5.0 & 1.8 & 6.8 \\
\hline 95 & $\begin{array}{l}\text { Administration of Environmental Quality and } \\
\text { Housing Programs }\end{array}$ & 9.8 & 1.9 & 11.8 \\
\hline 96 & Administration of Economic Programs & 6.8 & 1.1 & 7.8 \\
\hline 97 & National Security and International Affairs & 1.1 & 0.0 & 1.1 \\
\hline \multirow[t]{2}{*}{99} & Non-Classifiable Establishments & 60.4 & 3.8 & 64.2 \\
\hline & TOTAL & 1,869 & 468 & 2,338 \\
\hline
\end{tabular}


As shown in Table 7, there is a total technical potential of 2,338 MW of curtailment in New York State. This represents approximately $65 \%$ of the $3,582 \mathrm{MW}$ of total DG capacity. Most of this, 1,869 MW, is eligible for the NYISO EDRP and SCR programs. The balance, 468 MW, would be eligible for the Energy and Ancillary Services markets. Clearly, the stock of backup generators in New York is heavily weighted toward the NYISO emergency programs.

It should be noted that this technical potential does not represent the capacity that can be developed. Clearly, the economics of the NYISO markets will drive this. For example, the Energy and ICAP market prices in New York City and Long Island are significantly higher than those in the rest of the state. When one considers the full cost of participating in these markets - including metering, environmental permitting, and opportunity costs (diversion of staff time to the operation of generators and not site process, reduced reliability of generators, shorter service life of generators, etc.) - the incentives in areas other than NYISO zones J (New York City) and K (Long Island) may not be sufficient to bring these resources into the marketplace. 


\section{Conclusions}

Two objectives were planned for Task 7:

- Identify and recruit new participants with $30 \mathrm{MW}$ of generation for the commercial demonstration

- Provide an assessment of the potential for DG in New York State.

These objectives were pursued as separate activities. The conclusions are presented below.

\subsection{Recruitment for Demonstration Project}

Two major initiatives were carried out as part of Task 7:

- Identification and recruitment of new buildings/generators for participation in the demonstration project

- Evaluation of the optimum design of on-site DG monitoring equipment for participation of generators in energy markets.

The major results and conclusions were:

- Electrotek recruited 38 buildings in New York City, Long Island, and Westchester County for the commercial aggregated DG system. The total installed capacity of these buildings is $55.69 \mathrm{MW}$, with $31.75 \mathrm{MW}$ of curtailable load. All these buildings are registered with the NYISO for curtailment operations in the summer of 2003. All have environmental permits.

- For the purposes of settlements, the NYISO recognizes only energy metering data collected by certified metering instruments (interval-type electric meters) that belong to an MDSP or utility. For all recruited buildings, these data will be 15-min interval load data purchased from ConEd and LIPA. They will be received mid-month for the previous month.

- For participation in energy market programs, a building must be equipped with the interval-type meter at the service entrance. The installation of other monitoring equipment in newly recruited buildings is advantageous but not necessary.

- Data on building electric load and emergency generator output is necessary for the operation of the DG aggregation system. These data are used for load forecast, bidding preparation, coincident peak hunting, and other purposes. If not collected by on-site monitoring equipment, these data can be modeled using information previously collected on-site or interval meter data purchased from a utility or MDSP. 


\subsection{Survey of Backup Generation in New York State}

To evaluate the potential for DG capacity in New York State, it was necessary to determine (a) the total installed DG capacity, (b) the actual load served by this installed capacity, (c) economic incentives that would drive the use of these generators, and (d) environmental implications that would influence the operation of DG.

The economic incentives for DG as well as their environmental implications are mostly determined by requirements and conditions of energy markets. Therefore, an evaluation of all energy markets administered by the NYISO was conducted with the goal of finding the most suitable places for DG resources.

Major findings and conclusions were:

- There are more than 3,582 MW of installed DG capacity across the state. Most of this capacity-2,896 MW, or $80 \%$ - is from reciprocating engines, with the balance from turbines. There are 10,542 generators of at least $100 \mathrm{~kW}$ in New York State listed in the database. Of these, most are reciprocating engines; turbines account for only 460 . Across the state, the average capacity of a reciprocating engine is $285 \mathrm{~kW}$, and the average turbine is more than $1.5 \mathrm{MW}$.

- Diesel generators can only participate in the NYISO EDRP or ICAP market as an SCR. The emission levels associated with diesels preclude their participation in Energy or Ancillary Services markets. Furthermore, new DG rules being promulgated by DEC are likely to explicitly exclude their operation in the Energy and Ancillary Services markets.

- Turbines can participate in the EDRP and ICAP markets (as SCR) and in the Energy and Ancillary Services markets. However, the financial incentives for turbine participation in the Energy and Ancillary Services markets are much greater.

- The technical market potential for curtailment in New York State consists of about 1,869 MW for participation in the EDRP and SCR market (reciprocating engines) and about $468 \mathrm{MW}$ for participation in Energy and Ancillary Services markets (turbines). There is a technical potential of 2,338 MW of backup generation in New York State. This represents approximately $65 \%$ of the $3,582 \mathrm{MW}$ of total DG capacity. Clearly, the stock of backup generators in New York is heavily weighted toward the NYISO emergency programs.

- The total technical DG potential does not represent the capacity that can be developed. When one considers the full cost of participating in these markets-including metering, environmental permitting, and opportunity costs (diversion of staff time to operate generators, reduced reliability of generators, shorter service life of generators, etc.) - the incentives in areas other than NYISO zones J (New York City) and K (Long Island) may not be sufficient to bring these resources into the marketplace. 
Appendix A: Distributed Generation Database 


\section{Background}

Over the past 23 years, Power Systems Research has maintained a database known as PartsLink ${ }^{\mathrm{TM}}$. PartsLink uses a mathematical model to estimate the number of engine-powered products in service in the United States and the annual parts consumption associated with the operation of this equipment. This model is developed through the use of factual data developed and compiled by Power Systems Research on a continuing basis. Application populations are distributed geographically based on selected economic factors from the Bureau of Census County Business Patterns Survey.

Key elements of the data include:

- A continuing record of shipments from U.S. factories and imports from foreign suppliers

- Exports of U.S. product equipment

- An attrition model used to estimate the retirement of engine-powered products based on:

- Estimated engine life

- Annual hours of use

- Intensity of use - load factor

- Reported parts consumption and replacement.

These factors are used to calculate retirement rates and estimate the number of products remaining in operation as well as the market for parts and components. The data include information about engines placed into service prior to 1973, but this information is sometimes incomplete. Moreover, some types of turbine installation data are incomplete.

\section{Estimated Engine Life}

Because accurate data on actual engine life is not available, Power Systems Research has developed an estimating methodology that incorporates a variety of identifiable engine characteristics to predict the useful life of an engine at maximum continuous output.

These factors include:

- Engine horsepower

- $\quad$ Rated speed

- Number of cylinders

- Displacement

- Aspiration
- Engine weight

- Configuration

- Bore

- $\quad$ Stroke. 
Combined with constants, developed by Power Systems Research to compare projected engine life to a few known benchmarks, these variables have been used to calculate projected engine life for every engine in the database. Engine life is expressed in the average hours an engine will operate at its maximum continuous rated output. The product of this, horsepower, and the number of hours describe life in horsepower hours.

Because normal operation does not involve operation at full output, the assumption says that engine lifetime in actual hours is extended when the engine is operated at less-than-full output, but the number of horsepower hours will always be constant. We have assumed this lifetime will be a statistical mean and that a normal distribution can be used to describe all retirements.

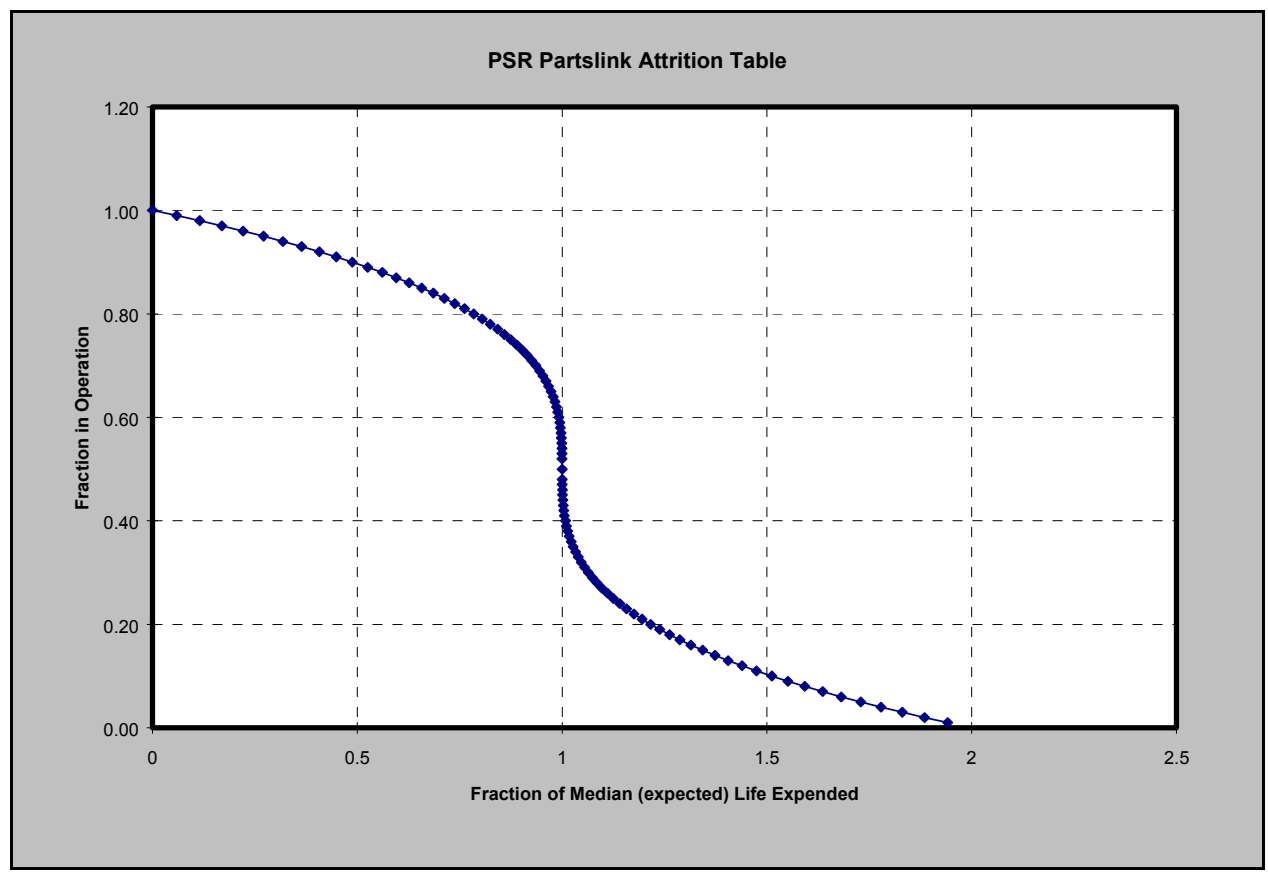

Figure A-1: Attrition

\section{Activity Levels}

The hours per year experienced by owners will vary considerably but are similar for any given product application. The survey asks for annual operating hours. The model uses the mean hours per year for each application, which is the result of responses to this question. 


\section{Fuel Consumption}

The average output or load factor is similar within an application. Because users are usually not able to measure load factor (the average percentage of maximum output at which they are operating), a good indicator is the fuel they consume. Fuel will vary almost directly with the horsepower produced. Annual fuel consumption is compared with fuel that would be consumed at maximum horsepower. The result is load factor. In many cases, respondents are not able to easily estimate annual hours of operation or fuel consumed. In those cases, respondents are asked to estimate the hours per week and fuel consumed per week. This also requires questions to determine if use is seasonal, the length of season, and use in off-season. The results were then projected over 52 weeks to get an annual result.

\section{Survey Research}

To develop reliable parameters for aftermarket indicators, Power Systems Research has developed an ongoing survey of owners of engine-powered products. Using random sampling techniques to provide statistical reliability, it interviews more than 10,000 owners each year. The objectives of this survey include the development of:

- Mean product lifetime

- Annual hours of operation

- Typical load factor

- Replacement frequency for key components.

This survey is conducted among randomly selected owners of each type of engine-powered equipment in each market region and asks users a simple set of questions. Topics include:

- Type of equipment operated

- Equipment manufacturer

- Equipment model

- Equipment age

- Cumulative hours

- Hours operated during the past 12 months

- Fuel consumed during the past 12 months

- Engine installed, if available

- Year of manufacture, if known

- Maintenance, internal and external engine parts and components purchased during the past year.

For generator sets, installations are categorized by several factors:

- Engine type

- Fuel

- Owner SIC

- Duty cycle

- Hours/year

- Grid-connected. 
Power Systems Research accepts the owner description of duty cycle - such as peak shaving, emergency standby, or base load — but it may adjust these descriptions based on annual hours of operation. Typically, it has found it necessary to establish these benchmarks through 100 interviews with owners of each type of equipment in each market region.

Over the years, Power Systems Research has implemented "rules" to facilitate data processing and storage rather than statistical reliability. Whenever possible, data is benchmarked against widely accepted authoritative sources. The effort is to establish credible, statistical reliability for the operating characteristics developed during the course of the survey.

\section{Geographic Distribution}

The geographic distribution of generator sets in service is accomplished by matching ownership and application norms to economic data provided by the Census Bureau County Business Patterns database. The ownership and application norms have been developed over the past 20 years by creating a profile for owners of each type of equipment. These profiles consist of correlations between any combination of up to 22 economic, geographic, demographic, and meteorological factors. For each county or combination of counties selected, the profile for owners of equipment in any application and power range is compiled based on census [SIC and employee size] data, and the strength of this profile is compared with the national profile for that same application. The proportionate allocation of equipment in that application and power range is then assigned to that county. The association can be made for application, power rating, engine or equipment brand and model, and age distribution. With each level of specificity, the statistical reliability deteriorates somewhat. The profile norms simply indicate the probability that a certain type of business entity or consumer owns a specific type of equipment. A normal distribution over the profile interval then determines what portion of the national population is located in any specific area.

\section{Components Replacement}

As part of the ongoing survey, respondents are asked to report the parts and components they have purchased during the past year. For preventive maintenance parts, they are asked about the replacement rates for filters, belts, hoses, spark plugs, and tune-up kits as well as other maintenance parts appropriate to the type of engine. The survey then asks about external components such as water pumps, starters, alternators, turbochargers, injectors, nozzles, and fuel pumps. Finally, it asks about overhaul and internal repair parts such as valves, springs, retainers, guides and seals, gaskets, bearings, and cylinder kits. The result is a replacement rate based on operating hours or calendar time, as appropriate. The replacement rate is unique to each engine model and application. Component and parts brand data have been collected since 1996. Although this information is not part of the basic database package, it is available for most major applications and brands on a custom extract basis. 


\section{Additional Notes on the Owner Survey}

Each year, the survey is given to a random sample of businesses and consumers. It identifies engine-powered products owned by respondents. Power Systems Research then collects operating, demographic, and economic data for the respondents. This information becomes the basis for projecting the geographic allocation of engine-powered products.

For example, Power Systems Research looks at the distribution of generator sets among businesses by SIC, number of employees, and location. From this information, it is able to establish a correlation from which it can project the population across the nation. For example, Power Systems Research may find that metal fabricating companies (SIC 331) with 400-600 employees own 14\% of the generator sets between 200 and $300 \mathrm{~kW}$. Power Systems Research knows from its sales record and attrition that there are 150,000 units nationwide in this power range and, thus, 21,000 units owned by companies of this size and SIC. It can find from census data that there are 63,000 such companies nationwide, so it can project that there will be one generator set in this power range for every three companies of this type. If there were 60 companies of this description in an area, it would project that there are 20 generator sets of this size owned among them.

This methodology and the completion of more than 200,000 interviews over the past 20 years has allowed Power Systems Research to construct a matrix for SIC versus product type. The data contained in this matrix are the nationwide incidence of ownership for each product type by companies within each SIC and employee size or by consumers. Further derivatives of this matrix - such as smaller geographic areas (down to the county level), more specific SICs, and more specific product specifications - can be compiled, but the statistical reliability declines as the information becomes more granular. 
Appendix B: Standard Industrial Classification Code and Curtailment Ratios 
The following table lists the two-digit standard industrial classification (SIC) codes of businesses in New York with back-up generating capacity. For each of these sectors, the ratio represents the amount of actual load curtailment that would be realized from the available generating capacity. Lower ratios suggest a higher level of generation redundancy. For example, a financial institution with a 1-MW load would likely have $2 \mathrm{MW}$ of generating capacity because of the criticality of the load. This redundancy ensures that load could still be served in the event of an outage of one of the generators. Higher ratios suggest a less critical load. Industrial sectors that have critical processes, such as computer chip manufacturing or data processing centers, tend to have a lower ratio.

\begin{tabular}{|c|c|c|}
\hline $\begin{array}{l}\text { SIC } \\
\text { Code }\end{array}$ & Description & $\begin{array}{c}\text { Curtailment } \\
\text { Load/Generator } \\
\text { Capacity }\end{array}$ \\
\hline 01 & Agricultural Production Crops & 1.00 \\
\hline 07 & Agricultural Services & 1.00 \\
\hline 08 & Forestry & 0.50 \\
\hline 09 & Fishing, Hunting, and Trapping & 0.70 \\
\hline 13 & Oil and Gas Extraction & 0.50 \\
\hline 15 & $\begin{array}{l}\text { Building Construction General Contractors and } \\
\text { Operative Builders }\end{array}$ & 1.00 \\
\hline 16 & $\begin{array}{l}\text { Heavy Construction Other Than Building } \\
\text { Construction Contractors }\end{array}$ & 1.00 \\
\hline 17 & Construction Special Trade Contractors & 0.50 \\
\hline 20 & Food and Kindred Products & 0.77 \\
\hline 21 & Tobacco Products & 0.70 \\
\hline 22 & Textile Mill Products & 0.70 \\
\hline 23 & $\begin{array}{l}\text { Apparel and Other Finished Products Made From } \\
\text { Fabrics and Similar Materials }\end{array}$ & 0.70 \\
\hline 24 & Lumber and Wood Products Except Furniture & 0.50 \\
\hline 25 & Furniture and Fixtures & 0.50 \\
\hline 26 & Paper and Allied Products & 0.80 \\
\hline 27 & Printing, Publishing, and Allied Industries & 0.50 \\
\hline 28 & Chemicals and Allied Products & 0.56 \\
\hline 29 & Petroleum Refining and Related Industries & 0.50 \\
\hline 30 & Rubber and Miscellaneous Plastics Products & 0.50 \\
\hline 31 & Leather and Leather Products & 0.70 \\
\hline 32 & Stone, Clay, Glass, and Concrete Products & 0.60 \\
\hline 33 & Primary Metal Industries & 0.50 \\
\hline 34 & $\begin{array}{l}\text { Fabricated Metal Products Except Machinery and } \\
\text { Transportation Equipment }\end{array}$ & 0.90 \\
\hline
\end{tabular}




\begin{tabular}{|c|c|c|}
\hline $\begin{array}{l}\text { SIC } \\
\text { Code }\end{array}$ & Description & $\begin{array}{l}\text { Curtailment } \\
\text { Load/Generator } \\
\text { Capacity }\end{array}$ \\
\hline 35 & $\begin{array}{l}\text { Industrial and Commercial Machinery and } \\
\text { Computer Equipment }\end{array}$ & 0.50 \\
\hline 36 & $\begin{array}{l}\text { Electronic and Other Electrical Equipment and } \\
\text { Components Except Computer Equipment }\end{array}$ & 0.67 \\
\hline 37 & Transportation Equipment & 0.60 \\
\hline 38 & $\begin{array}{l}\text { Measuring, Analyzing, and Controlling } \\
\text { Instruments; Photographic, Medical, and Optical } \\
\text { Goods; Watches and Clocks }\end{array}$ & 0.70 \\
\hline 39 & Miscellaneous Manufacturing Industries & 0.80 \\
\hline 40 & Railroad Transportation & 0.50 \\
\hline 41 & $\begin{array}{l}\text { Local and Suburban Transit and Interurban } \\
\text { Highway Passenger Transportation }\end{array}$ & 0.75 \\
\hline 42 & Motor Freight Transportation and Warehousing & 0.80 \\
\hline 43 & United States Postal Service & 0.50 \\
\hline 44 & Water Transportation & 0.80 \\
\hline 45 & Transportation by Air & 0.50 \\
\hline 47 & Transportation Services & 0.50 \\
\hline 48 & Communications & 0.40 \\
\hline 49 & Electric, Gas, and Sanitary Services & 0.40 \\
\hline 50 & Wholesale Trade - Durable Goods & 0.80 \\
\hline 51 & Wholesale Trade - Non-Durable Goods & 0.50 \\
\hline 52 & $\begin{array}{l}\text { Building Materials, Hardware, Garden Supply, } \\
\text { and Mobile Home Dealers }\end{array}$ & 0.80 \\
\hline 53 & General Merchandise Stores & 0.80 \\
\hline 54 & Food Stores & 0.60 \\
\hline 55 & $\begin{array}{l}\text { Automotive Dealers and Gasoline Service } \\
\text { Stations }\end{array}$ & 0.60 \\
\hline 56 & Apparel and Accessory Stores & 0.80 \\
\hline 57 & $\begin{array}{l}\text { Home Furniture, Furnishings, and Equipment } \\
\text { Stores }\end{array}$ & 0.80 \\
\hline 58 & Eating and Drinking Places & 0.50 \\
\hline 59 & Miscellaneous Retail & 0.80 \\
\hline 60 & Depository Institutions & 0.40 \\
\hline 61 & Non-Depository Credit Institutions & 0.40 \\
\hline 62 & $\begin{array}{l}\text { Security and Commodity Brokers, Dealers, } \\
\text { Exchanges, and Services }\end{array}$ & 0.40 \\
\hline 63 & Insurance Carriers & 0.40 \\
\hline
\end{tabular}




\begin{tabular}{|c|c|c|}
\hline $\begin{array}{l}\text { SIC } \\
\text { Code }\end{array}$ & Description & $\begin{array}{c}\text { Curtailment } \\
\text { Load/Generator } \\
\text { Capacity }\end{array}$ \\
\hline 64 & Insurance Agents, Brokers, and Service & 0.90 \\
\hline 65 & Real Estate & 0.36 \\
\hline 67 & Holding and Other Investment Offices & 0.40 \\
\hline 70 & $\begin{array}{l}\text { Hotels, Rooming Houses, Camps, and Other } \\
\text { Lodging Places }\end{array}$ & 0.50 \\
\hline 72 & Personal Services & 1.00 \\
\hline 73 & Business Services & 0.51 \\
\hline 75 & Automotive Repair, Services, and Parking & 0.80 \\
\hline 76 & Miscellaneous Repair Services & 0.80 \\
\hline 78 & Motion Pictures & 1.00 \\
\hline 79 & Amusement and Recreation Services & 0.70 \\
\hline 80 & Health Services & 0.56 \\
\hline 81 & Legal Services & 0.80 \\
\hline 82 & Educational Services & 1.00 \\
\hline 83 & Social Services & 0.60 \\
\hline 84 & $\begin{array}{l}\text { Museums, Art Galleries, and Botanical and } \\
\text { Zoological Gardens }\end{array}$ & 0.70 \\
\hline 86 & Membership Organizations & 0.80 \\
\hline 87 & $\begin{array}{l}\text { Engineering, Accounting, Research, } \\
\text { Management, and Related Services }\end{array}$ & 0.70 \\
\hline 89 & Actuaries & 0.80 \\
\hline 91 & Executive, Legislative, and General Government & 0.50 \\
\hline 92 & Justice, Public Order, and Safety & 0.50 \\
\hline 93 & Public Finance, Taxation, and Monetary Policy & 0.50 \\
\hline 94 & Administration of Human Resource Programs & 0.80 \\
\hline 95 & $\begin{array}{l}\text { Administration of Environmental Quality and } \\
\text { Housing Programs }\end{array}$ & 0.80 \\
\hline 96 & Administration of Economic Programs & 0.80 \\
\hline 97 & National Security and International Affairs & 0.50 \\
\hline 99 & Non-Classifiable Establishments & 0.70 \\
\hline
\end{tabular}

Task 7

B-4 
Task 8: Design of Distributed Generation Aggregation System for Commercial Demonstration 


\section{List of Acronyms}

$\begin{array}{ll}\text { ADC } & \text { Aggregation and Dispatch Center } \\ \text { DAM } & \begin{array}{l}\text { Day-Ahead Market } \\ \text { distributed generation }\end{array} \\ \text { DG } & \text { Data Collection and Management Center } \\ \text { DMC } & \begin{array}{l}\text { digital subscriber line } \\ \text { DSL }\end{array} \\ \text { FO } & \text { Field Operation } \\ \text { ICAP } & \text { Installed Capacity } \\ \text { IP } & \text { Internet protocol } \\ \text { ISO } & \text { independent system operator } \\ \text { LSE } & \text { load-serving entity } \\ \text { NYISO } & \text { New York Independent System Operator } \\ \text { NYPA } & \text { New York Power Authority } \\ \text { PQDIF } & \text { Power Quality Data Interchange Format } \\ \text { WPT } & \text { World Power Technologies }\end{array}$




\section{Table of Contents}

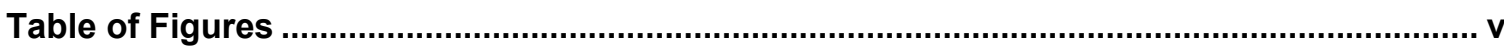

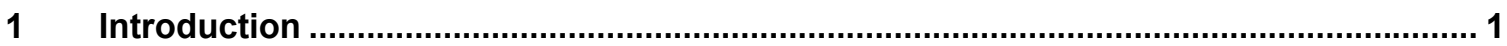

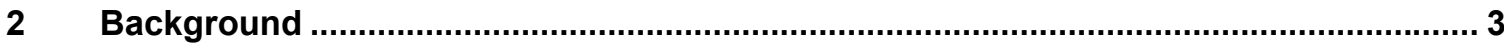

3 Distributed Generation Aggregation System Architecture........................................ 4

3.1 Physical/Logical Design of the Distributed Generation Aggregation System.. 4

3.1.1 Field Operation ......................................................................... 4

3.1.2 Data Collection and Management Center ...................................... 4

3.1.3 Aggregation and Dispatch Center ............................................. 5

3.2 Information Flow ............................................................................... 5

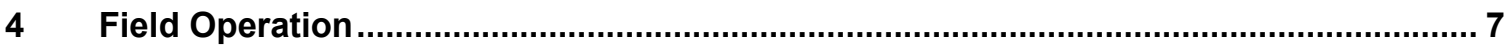

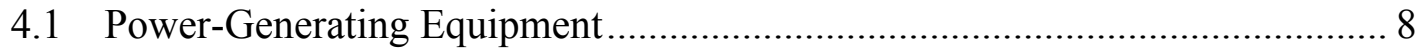

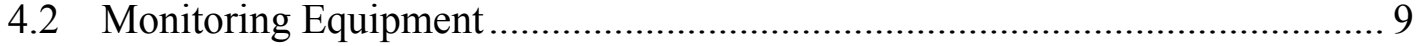

4.2.1 GE kV Meter DataNode.................................................................. 9

4.2.2 ADAM Module .............................................................................. 9

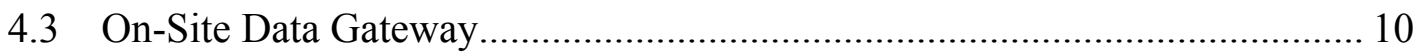

$5 \quad$ Data Collection and Management Center ................................................................ 11

5.1 Physical Design and System Architecture of the Data Collection and

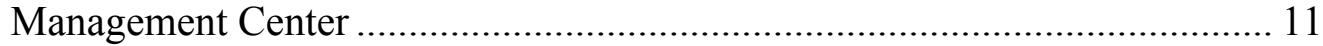

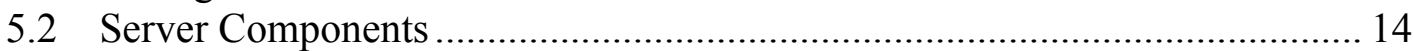

5.2.1 NodeCenter .............................................................................. 14

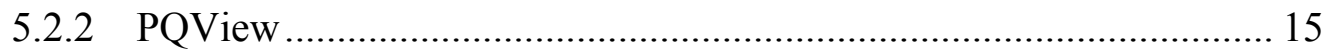

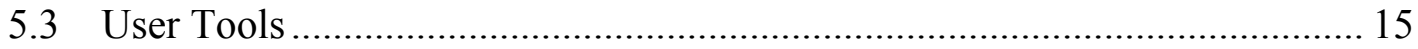

5.3.1 Distributed Generation Operation Tools ...................................... 15

5.3.2 Distributed Generation Client Visualization Tools............................. 16

5.4 Data Collection and Management Center Operations................................... 17

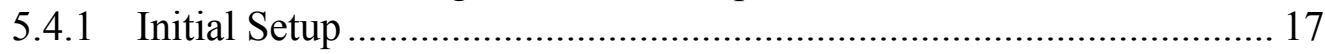

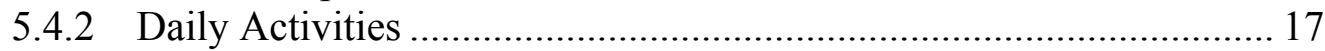

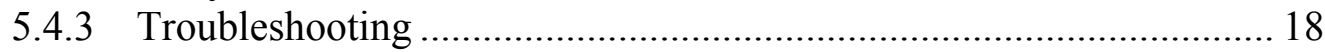

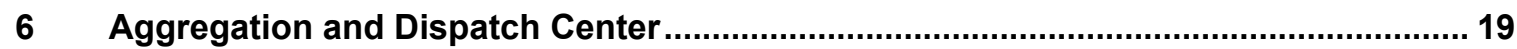

6.1 Physical Design of the Aggregation and Dispatch Center ............................ 19

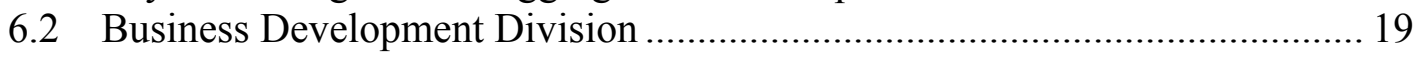

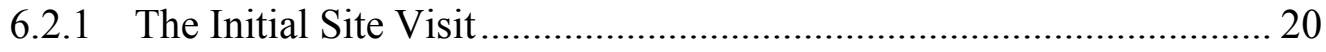

6.2.2 Economic and Financial Evaluation............................................ 20

6.2.3 Environmental Permitting ............................................................... 21

6.2.4 Equipment Design, Procurement, Installation, and Start-Up............. 21 


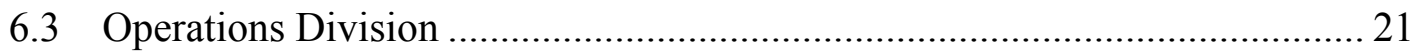

6.3.1 Addition of New Customers ...................................................... 22

6.3.2 Operation Strategy and Procedures ................................................... 22

6.3.3 Bidding Preparation and Execution ................................................ 24

6.3.4 Dispatching and Monitoring Generators...................................... 24

6.3.5 Settlement and Accounting Procedures ....................................... 24

6.4 Monitoring and Communication Division ............................................ 24

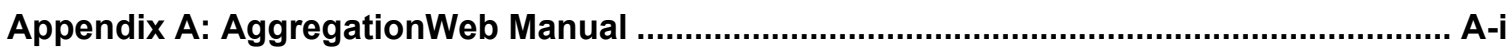

Appendix B: NodeCenter and PQView Guide ............................................................. B-i Appendix C: Emergency Load Curtailment Program: Evaluation of a Candidate Facility.. C-i Appendix D: Building Economics Model (BEM 9.1) Description and User Manual ............. D-i Appendix E: Hunt for Coincident Peak ............................................................................ 


\section{Table of Figures}

Figure 1. Distributed generation aggregation system ..................................... 5

Figure 2. Information flow in the distributed generation aggregation system .......... 6

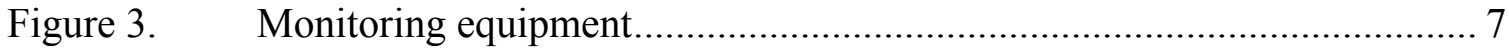

Figure 4. Installed monitoring equipment .................................................. 8

Figure 5. Physical layout of the Data Collection and Management Center ............. 11

Figure 6. Data Collection and Management Center ............................................ 12

Figure 7. Distributed generation aggregation system architecture ........................ 13

Figure 8. Control room of the Aggregation and Dispatch Center .......................... 19 


\section{Introduction}

The aggregation of multiple distributed generators into a virtual power plant requires a system that can control and monitor the generators remotely. Because of their small individual capacities, these generators are not normally tracked by the New York Independent System Operator (NYISO). But when they are combined into a virtual power plant, these generators can be treated as a single central generator, which is given a point identification number and modeled and scheduled to participate in the Day-Ahead Market (DAM) administered by the NYISO.

As a requirement of Task 8, the design of the control center-which monitors the status of participating backup generators, conducts transactions with the NYISO, and dispatches the units - was developed. The objectives of this task were to develop:

- The physical design of a distributed generation (DG) aggregation control center

- The hardware configuration and software to:

- Monitor the status of participating backup generators

- Dispatch units remotely

- Conduct transactions with the NYISO.

During execution of the task, it was found that instead of a single control center, an aggregation system should be developed to handle the multitude of functions required for commercial operation of the virtual power plant. Therefore, to fulfill Task 8 objectives, the following steps were taken:

- The architecture of the DG aggregation system was developed, with the DG aggregation Web page as the central point of information flow among system entities.

- The DG aggregation Web page was developed and implemented.

- The physical design of the aggregation and monitoring center was developed.

- A library of computer tools, manuals, and procedures was developed. These tools conduct and support activities of the DG aggregation system.

- All elements and the entire DG aggregation system were tested using a pilot operation of 12 generators with a total capacity of $4.5 \mathrm{MW}$. The system was designed for commercial operation of $30 \mathrm{MW}$ of aggregated capacity. 
The steps to be accomplished before commercial operation is started are include the:

- Physical construction of the Aggregation and Dispatch Center in Edison, New Jersey

- Evaluation of and, if necessary, upgrade to the server equipment at the Data Collection and Management Center at Knoxville, Tennessee

- Recruitment of new facilities with backup generators to increase the total capacity to $30 \mathrm{MW}$

- Installation of on-site monitoring equipment.

This report describes the final architecture, design considerations, and planned operation of the DG aggregation system. 


\section{Background}

The original plan for the commercial demonstration of DG aggregation on Long Island, New York, called for the design and construction of a single control center that would handle all activities connected to the operation of participating backup generators. During the execution of this task, it was decided to separate virtual power plant activities into three functional parts and develop a DG aggregation system instead of a single DG control center. This system includes three entities: the Data Collection and Management Center (DMC) in Knoxville, Tennessee; the Aggregation and Dispatch Center (ADC) in Edison, New Jersey; and Field Operation (FO), the participating buildings/generators in New York, Long Island, and Westchester County. Each entity includes several operation modules that are interconnected via Internet and other communication media.

The decision to distribute management and operation activities between two locations was based on the following:

- The operation of the virtual power plant requires powerful servers and computer stations to collect, store, and manage large amounts of data. Electrotek has this equipment available at its Knoxville office. In addition, the manpower experienced in data management, software development, and system operations are located Knoxville. These were the deciding factors in choosing the location of the DMC.

- The proximity of the World Power Technologies ${ }^{1}$ (WPT) headquarters to New York and Long Island, along with WPT's staff of experienced electronic/computer engineers and technicians, made it the logical choice for the ADC.

- The Web-based application, AggregationWeb, provides a single point of access for all users (clients, the NYISO, ADC staff, etc.) to system information. The physical location of the system components is immaterial in this respect.

This report presents a general architecture of the aggregation system and describes the design, duties, and operation of each of the system components.

\footnotetext{
${ }^{1}$ WPT is the parent company of Electrotek Concepts Inc. WPT is located in Edison, New Jersey.
} 


\section{Distributed Generation Aggregation System Architecture}

The DG aggregation system architecture includes two essential elements: (1) the physical/logical design of the entire system and its components and (2) the information flow among all system components and between the system and outside counterparts. These elements of the proposed DG aggregation system are briefly described below.

\subsection{Physical/Logical Design of the Distributed Generation Aggregation System}

The architecture of the DG aggregation system is presented in Figure 1. The major components of the DG aggregation system are described below.

\subsubsection{Field Operation}

The FO aggregates backup generators in buildings throughout the New York, Long Island, and Westchester County areas. The current system includes 12 generators at 10 buildings. These buildings are in Nassau and Suffolk counties on Long Island. However, the aggregation system has the ability to incorporate as many generators as necessary.

Major duties of the FO are:

- Power generation

- Generator monitoring

- Data collection.

\subsubsection{Data Collection and Management Center}

The DMC is the central site for the collection and management of information necessary for the DG aggregation system. It is in Knoxville, Tennessee.

The DMC's main duties include the:

- Collection and storage of information about the activities at FO, energy market pricing and load forecasts, and forecasted and historical weather data

- Development and maintenance of the DG aggregation Web site

- Development and maintenance of new software necessary for the operation and expansion of the DG aggregation system. 


\subsubsection{Aggregation and Dispatch Center}

The ADC is the central point of operation of the DG aggregation system and will include three divisions: Operations, Business Development, and Monitoring and Communication.

The responsibilities of these divisions are:

- Operations is responsible for operations strategy, bidding preparation and execution, dispatching and monitoring of generators, and settlement and accounting procedures.

- Business Development is responsible for recruiting new clients, economic and technical site evaluation, permitting, and field equipment installation and start-up.

- Monitoring and Communication is responsible for the support and maintenance of field monitoring equipment and all communication channels (Internet, dial-up, pagers, etc.).

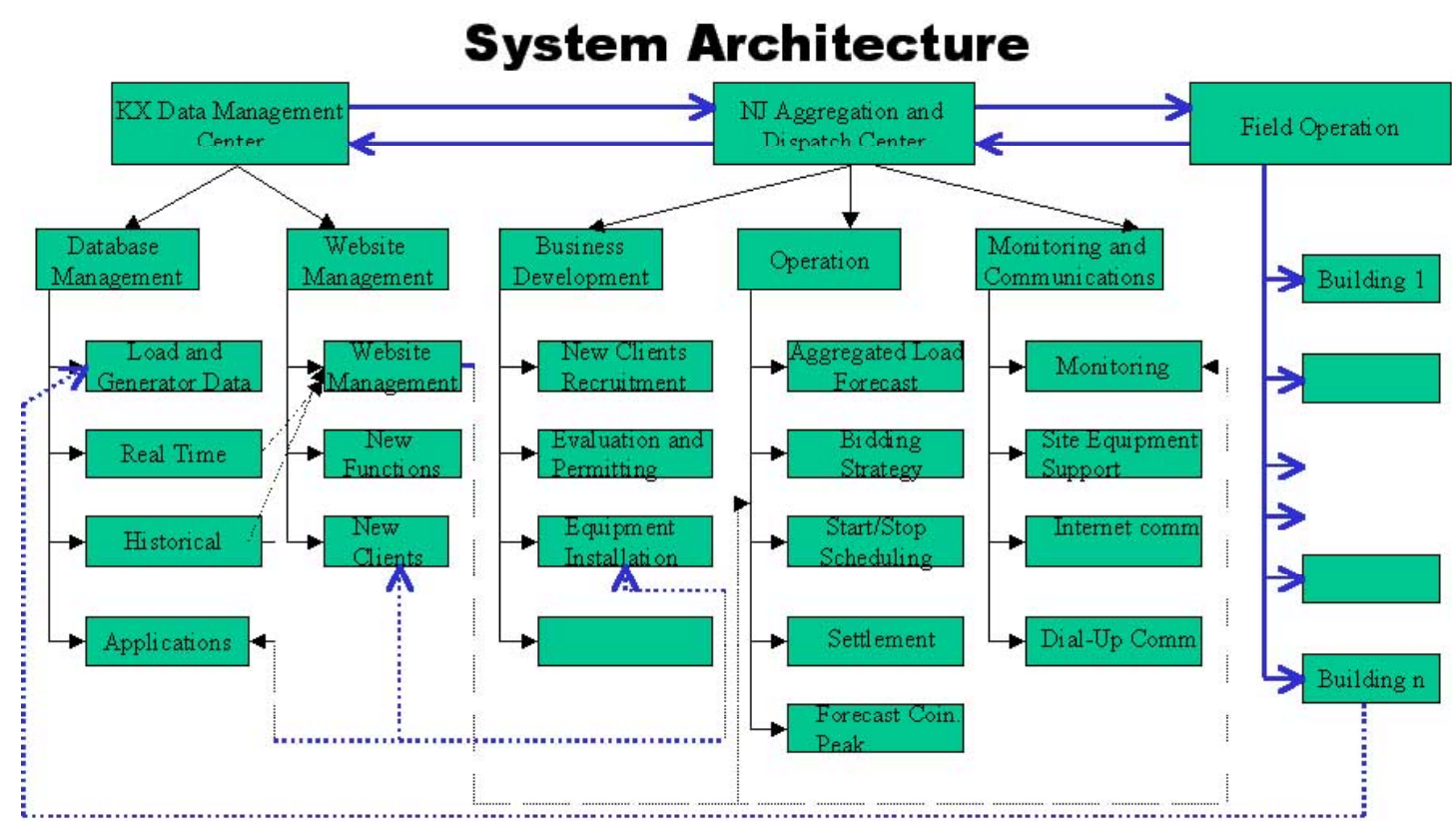

Figure 1. Distributed generation aggregation system

\subsection{Information Flow}

A proposed design of the information flow between system components and outside counterparts is presented in Figure 2. 


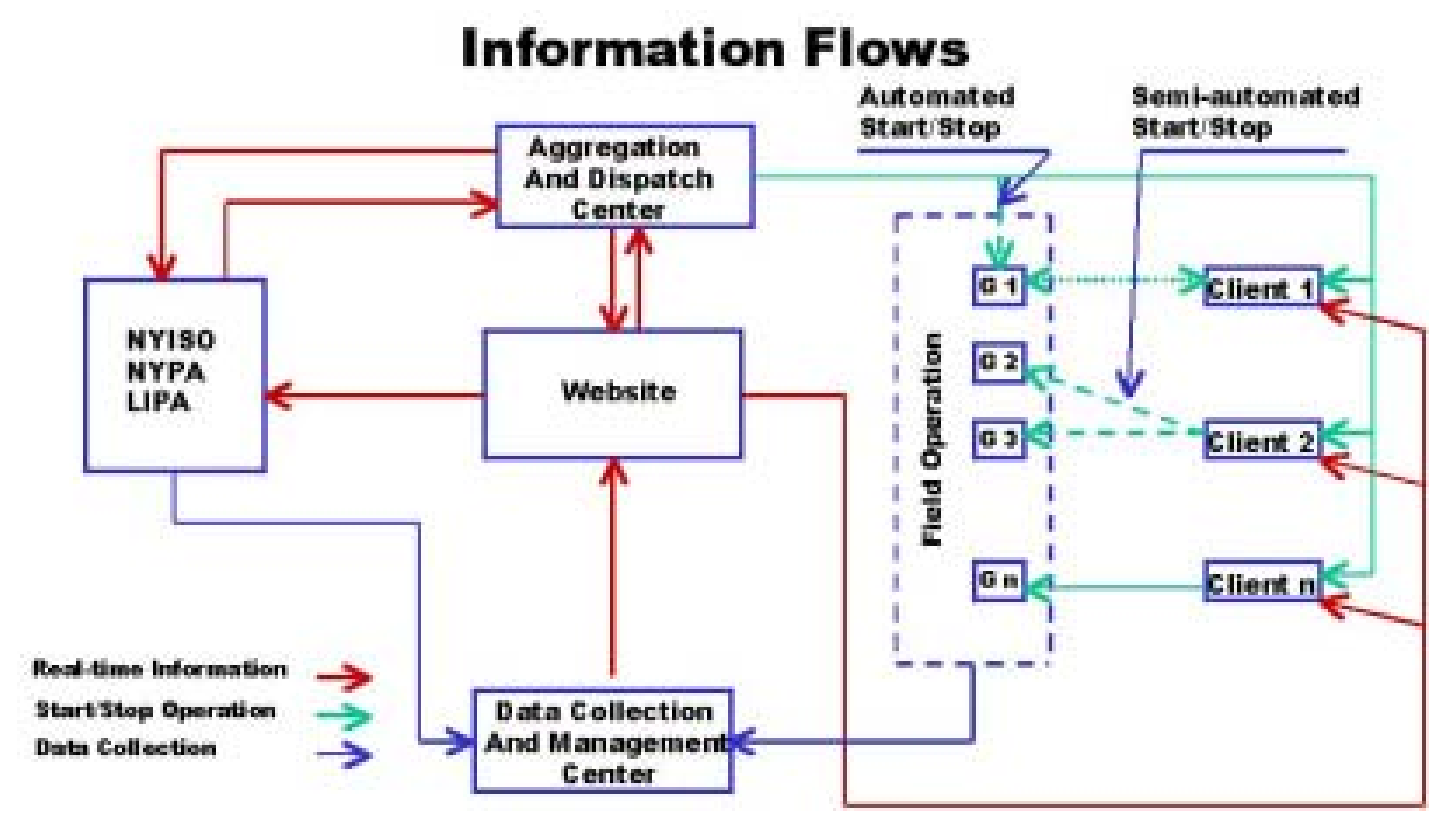

Figure 2. Information flow in the distributed generation aggregation system

- The central point of access for system information is the DG aggregation Web site, AggregationWeb. This Web site provides access to live and historical events. It is the interface for the ADC and external users (i.e., clients, the NYISO, and the Long Island Power Authority). It is also the interface for all computer tools necessary for normal DG aggregation system operation. These tools include the bidding/dispatch, settlement and accounting, coincident peak-hunting, and economic evaluation tools. A detailed description of the aggregation Web page is provided in Appendix A.

- Data collected at generation sites are downloaded to the DMC via digital subscriber lines (DSL) or dial-up telephone lines.

- The ADC is responsible for issuing the engine start/stop commands. The mechanisms for issuing these commands are automated engine start/stop, semi-automated engine start/stop, and manual engine start/stop.

- Automated engine start/stop requires a direct connection (leased line) between the ADC and the client's control system.

- For semi-automated engine start/stop, the ADC contacts the client's area managers, who remotely start/stop engines on site.

- For manual engine start/stop, the ADC contacts on-site personnel with the request to start or stop engines.

- The ADC contacts the NYISO, the LIPA, the New York Power Authority (NYPA), and other power authorities via telephone and Internet for bidding and settlement operations.

- The DMC downloads load forecast and market prices from the NYISO.

More details of these information pathways will be provided in relevant sections of this report. 


\section{Field Operation}

Client sites may differ in terms of engine type and size and building electric system design. For the DG aggregation system, all sites have three major components: power generation equipment, power monitoring equipment, and data collection and transmission equipment.

Only the last two components are designed, installed, and maintained by the DG aggregator (Electrotek Concepts Inc.). The design of these components is based on the Signature System $^{\mathrm{TM}}$ developed by WPT and Electrotek Concepts Inc. The Signature System is an integrated, Web-based platform that incorporates multiple measuring and monitoring instruments called DataNodes ${ }^{\circledR}$ that report to a gateway/Web server called an InfoNode ${ }^{\circledR}$.

A typical design of the on-site instrumentation necessary for DG aggregation is presented in Figure 3.

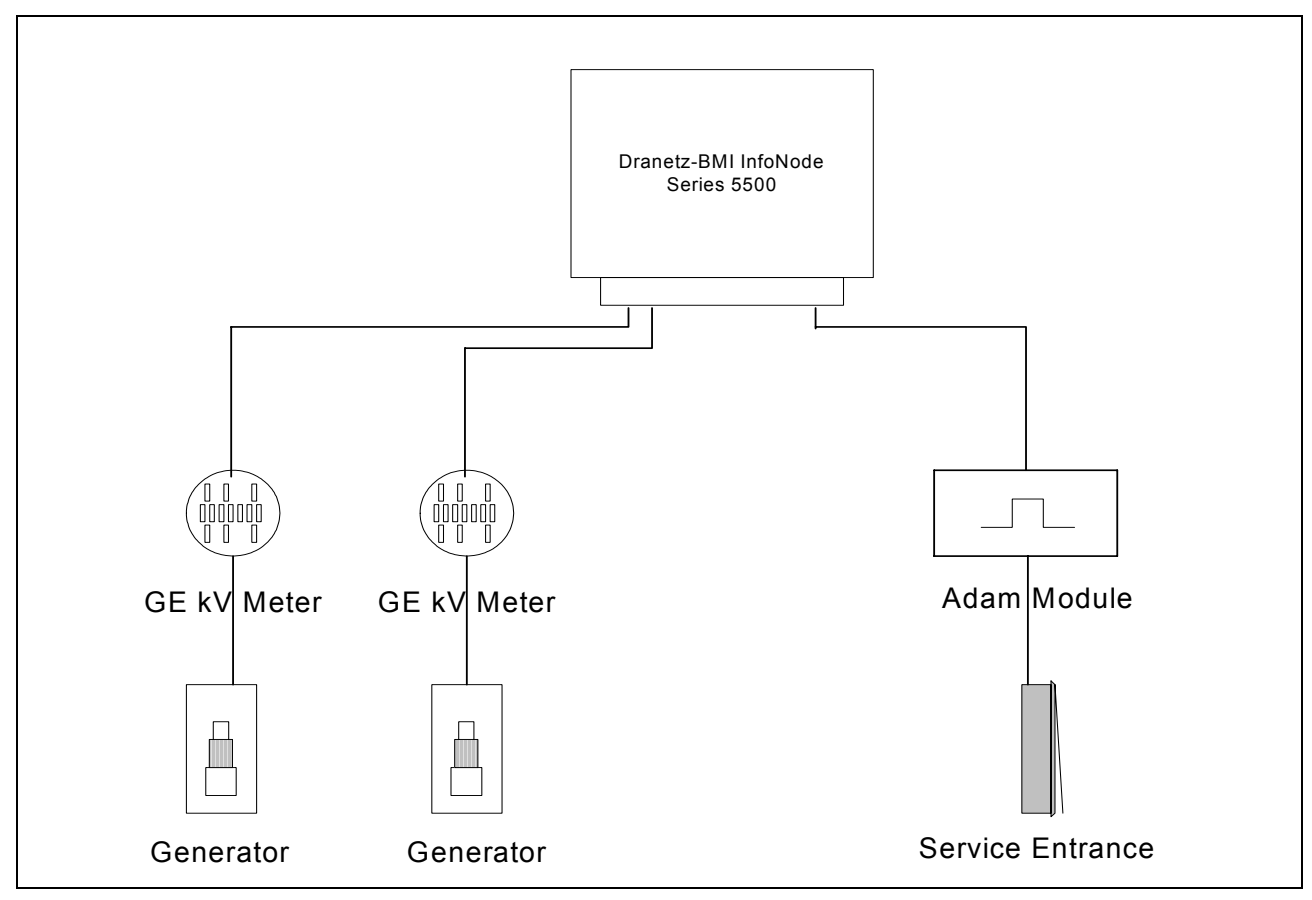

Figure 3. Monitoring equipment

Figure 4 shows the monitoring equipment installed at one of the sites on Long Island. 


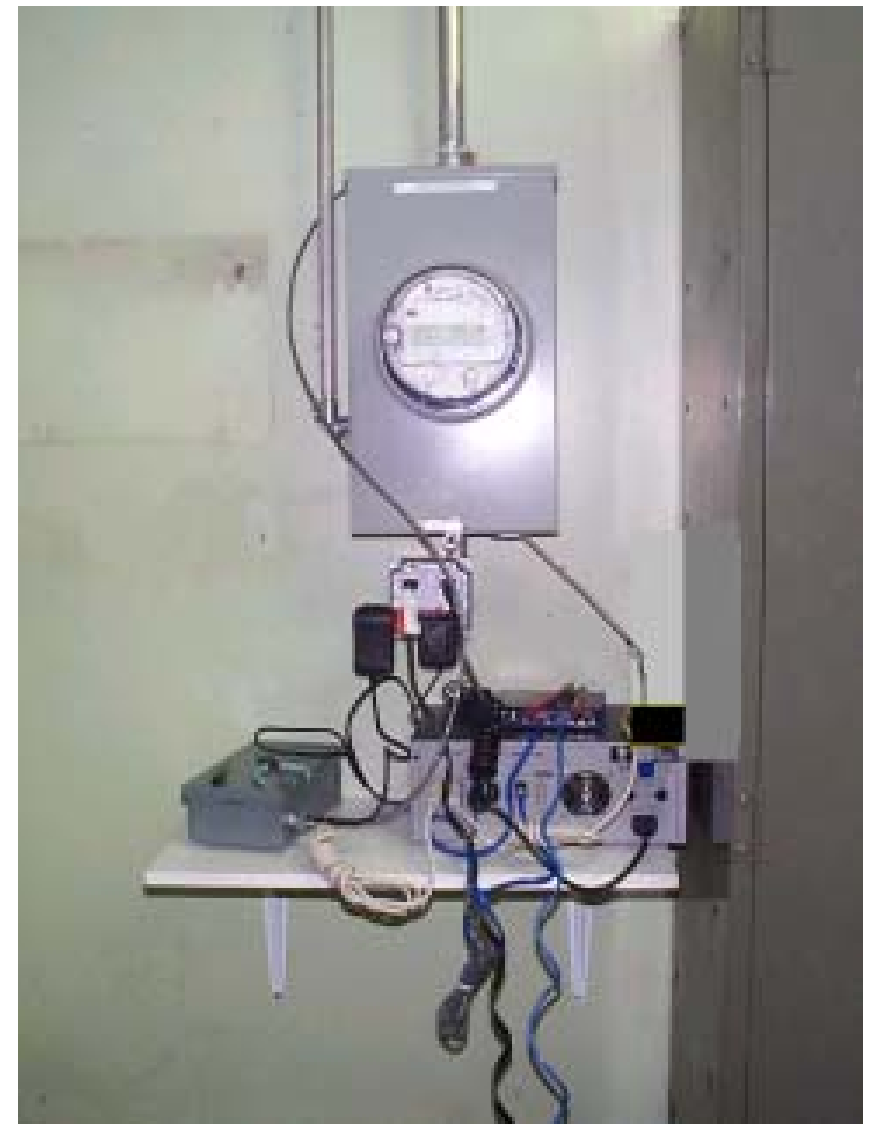

Figure 4. Installed monitoring equipment

\subsection{Power-Generating Equipment}

Backup emergency power generators driven by diesel engines or gas turbines are the usual power-generating equipment. This equipment belongs to and is maintained by the client.

Some clients prohibit the DG aggregator from having direct access to their control systems. In these cases, the DG aggregator cannot control the generators in a completely automated fashion. It therefore operates them through client-authorized personnel. Nevertheless, the DG aggregator has intimate knowledge of these generators and sites. It also has the capability of tracking some their key characteristics.

- Engine reliability and availability are important because bidding and dispatch procedures for participation in energy markets are based on the creation of groups of engines with a capacity reported to the independent system operator (ISO). The failure of a single engine during the operation could result in significant financial penalties.

- Fuel cost represents a significant part of the cost of electricity generated by DG. Therefore, precise calculation of the fuel consumed by each engine is very important for the bidding strategy. 
- The curtailable load of a building is the maximum load that may be transferred to its generators. Very often, the installed capacity of emergency generators (especially in telecommunication and data management centers) is bigger than the building's maximum load. Also, in some buildings, the electrical load is separated into essential and non-essential load; only essential load is automatically transferred to emergency generators during a commercial power failure. Therefore, it is the curtailable load that is of interest to the DG aggregator, not the capacity of the installed generators.

For the successful operation of the DG aggregation system, it is necessary to forecast both building load and relevant fuel consumption.

\subsection{Monitoring Equipment}

It is necessary to monitor two points at all DG generation sites: power output from generators and energy flow at the commercial power service entrances. These functions are performed at DG sites by different instruments, which are referred to by the generic name "DataNode" in the system architecture.

\subsubsection{GE kV Meter DataNode}

An energy revenue meter measures power output from the generator. The GE kVTM meter was selected as the standard generator output DataNode. For the DG operation, the GE kV meter collects the:

- Three-phase energy (watt-hours)

- Three-phase peak active power demand

- Three-phase "instantaneous" active power

- Phase voltages

- Phase currents.

\subsubsection{ADAM Module}

Unfortunately, meters installed at the generators could not be used for settlement with power markets and power authorities such as the NYISO and LIPA. Only measurements made by meters installed and operated by certified metering companies can be used for energy sales transactions. These meters are installed on commercial power services and operated by energy supply companies. To obtain the information necessary for the DG aggregation operation, the DG aggregator must have access to the information collected by these meters. This role is performed by another type of DataNode: an Advantech ${ }^{\circledR}$ ADAM module.

The ADAM module is a pulse counter that measures the building load at the electric service entrance. The energy meters of the electric utilities have KYZ pulse output. This is a demarcation box, a unit that permits Electrotek to have output from the utility's revenue meter in the form of pulses. For every $x$ kilowatt-hours measured, a set of relay contacts are pulsed. The $x$ is a scale factor determined for each site. From the other side, the demarcation box prevents Electrotek from interfering with the operation of the utility-installed revenue meter. The ADAM module is able to detect the pulse and increment its counter. The multiplier for each meter must be known to scale the count of pulses to kilowatt-hours used. 


\subsection{On-Site Data Gateway}

The Dranetz-BMI InfoNode 5500 is the gateway between the DataNodes and the DMC. The features of the InfoNode are:

- Data collection

The InfoNode is the data concentrator for the data collected by the GE $\mathrm{kV}$ meters and ADAM modules. It is also the interface for downloading data to the DMC.

- Remote setup of DataNodes

The InfoNode provides a Web interface for setting up the DataNodes, GE kV meters, and ADAM modules. Through this interface, the DataNodes are named, channels selected, and storage intervals set.

- Live-data interface

The InfoNode has a live-data interface that allows a client to get 10-s updates of voltage, current, and power quantities. 


\section{Data Collection and Management Center}

Servers and workstations comprise the data collection and management system of the DG operation. The storage capacity of the Dranetz-BMI InfoNode 5500 on the generation site is limited; it is not designed for long-term data storage.

\subsection{Physical Design and System Architecture of the Data Collection and Management Center}

The physical layout of the DMC is shown in Figure 5. The DMC central room is shown in Figure 6. The system architecture of the DMC is detailed in Figure 7. The system architecture for the DMC can be broken down into two major areas: server components and user tools.

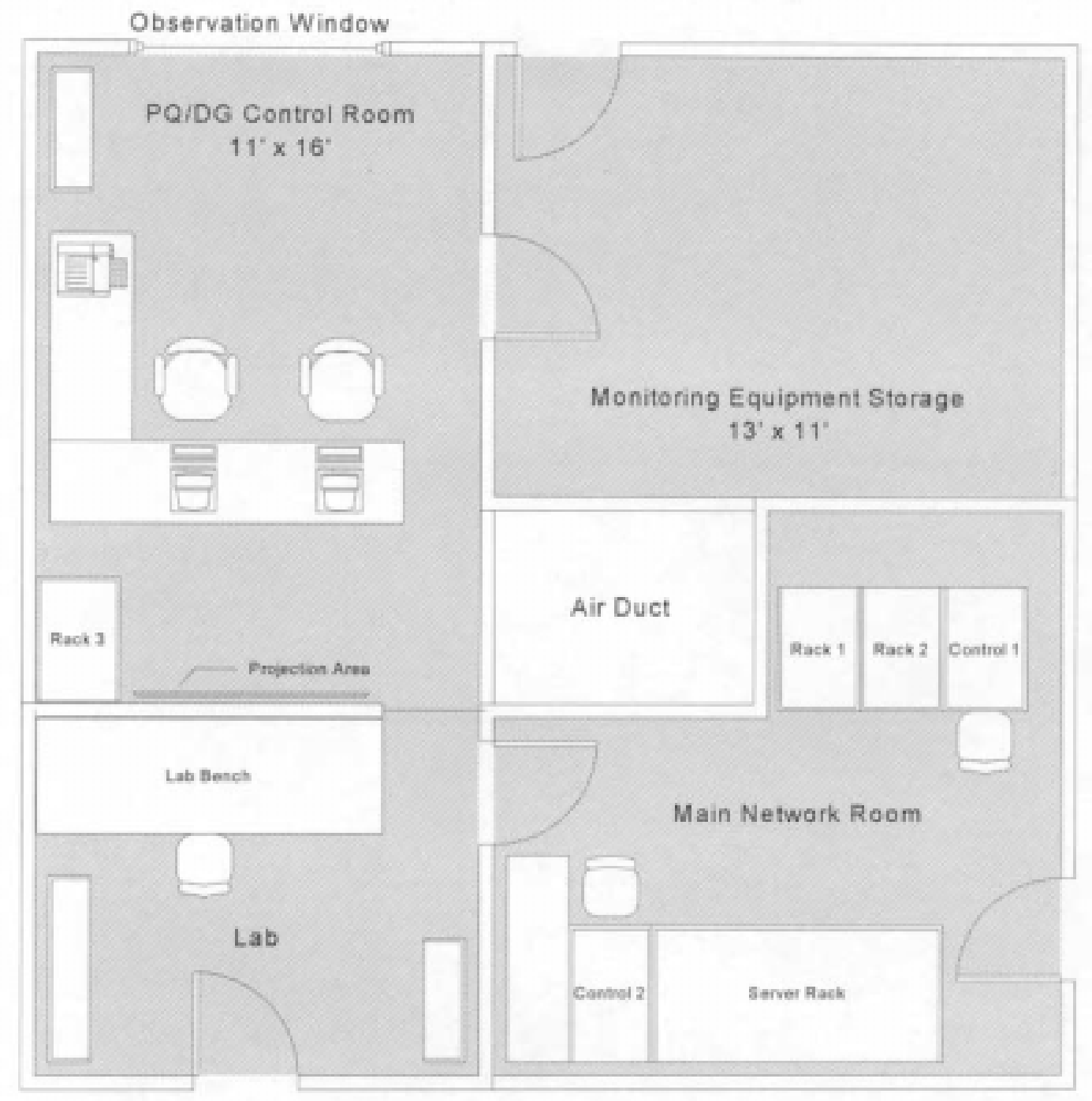

Figure 5. Physical layout of the Data Collection and Management Center 


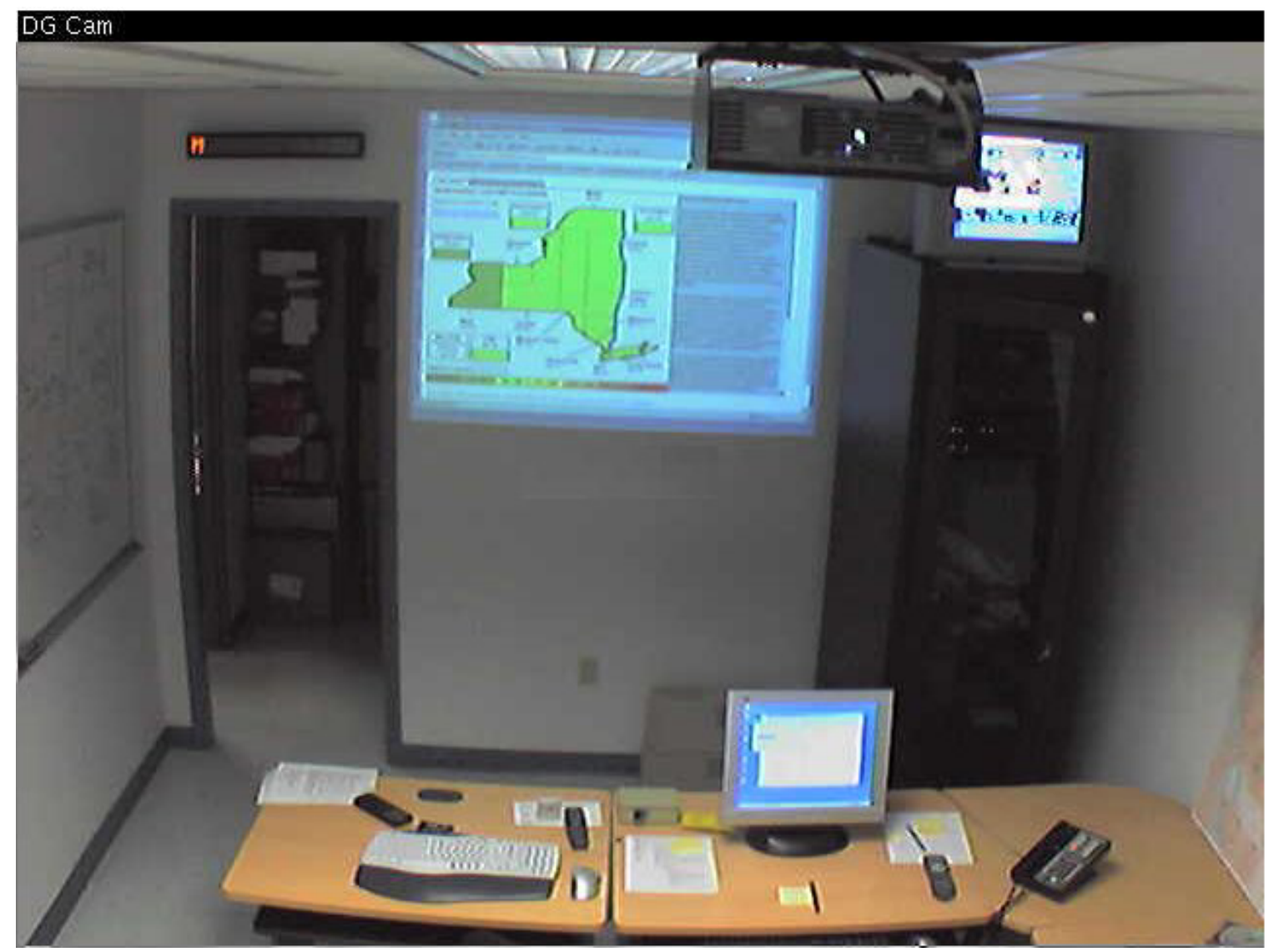

Figure 6. Data Collection and Management Center (View through the observation window) 


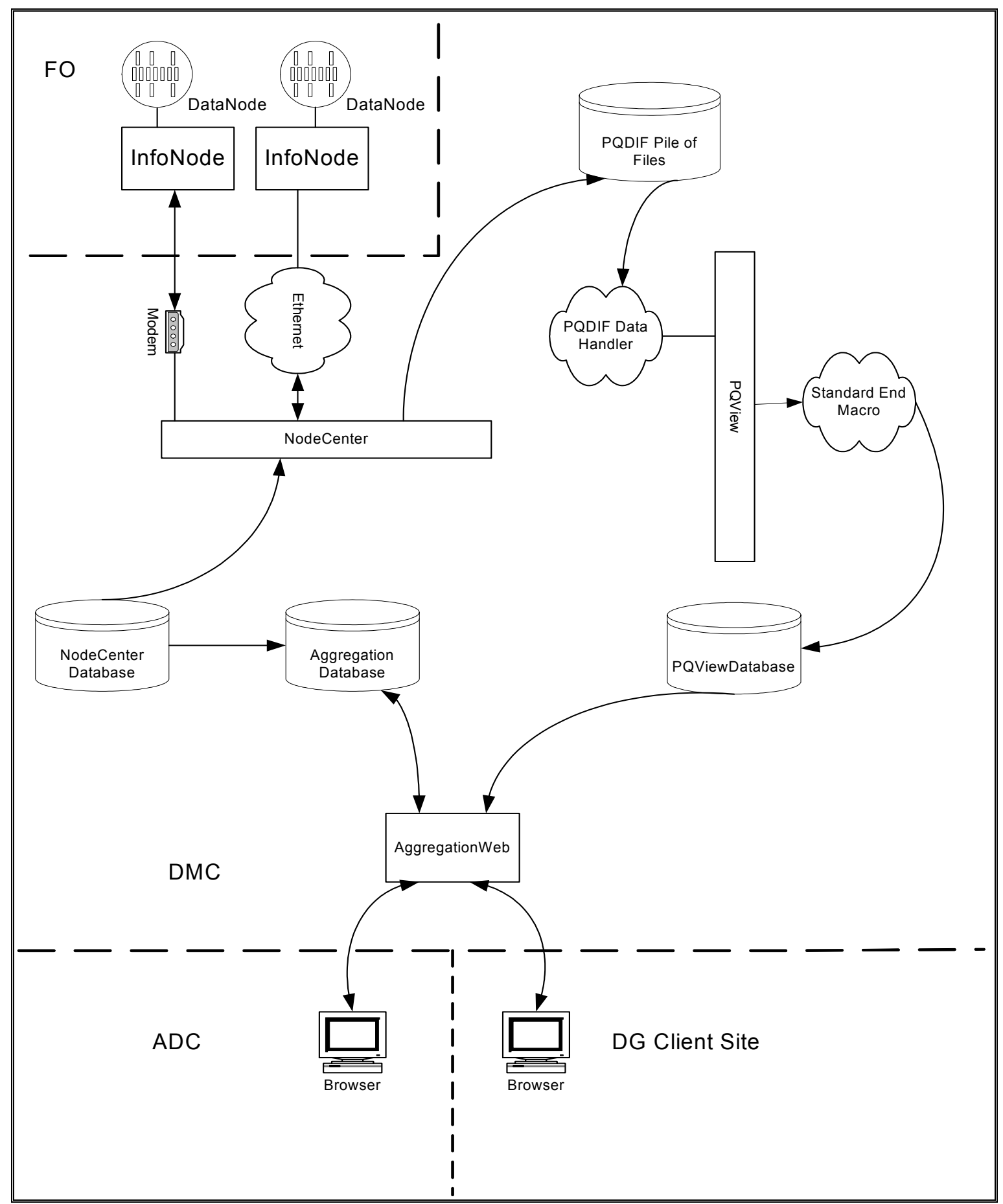

Figure 7. Distributed generation aggregation system architecture

Task 8 


\subsection{Server Components}

There are two subsystems: NodeCenter ${ }^{\mathrm{TM}}$ and PQView ${ }^{\circledR}$.

\subsubsection{NodeCenter}

NodeCenter is the enterprise software of Signature System. NodeCenter software runs on a Microsoft ${ }^{\circledR}$ Windows 2000 server. NodeCenter is the system that downloads data from InfoNodes. The capabilities of the NodeCenter software will be discussed as they pertain to the DG operation. The main components of NodeCenter are the NodeCenter database and NodeCenter Service. The NodeCenter database is built on the platform of a Microsoft Access database. NodeCenter Service is a service program developed by Electrotek.

\subsubsection{NodeCenter Database}

To contact and download data from the InfoNodes at a DG client's site, certain information is required. This information is stored in the NodeCenter database. Listed below are the fields required for NodeCenter to perform the download function. Any restrictions or requirements are not necessarily inherent to NodeCenter but have been imposed by the DG operation.

- Downloadable Instrument - This corresponds to an InfoNode. A downloadable instrument requires a name and an Internet protocol (IP) address.

- Site - This is a grouping of downloadable instruments. For the DG operation, this is a one-to-one mapping. One site corresponds to one downloadable instrument.

- Monitor - This corresponds to a DataNode (i.e., a GE $\mathrm{kV}$ revenue meter or an ADAM module). Each DataNode has an InfoNode as a parent.

- Download Group - This is a group of monitors with data to be downloaded.

- Schedule - A schedule specifies the time and frequency of a download for a download group.

\subsubsection{NodeCenter Service}

NodeCenter Service is started automatically when the server boots up. At start-up, NodeCenter Service loads the information listed above. NodeCenter Service is responsible for downloading the data based on the schedule and download groups in the database. NodeCenter Service logs all stages of the download and handles retries and queuing of download requests. If an InfoNode fails to download after all retries, then the technical coordinator alerts support technicians at the ADC. Data may or may not be lost because of download failures. Data are lost if they are purged from the InfoNode database prior to being downloaded; otherwise, they will be downloaded on the next successful attempt.

On the NodeCenter server is a Power Quality Data Interchange Format (PQDIF) ${ }^{2}$ pile of file folders, and all downloaded data are written to that folder. For each InfoNode-DataNode combination, a directory is created there, and the data for that pair are written in files using the PQDIF format.

\footnotetext{
${ }^{2}$ PQDIF is an industry standard format for representing power quality data.
} 


\subsubsection{PQView}

$\mathrm{PQView}$ is a database management system that stores and analyzes large quantities of power quality-related disturbance and steady-state measurement data. The data collected by the DataNodes (GE kV meters and ADAM modules) are steady-state data. Steady-state data are collected on time intervals. The DG operation was able to use this application for the management of the data collected at DG client sites. PQView stores the data in one relational database for each DG client. PQView can be configured to automatically import the PQDIF files created by NodeCenter.

\subsection{User Tools}

The DMC houses the Web site AggregationWeb, which is the user's interface to all data and support tools. AggregationWeb is the interface for all DG operations. It features tools that support all activities at the ADC and data views accessible by DG clients.

\subsubsection{Distributed Generation Operation Tools}

The ADC must perform many activities. There are setup activities as DG clients are added to the system. There are daily activities, activities when curtailments occur, and monthly activities for settlement. AggregationWeb provides the tools to perform these activities.

\subsubsection{Distributed Generation Client Management Tools}

AggregationWeb provides setup tools for adding new DG clients to the system. For each client, there is an interface for entering address, contact, user, and contract information. In addition, the control operator enters information about all buildings participating in the operation for each client. The buildings are linked to NodeCenter sites. The control operator can also enter information about each generator.

The use of this tool is described in detail in Appendix A, the AggregationWeb User's Manual.

\subsubsection{Operation of Generators}

Generators are operated anytime the ADC is notified to run. A call to run may be the result of a bid being accepted in the DAM, or it may be a call from the Emergency Demand Response Program or another energy program. The running of generators in response to a call is entered in the aggregation database as a curtailment. ${ }^{3}$ AggregationWeb is the interface for creating the curtailment. Curtailments are used for tracking generator runs and estimating revenue. The details of a curtailment are described in Appendix A, the AggregationWeb User's Manual.

To support the operation of the ADC, a library of computer tools, manuals, and guidelines was developed and placed on AggregationWeb. These tools include bidding, coincident peakhunting, and building economics tools.

\footnotetext{
${ }^{3}$ Any generator run in AggregationWeb is called "curtailment" because the generators are not interconnected and are dispatched without delivery of energy to the grid. Even if a generator is used in an economic program and is paid for energy generation, the building is fully or partially disconnected from the grid, and generators are providing the energy to fulfill the building load. In other words, the building load is curtailed from the commercial grid.
} 


\subsubsection{Distributed Generation Client Visualization Tools}

These tools provide views of archived and live data directly from the InfoNode. These tools are available to the ADC and DG clients. The views are listed below.

- Live generation

$$
\begin{array}{ll}
\circ \text { Real-time } \\
\circ \text { Hourly }
\end{array}
$$

- Revenue

- Load profile

- Generator run summary

These views are available through AggregationWeb. Instructions and a more detailed discussion of these views can be found in Appendix A, the AggregationWeb User's Manual.

\subsubsection{Live Generation}

AggregationWeb has a real-time view with an update rate of $10 \mathrm{~s}$. AggregationWeb establishes connections with InfoNodes based on requests received from AggregationWeb clients. Multiple requests to the same InfoNode require only one connection, and the connection will be maintained as long as requests are made within a predefined interval. The Web page automatically sends requests as long as the page is displayed to the client. Once all clients leave their respective pages, the connection will be dropped after the time-out period has expired.

For the hourly view, data are updated every $15 \mathrm{~min}$., so it is not necessary to use the proxy cache for this data.

\subsubsection{Revenue}

Revenue is a curtailment-based view. It provides an estimate of revenue for the DG client based on the curtailments in which it has participated. The client may view monthly revenue or revenue for individual curtailments.

\subsubsection{Load Profile}

The load profile view provides the DG client with the electrical load at each building service entrance. The interval load data is stored in 5-min intervals, but the load profile view allows the user to aggregate the data into larger intervals prior to display.

\subsubsection{Generator Run Summary}

The generator run summary provides the DG client with a summary of all its generator runs. For each generator, the summary includes the date of run, the length of run, and the average power generated for each hour the generator ran. 


\subsection{Data Collection and Management Center Operations}

The DMC, home of the data collection system of the DG operation, is an integration of multiple subsystems. The DMC is managed by a technical coordinator, who is responsible for data collection and storage processes. The technical coordinator must interface with each subsystem for the data collection process of the DG operation to function properly. Duties of the technical coordinator can be organized into the categories of initial setup, daily activities, and troubleshooting.

\subsubsection{Initial Setup}

When DG clients are added to the DG operation, certain tasks must be completed after the installation of the monitoring equipment. These are:

1. Create a site in the NodeCenter database that corresponds to the Dranetz-BMI InfoNode installed at the DG client site. Add the InfoNode as a downloadable instrument for the site.

2. Perform a health check on the InfoNode from NodeCenter. The health check reports the status of the Dranetz-BMI InfoNode and associated DataNodes. It is through this health check that DataNodes are added to the NodeCenter database.

3. Create one or more download groups in NodeCenter for the DG client.

4. Add the download group(s) to a schedule in NodeCenter.

5. Perform an initial manual download.

6. Create a PQView database for the new DG client.

7. Set up automatic importing of steady-state data stored in the PQDIF pile of files into the PQView database.

8. Set up configurations for the energy quantities collected at the generators and the service entrances.

This is a summary of tasks performed by the technical coordinator for every new DG client.

\subsubsection{Daily Activities}

InfoNodes installed at DG client sites have been set up to download steady-state data collected by associated DataNodes every 24 hours. The downloaded data have also been set up for automatic importing into PQView.

1. Downloads start after midnight every night. For the automatic import of data into PQView to occur, the technical coordinator must make sure PQView is left open and running on the import machine.

2. When arriving in the morning, the technical coordinator reviews the logs to check the status of all downloads.

3. After reviewing the logs, the technical coordinator checks the data with data validation tools in the PQView software. 
This is a summary of the daily tasks for the technical coordinator.

\subsubsection{Troubleshooting}

\subsubsection{Download Failures}

Many times, downloads fail for one reason or another. Some reasons a download may fail include modem problems or network problems at the DMC. Both of these problems are internal to the DMC. The technical coordinator contacts the staff at the DMC and reports the problem. Once the problem has been resolved, the technical coordinator initiates on-demand downloads.

Downloads also fail because of problems in the field. These problems include equipment failure and connection problems. The technical coordinator attempts to contact the individual InfoNode(s) that failed to download to determine if the problem is a connection problem. If there is a connection problem at the DG client site, then the technical coordinator reports it to the field support technicians at the ADC.

\subsubsection{Data Problems}

Although data problems occur less frequently than download failures, the technical coordinator may a find a problem while reviewing the data. A data problem that has been experienced is gaps in data. These may be caused by a connection failure between the InfoNode and DataNode. DataNode setup errors or problems with firmware upgrades may cause problems with the data. The technical coordinator gathers information such as data plots or DataNode setup sheets and reports the problem to the ADC field support staff. 


\section{$6 \quad$ Aggregation and Dispatch Center}

The ADC is the central point of operation of the DG aggregation system. It will be built in Edison, New Jersey, and will include three divisions: Business Development, Operations, and Monitoring and Communication. To support the activities of the ADC, a library of computer tools, manuals of procedures, and instructions has been developed.

\subsection{Physical Design of the Aggregation and Dispatch Center}

The physical design of the control room for the ADC is shown in Figure 8.

\section{NJ AGGREGATION AND DISPATCH CENTER}

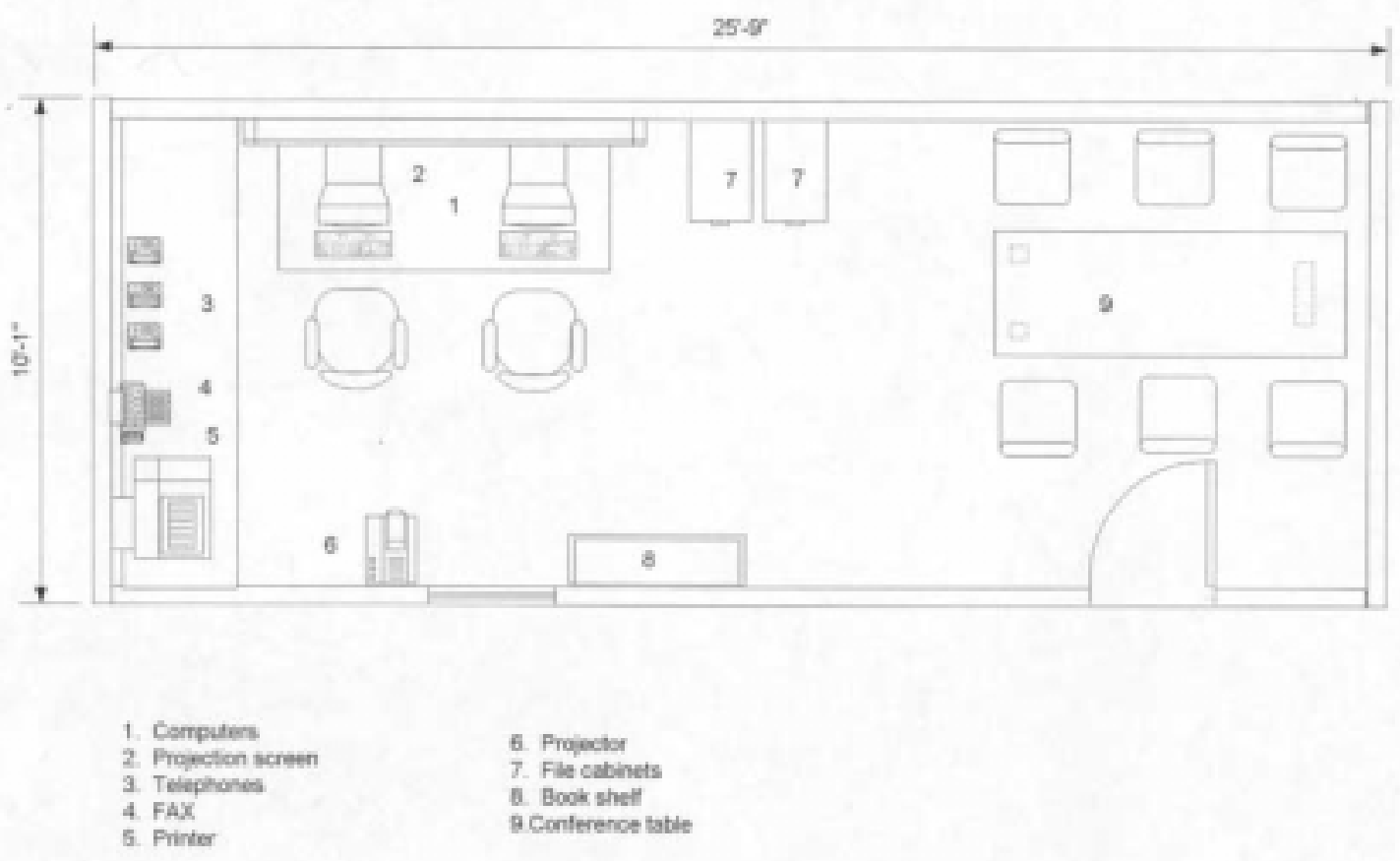

Figure 8. Control room of the Aggregation and Dispatch Center

\subsection{Business Development Division}

The Business Development division is responsible for recruiting new clients, economic and technical site evaluations, permitting, and field equipment installation and start-up.

After a potential client is identified, a chain of activities should be performed, including:

- An initial site visit

- An economic/financial evaluation

- Environmental permitting

- Design

- Equipment procurement, installation, and start-up

- Certification of installed equipment. 
Some facilities may require additional activities such as the installation of fuel flow meters and the implementation of emission-reduction technologies.

\subsubsection{The Initial Site Visit}

The objectives of the initial facility site visit are to obtain the information necessary for the next steps of evaluation, evaluate generator operation, and determine what environmental permits and emission reduction measures are necessary for the facility to participate in load curtailment and energy markets programs.

\subsubsection{Economic and Financial Evaluation}

The objective of this step is to evaluate whether a facility is a good candidate for participation in a curtailment or energy market program - in other words, if the operation of the facility for these programs would be profitable for the building owner and aggregator.

Preliminary economic evaluation is based on information collected during the initial site visit. This information includes:

- Facility location

- Electricity provider

- Type of business (industrial, commercial, hospital, etc.)

- Nameplate data on emergency generator(s) installed on-site

- Building summer and winter load

- Load curtailable by emergency generators

- Existing and necessary environmental permitting.

Other information necessary for economic/financial analysis must be obtained from specialized organizations. This includes the anticipated expenses for testing, maintenance, and repair of generating and switchgear equipment before it can be used in the load reduction program and the cost of the aggregator's equipment installation.

This information is used in Building Economic Model (BEM 9.1). The spreadsheet model BEM 9.1 was developed to examine the financial benefits (or losses) of integrating a new distributed generator into the DG aggregation system. The spreadsheet is written in Microsoft ${ }^{\circledR}$ Excel and allows users to perform a number of cash flow analyses to determine the best option for DG incorporation.

The model provides both the DG owner and DG aggregator with project financial indicators such as:

- Internal rate of return

- Net present value

- Payback period.

The model calculates the financial indicators for 1, 2, 3, 4, and 5 years. 
Cash flow analyses are based on owner and aggregator project development cost estimates, monthly operating expense estimates, and projections of monthly revenues from capacity and electric energy sales and electric energy savings.

\subsubsection{Environmental Permitting}

To use emergency generators for the load reduction program, a facility must obtain some kind of environmental permit. Permitting is based on:

- The type and size of emergency generators

- The type and hourly consumption of fuel

- Diesel/turbine manufacturer's data on NOX, CO, CO2, and PM emissions

- Design parameters of the engine exhaust system.

Very often, emissions are capped by facility, not per engine. Therefore, it is also necessary to obtain data about all other combustion sources on the premises. These include boilers, hot water heaters, and absorption chillers (using natural gas). For this equipment, similar information is necessary, but in addition, operating schedules and the total duration of operation should be obtained. This is important for calculating annual fuel use and annual air emissions.

In some cases, fuel consumed by emergency generators during load curtailment must be tracked. This often requires the installation of fuel flow meters or fuel level meters. Usually, preliminary information obtained before a site visit determines if installation of fuel flow meters is necessary. In such a case, a detailed evaluation of the fuel handling and supply system is performed to determine the size and type of needed flow meters and a suitable place for their installation.

\subsubsection{Equipment Design, Procurement, Installation, and Start-Up}

Electrotek procures equipment on the basis of design specifications. Installation usually does not require Electrotek involvement, except in cases in which some corrections should be made to design specifications according to local conditions.

The final stage of implementation is a start-up of monitoring equipment. This operation requires starting all generators and transferring essential and non-essential facility loads to the emergency generators. Quite often, the essential and non-essential facility loads are supervised and operated by different management groups, and good coordination between these groups is essential for successful start-up and future curtailment operations.

\subsection{Operations Division}

The Operations division is responsible for adding information about new customers to the system, operation strategy, bidding preparation and execution, dispatching and monitoring generators, and settlement and accounting. These activities are performed through the DG aggregation Web site, which contains several tools to support dispatchers in the operation of the DG aggregation system. 


\subsubsection{Addition of New Customers}

After a contract with a new customer is signed and on-site monitoring equipment is installed, the customer and its equipment should be included in the DG aggregation database. This is accomplished by filling out forms in the setup section of the aggregation Web site.

The Web site collects:

- Customer name and location

- Primary contact(s)

- AggregationWeb user information

- Information about customer equipment and curtailable load

- Programs in which this customer will participate

After that, the customer's monitors are added to the NodeCenter database and accounting system.

\subsubsection{Operation Strategy and Procedures}

The DG aggregation system is designed with the flexibility to permit generators to run for different energy programs or participate in the Installed Capacity market (ICAP) or DAM. It is the duty of the Operations division to determine the best strategy for each generator or group of generators. For example, all 10 buildings that participated in the Pilot Testing Program of this project were dispatched as a single System Resource in the $\mathrm{DAM}^{4}$, but other business models are also possible.

For each program or business model, specific procedures should be followed, but the common requirement for participation in programs is that the operator know the amount and cost of energy that could be delivered at any given time from each and all aggregated generators. In other words, the operator should have a tool to forecast building/generator load and cost of electricity. Another strategic decision is whether generators should be operated to attempt to hit the system coincident peak.

\subsubsection{Forecasting of Building/Generator Load and Cost of Electricity}

A computer tool was developed to forecast hourly load for each site every day. The load forecast tool uses a linear regression model based on actual loads, actual hourly temperature and humidity, and forecasted hourly temperature and humidity. After an hourly load forecast is developed for each site, each site's hourly running costs for the on-site generation is calculated, again using forecasted hourly temperature and humidity and forecasted loads.

\footnotetext{
${ }^{4}$ The NYISO approved Electrotek as its first System Resource. System Resource is the NYISO designation for an aggregated collection of DG units. These units normally are not tracked by the NYISO because of their small individual capacities. However, a System Resource is treated as a single central generator. It is given a point identification number and modeled and scheduled as a single generator by the NYISO. This allows the System Resource to participate in the DAM. This experiment is described in detail in the Task 6 report, "Field Testing of Aggregated Backup Generator Control System.”
} 
The first step is to obtain an hourly temperature and humidity forecast for the generator location. This data is usually available from nearby National Weather Service Field Offices. Given the significant computational effect of using multiple temperature forecasts and the minor temperature differences of places located in close areas, only one temperature/humidity forecast for this area is usually used. For the 10 facilities on Long Island, these data were obtained for the Central Islip. The hourly temperature and humidity forecast is automatically obtained over the Internet at http://www.weather.com/ and updated every 4 hours.

The next step is to forecast hourly loads and calculate running costs by site. This is done in two steps. The load forecast regression model is used to calculate each site's hourly load, and a spreadsheet model is used to calculate each site's hourly running cost. The hourly running costs use forecasted loads and hourly forecasted temperatures. Running costs are based on unit availability, unit fuel and operations and maintenance costs, and start-up costs. The unit operating cost (fuel plus operations and maintenance) is based on site load and temperature for each hour. Given that these units are not expected to operate more than 6 hours a day, start-up cost is a significant factor in determining the least-cost dispatch schedule.

Another component necessary for the decision-making process is the DAM electricity price. This price is also automatically downloaded from the NYISO Web site daily.

All information is then presented on the DG aggregation Web site. The decision of whether to dispatch a generator is made by analyzing the cost of electricity, the DAM price, and special constrains (such as minimum run time and start-up and shutdown times) associated with each economic model.

\subsubsection{Hunting for Coincident Peak}

The ICAP requirement of a load serving entity (LSE) in New York State is based on the collective demand of aggregated customers (by zone) at the 1-hour system peak in the zone. In fact, for summer peaking zones (all but one in New York State), the coincident peak occurs from June through September. LSEs are required to meet their ICAP requirement by buying sufficient capacity bilaterally or from the NYISO ICAP market or by having sufficient generating capacity available. Therefore, if an LSE can reduce its ICAP requirement by having customers curtail load at the coincident system peak, then its financial commitments for ICAP will be reduced the following capability period.

For most cases, the LSE contribution is computed by estimating its contribution to the system peak based on the collective consumption of its customers relative to the total in each zone. However, the LSE has the option of measuring its actual demand at the peak hour, and the next year's ICAP requirement will be determined using that measurement. Therefore, it is acceptable for the generator owner or operator to operate the engines during the LIPA coincident peak. If the owner/operator is successful in this task, then the ICAP requirement for the following year will be reduced. 
The challenge with this approach is guessing when the system peak will occur. It would be easy to run engines every time the temperature (or temperature-humidity index) is predicted to be higher than any previous day. But the generator's owner usually wants to limit the hours of operation to minimize the net cost of operation and because New York State Department of Environmental Conservation permits limit the hours each engine can operate.

A computer adviser tool, "Peak Hunting Strategy," was developed with the practical goal of not missing a season coincident peak and not activating engines more than 10 hours a month during the peak season. This strategy helps operators predict at least two events:

- When the first activation should be called at the beginning of the peak season

- When each successive activation should be called.

The program is automatically operated once a day by the aggregation Web site. It presents its results on a special screen in the form of advice: run or not run generators tomorrow.

\subsubsection{Bidding Preparation and Execution}

If generators are participating in economic programs and a decision is made to run them, the control center operators submit a bid on the secure NYISO Web page.

\subsubsection{Dispatching and Monitoring Generators}

Upon acceptance of a bid, or upon receipt of run notification for other load curtailment programs, the ADC operator should:

- Create a curtailment event via AggregationWeb

The operator enters the start and end time for a curtailment, the building to run, which energy market programs are paying for each hour, and the rate they paying.

- Notify the persons designated by the customer of the run

- Dispatch the generators during the run times.

\subsubsection{Settlement and Accounting Procedures}

The ADC operator compares monthly settlement statements from the ISO with archived data for a curtailment. The archived data is viewed via AggregationWeb.

\subsection{Monitoring and Communication Division}

The Monitoring and Communication division is responsible for the reliability of monitoring and communication equipment in the $\mathrm{ADC}$ and FO. This includes:

- Preventive and emergency maintenance of telecommunication equipment in the ADC

- Preventive and emergency maintenance of on-site monitoring and telecommunication equipment installed in facilities with aggregated generators. 
Appendix A: AggregationWeb Manual 
Task 8

A-ii 


\section{Table of Contents}

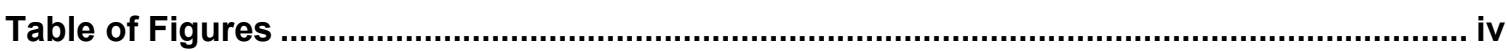

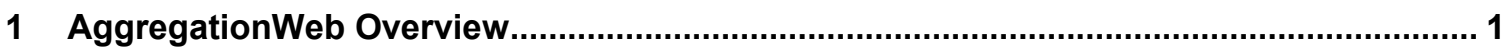

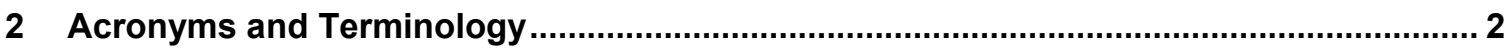

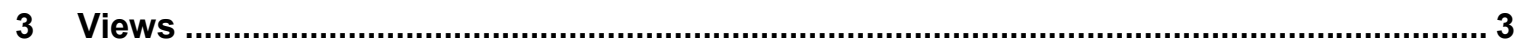

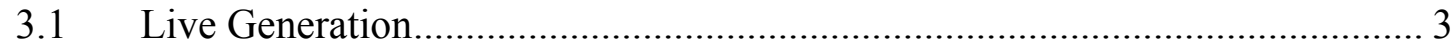

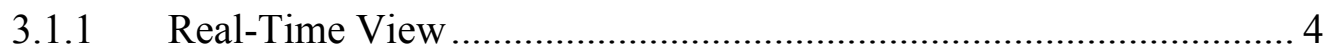

3.1.2 Hourly View ............................................................................ 5

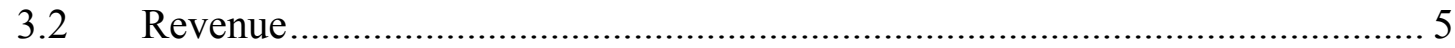

3.2.1 Monthly Revenue ..................................................................... 5

3.2.2 Revenue by Curtailment......................................................... 7

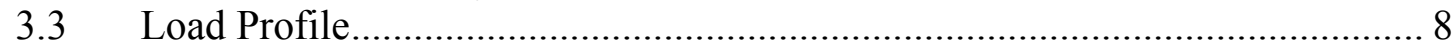

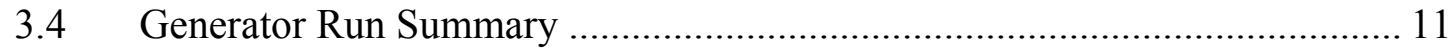

3.4.1 Individual Generator Run Summary …………................................ 12

3.4.2 Aggregated Generator Run Summary …………............................... 13

4 Setup

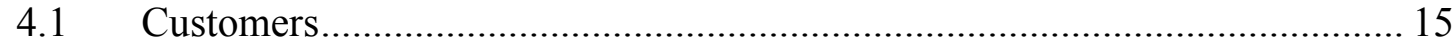

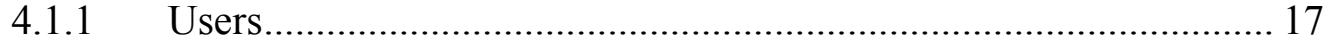

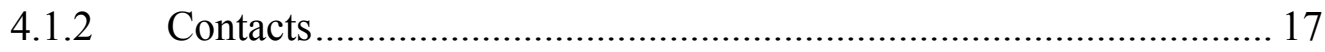

4.1.3 Contract................................................................................. 18

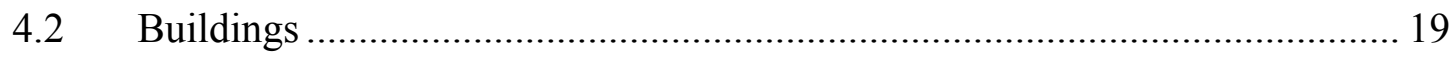

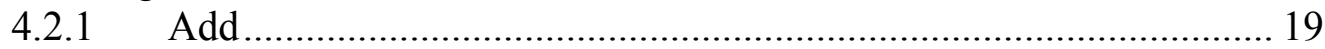

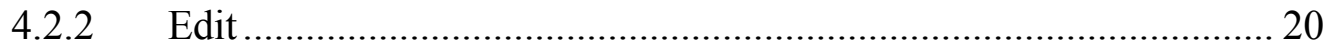

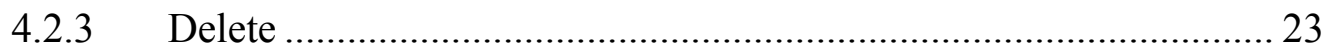

4.3 Energy Market Programs ........................................................................... 24

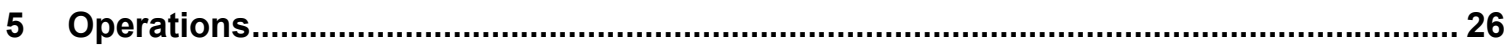

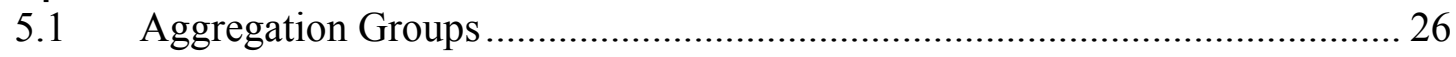

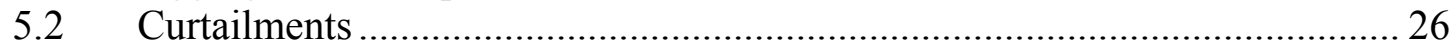

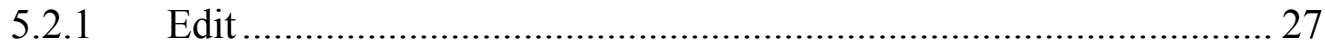

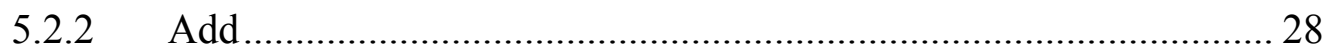

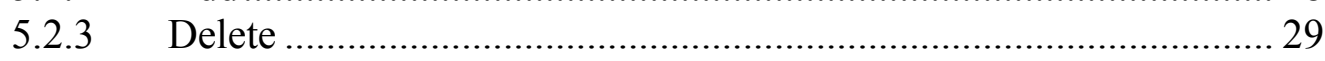

$5.3 \quad$ Peak Hunt Advisory ……………………………..................................... 30

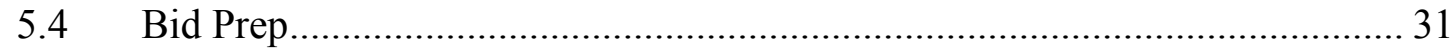

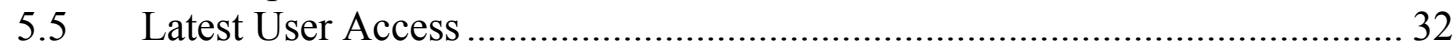




\section{Table of Figures}

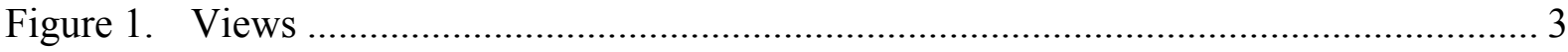

Figure 2. Live Generation selection page ........................................................................ 4

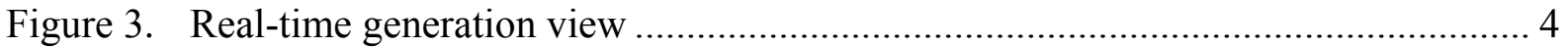

Figure 4. Energy consumption over 1-hour intervals ………............................................. 5

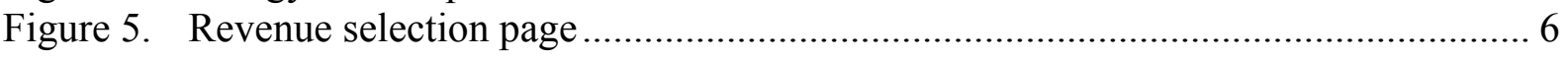

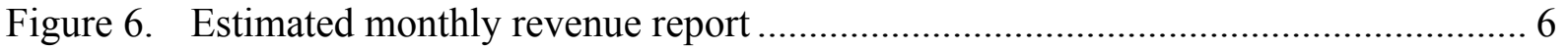

Figure 7. Revenue by Curtailment selection page ................................................................ 7

Figure 8. Estimated Revenue By Curtailment report ………............................................... 7

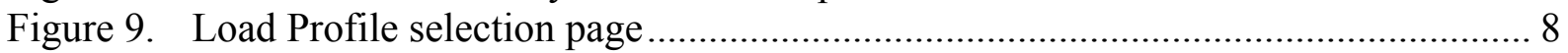

Figure 10. Load Profile plot - energy consumption over 1-hour intervals ................................. 9

Figure 11. Load Profile plot - energy consumption over 1-day intervals.................................. 9

Figure 12. Load Profile plot - 5-minute interval ………………....................................... 10

Figure 13. Aggregated Load Profile plot - energy consumption over 1-hour intervals .......... 10

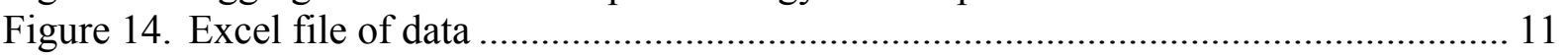

Figure 15. Generator Run Summary selection page............................................................ 12

Figure 16. Individual Generator Run Summary …………............................................... 13

Figure 17. Aggregated Generator Run Summary ……………………........................... 14

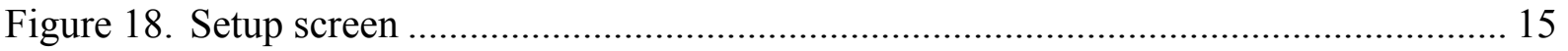

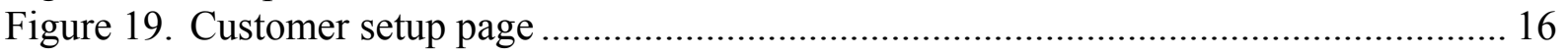

Figure 20. Customer edit/add page ................................................................................. 16

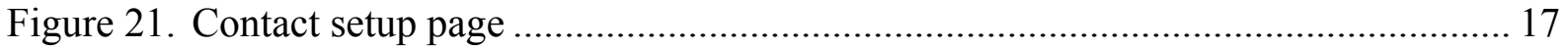

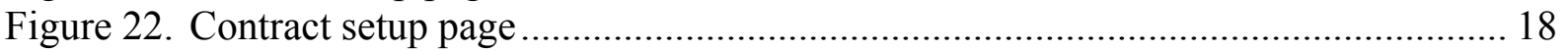

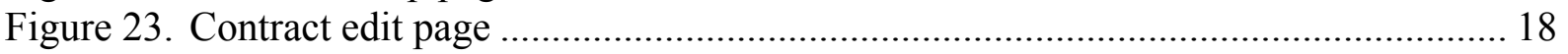

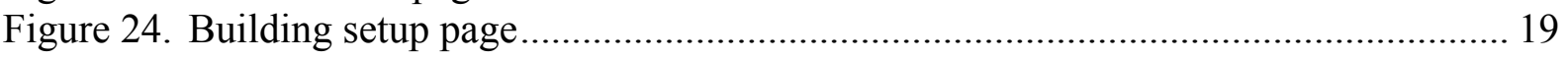

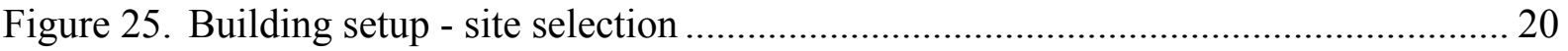

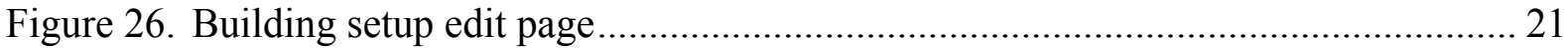

Figure 27. Building setup - aggregation monitors …………............................................. 22

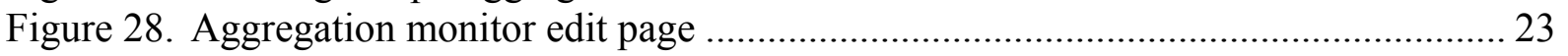

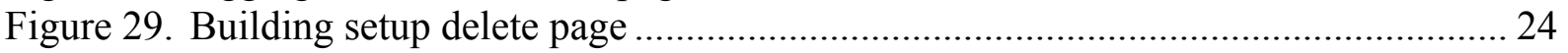

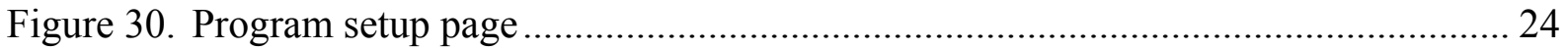

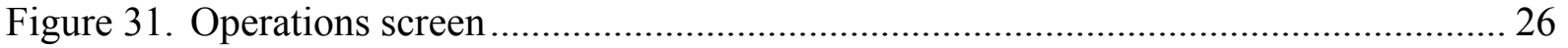

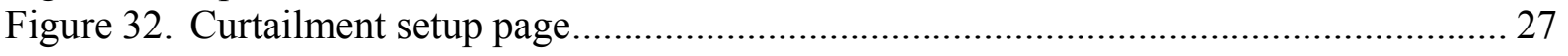

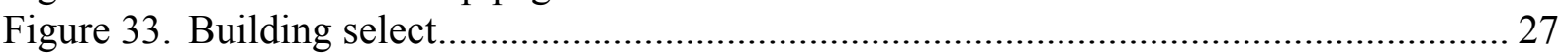

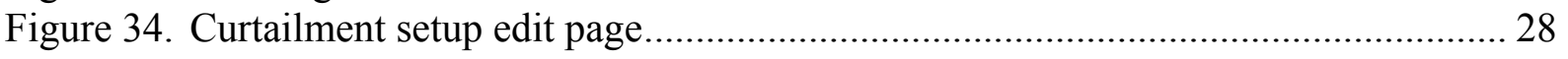

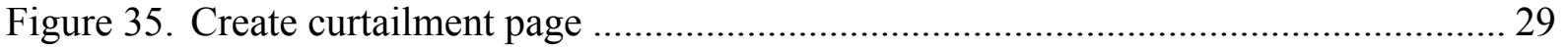

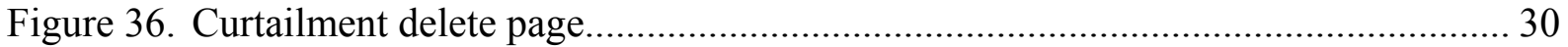

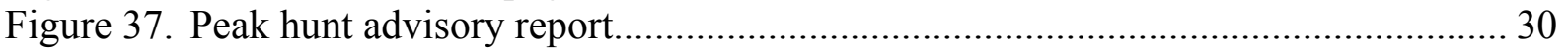

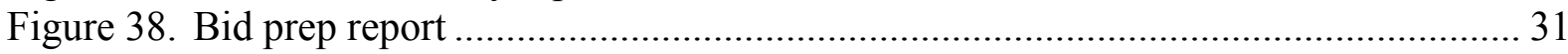

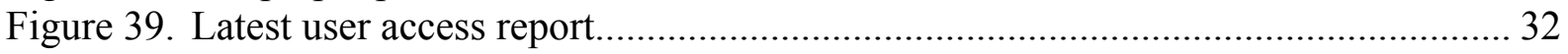




\section{$1 \quad$ AggregationWeb Overview}

AggregationWeb is the primary tool for the distributed generation (DG) operation at Electrotek Concepts Inc. This Web site serves users within the DG operation. The main users are system aggregators and DG clients.

The system aggregators work at the DG Dispatch Control Center. AggregationWeb is the tool for operating the New Jersey DG Dispatch Control Center.

DG clients are the corporations that own the generators that participate in the DG operation. AggregationWeb is the tool through which DG clients view energy and financial data.

AggregationWeb has been organized into functional areas. These areas are Views, Operations, and Setup. Each will be discussed in detail. 


\section{Acronyms and Terminology}

DG - distributed generation

DG operation - The functional name given to the operation of an aggregator of generators in the energy market programs of the independent system operator.

New Jersey Dispatch Control Center — The center in Edison, New Jersey, where all the operations for bidding and scheduling generators are performed.

SA - System aggregators are responsible for the operation of the New Jersey Dispatch Control Center. 


\section{Views}

To select Views, the user must place the cursor over the word Views and click the left mouse button. If Views is selected, its text will be yellow. A list of options under Views appears in the left pane. To select any of these options, the user must place the cursor over the text of the option and click the left mouse button. When selected, the text will turn yellow. Each option is described in detail below.

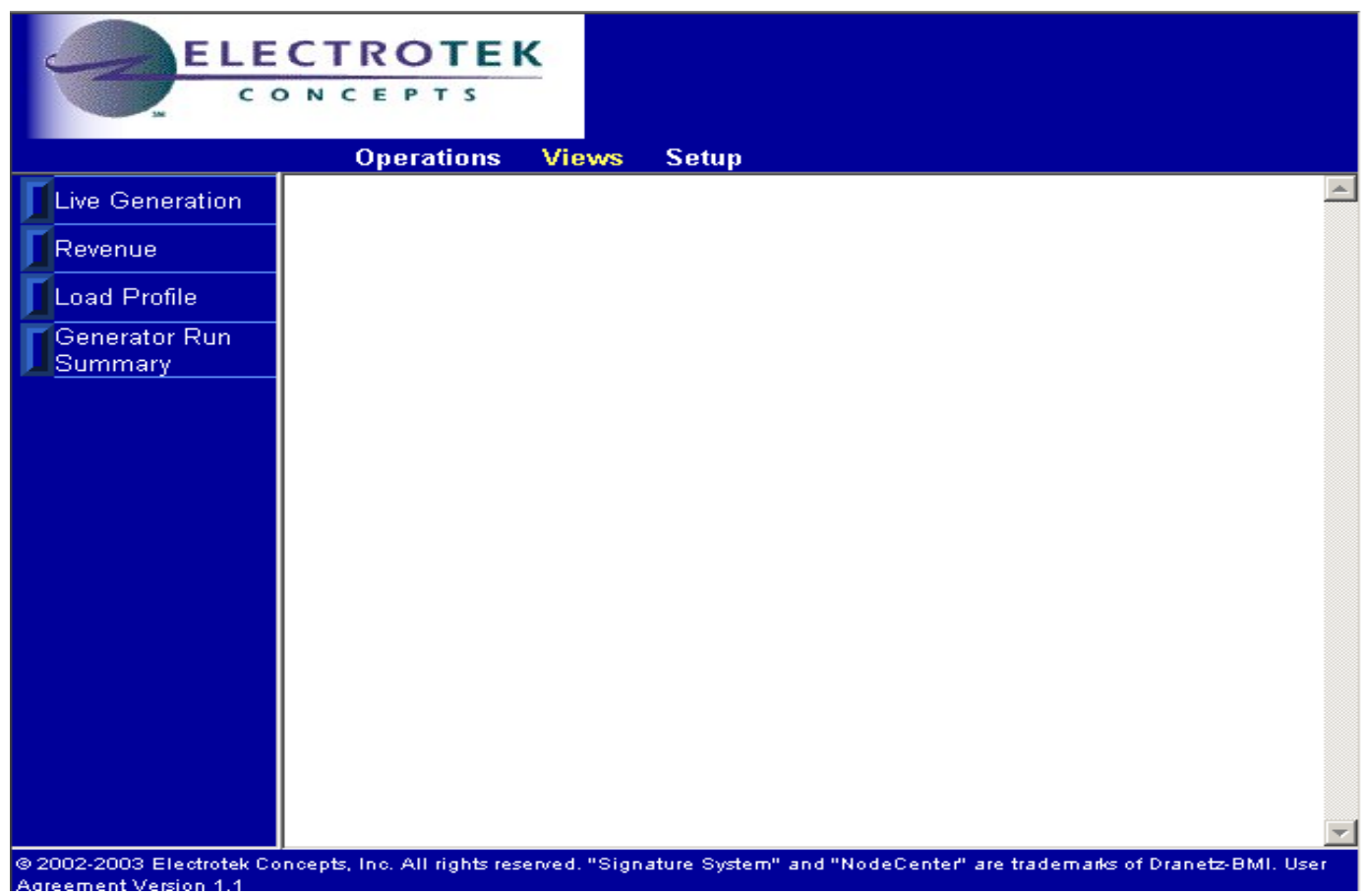

Figure 1. Views

\subsection{Live Generation}

Live Generation is used to monitor the generators. This view is not of interest when the generators are not running. When the user selects Live Generation, the page in Figure 2 is displayed. The user selects generator groups and real-time updates or live, hourly views. 


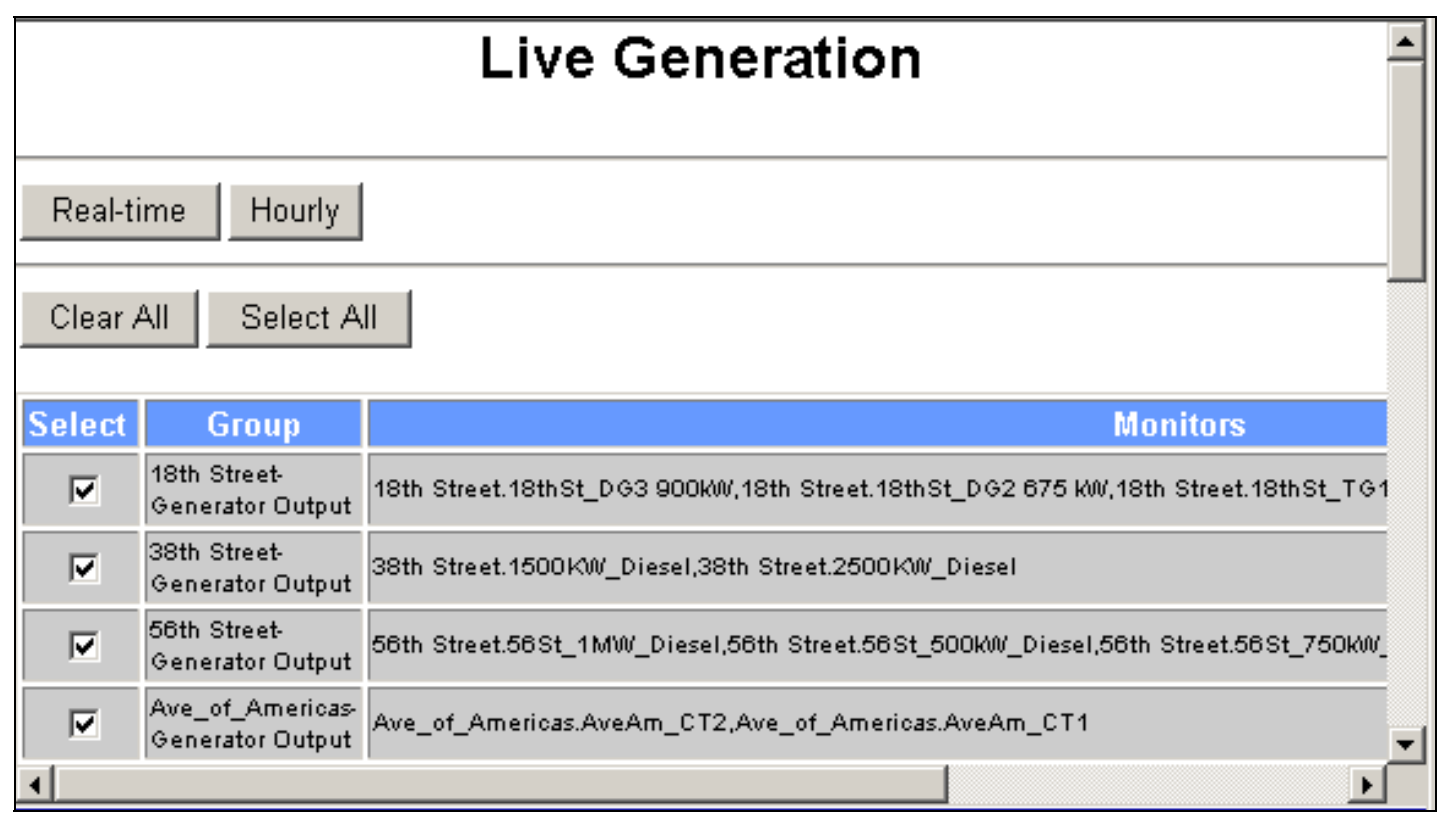

Figure 2. Live Generation selection page

\subsubsection{Real-Time View}

The real-time generation view includes a table of voltage and current on all three phases and power. Power is an instantaneous value that is retrieved every 10 seconds. If more than one generator is in the group, power is an aggregation of all the generators. The voltage and current columns, however, only display the first generator in the group. Power may be aggregated across groups as well by placing a check in the Aggregate box for the selected group. Power is displayed on the plot and updated in real time.

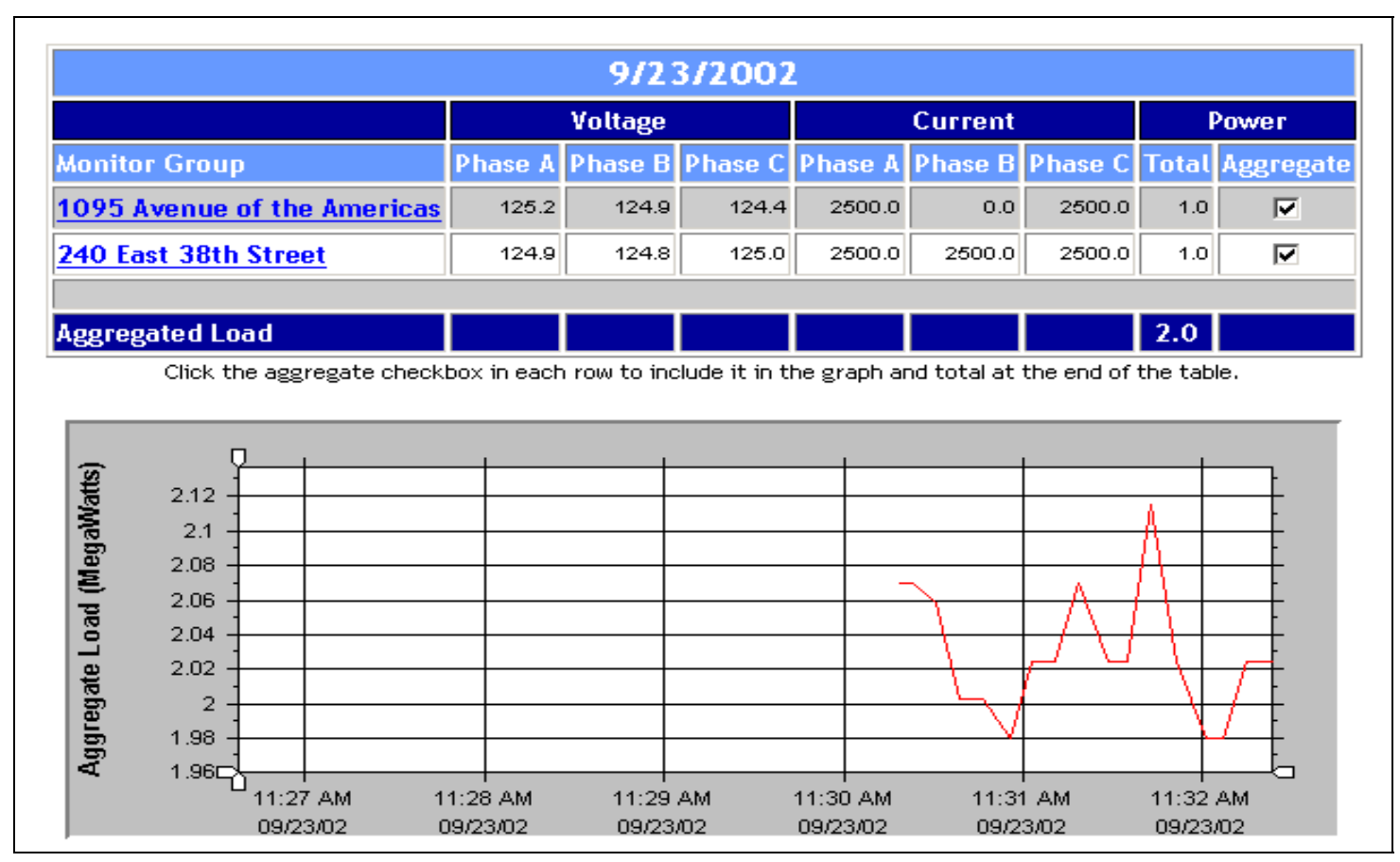

Figure 3. Real-time generation view

Task 8 


\subsubsection{Hourly View}

The hourly profile shows the total megawatts produced each hour of the day. Figure 4 shows the engine started up and ran at $0.04 \mathrm{MW}$ for the first hour. The generator then ran at 0.08 MW for the next two hours. If multiple generators are selected, the plot shows aggregated megawatts. If the page is left displayed, the view will update every 15 minutes.

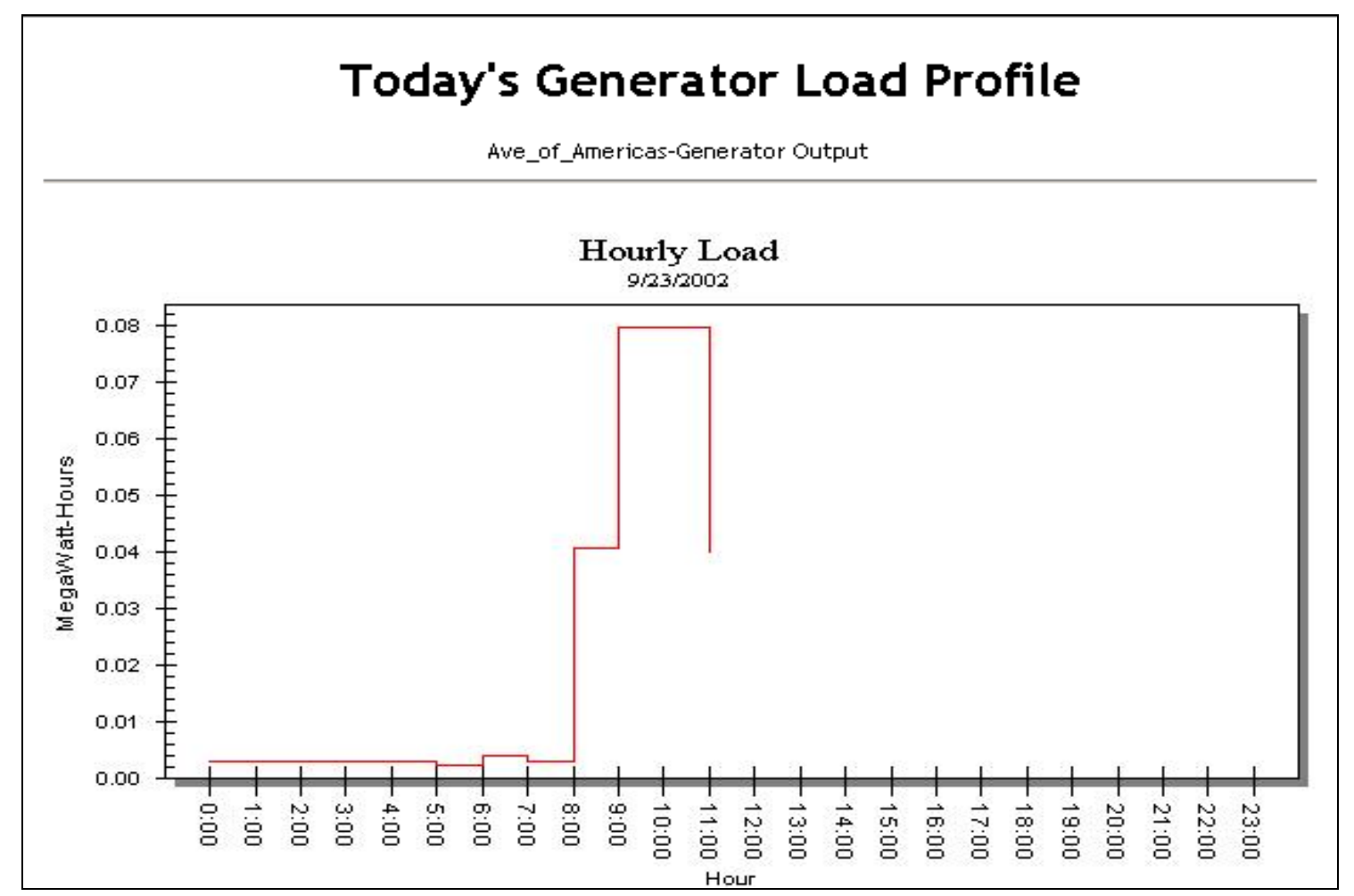

Figure 4. Energy consumption over 1-hour intervals

\subsection{Revenue}

This view provides the DG client with revenue earned by running the generators when called. A call on a given day is called a curtailment, and it is entered and managed by the SA. The revenue view provides two options for viewing estimated revenue.

\subsubsection{Monthly Revenue}

In this mode, the customer may enter the time range in which he is interested. The maximum span is 5 years. The customer may type in a time range or use shortcuts provided in the selection box. 


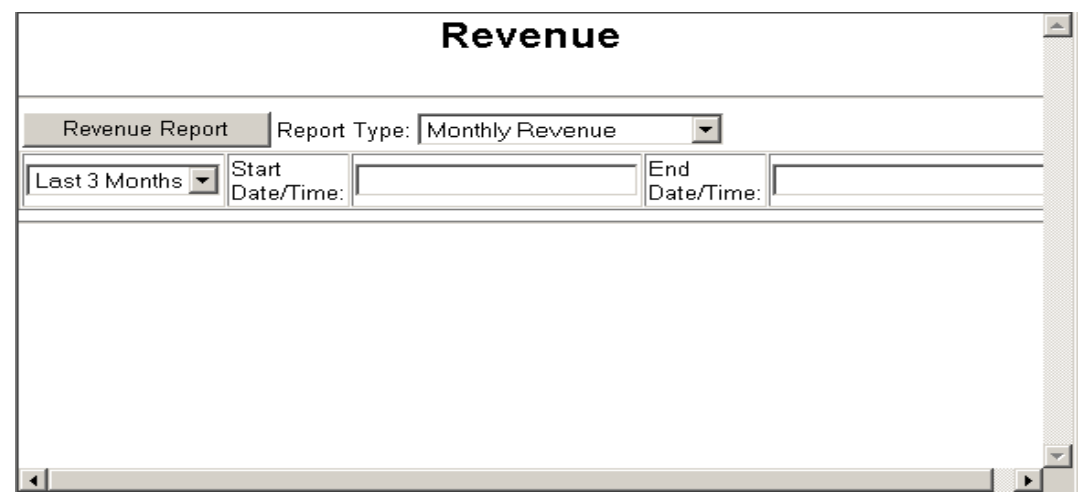

Figure 5. Revenue selection page

The customer then clicks the Revenue Report button to generate a report.

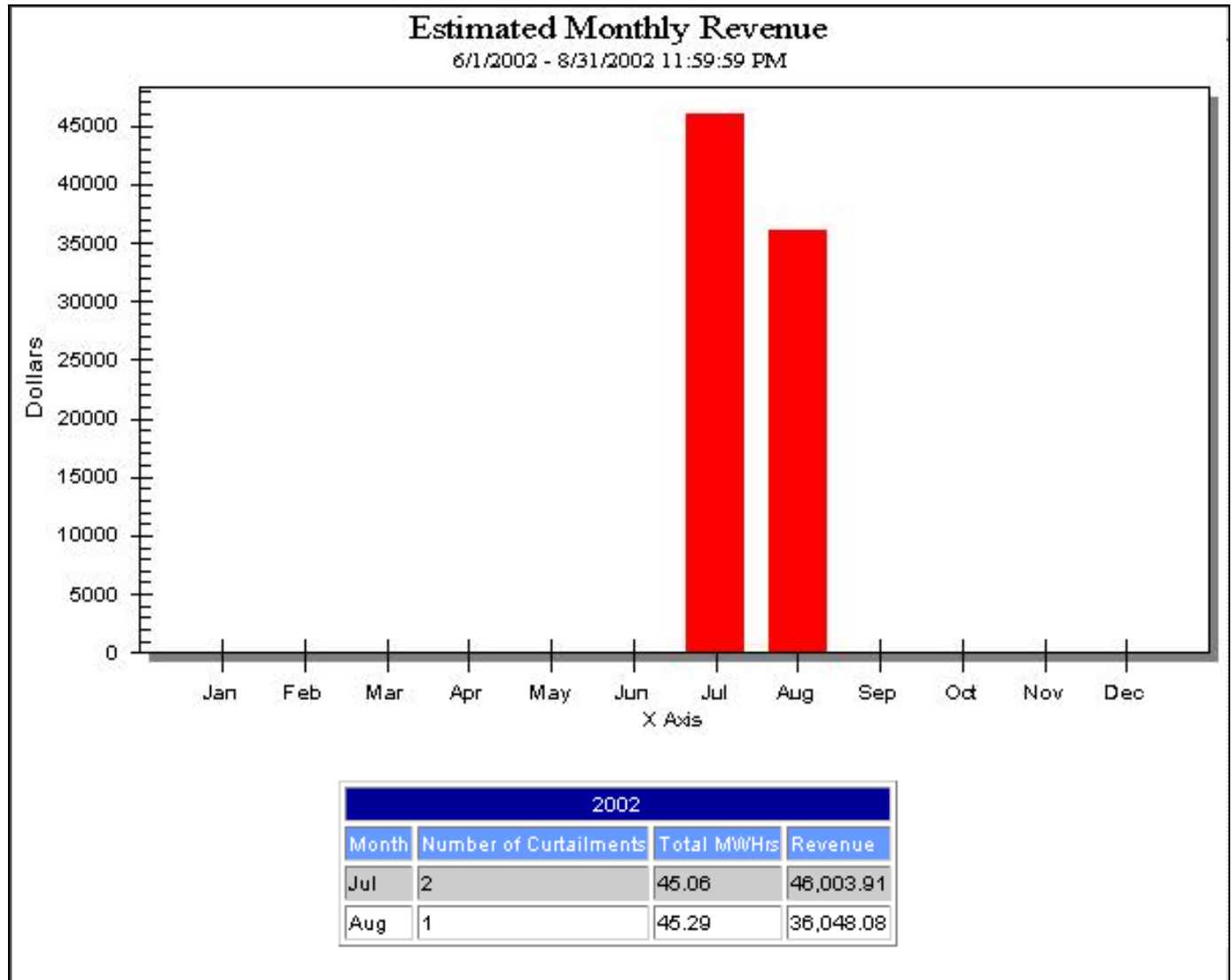

Figure 6. Estimated monthly revenue report

The estimated monthly revenue report shows a bar chart of the estimated revenue for each month. If multiple years are selected, there will be individual bars for each year. Each year will also have a table that summarizes each month by number of curtailments and revenue. 


\subsubsection{Revenue by Curtailment}

There is also a more detailed view of revenue: Revenue by Curtailment. Selecting this report will display a list of curtailments.

\begin{tabular}{|c|c|c|c|}
\hline & & & evenue \\
\hline Rever & nue Report & Report Type: Reve & enue by Curtailment \\
\hline Clear A & Select & All & \\
\hline Select & Curtailment & Start Time & End Time \\
\hline V & LIPA Call & 7/3/2002 2:00:00 PM & 7/3/2002 6:00:00 PM \\
\hline V & EDRP/LIPA & 8/14/2002 1:00:00 PM & 8/14/2002 6:00:00 PM \\
\hline 渚 & EDRP/LIPA & 7/30/2002 11:00:00 AM & 7/30/2002 6:00:00 PM \\
\hline
\end{tabular}

Figure 7. Revenue by Curtailment selection page

The user selects the curtailments of interest and clicks the Revenue Report button. A sample report is shown below.

\begin{tabular}{|c|c|c|c|c|c|c|}
\hline Curtailment & Start Time & End Time & Buildings & MWOH Hrs & Programs & Revenue \\
\hline LIPA Call & $\begin{array}{l}7 / 3 / 2002 \\
2: 00: 00 \mathrm{PM}\end{array}$ & $\begin{array}{l}7 / 3 / 2002 \\
6: 00: 00 \mathrm{PM}\end{array}$ & $\begin{array}{l}\text { Cutchogue, Bay Shore, East Hampton, Sag Harbor, } \\
\text { Brentwood, Smithtown }\end{array}$ & 6.53 & LIPA PRP & 10.516 .54 \\
\hline EDRP/LIPA & $\begin{array}{l}\text { 8/14/2002 } \\
1: 00: 00 \mathrm{PM}\end{array}$ & $\begin{array}{l}\text { 8/14/2002 } \\
\text { 6:00:00 PM }\end{array}$ & $\begin{array}{l}\text { Cutchogue, Bay Shore, East Hampton, Sag Harbor, } \\
\text { Brentwood, Smithtown, 38th Street, Hidsoville. } \\
\text { Hempstead, Ave_of_Americas, Mt Vernon, White } \\
\text { Plains, Yonkers, Clinton, 18th Street, 56th Street. } \\
\text { Laurelton }\end{array}$ & 51.83 & $\begin{array}{l}\text { LIPA PRP, } \\
\text { NYISO } \\
\text { EDRP }\end{array}$ & 46.564 .62 \\
\hline EDRP/LIPA & $\begin{array}{l}\text { 7/30/2002 } \\
11: 00: 00 \\
\text { AM }\end{array}$ & $\begin{array}{l}7 / 30 / 2002 \\
6: 00: 00 \mathrm{PM}\end{array}$ & $\begin{array}{l}\text { Cutchogue, Bay Shore, East Hampton, Sag Harbor, } \\
\text { Brentmood, Smithtown, 38th Street, Hickoville, } \\
\text { Hempstead, Ave_of_Americas, Mt Vernon, White } \\
\text { Plains, Yonkers, Clinton, 18th Street, 56th Street, } \\
\text { Laurelton }\end{array}$ & 90.35 & $\begin{array}{l}\text { LIPA PRP, } \\
\text { NYISO } \\
\text { EDRP }\end{array}$ & $82,051.98$ \\
\hline
\end{tabular}

Figure 8. Estimated Revenue By Curtailment report

This report shows each curtailment selected. It shows the start and end times of the curtailment, the buildings participating in the curtailment, the megawatt-hours for the curtailment period, the programs that called for the curtailment, and an estimate of the revenue earned for the curtailment. 


\subsection{Load Profile}

The Load Profile view provides the DG client with the load at each service entrance. This view is based on load data, measured in megawatt-hours, downloaded from the InfoNode into a database for archiving. The user may view historical data up to the previous day. Load data are stored in the database in 5-minute intervals. Although the data are stored in 5-minute intervals, they may be viewed in any of the intervals listed below.

\begin{tabular}{|c|l|l|l||}
\hline \multicolumn{1}{|c|}{ Load Profile } \\
\hline Load Profile
\end{tabular}

Figure 9. Load Profile selection page

The user may type in the time range or use the shortcut selections provided. The default interval is 1 hour. An example plot is shown in Figure 10. 


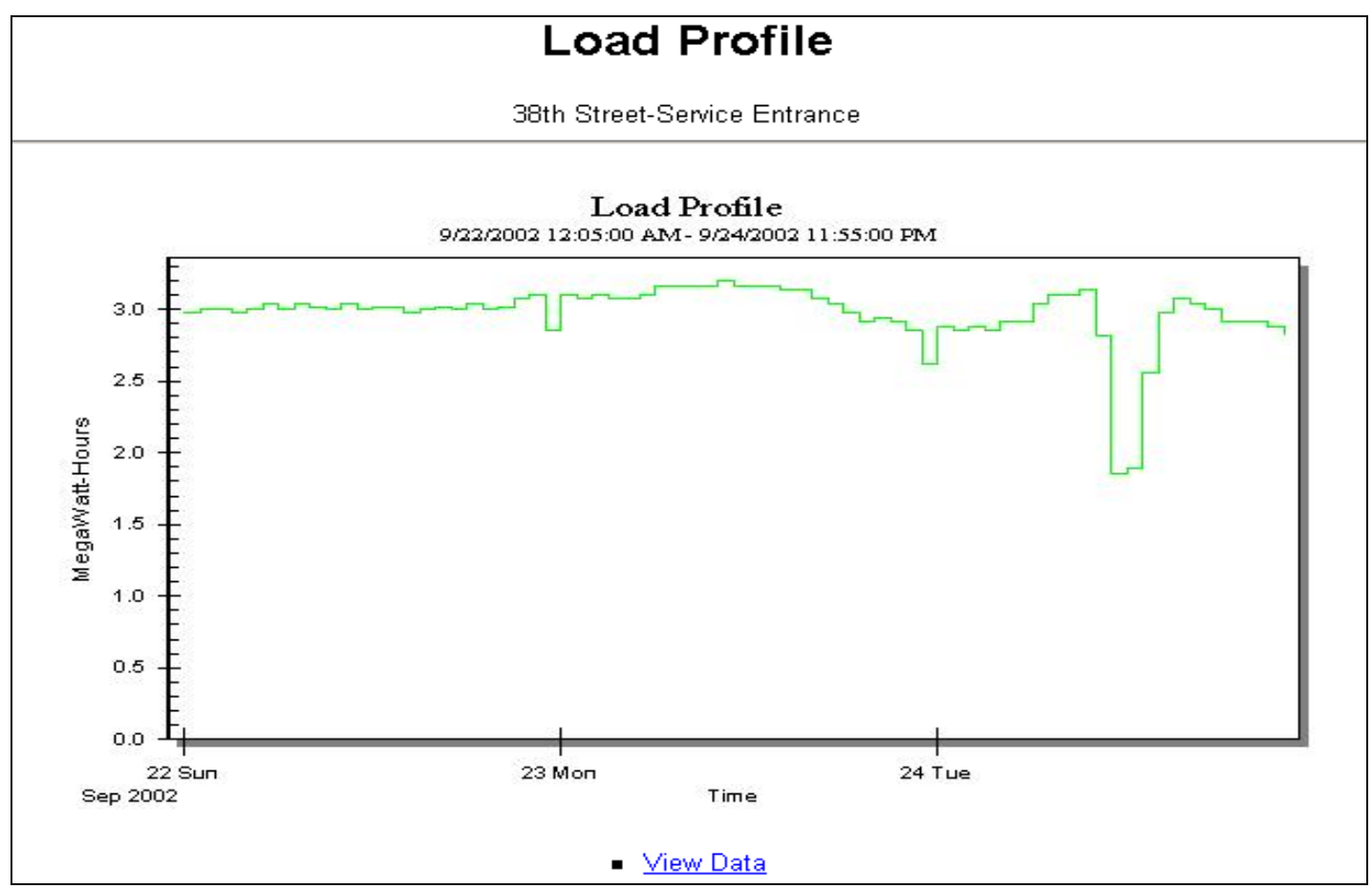

Figure 10. Load Profile plot - energy consumption over 1-hour intervals

If the user chooses to view data for a long period, a more useful interval may be 1 day. An example is shown in Figure 11.

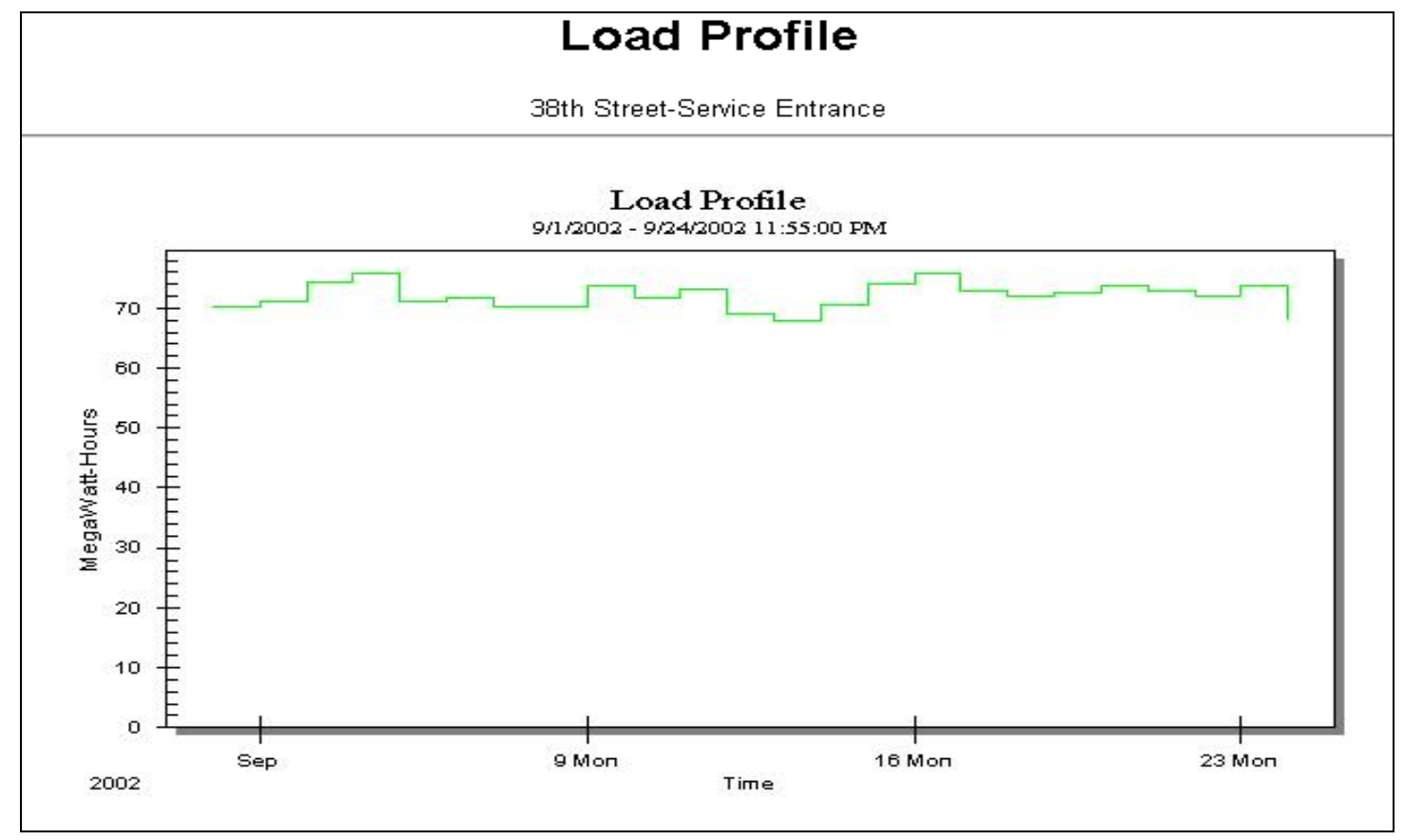

Figure 11. Load Profile plot - energy consumption over 1-day intervals

For a more detailed look at load behavior, the user may select a short time range with a 5minute interval. An example of a load profile with a 5-minute interval is shown in Figure 12. 


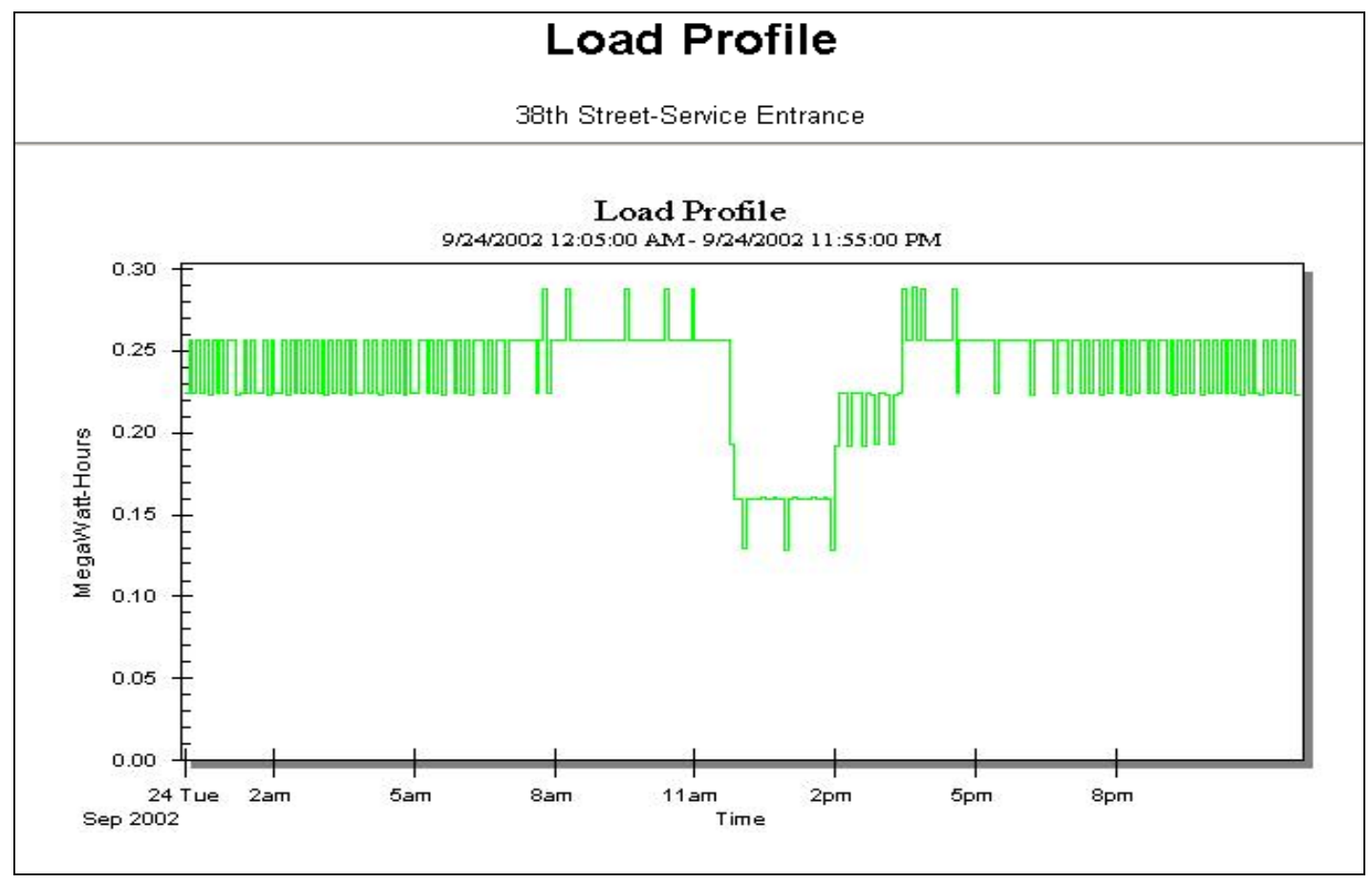

Figure 12. Load Profile plot - 5-minute interval

In addition, the user may wish to see all service entrances for his buildings. Selecting multiple service entrance groups will display an aggregated load profile.

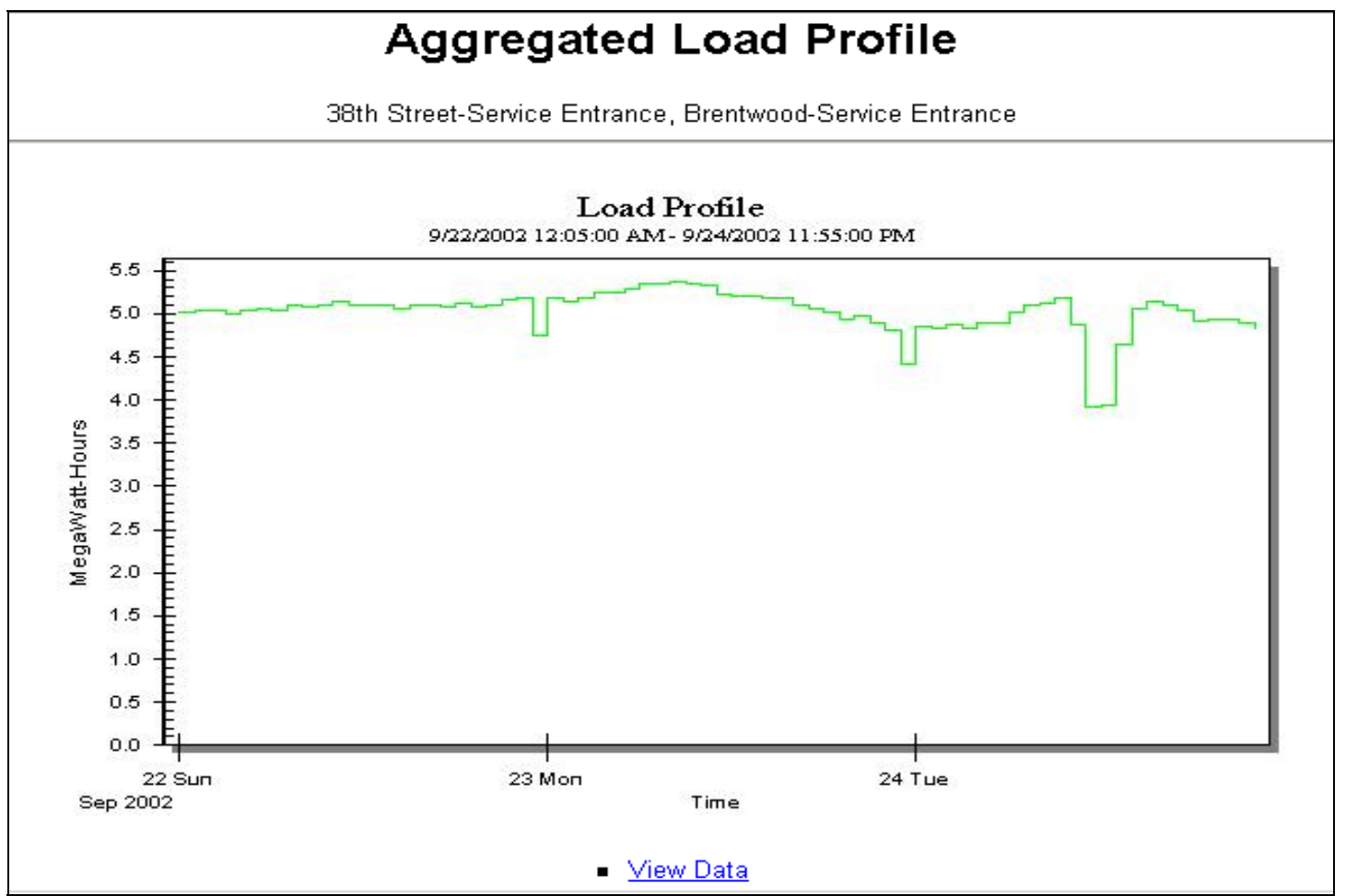

Figure 13. Aggregated Load Profile plot - energy consumption over 1-hour intervals

Task 8

A-10 
Selecting View Data will display a listing of the data in Excel format. See Figure 14.

\begin{tabular}{|c|c|c|c|c|c|c|}
\hline \multicolumn{2}{|r|}{ A4 } & \multicolumn{5}{|l|}{$=$} \\
\hline & A & $B$ & $\mathrm{C}$ & $\mathrm{D}$ & $E$ & $\overline{-}$ \\
\hline 1 & \multicolumn{3}{|c|}{ 38th Street-Service Entrance } & & & \\
\hline 2 & \multicolumn{3}{|c|}{ Load Profile for 9/22/2002 1:00:00 AM - } & & & \\
\hline \multicolumn{7}{|l|}{3} \\
\hline \multicolumn{7}{|l|}{4} \\
\hline 5 & Time/Date & MWHrs & & & & \\
\hline 6 & $9 / 22 / 20021: 00$ & 2.976768 & & & & \\
\hline 7 & $9 / 22 / 20022: 00$ & 3.007488 & & & & \\
\hline 8 & $9 / 22 / 20023: 00$ & 3.007488 & & & & \\
\hline 9 & $9 / 22 / 20024: 00$ & 2.976768 & & & & \\
\hline 10 & $9 / 22 / 20025: 00$ & 3.007488 & & & & \\
\hline 11 & 9/22/2002 6:00 & 3.040256 & & & & \\
\hline 12 & $9 / 22 / 20027: 00$ & 3.007488 & & & & \\
\hline 13 & 9/22/2002 8:00 & 3.040256 & & & & \\
\hline 14 & 9/22/2002 9:00 & 3.008512 & & & & \\
\hline 15 & $9 / 22 / 200210: 00$ & 3.007488 & & & & \\
\hline 16 & $9 / 22 / 200211: 00$ & 3.040256 & & & & \\
\hline 17 & $9 / 22 / 200212: 00$ & 3.007488 & & & & \\
\hline 18 & $9 / 22 / 200213: 00$ & 3.008512 & & & & \\
\hline 19 & $9 / 22 / 200214: 00$ & 3.008512 & & & & \\
\hline 20 & $9 / 22 / 2002$ 15:00 & 2.975744 & & & & \\
\hline 21 & $9 / 22 / 200216: 00$ & 3.007488 & & & & \\
\hline 22 & $9 / 22 / 2002$ 17:00 & 3.008512 & & & & \\
\hline 23 & $9 / 22 / 200218: 00$ & 3.007488 & & & & \\
\hline 24 & $9 / 22 / 2002$ 19:00 & 3.040256 & & & & \\
\hline 25 & $9 / 22 / 200220: 00$ & 3.007488 & & & & \\
\hline 26 & 9/22/2002 21:00 & 3.008512 & & & & 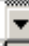 \\
\hline 14 & - $\mid 925200210492$ & $1 \mathrm{pp} /$ & 1 & & 1 & \\
\hline
\end{tabular}

Figure 14. Excel file of data

\subsection{Generator Run Summary}

This view provides the DG client with a view of when his generators have run. The Generator Run Summary offers a detailed view of each generator or an aggregated view of all generators. The customer selects the level of detail by choosing the summary type. The individual summary shows detailed tables, and the aggregated summary provides a single table with no detail on individual generators. The customer may type in a time range or use the shortcuts provided in the selection box. The selection page is shown below. 


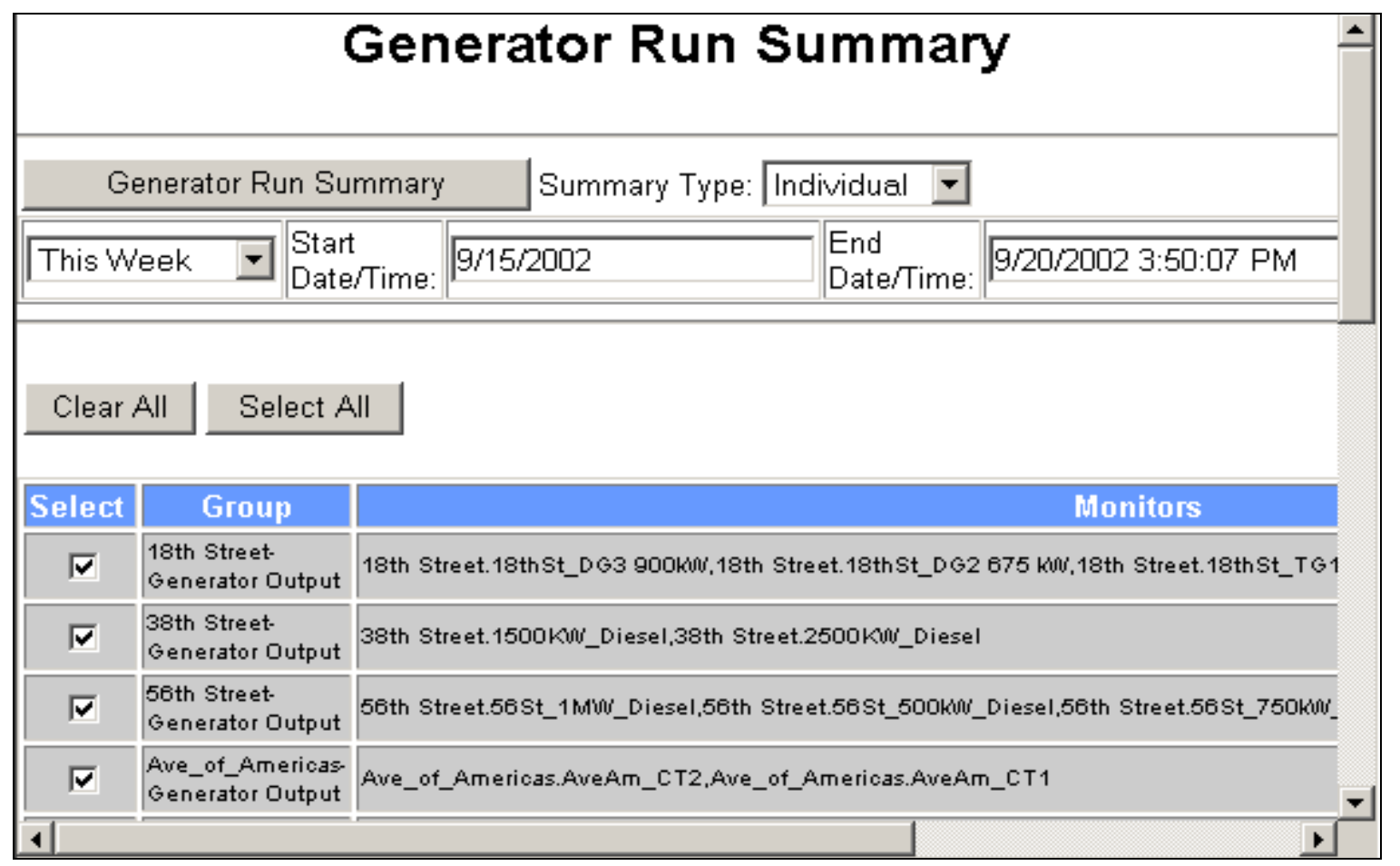

Figure 15. Generator Run Summary selection page

Once the user has made his selections, he clicks the Generator Run Summary button.

\subsubsection{Individual Generator Run Summary}

If the user selects an individual summary, then the details for each generator are displayed. The Generator Run Summary shown in Figure 16 shows the average generation, measured in kilowatts, for each generator for each hour it ran.

Figure 16 shows that generators AveAm-CT1 and AveAm-CT2 of the Avenue of Americas Building ran on July 30 and Aug. 14 of 2002. Each run was from 1 p.m. to 6 p.m. It shows that the average generation, measured in kilowatts, for the 1 p.m. hour is significantly lower than the 2 p.m. to 5 p.m. hours. This is an indication of the engines starting up. The average generation for the 6 p.m. hour is very small. This is because the engines were shut down shortly after 6 p.m. 


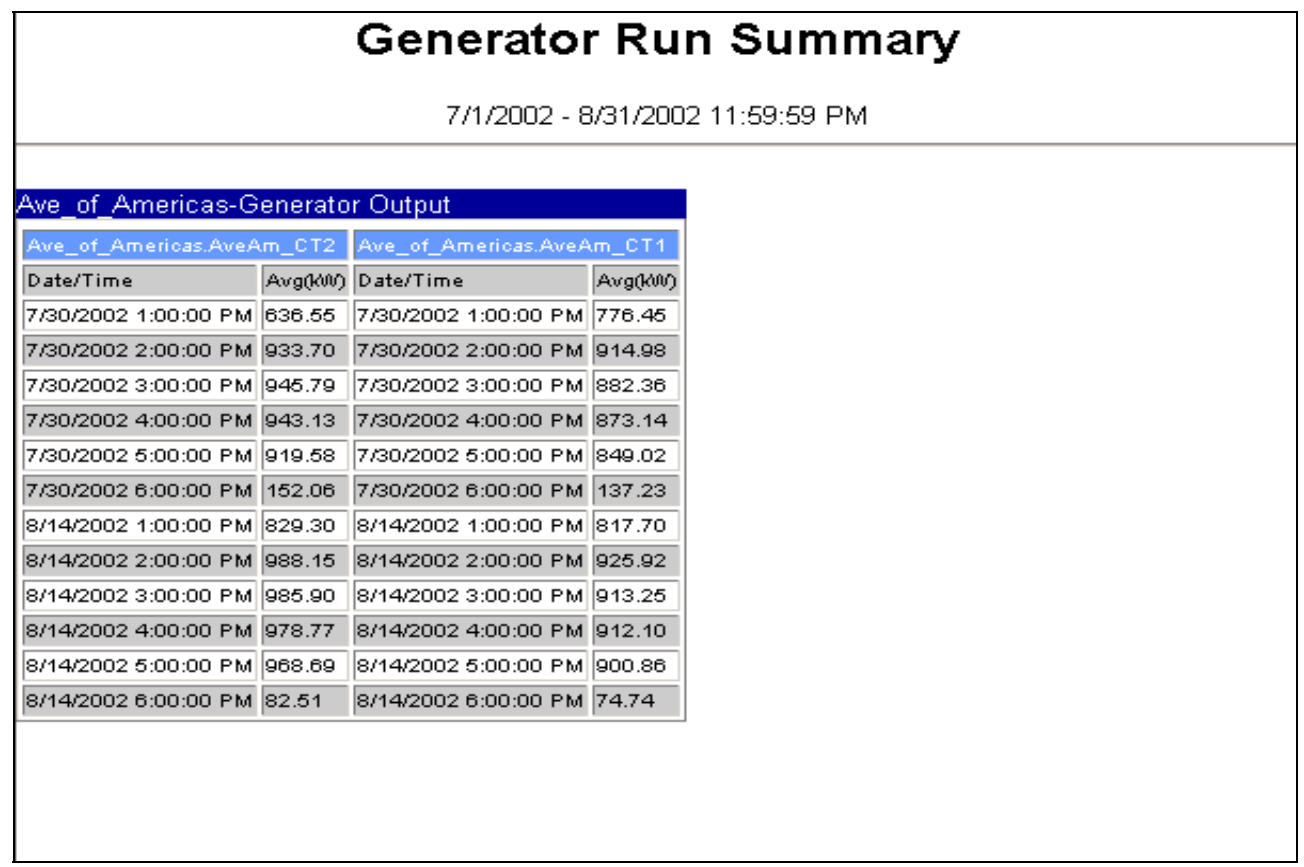

Figure 16. Individual Generator Run Summary

\subsubsection{Aggregated Generator Run Summary}

If the user selects the aggregated summary, then the details of the individual generators are not shown. In this report, if multiple generators ran over the same time span, then their average generation, measured in kilowatts, is summed. It is typical for multiple generators to run for the same time span because curtailments have multiple buildings participating.

This summary provides a general overview. 


\section{Aggregated Generator Run Summary}

PS_TG2C Pearl Street, PS_TG1C Pearl Street, WP_CT_B2_750kW White Plains, WP_CT_B1_750kW White Plains, WP_CT_A3_750kWW White Plains, WP_CT_A2 $7 \overline{50 k} \bar{W}$ White Plains, WP_CT_A1_750k $\bar{W}$ White Plains

\begin{tabular}{|l|l|}
\hline \multicolumn{2}{|c|}{ Aggregated kW } \\
\hline Date/Time & Avg(kii) \\
\hline $8 / 14 / 2002$ 1:00:00 PM & $2,001.56$ \\
\hline $8 / 14 / 2002$ 2:00:00 PM & $2,127.90$ \\
\hline $8 / 14 / 20023: 00: 00 \mathrm{PM}$ & $4,428.18$ \\
\hline $8 / 14 / 20024: 00: 00 \mathrm{PM}$ & $4,555.47$ \\
\hline $8 / 14 / 20025: 00: 00 \mathrm{PM}$ & $4,527.53$ \\
\hline $8 / 14 / 20026: 00: 00 \mathrm{PM}$ & 793.17 \\
\hline $8 / 15 / 2002$ 12:00:00 PM & $2,135.07$ \\
\hline $8 / 15 / 20021: 00: 00 \mathrm{PM}$ & $2,293.20$ \\
\hline $8 / 15 / 2002$ 2:00:00 PM & $2,304.54$ \\
\hline $8 / 15 / 20023: 00: 00 \mathrm{PM}$ & $2,302.65$ \\
\hline $8 / 15 / 20024: 00: 00 \mathrm{PM}$ & $2,276.82$ \\
\hline $8 / 15 / 20025: 00: 00 \mathrm{PM}$ & $2,229.57$ \\
\hline $8 / 15 / 20026: 00: 00 \mathrm{PM}$ & 48.51 \\
\hline
\end{tabular}

Figure 17. Aggregated Generator Run Summary 


\section{Setup}

The SA is the only user of Setup options. Under Setup, the SA can add, edit, and delete customers, buildings, and energy market programs.

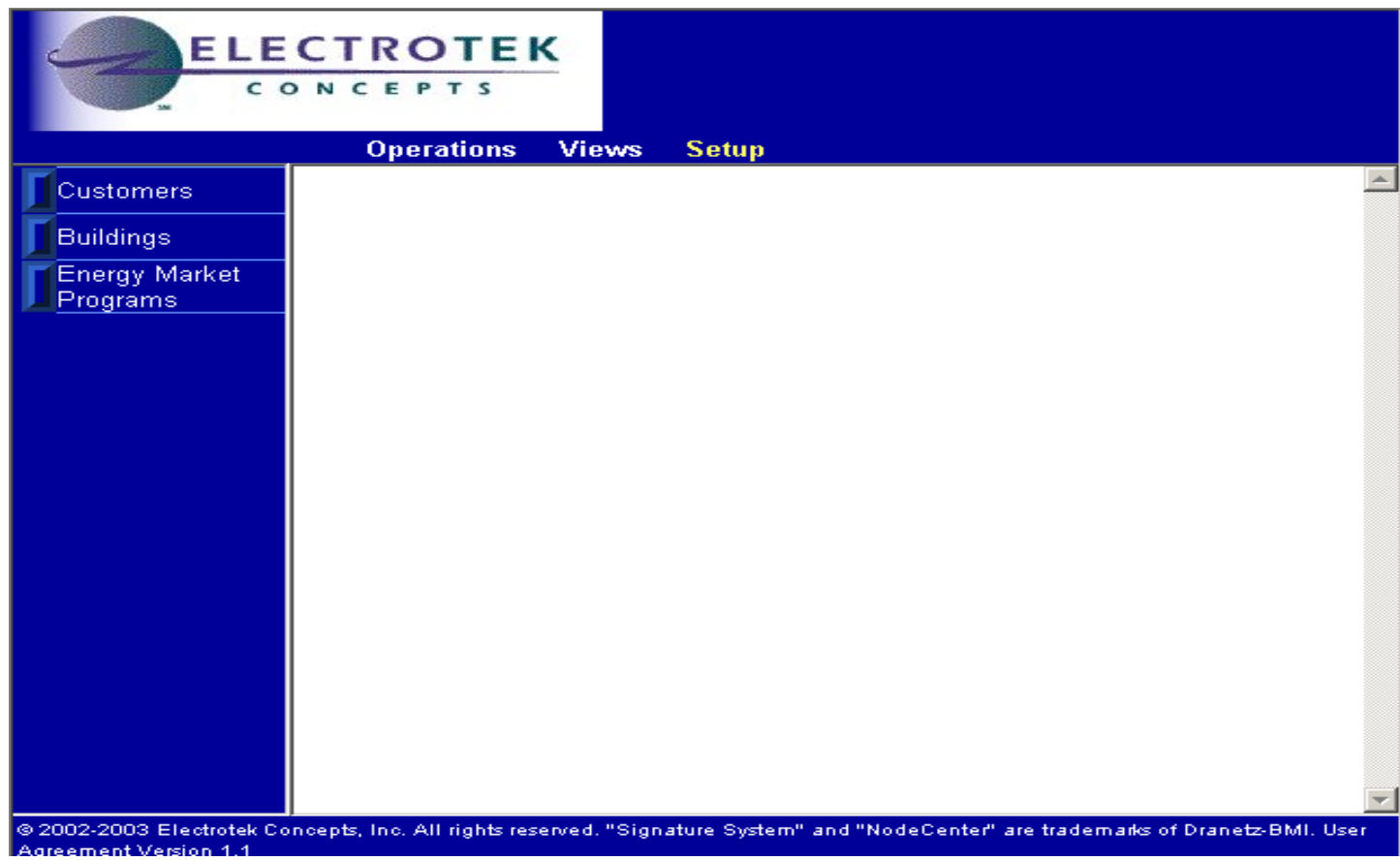

Figure 18. Setup screen

\subsection{Customers}

Here the SA adds customers to the energy management database. These customers provide the generators that the SA is responsible for offering to various energy markets. 


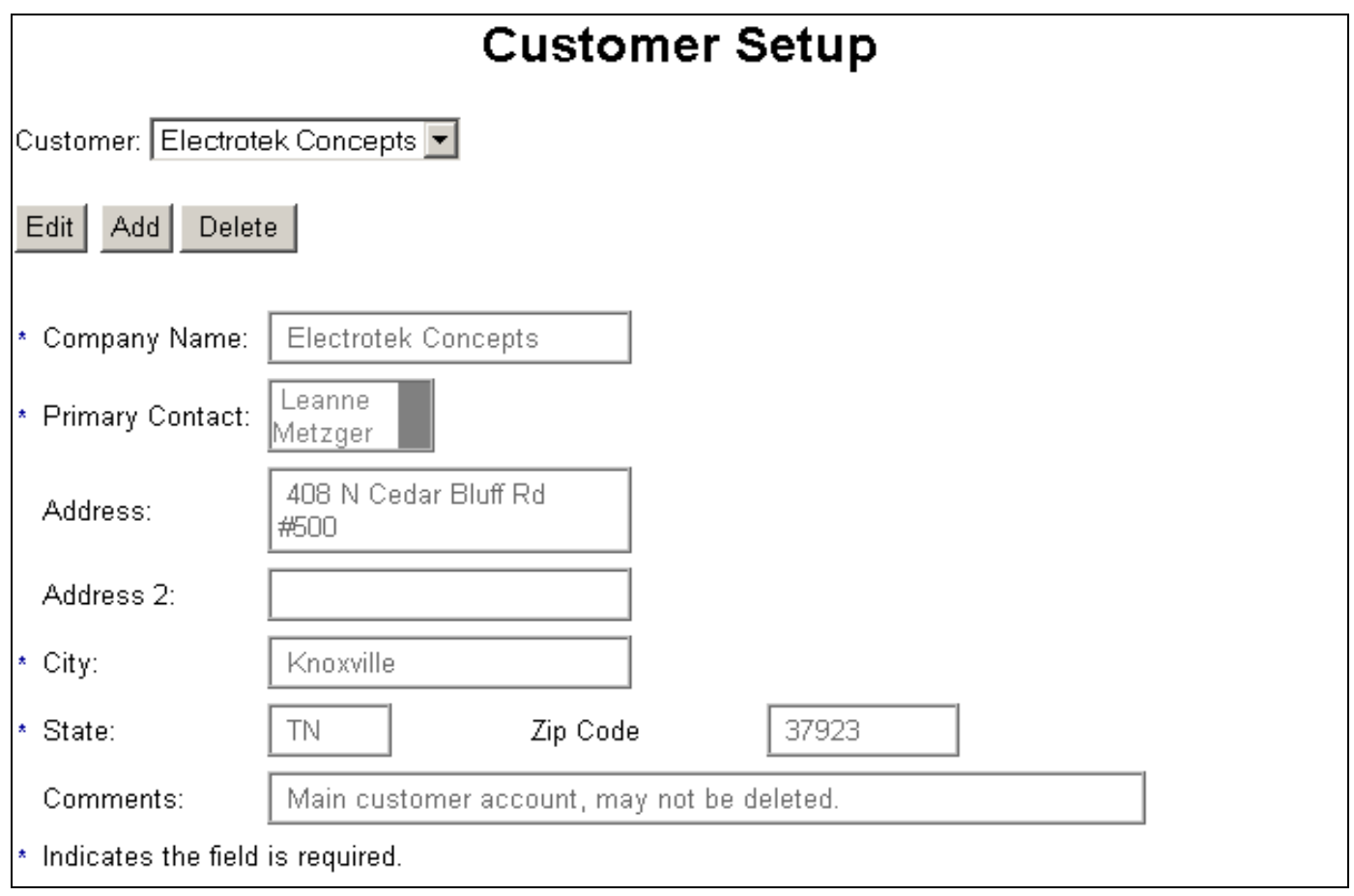

Figure 19. Customer setup page

When the user selects Edit or Add, the page in Figure 20 is displayed.

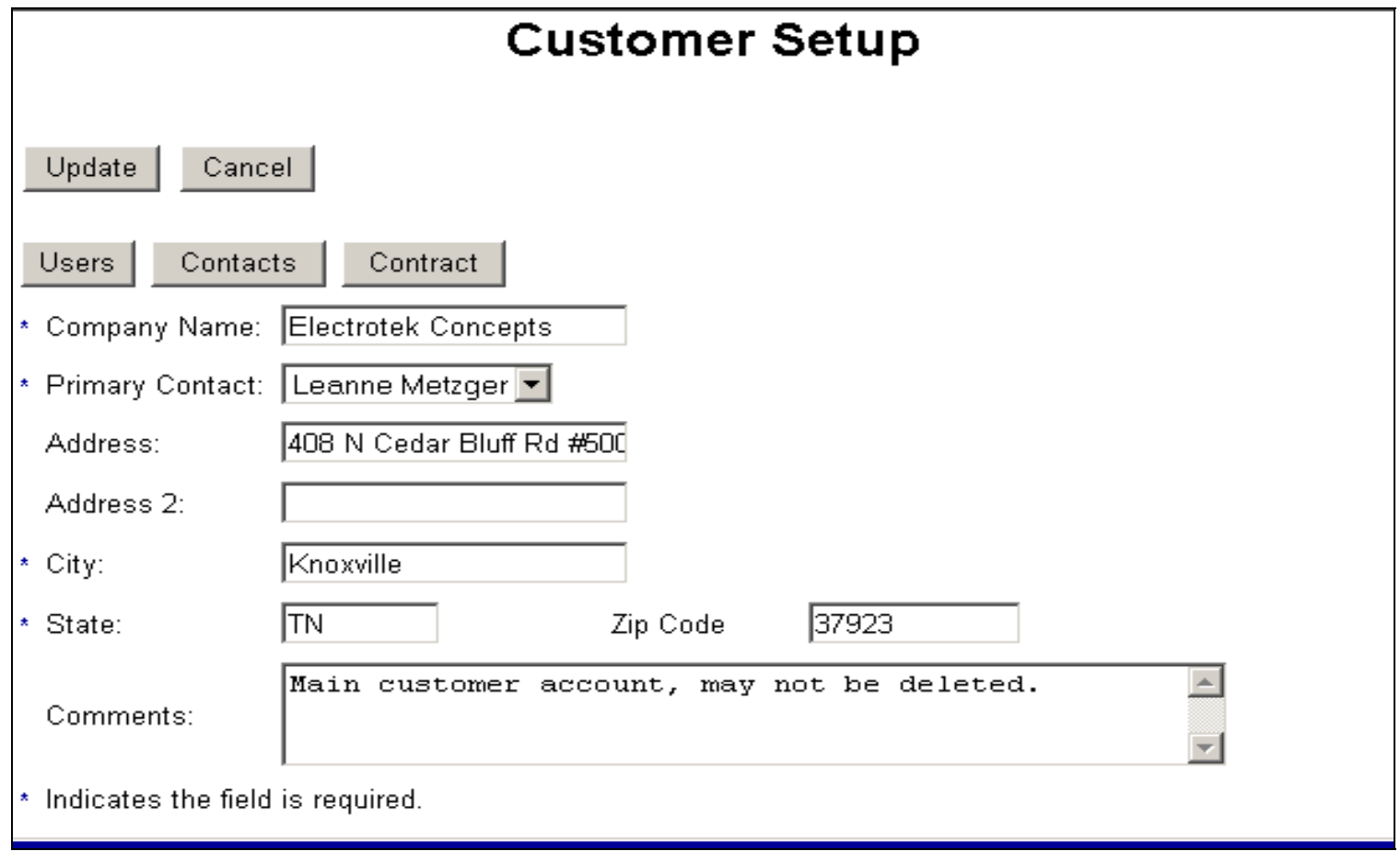

Figure 20. Customer edit/add page

Task 8

A-16 
The SA may then modify any of the fields shown above. The SA can click Update to accept changes or Cancel to ignore changes made. The SA may add users and contacts and modify contract information.

\subsubsection{Users}

This function is not yet available from the Web site.

\subsubsection{Contacts}

The SA can add, edit, and delete as many contacts as needed.

To return to the customer setup page, the SA clicks Customer in the left pane.

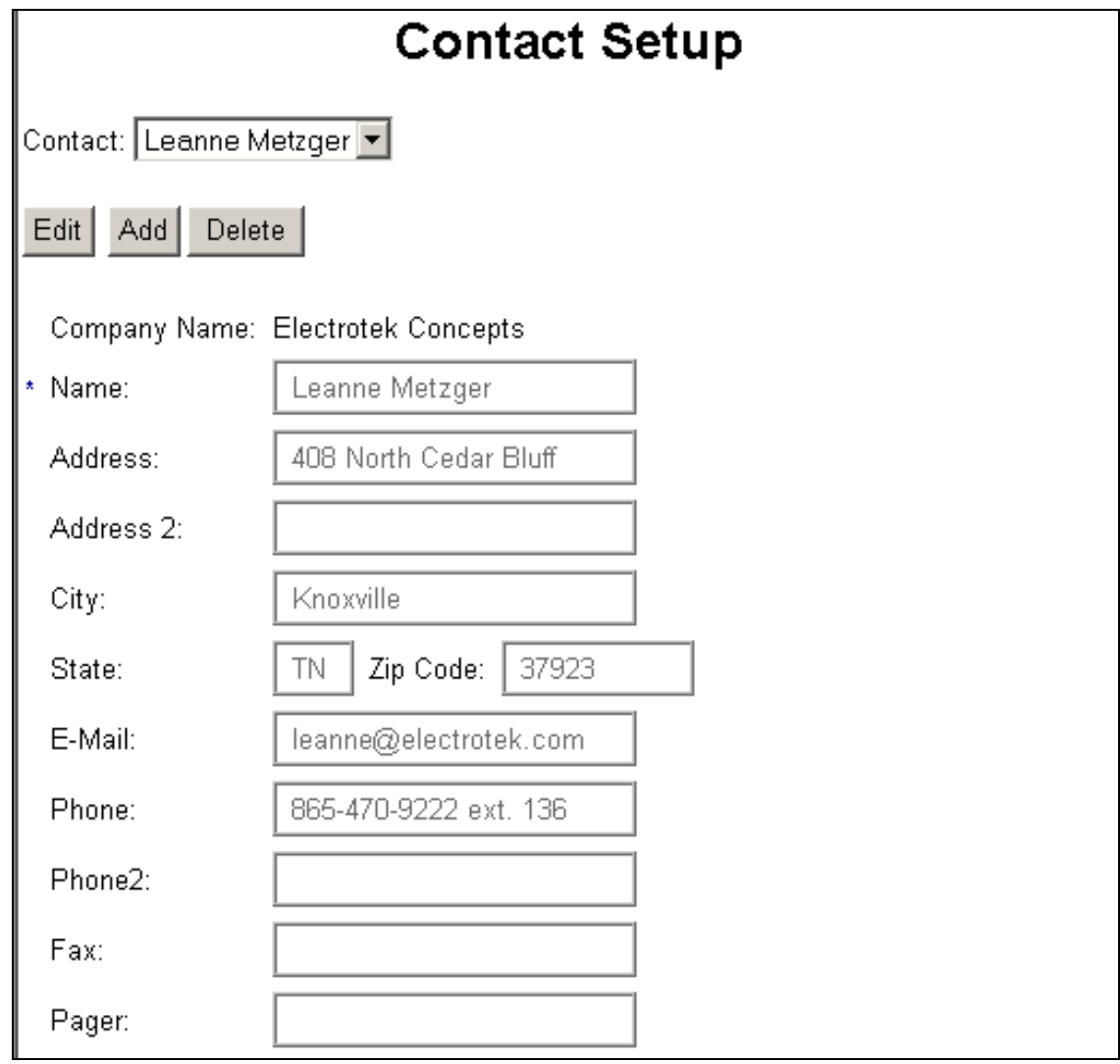

Figure 21. Contact setup page 


\subsubsection{Contract}

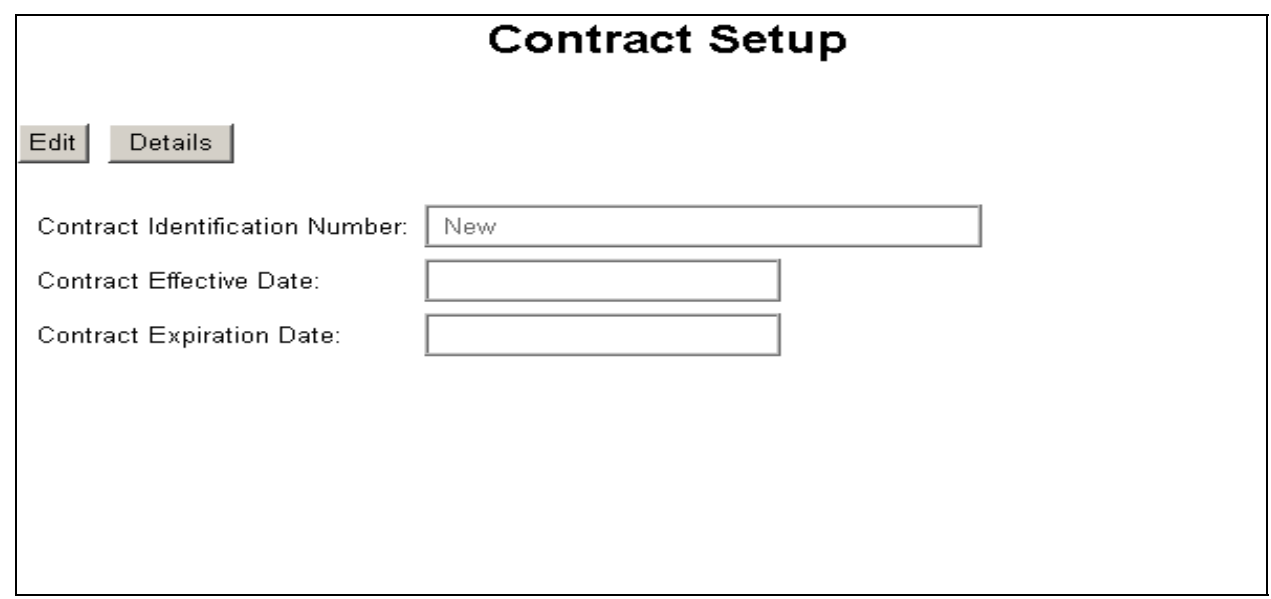

Figure 22. Contract setup page

The SA may view program details by clicking Details or edit the contract by clicking Edit. Clicking Edit will display the following page.

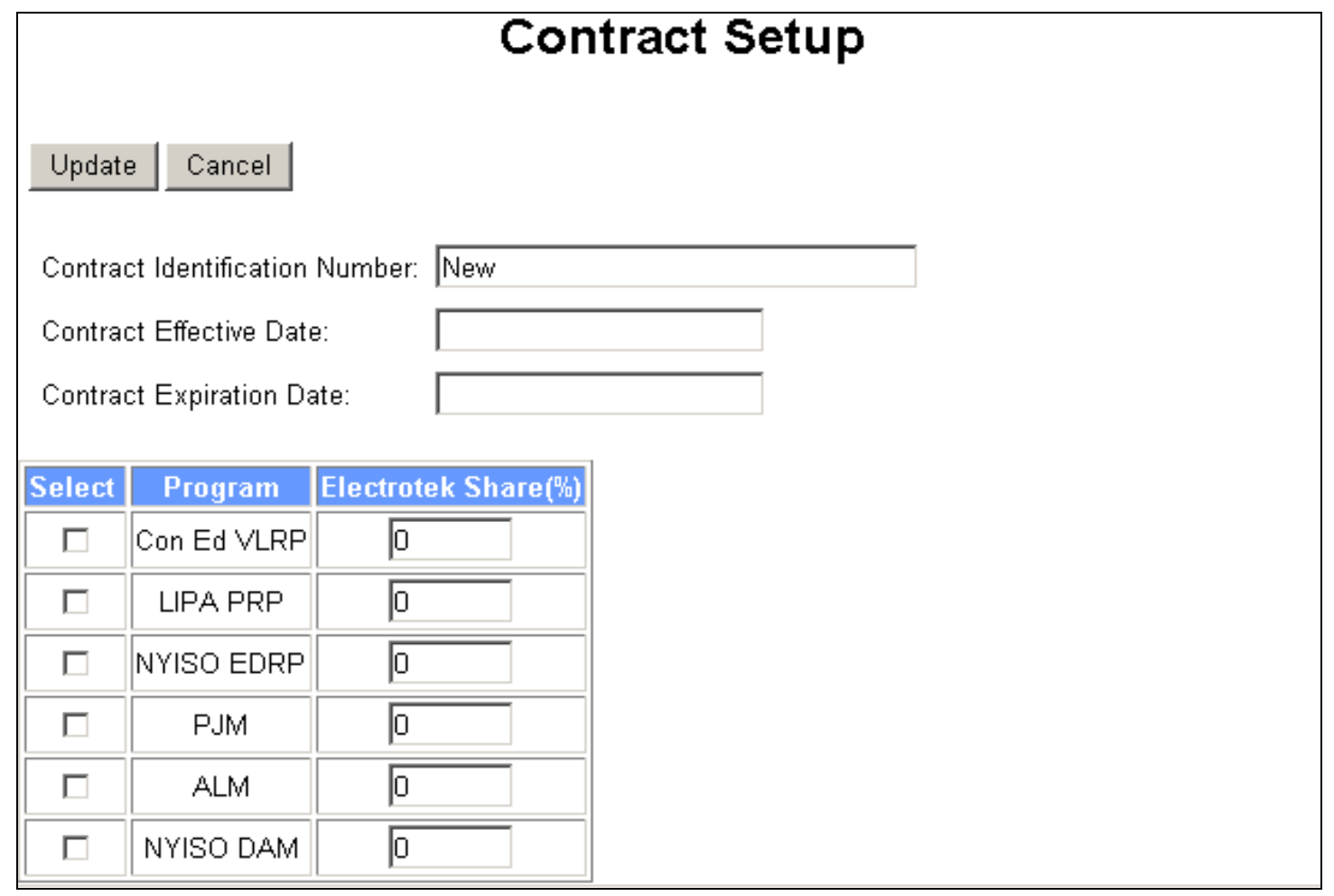

Figure 23. Contract edit page

The SA may include or exclude any program by checking the corresponding box. If a box is checked, then the SA may enter the percentage of revenue that Electrotek Concepts Inc. will receive from that program. The value is entered in decimal format (i.e., 0.25). 
When he is finished, the SA clicks Update to accept changes or Cancel to ignore changes. To return to customer setup, the SA clicks Customer in the left pane.

\subsection{Buildings}

Each customer will have one or more buildings where generators are located. It is here that the SA will add these buildings. Clicking Buildings in the left pane displays the following page. Creating or editing a building is a multi-step process, so a wizard design has been implemented to guide the SA through the process.

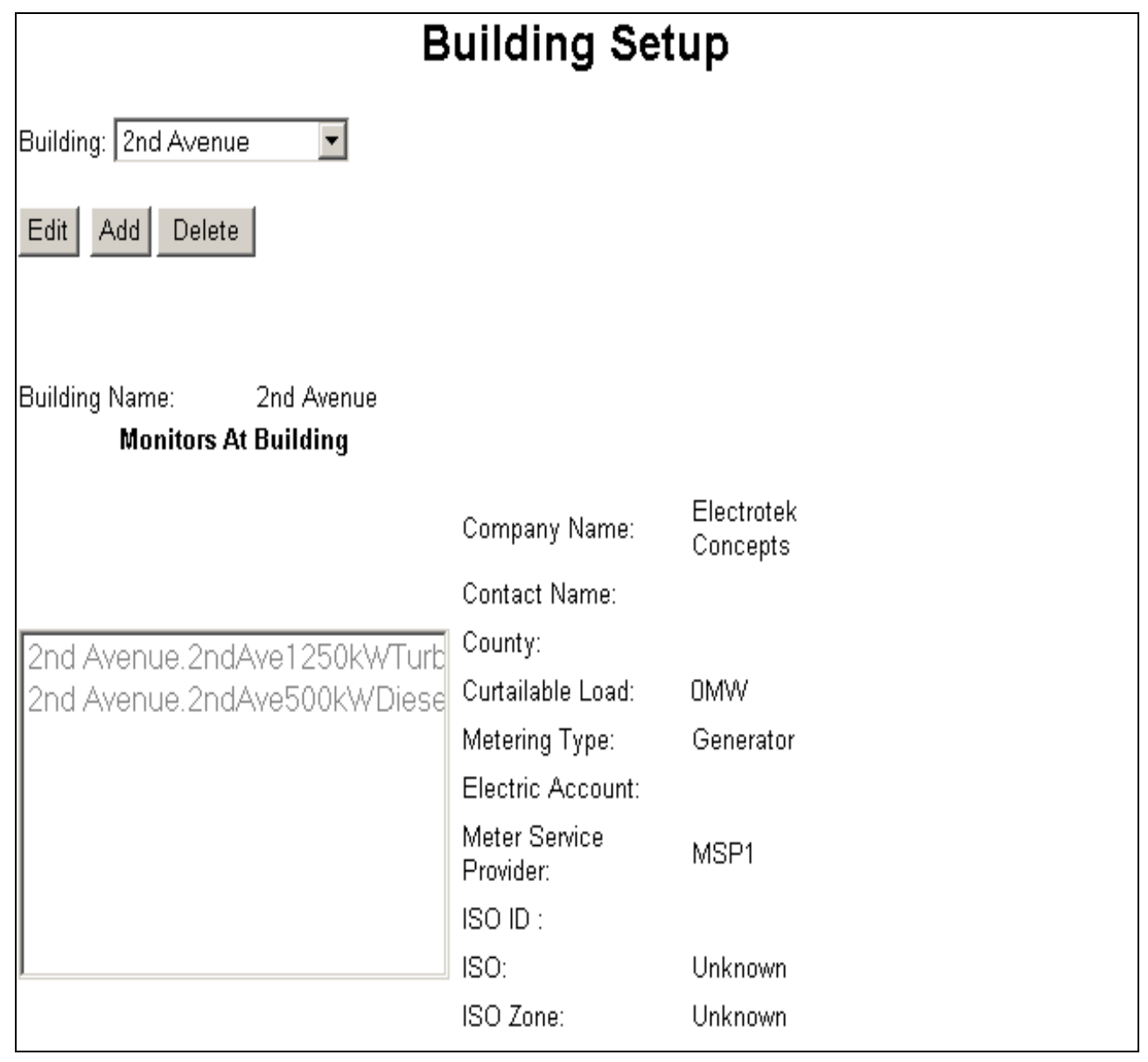

Figure 24. Building setup page

Here the SA will select an already existing building for editing or deleting, or he will choose to add a new building.

\subsubsection{Add}

Adding a new building requires a corresponding site be set up in the NodeCenter database. The technical coordinator at Electrotek Concepts Inc. does this. Clicking the Add button displays the page shown in Figure 25. 


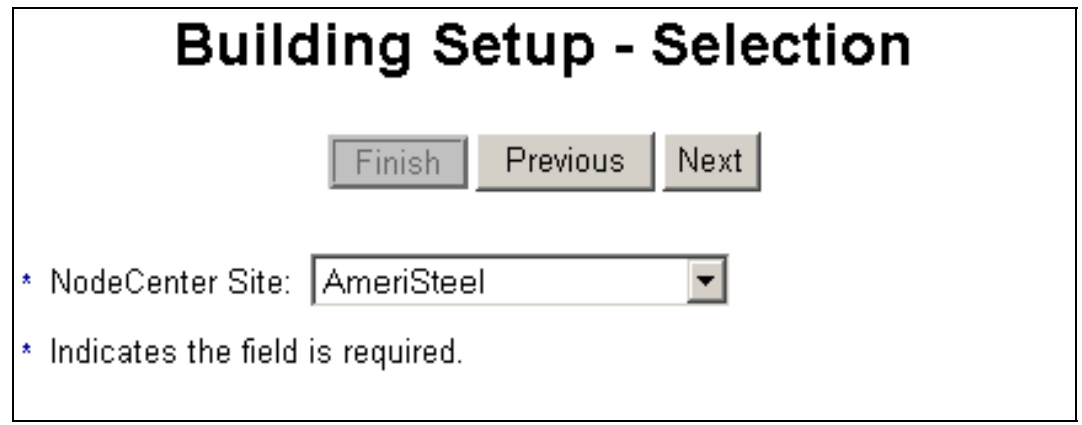

Figure 25. Building setup - site selection

Once the corresponding NodeCenter Site has been selected, the Next button is clicked to proceed with adding a building. Clicking Previous aborts the addition.

After clicking the Next button, the process is identical to that of an edit. Note that by clicking the Next button, the selected site is removed from the available NodeCenter Sites.

\subsubsection{Edit}

After selecting the corresponding NodeCenter Site, the SA can enter or modify the fields shown below. 


\subsubsection{Building Setup}

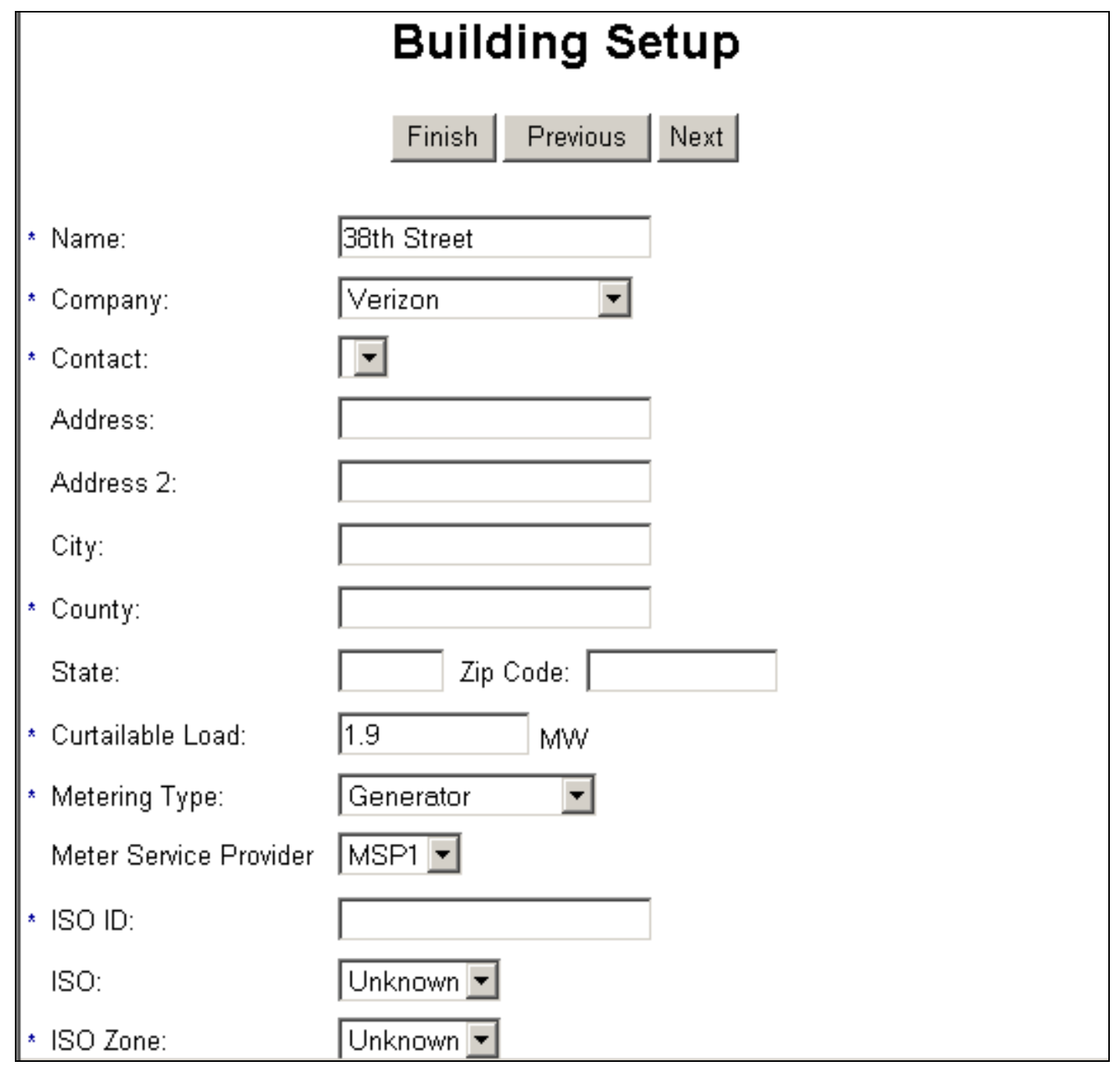

Figure 26. Building setup edit page

The SA clicks the Next or Previous buttons to accept changes and remain in the Building Setup Wizard. To cancel changes and exit the Building Setup Wizard, the SA clicks on a selection in the left or top panes.

\subsubsection{Aggregation Monitor Setup}

Because a building has a corresponding NodeCenter site, all monitors belonging to that site will be available for setting the aggregation fields. 


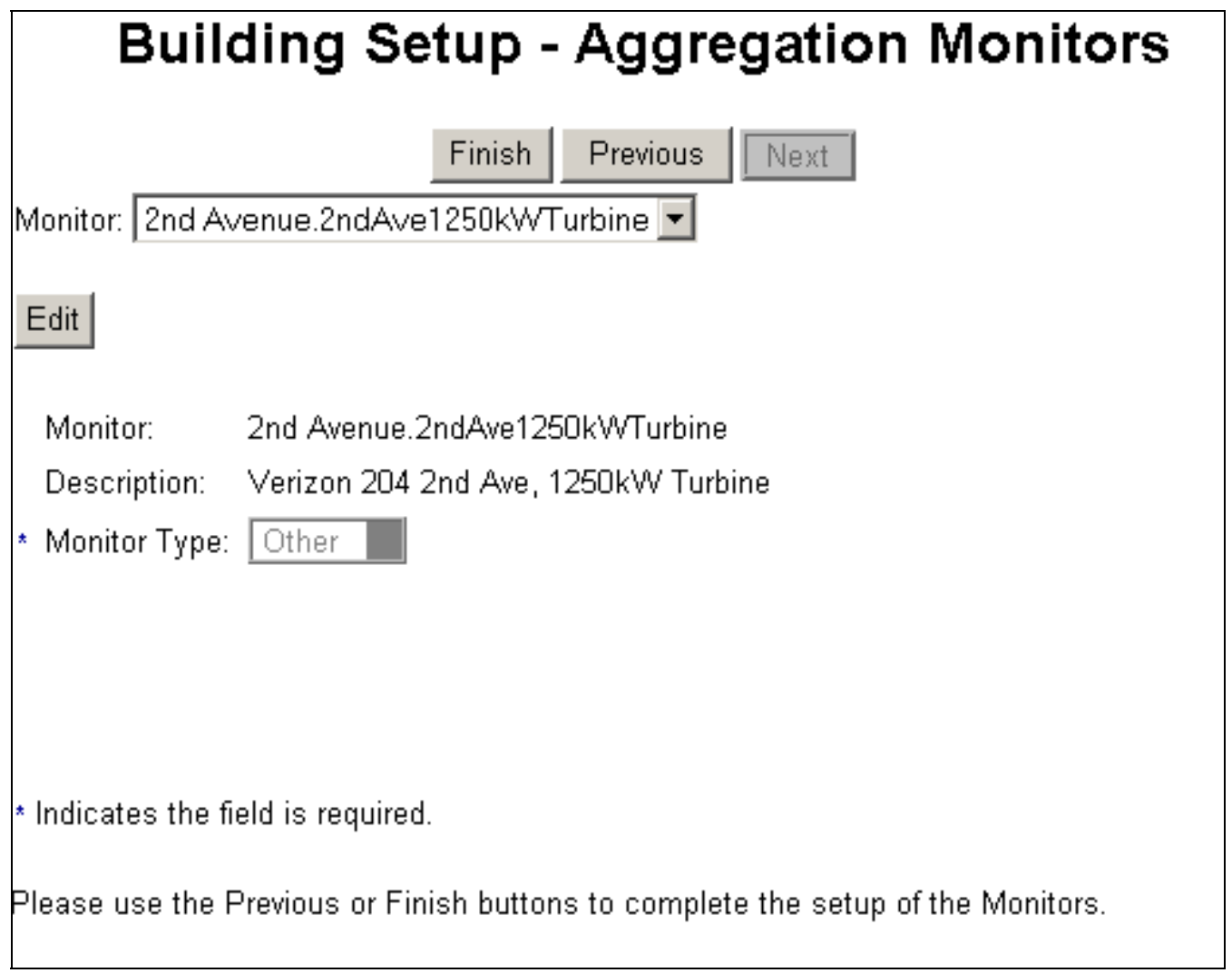

Figure 27. Building setup - aggregation monitors

When monitors are discovered, they default to a type of Other. The first step is to select a monitor and click Edit. Presently, AggregationWeb supports two types of monitors: generator output and service entrance. No further setup is required for service entrance. The setup screen for generator output is shown in Figure 28. 


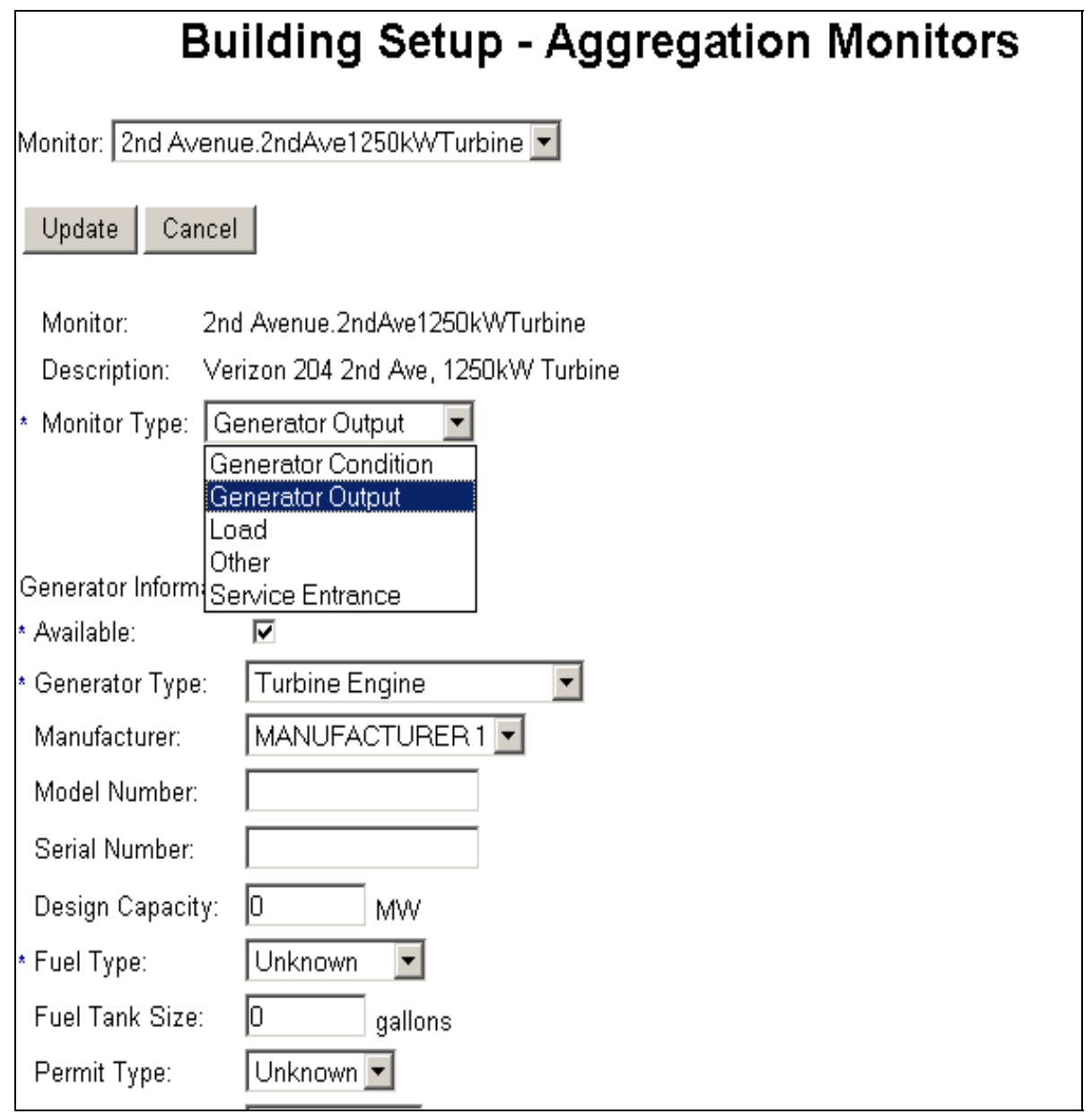

Figure 28. Aggregation monitor edit page

The SA enters the information for the fields displayed and clicks the Update button to accept the changes or the Cancel button to ignore the changes. This process is repeated for all monitors. Once all monitors have been defined, the SA clicks the Finish button. Clicking the Finish button causes default aggregation groups to be created for this building. These groups are used in Views.

\subsubsection{Delete}

Deleting a building deletes all the information entered in the Building Setup Wizard. It does not delete the site from NodeCenter or the monitors. The site will once again be in the NodeCenter Site list when a new building is added. Clicking the Delete button does not delete immediately but displays the page below. 


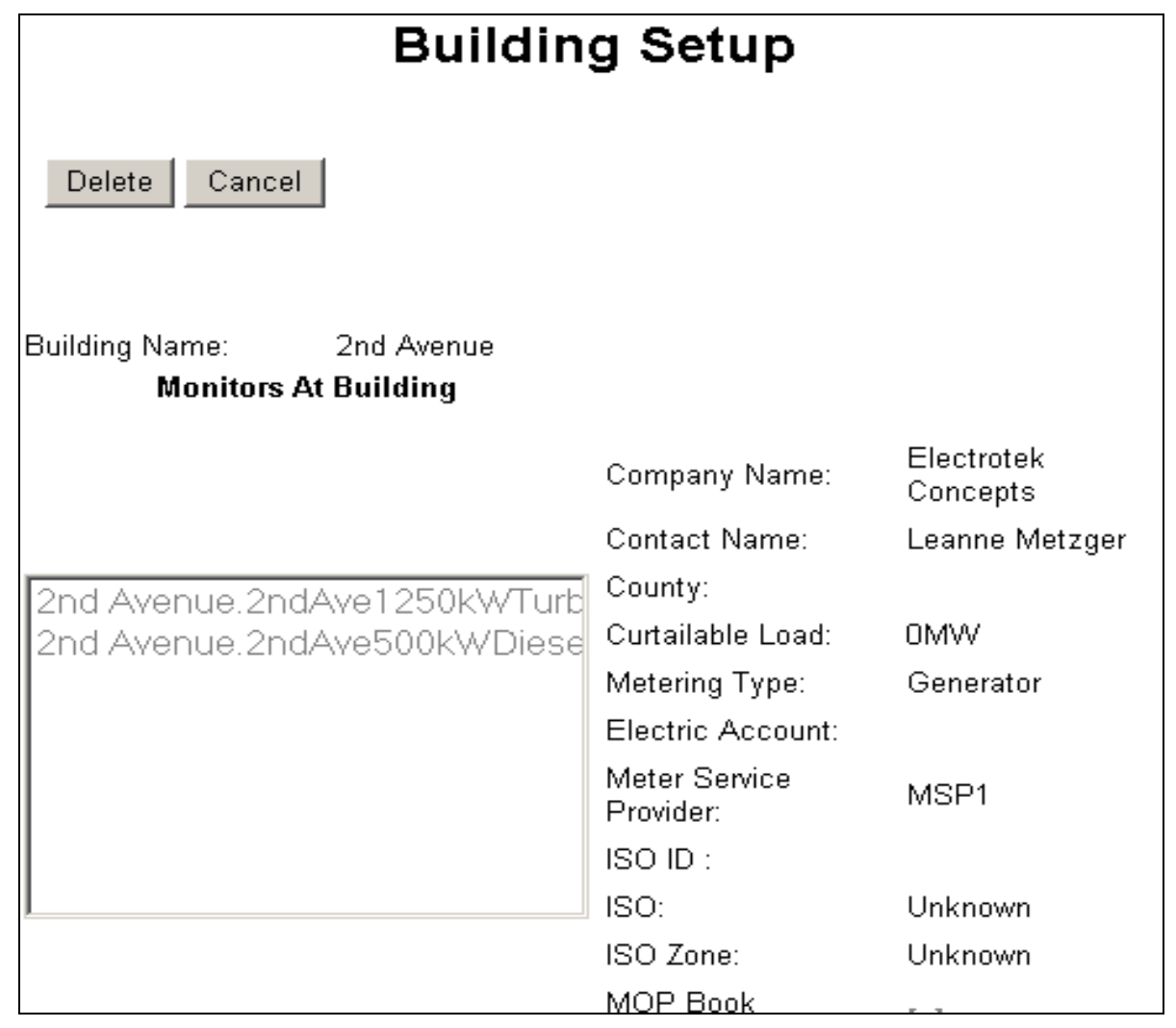

Figure 29. Building setup delete page

\subsection{Energy Market Programs}

The SA enters the energy market programs for which he is responsible for aggregating and managing DG client generators.

Clicking Energy Management Programs in the left pane displays the page below.

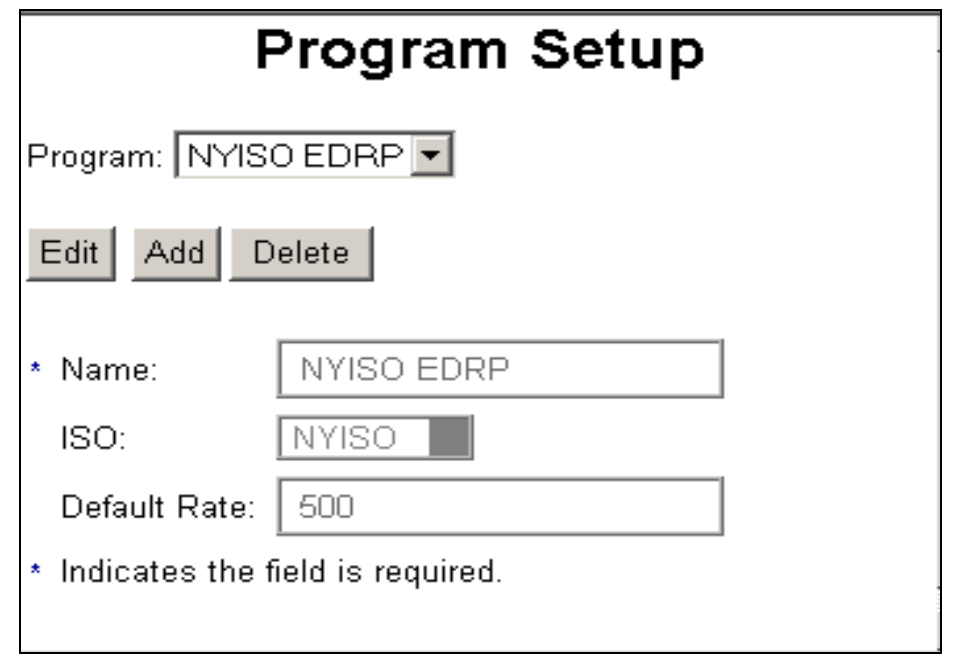

Figure 30. Program setup page 
The Edit, Add, and Delete buttons work in the same way as other setup buttons. The default rate can be applied in a curtailment but may be overwritten with another rate. 


\section{Operations}

The Operations feature is for running and managing a program once it has been set up.

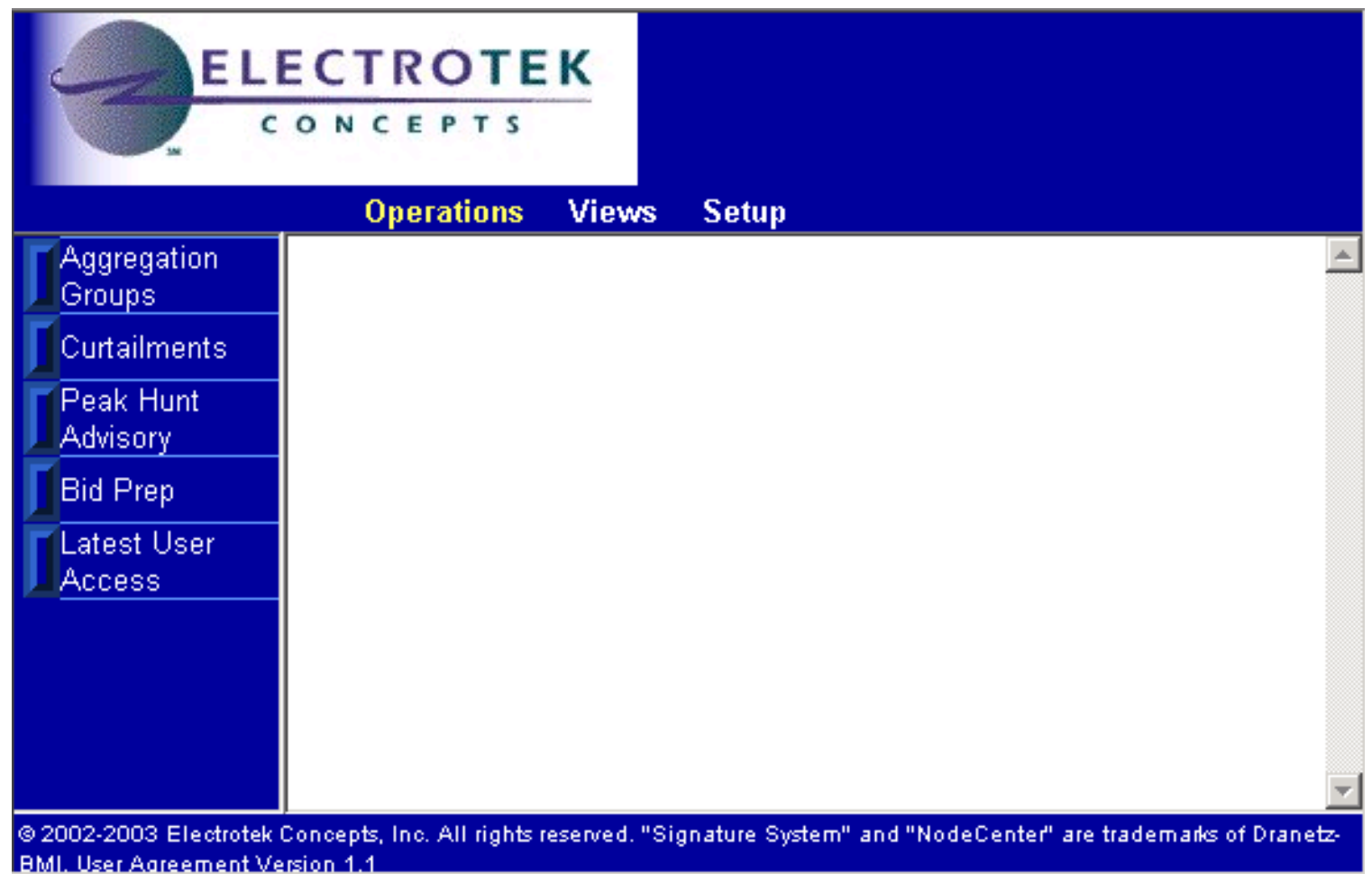

Figure 31. Operations screen

\subsection{Aggregation Groups}

This feature is not yet available.

\subsection{Curtailments}

A curtailment represents the running of generators. It defines which generators will run, for how long, and at what rate they will be paid for each megawatt-hour.

Clicking Curtailments displays the page shown in Figure 32. 


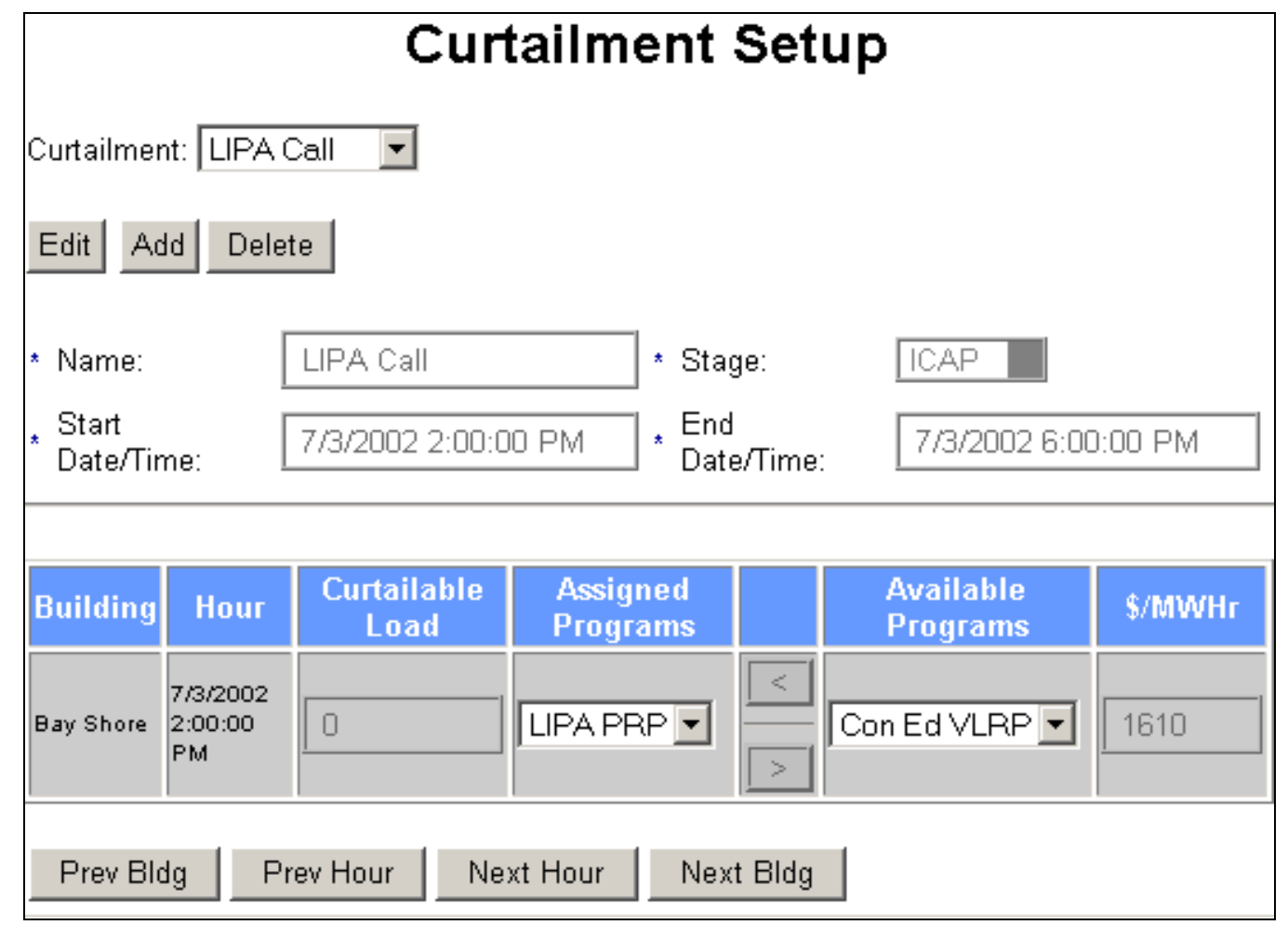

Figure 32. Curtailment setup page

On this page, the SA may view, edit, or delete any existing curtailment, or he may add a new curtailment.

\subsubsection{Edit}

Clicking the Edit button shown in Figure 32 will display the page shown in Figure 33. This page is displayed so that the SA may select the building to be edited. Only records pertaining to that building will be shown in the edit session.

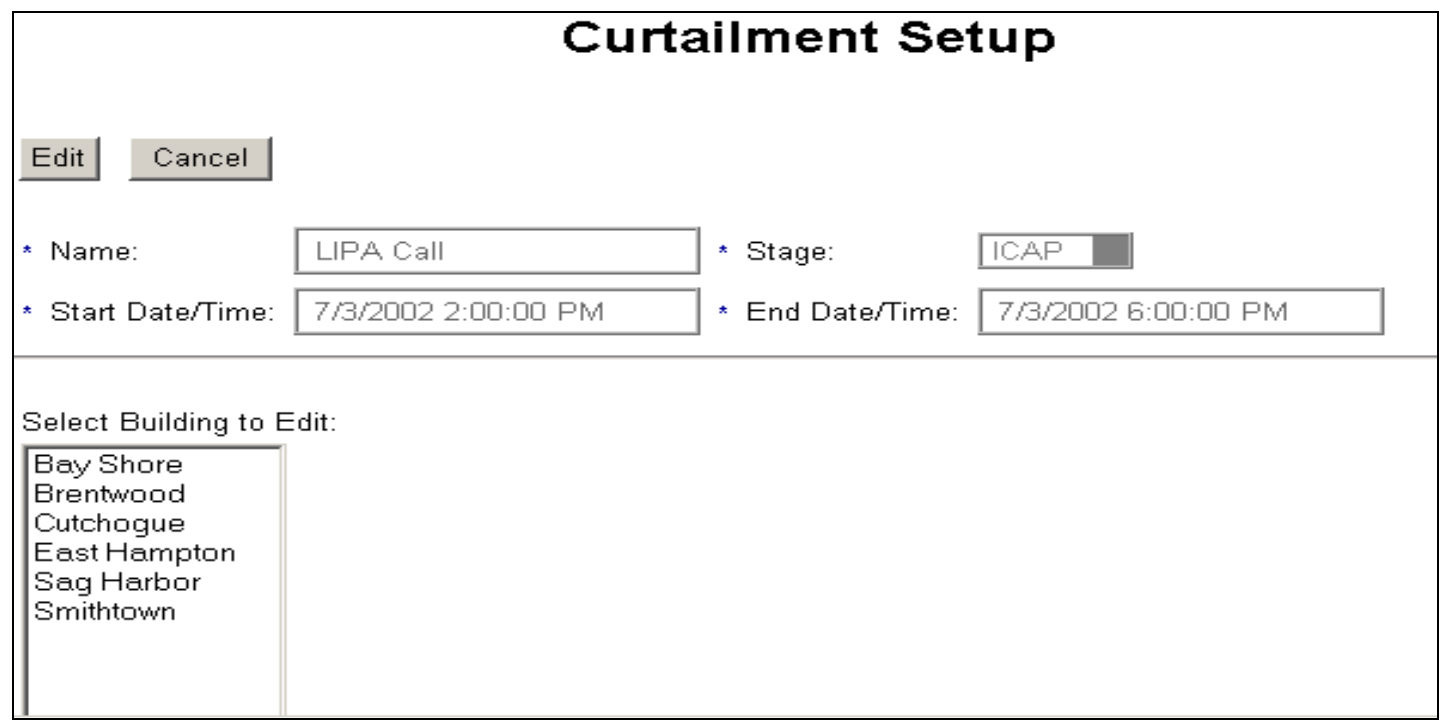

Figure 33. Building select

Task 8

A-27 
Once the building is selected, the SA clicks the Edit button to continue.

Clicking Edit will display the page shown in Figure 35.

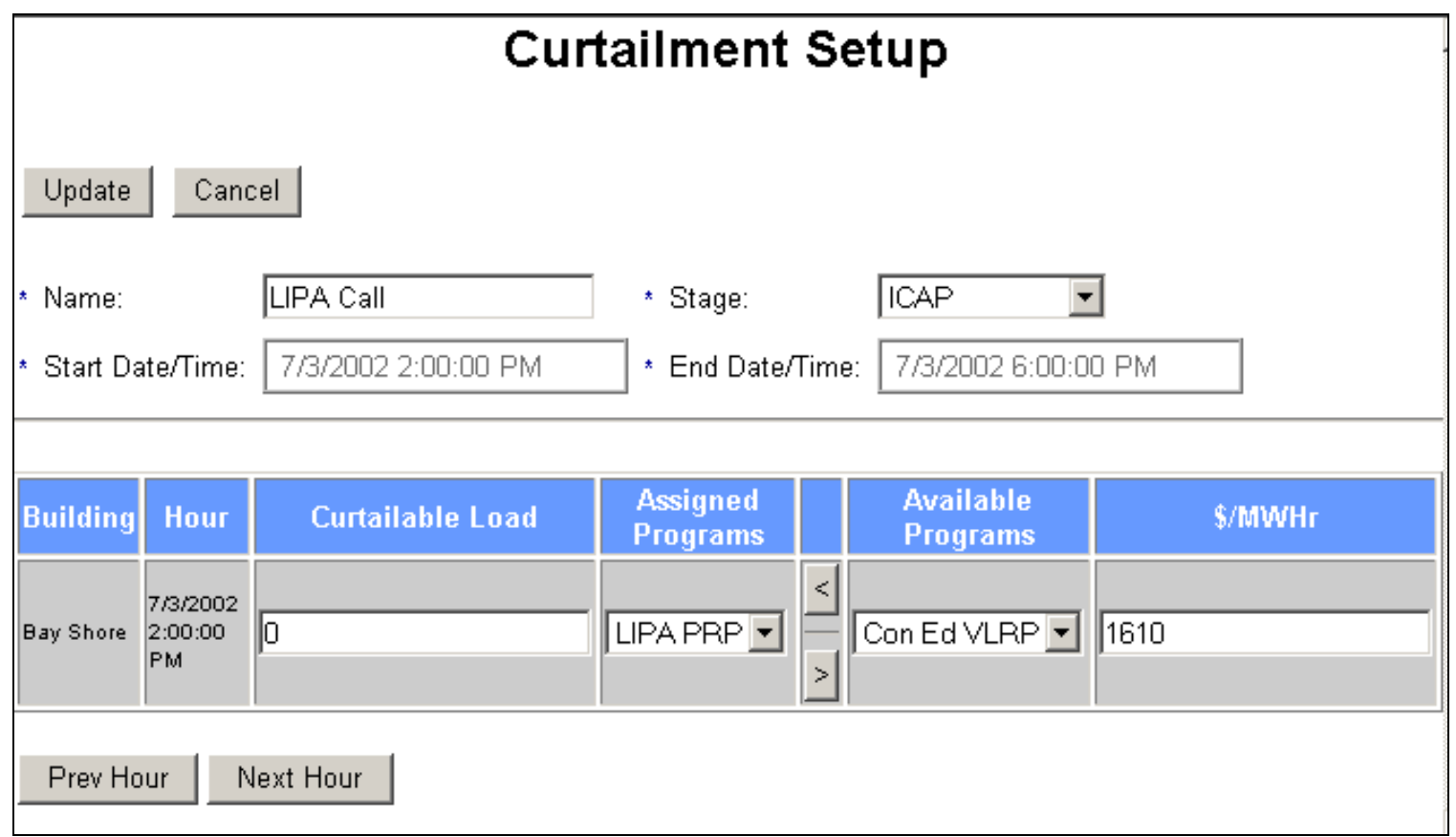

Figure 34. Curtailment setup edit page

The SA may change the name and stage of the curtailment but not the start and end times. In the present version of AggregationWeb, once the start and end are defined, they may not be changed, and no buildings may be added. The curtailment has to be deleted and the desired one added.

The SA may also change for each building and each hour of the curtailment the program assigned to it and the rate for that hour. The SA may navigate through hours of a curtailment for the selected building with the Next Hour and Prev Hour buttons. When the SA is finished, he clicks Update to accept changes or Cancel to ignore changes.

\subsubsection{Add}

Clicking the Add button in Figure 32 will display the page shown in Figure 35. 


\begin{tabular}{|c|c|c|c|c|c|c|c|c|c|c|c|c|}
\hline \multicolumn{4}{|c|}{ CreateCurtailment } & & & & \multirow[b]{2}{*}{ Type: } & & & & & \\
\hline \multicolumn{4}{|l|}{ Name: } & & & & & \multicolumn{2}{|c|}{ Bid Only } & & & \\
\hline \multicolumn{3}{|c|}{ Start Time: } & \multicolumn{4}{|c|}{ 9/27/2002 14:00:00 } & \multicolumn{4}{|c|}{ End Time: $9 / 27 / 2002$ 18:00:00 } & & \\
\hline \multicolumn{2}{|c|}{ Clear All } & \multicolumn{2}{|c|}{ Select All } & & & & & & & & & \\
\hline Select & & uilding & & ustomer & County & ISO & $\begin{array}{c}\text { ISO } \\
\text { Zone }\end{array}$ & $\begin{array}{l}\text { Load } \\
\text { (HWW) }\end{array}$ & \multicolumn{2}{|c|}{ Program } & Default & \$/HWHr \\
\hline$\sqrt{\checkmark}$ & 2nd & venue & & $\begin{array}{l}\text { ctrotek } \\
\text { ncepts }\end{array}$ & & Unknown & Unknown & 0 & None & \pm & Yes 7 & \\
\hline$\sqrt{\nabla}$ & Elec & rotek & & $\begin{array}{l}\text { ctrotek } \\
\text { ncepts }\end{array}$ & & Unknown & Unknown & 0 & None & $\nabla$ & Yes $=$ & \\
\hline$\sqrt{V}$ & Host & & & $\begin{array}{l}\text { ctrotek } \\
\text { ncepts }\end{array}$ & & Unknown & Unknown & 0 & None & \pm & Yes 7 & \\
\hline$\sqrt{\nabla}$ & 2nd & Ave Nem & & rizon & & Unknown & Unknown & 0 & None & $\nabla$ & |Yes $\nabla$ & \\
\hline$\sqrt{\checkmark}$ & Varic & Street & & rizon & & NYISO & NYC & 0 & None & $\nabla$ & Yes - & \\
\hline$\sqrt{\nabla}$ & Clint & & & rizon & \begin{tabular}{|l} 
GNYC- \\
Brooklyn
\end{tabular} & Unknown & Unknown & 0.6 & None & $\nabla$ & Yes 7 & \\
\hline
\end{tabular}

Figure 35. Create curtailment page

The SA enters the name, type of curtailment, and start and end times, and he checks the buildings committed to running generators in the curtailment. For each building, the SA enters the priority energy market program for that building. If he wants the rate of pay to default to the default rate for the selected program, he selects Yes under the Default heading. Otherwise, he selects NO and enters a rate.

Once the SA has completed the setup, he clicks Create Curtailment. To abort, he may select another option on the left. After clicking Create Curtailment, the page in Figure 32 is displayed with the new curtailment selected. This curtailment is now available for editing.

\subsubsection{Delete}

Clicking the Delete button in Figure 32 will not delete the selected curtailment. Instead, the page shown in Figure 36 will be displayed. 


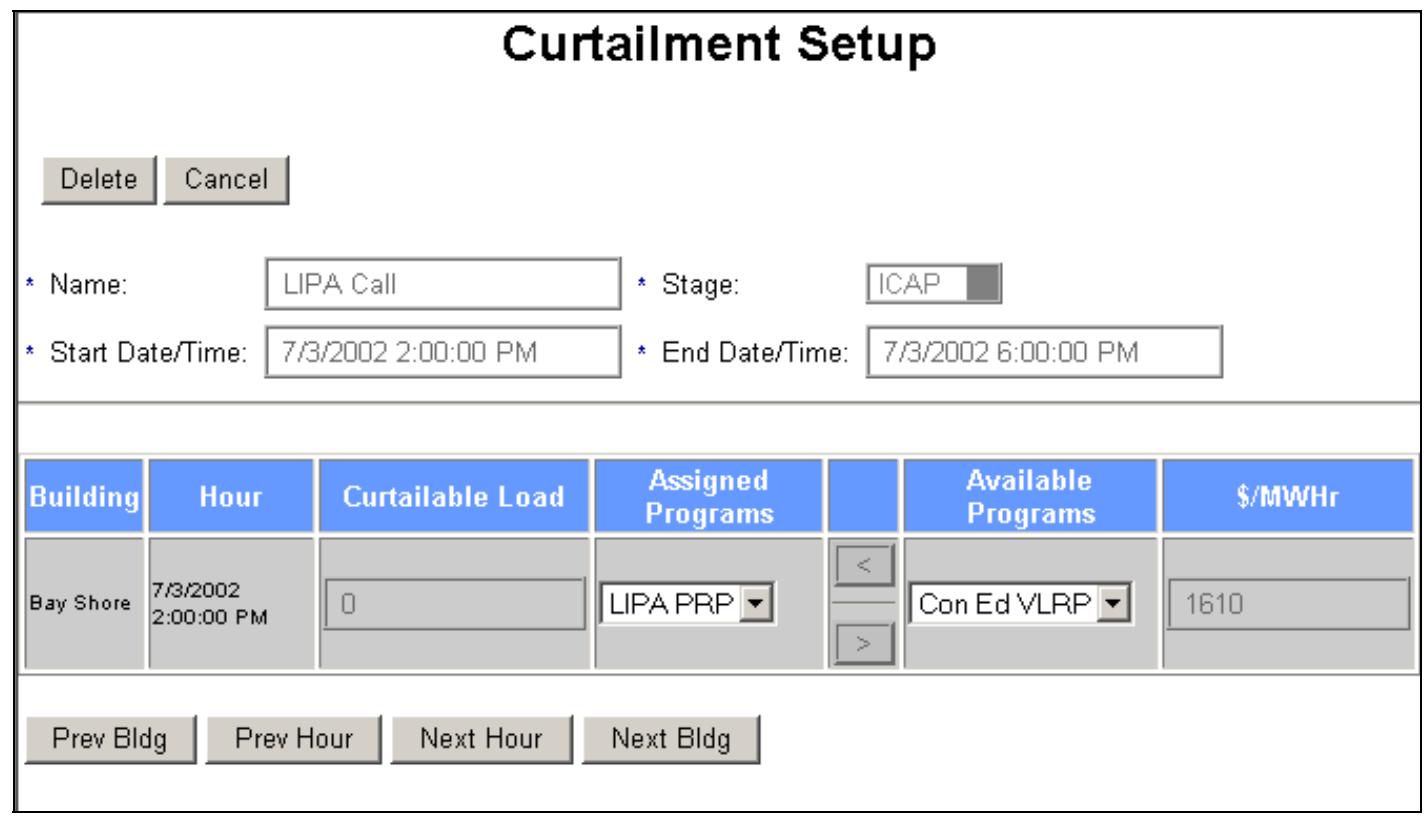

Figure 36. Curtailment delete page

If the SA still wishes to delete the curtailment displayed, then he may do so by clicking the Delete button on this page. To cancel the deletion, he may click the Cancel button. The navigation buttons at the bottom of the page are for viewing the curtailment in more detail.

\subsection{Peak Hunt Advisory}

The peak hunt advisory tool advises the SA whether he should run the generators in an effort to avoid a coincident system peak. Clicking Peak Hunt Advisory will display the page shown in Figure 37.

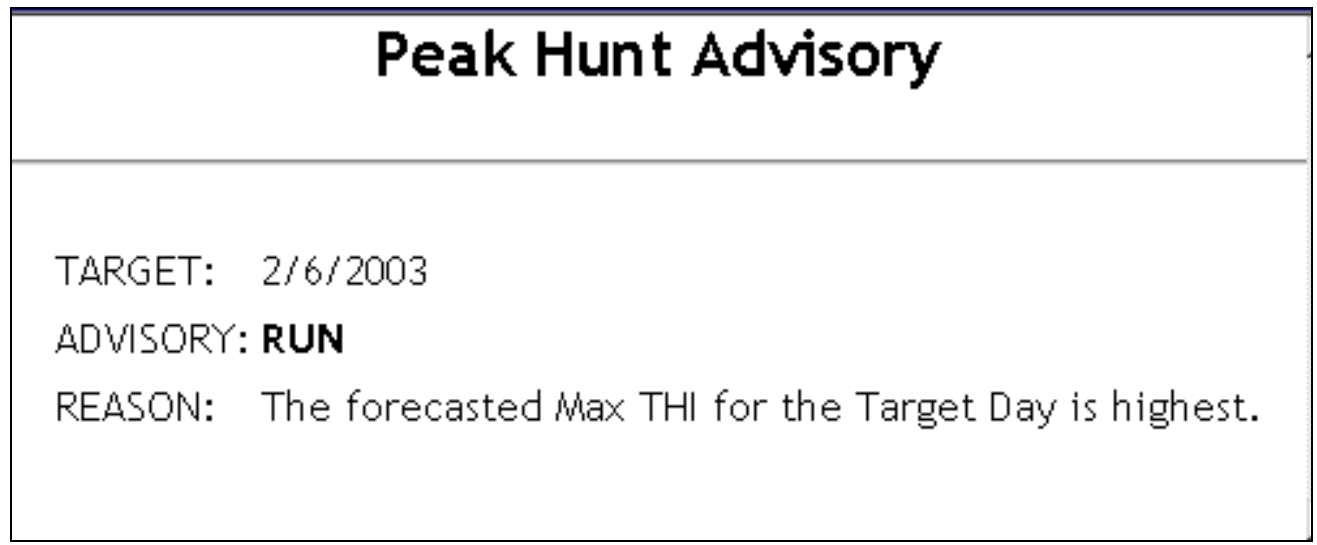

Figure 37. Peak hunt advisory report

The first item in the report is the date for which the advisory is made. The advisory is either RUN or Do NOT Run. Next is the reason the advisory is made. 
The advisories and possible reasons for each are listed below.

- RUN

- The forecasted Max THI for the Target Day is highest.

- Do NOT Run

- The Max THI on the day of the last run is higher than that forecasted for the Target Day.

○ The Target Day is a weekend or holiday.

○ The day after the Target Day has a higher THI than that of the Target Day.

\subsection{Bid Prep}

The bid prep tool calculates the cost of electricity for each participating site. The cost of electricity is based on site-specific parameters, customer-specific parameters, and a forecasted load for that site. Based on the cost of electricity for each building for each hour and the DayAhead Market price, the tool determines how much electricity should be generated and how much should be purchased. Clicking Bid Prep displays the page shown in Figure 38.

\section{Bid for 02/07/2003}

\section{Cost of Electricity $(\$ / \mathrm{WHr})$}

\begin{tabular}{|c|c|c|c|c|c|c|c|c|c|c|}
\hline Site Name & 0:00 & 1:00 & 2:00 & 3:00 & 4:00 & 5:00 & 6:00 & 7:00 & 8:00 & 9:00 \\
\hline $\begin{array}{l}\text { East } \\
\text { Hampton }\end{array}$ & $\$ 0.84$ & $\$ 0.84$ & $\$ 0.84$ & $\$ 0.84$ & $\$ 0.84$ & $\$ 0.84$ & $\$ 0.84$ & $\$ 0.84$ & $\$ 0.47$ & $\$ 0.47$ \\
\hline Hidsuille & $\$ 0.22$ & $\$ 0.22$ & $\$ 0.22$ & $\$ 0.22$ & $\$ 0.22$ & $\$ 0.22$ & $\$ 0.22$ & $\$ 0.22$ & $\$ 0.12$ & $\$ 0.12$ \\
\hline Sag Harbor & $\$ 1.01$ & $\$ 1.01$ & $\$ 1.01$ & $\$ 1.01$ & $\$ 1.01$ & $\$ 1.01$ & $\$ 1.01$ & $\$ 1.01$ & $\$ 0.49$ & $\$ 0.49$ \\
\hline Hempstead & $\$ 0.15$ & $\$ 0.15$ & $\$ 0.15$ & $\$ 0.15$ & $\$ 0.15$ & $\$ 0.15$ & $\$ 0.15$ & $\$ 0.15$ & $\$ 0.11$ & $\$ 0.11$ \\
\hline Brentivood & $\$ 0.27$ & $\$ 0.27$ & $\$ 0.27$ & $\$ 0.27$ & $\$ 0.27$ & $\$ 0.27$ & $\$ 0.27$ & $\$ 0.27$ & $\$ 0.21$ & $\$ 0.21$ \\
\hline $\begin{array}{l}\text { DA Market } \\
\text { Price }\end{array}$ & $\$ 0.05$ & $\$ 0.04$ & $\$ 0.04$ & $\$ 0.04$ & $\$ 0.04$ & $\$ 0.05$ & $\$ 0.07$ & $\$ 0.08$ & $\$ 0.07$ & $\$ 0.07$ \\
\hline Categony & 0:00 & 1:00 & 2:00 & 3:00 & 4:00 & 5:00 & 6:00 & $7: 00$ & 8:00 & 9:00 \\
\hline $\begin{array}{l}\text { Total } \\
\text { Required }\end{array}$ & $3,245.44$ & $3,223.64$ & 3.223 .64 & $3,223.64$ & $3,223.64$ & $3,201.85$ & $3,201.85$ & $3,201.85$ & $3,245.44$ & $3,289.03$ \\
\hline $\begin{array}{l}\text { Total } \\
\text { Generated }\end{array}$ & 0.00 & 0.00 & 0.00 & 0.00 & 0.00 & 0.00 & 0.00 & 0.00 & 0.00 & 0.00 \\
\hline $\begin{array}{l}\text { Total } \\
\text { Purchased }\end{array}$ & $3,245.44$ & 3.223 .64 & 3.223 .64 & 3.223 .64 & $3,223.64$ & $3,201.85$ & $3,201.85$ & $3,201.85$ & $3,245.44$ & $3,289.03$ \\
\hline
\end{tabular}

Figure 38. Bid prep report 


\subsection{Latest User Access}

The SA may track the last time his DG customers accessed the Web site.

Clicking Latest User Access displays the report shown in Figure 39.

\begin{tabular}{|l|l|l|}
\hline \multicolumn{2}{|l|}{ Latest User ACCeSS } \\
$\qquad$\begin{tabular}{|l|l|l|}
\hline User Name & Company Name & \multicolumn{1}{|c|}{ Last Visit } \\
\hline Verizon & Verizon & $12 / 17 / 20029: 58: 02 \mathrm{AM}$ \\
\hline Leanne & Electrotek Concepts & $2 / 6 / 20039: 08: 53 \mathrm{PM}$ \\
\hline Craig & Electrotek Concepts & $1 / 31 / 20033: 19: 32 \mathrm{AM}$ \\
\hline Howard & Electrotek Concepts & $1 / 5 / 20033: 14: 39 \mathrm{PM}$ \\
\hline Victor & Electrotek Concepts & $1 / 3 / 20033: 46: 43 \mathrm{PM}$ \\
\hline Rob & Electrotek Concepts & $1 / 3 / 20031: 35: 25 \mathrm{PM}$ \\
\hline Larry & Electrotek Concepts & $11 / 19 / 20025: 22: 12 \mathrm{PM}$ \\
\hline
\end{tabular} \\
\hline
\end{tabular}

Figure 39. Latest user access report

The report shows each user, the company for whom he works, and the last time he visited AggregationWeb. 
Appendix B: NodeCenter and PQView Guide 
Task 8

B-ii 


\section{Table of Contents}

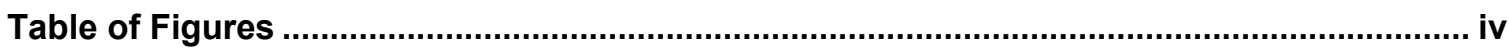

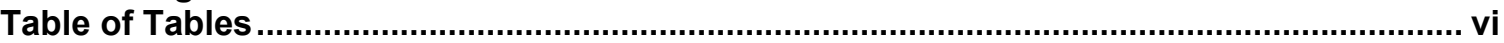

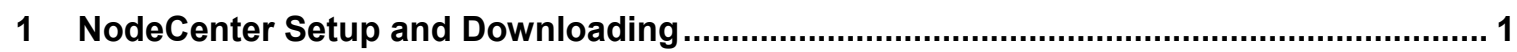

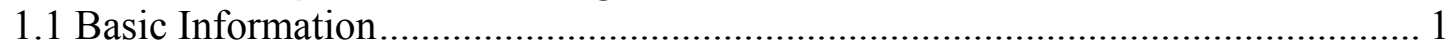

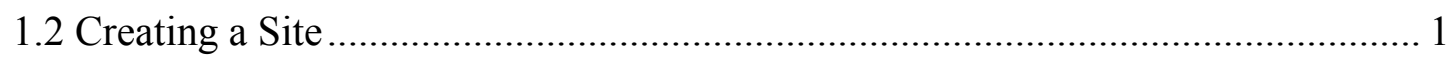

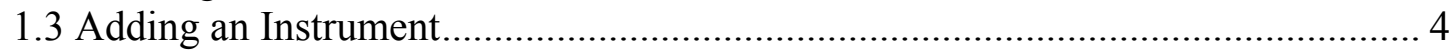

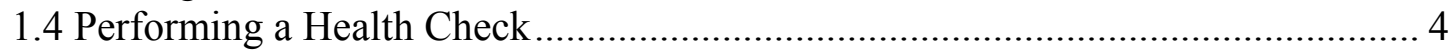

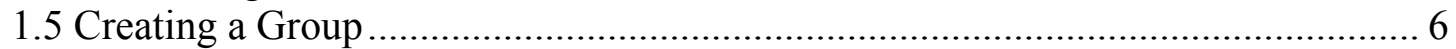

1.6 Adding Monitors to a Group ................................................................................ 7

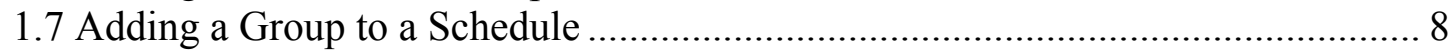

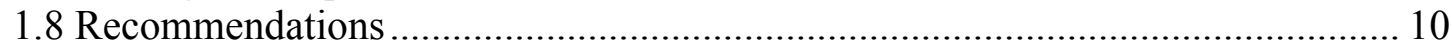

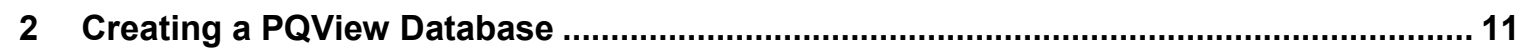

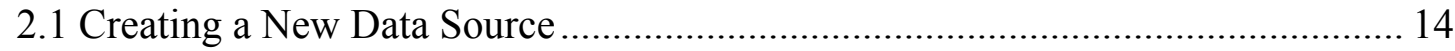

2.1.1 Designating the Data Format and Location ......................................... 16

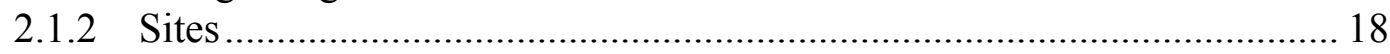

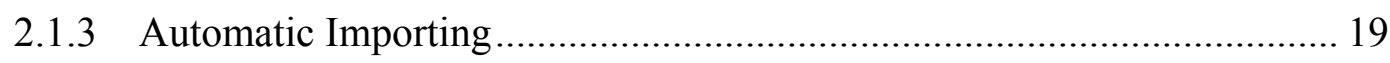

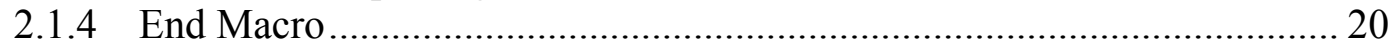

2.1.5 Date and Time Range.................................................................. 20

2.1.6 Disturbances and Steady-State Measurements....................................... 20

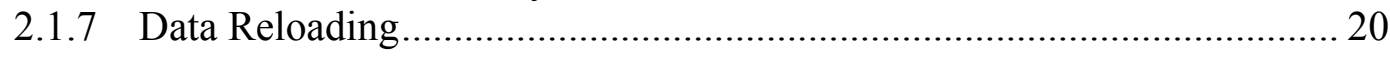

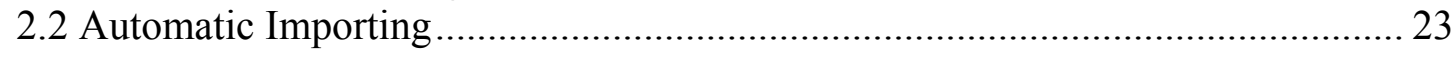

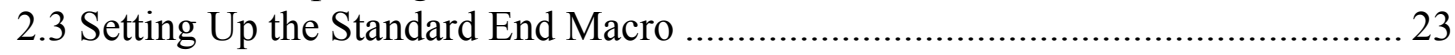

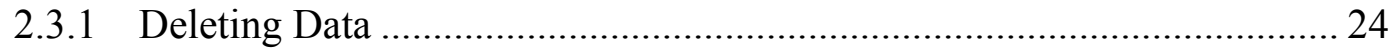

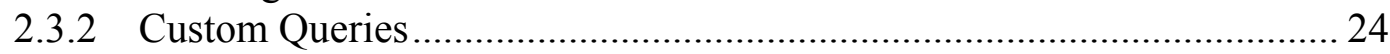

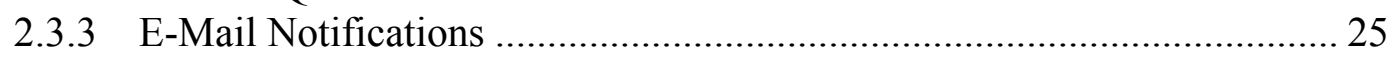

2.3.4 Unpacking Steady-State Measurements............................................... 26

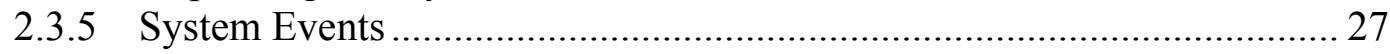

2.3.6 Controlling Data Source Imports ...................................................... 27

3 Using NodeCenter and PQView for Optimum Data Acquisition ................................... 29

3.1 NodeCenter Instrument Contact Status Log ..................................................... 29

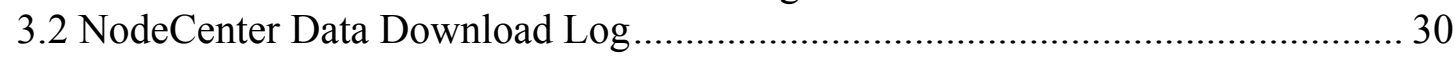

3.3 Steady-State and Power Trends .................................................................... 31

4 Creating a PQView SQL Database With Microsoft SQL Server 7.0 or Microsoft

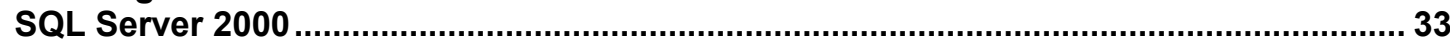

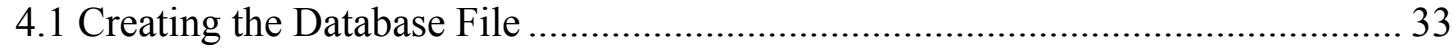

4.2 Creating the PQView Database Structure With SQL Query Analyzer.................. 36

4.3 Assigning Permissions to User Accounts Used by PQView and PQWeb ........... 40

4.4 Bulk-Copying Data into Lookup Tables ............................................................ 45

4.5 Creating an ODBC Data Source on Each PQView Workstation ......................... 45 


\section{Table of Figures}

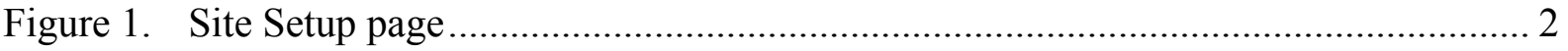

Figure 2. Site Setup page: adding a new site ..................................................................... 3

Figure 3. Site Setup page: adding a new instrument .......................................................... 3

Figure 4. Downloadable Instrument Setup page ................................................................ 4

Figure 5. Health Check On Demand page ............................................................................. 5

Figure 6. Health Check On Demand page: performing a health check ................................... 5

Figure 7. Data Download Group Setup page....................................................................... 6

Figure 8. Data Download Group Setup page: adding a new group ......................................... 7

Figure 9. Data Download Group Setup page message ………………................................. 8

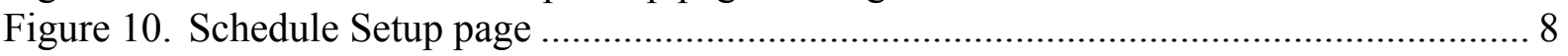

Figure 11. Schedule Setup page: adding a new schedule ……………………...................... 9

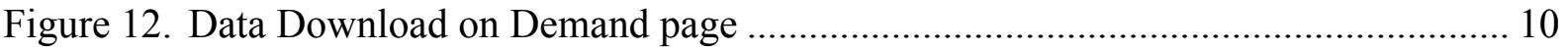

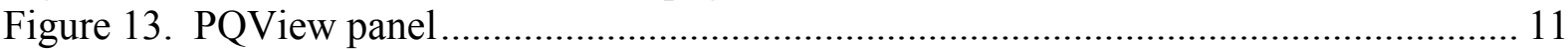

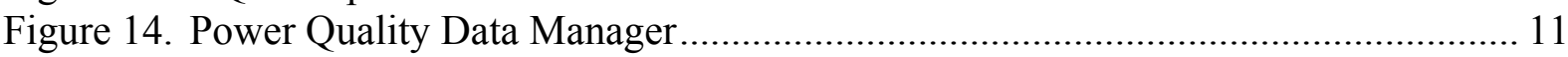

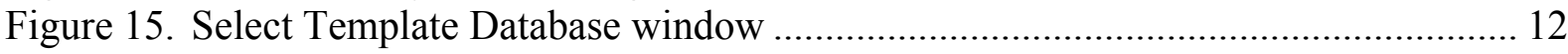

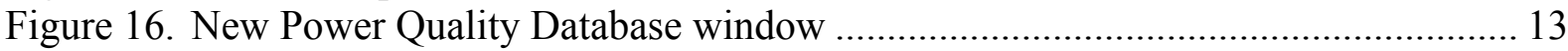

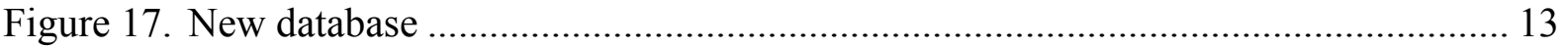

Figure 18. Creating a new data source ………………................................................. 14

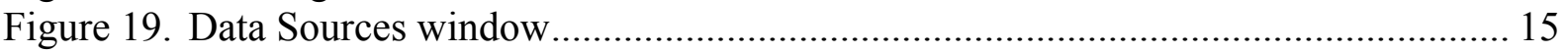

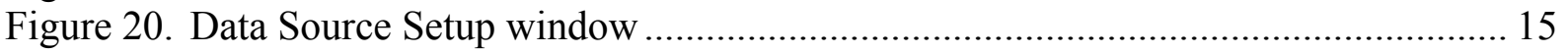

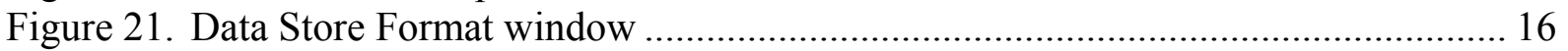

Figure 22. Specifying data location........................................................................... 17

Figure 23. PQDIFPOF folder on the NodeCenter server .................................................... 18

Figure 24. Data Source Setup window: sites..................................................................... 19

Figure 25. Start Background Processing for automatic downloading ..................................... 19

Figure 26. End Macro: Standard End Macro selected............................................................ 20

Figure 27. Data Reloading: leave previously unloaded data unchanged................................ 20

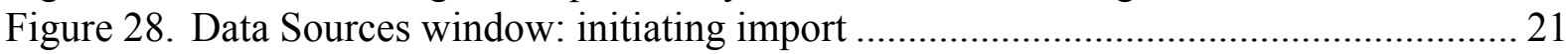

Figure 29. Sites, events, and steady-state measurement count.............................................. 21

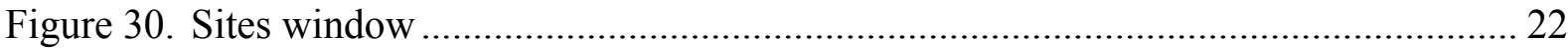

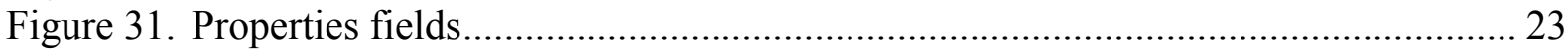

Figure 32. Start Background Processing: automatic importing.............................................. 23

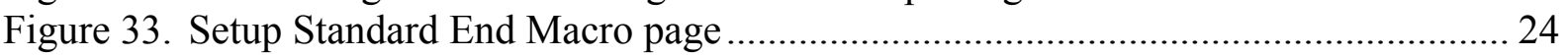

Figure 34. Custom SQL tab ……………………………............................................. 25

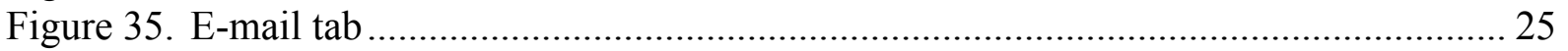

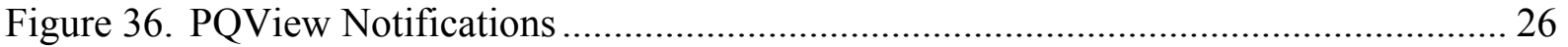

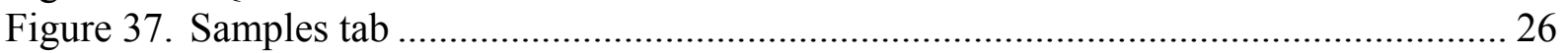

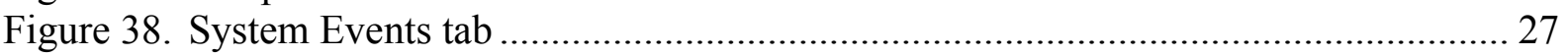

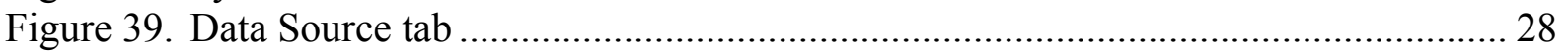

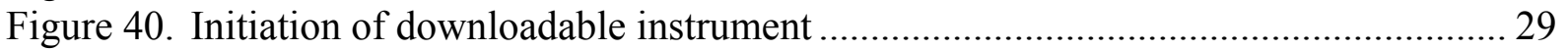

Figure 41. Termination of communication session of downloadable instrument ................... 29

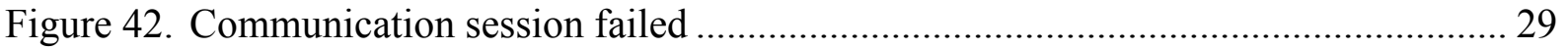

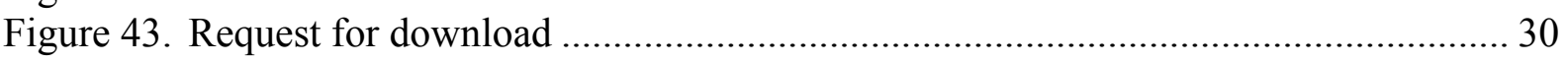

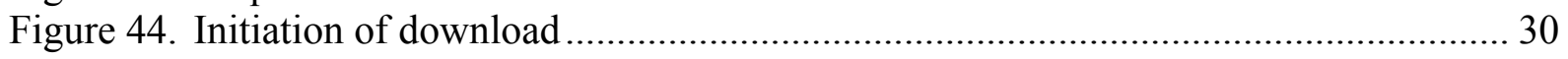


Figure 45. Size of data download and completion of download for specific DataNode......... 30

Figure 46. Notice of InfoNode completion of Infonode download ..................................... 30

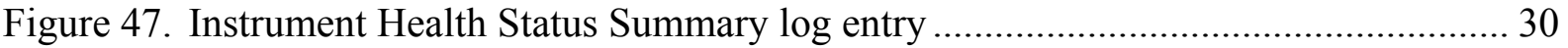

Figure 48. Steady-state trend displaying data gap ........................................................... 31

Figure 49. Data points in Microsoft Excel displaying data gap ......................................... 31

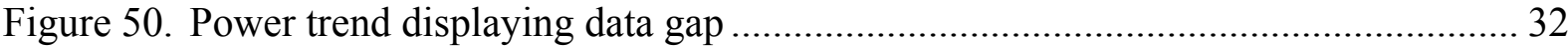

Figure 51. Data points in Microsoft Excel displaying data gap ....................................... 32

Figure 52. Selecting the server for creating a new database .......................................... 34

Figure 53. Console Root Menu: Action, New Database .................................................. 34

Figure 54. Database Properties window ....................................................................... 35

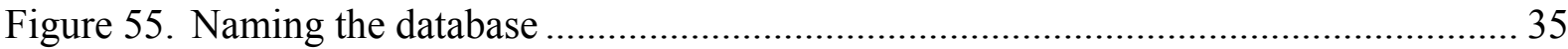

Figure 56. Default settings on Data Files and Transaction Log tabs.................................. 36

Figure 57. Select the database to be populated with PQView tables ................................. 37

Figure 58. Selecting Tools and SQL Query Analyzer...................................................... 37

Figure 59. Opening a file in the SQL Query Analyzer.................................................... 38

Figure 60. PQView33.sql file located in PQView30 \SQL folder ...................................... 38

Figure 61. PQView33.sql file contents displayed in the SQL Query Analyzer .................... 39

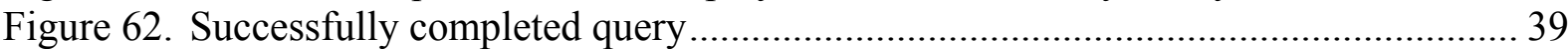

Figure 63. Tables added to database using SQL Query Analyzer...................................... 40

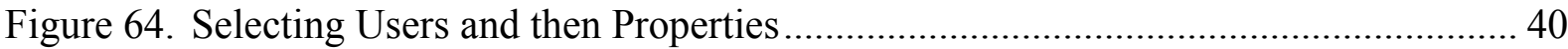

Figure 65. Database User Properties - New User window ............................................ 41

Figure 66. Assigning PQView roles in the Database Users Properties window .................... 41

Figure 67. Database User Properties - pqview window ............................................... 42

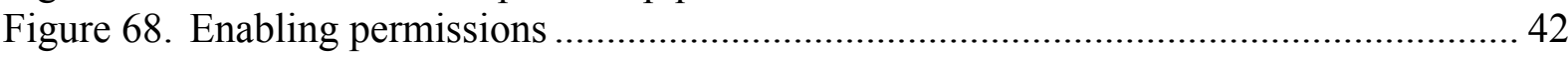

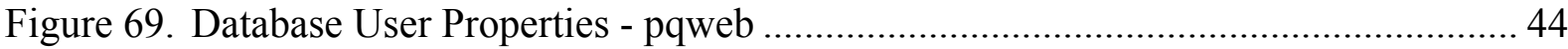

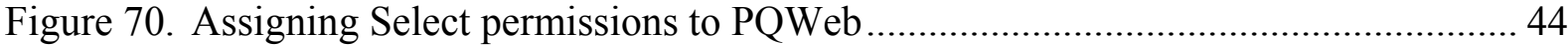

Figure 71. ODBC Data Source Administrator Window ..................................................... 46

Figure 72. Selecting a database for which to create a system DSN .................................. 46

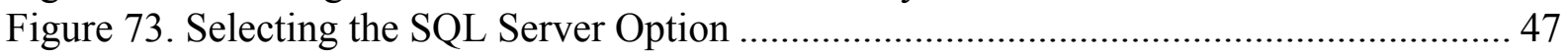

Figure 74. Create a New Data Source to SQL Server window ......................................... 47

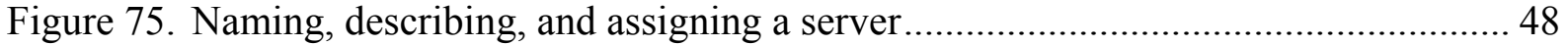

Figure 76. Assigning a User ID and Password ............................................................... 48

Figure 77. Changing the default database ..................................................................... 49

Figure 78. "Perform translation for character data" check box enabled ............................... 49

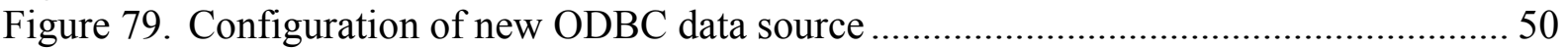

Figure 80. Confirmation of successful ODBC connectivity tests ..................................... 50 


\section{Table of Tables}

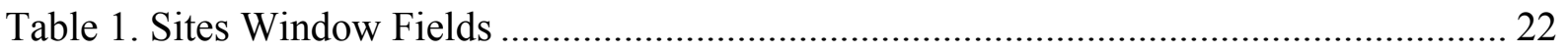

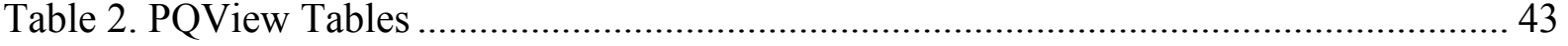

Task 8

B-vi 


\section{$1 \quad$ NodeCenter Setup and Downloading}

This user's guide provides instructions for downloading Dranetz-BMI Signature System ${ }^{\mathrm{TM}}$ PQDIF data using the Drantez-BMI Signature System NodeCenter ${ }^{\mathrm{TM}}$. It provides instructions for creating a PQView ${ }^{\circledR 1}$ database and characterizing the downloaded PQDIF files. This database offers users a method of viewing and manipulating the characterized data.

\subsection{Basic Information}

To set up an InfoNode in NodeCenter, some basic information is needed:

- InfoNode name

- Telephone number for dial-up connection (TCP/IP) over point-to-point protocol (PPP) InfoNode Modem Gateway IP

- Direct connect (Ethernet) IP

If the connection is dial-up, set up a phonebook entry on the NodeCenter server. Test the entry from the server to make sure it can connect with the InfoNode.

All the modem IP addresses should be unique in the monitoring system. This will allow NodeCenter to communicate with multiple InfoNodes simultaneously via multiple modems. Likewise, the DUN IP addresses (the IP addresses used by the server during a connection) should be unique in each phonebook entry. This may not always be the case; often; the default IP (192.168.1.10) is used.

Note that more than one modem can be used for downloading. If there are two modems, make sure all unique IPs are downloaded by one modem and all InfoNodes using the default modem IP are downloaded by the other.

Normally, the dial-up connections should not use the default gateway on the server (i.e., on the InfoNode) because NodeCenter would be unable to communicate with any InfoNodes via a direct connection (because it would be trying to route through the dial-up InfoNode). However, in some specialized situations, it may be necessary to use the default gateway on a particular InfoNode (e.g., to communicate with another InfoNode on the same dial-up connection). In these circumstances, permanent routes should be created for the InfoNodes.

When InfoNodes are to be downloaded using Direct Connect, be sure to test the IP by using the Microsoft ${ }^{\circledR}$ Internet Explorer browser.

\subsection{Creating a Site}

It is necessary to create a site with which to associate the downloadable instrument (InfoNode). Sites are also used to logically group downloadable instruments. The simplest setup is one downloadable instrument associated with one site.

\footnotetext{
${ }^{1}$ PQView is a registered trademark of Electrotek Concepts Inc. and is part of the EPRI Power Quality Diagnostic System.
} 
To create a site, select the Operations tab. From the tree, select Sites. The Site Setup page is displayed (Figure 1). Select the Add button.

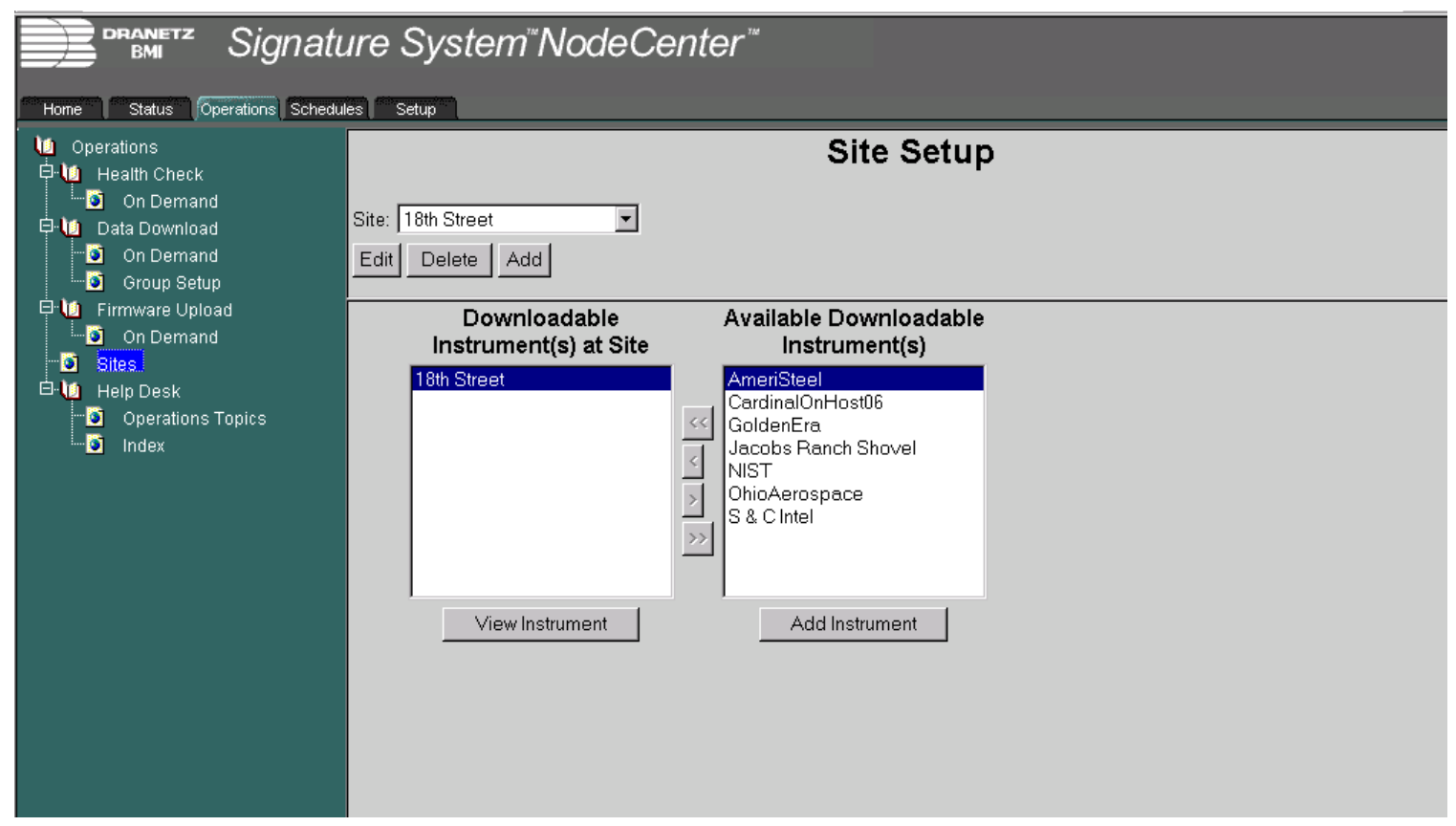

Figure 1. Site Setup page

Selecting the Add button displays the message "You are in the process of adding a site" (Figure 2).

In the Name field, enter the name of the site to be added. Select the Add button, and the new site is added.

Note that for the DG operation, this is a one-to-one mapping. One site corresponds to one downloadable instrument. Make sure that the site name corresponds with the name of the downloadable instrument (InfoNode). 


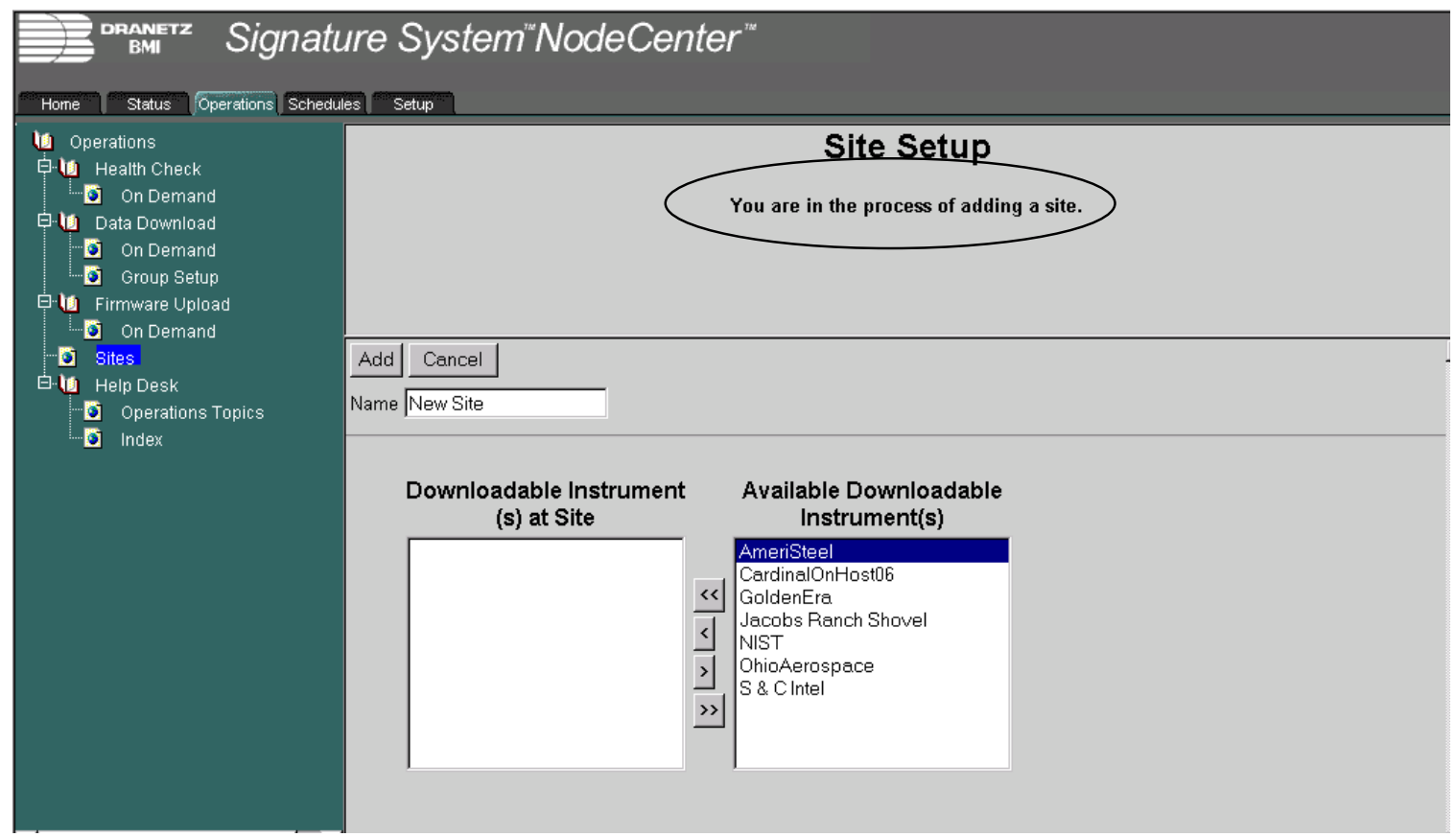

Figure 2. Site Setup page: adding a new site

After the site has been added, a downloadable instrument (InfoNode) must be associated with it. The downloadable instrument can be existing or new. In this case, a new instrument will be added.

Select the newly added site from the drop-down box on the Site Setup page (Figure 3). Select the Add Instrument button. The Downloadable Instrument Setup is displayed.

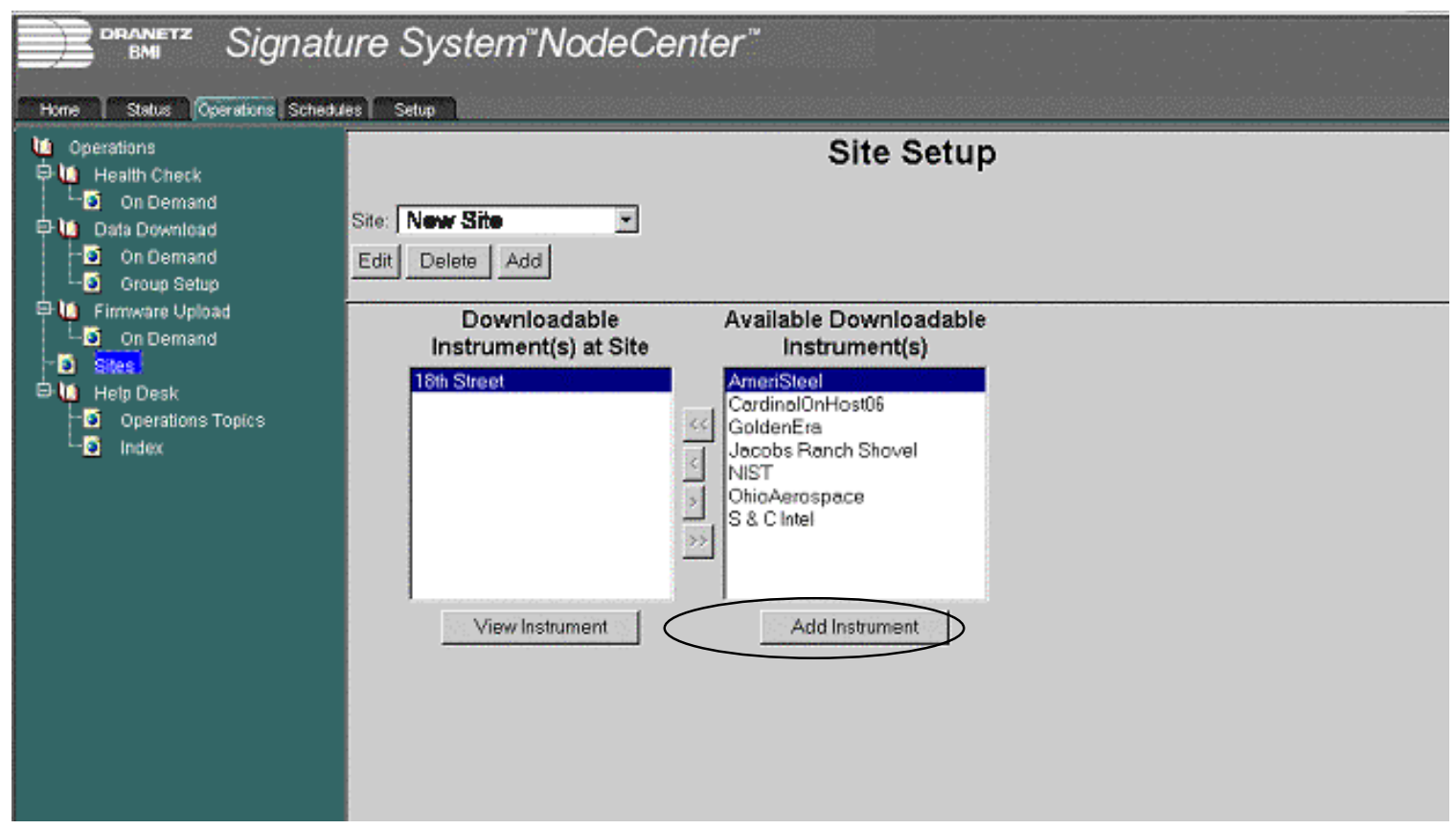

Figure 3. Site Setup page: adding a new instrument 


\subsection{Adding an Instrument}

On the Downloadable Instrument Setup page (Figure 4), select the name of the site that was created from the Site drop-down box. Enter the name of the downloadable instrument (InfoNode). A brief description of the downloadable instrument may be provided, but this is not mandatory. Enter the IP address of the InfoNode. If the InfoNode will be contacted via dial-up networking, enter the phonebook entry name.

If dial-up networking is to be used, check the DUN box. Enter the user name and password used to access the InfoNode. After supplying this information, select the Add button.

If the InfoNode is being contacted via DSL, it is necessary to supply only the IP, user name, and password. Make sure the DUN box is not selected.

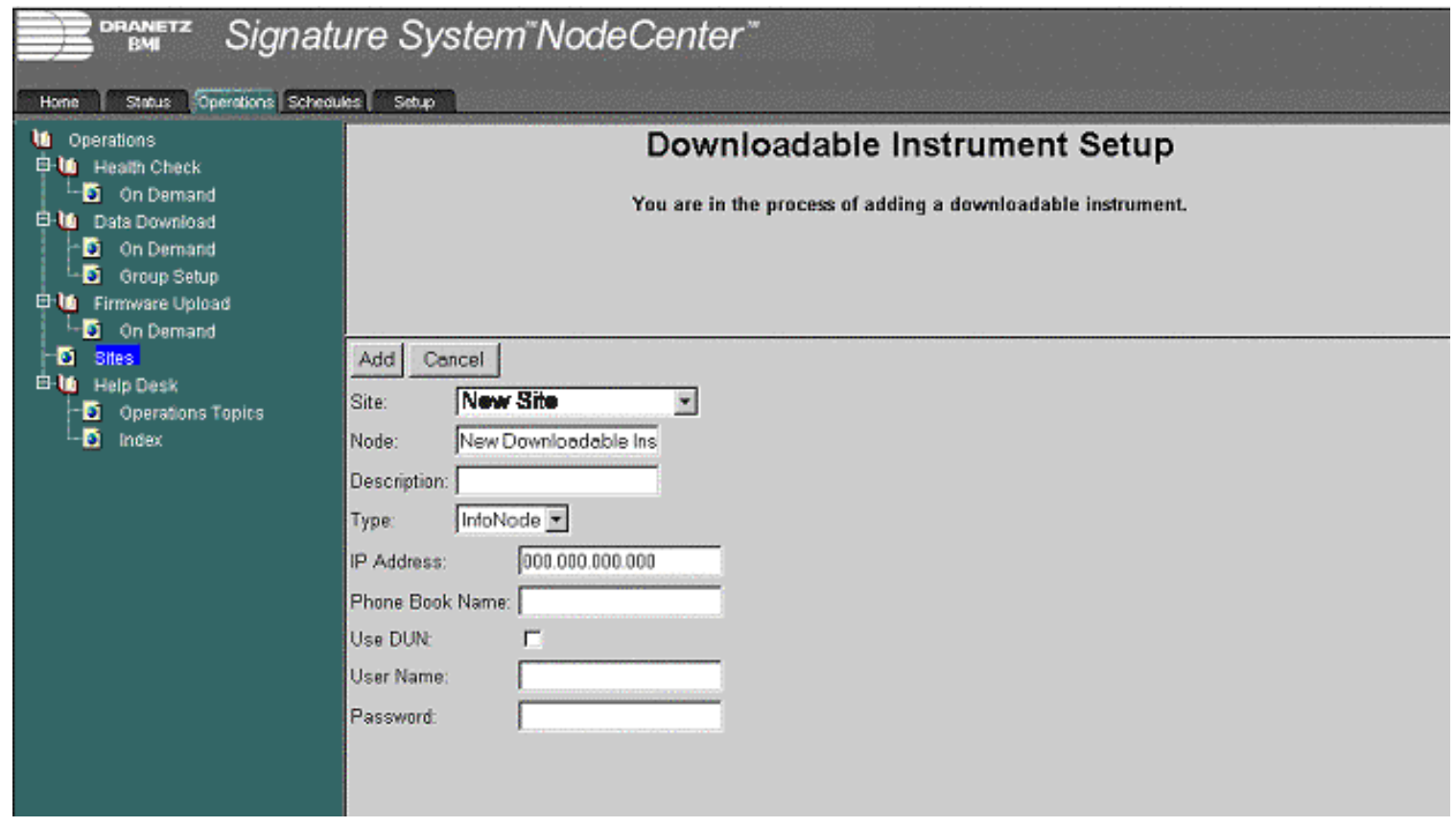

Figure 4. Downloadable Instrument Setup page

\subsection{Performing a Health Check}

After the InfoNode has been added, test the validity of the addition by performing a health check. Select Health Check and then On Demand from the Operations tree. This displays the Health Check On Demand page (Figure 5). From the drop-down box, select the newly added downloadable instrument by highlighting it. Then select the Check Health button. A message is displayed at the bottom of the page indicating a health check will be performed (Figure 6). 


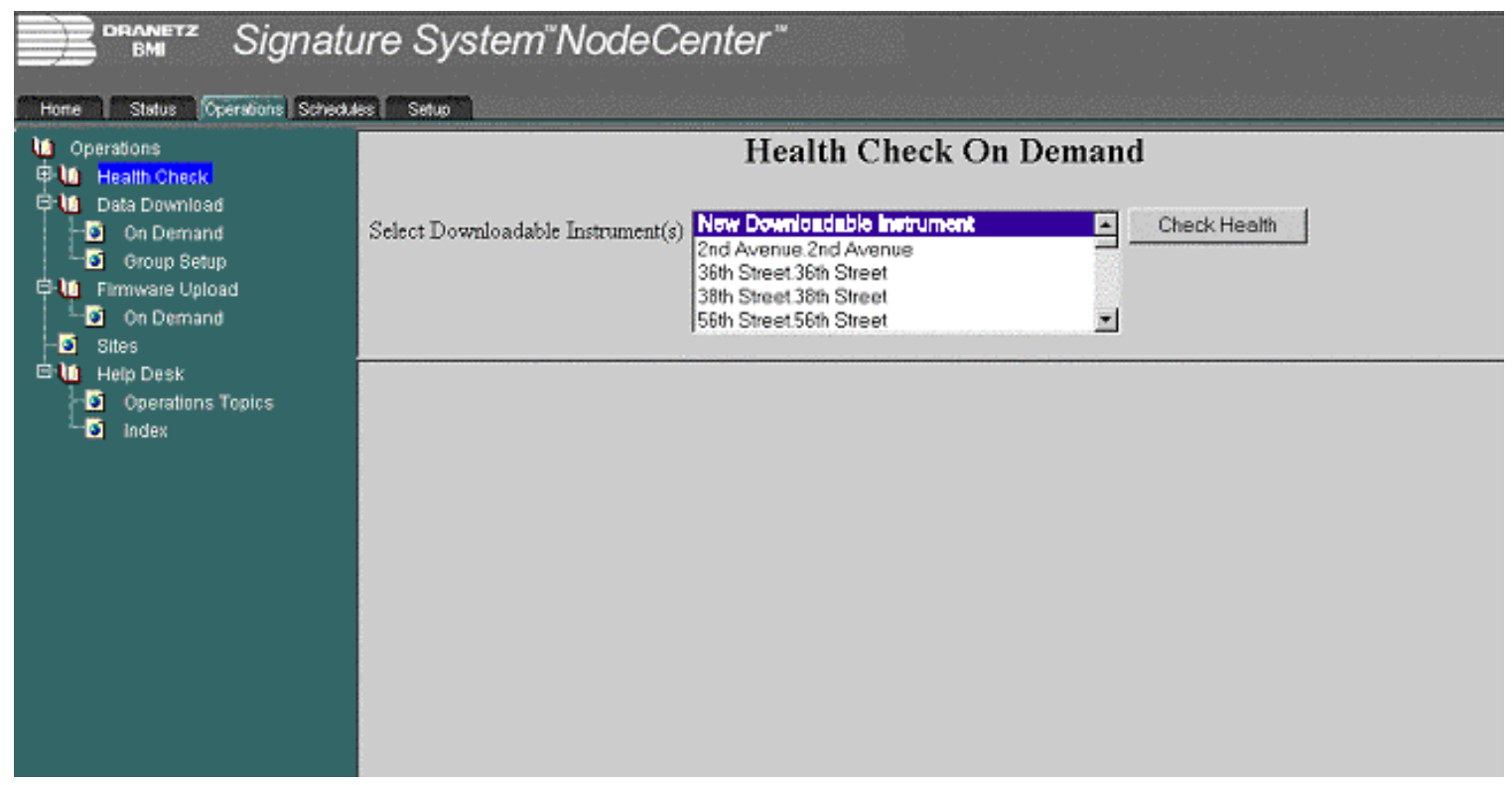

Figure 5. Health Check On Demand page

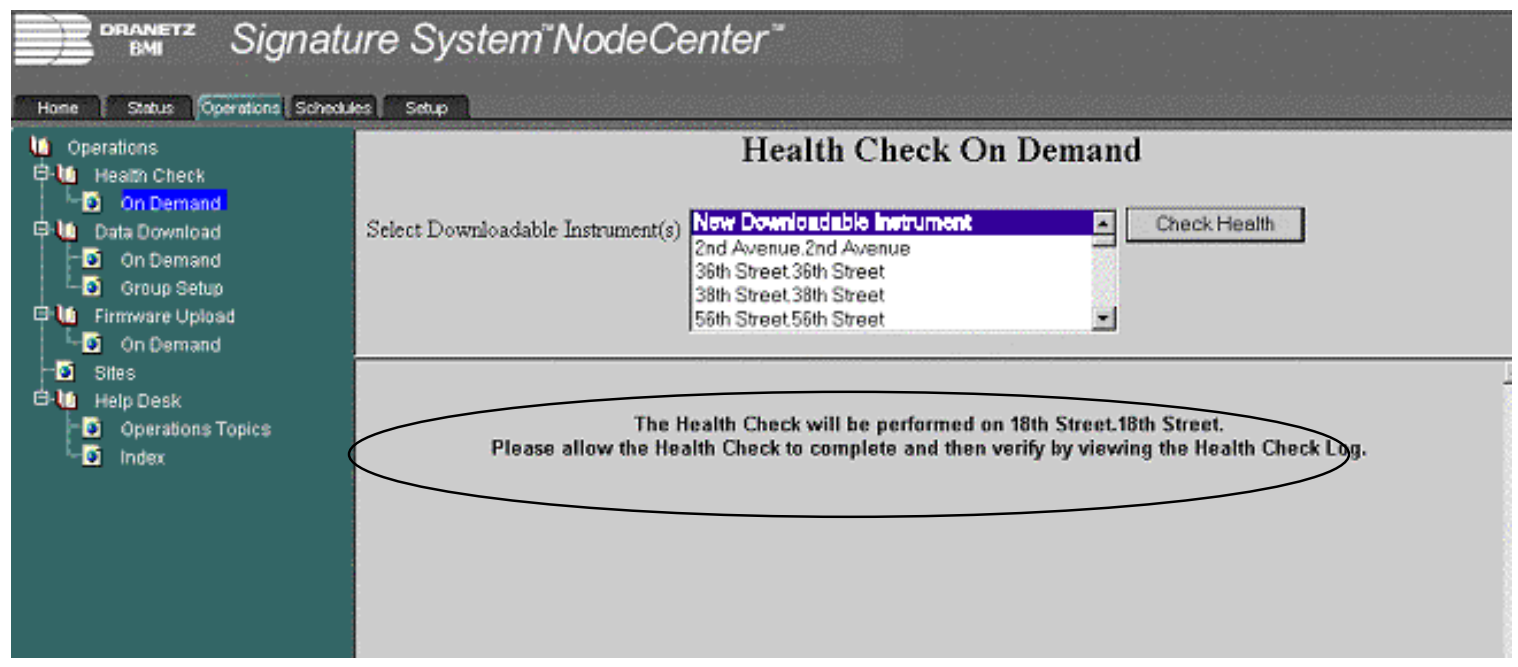

Figure 6. Health Check On Demand page: performing a health check

The health check reports the status of the InfoNode and associated DataNodes. To verify the health check has occurred, check the Health Check Log on the Operations page, the Health Check Log on the Status tab, or the Instrument Health Status Summary on the Status tab. It is best to perform this check from the NodeCenter machine so that if the health check fails, connectivity can be verified. 


\subsection{Creating a Group}

A group is an abstract collection of InfoNodes that have a common association.

There are many ways to define a group. Some examples are:

- The time interval for scheduled downloads (e.g., 24-hour, 2-hour)

- The type of connection used for downloads (e.g., direct downloads, dial-up downloads)

- The company or business type.

To create a download group, from the Operations tab, select Group Setup. This displays the Data Download Group Setup page (Figure 7).

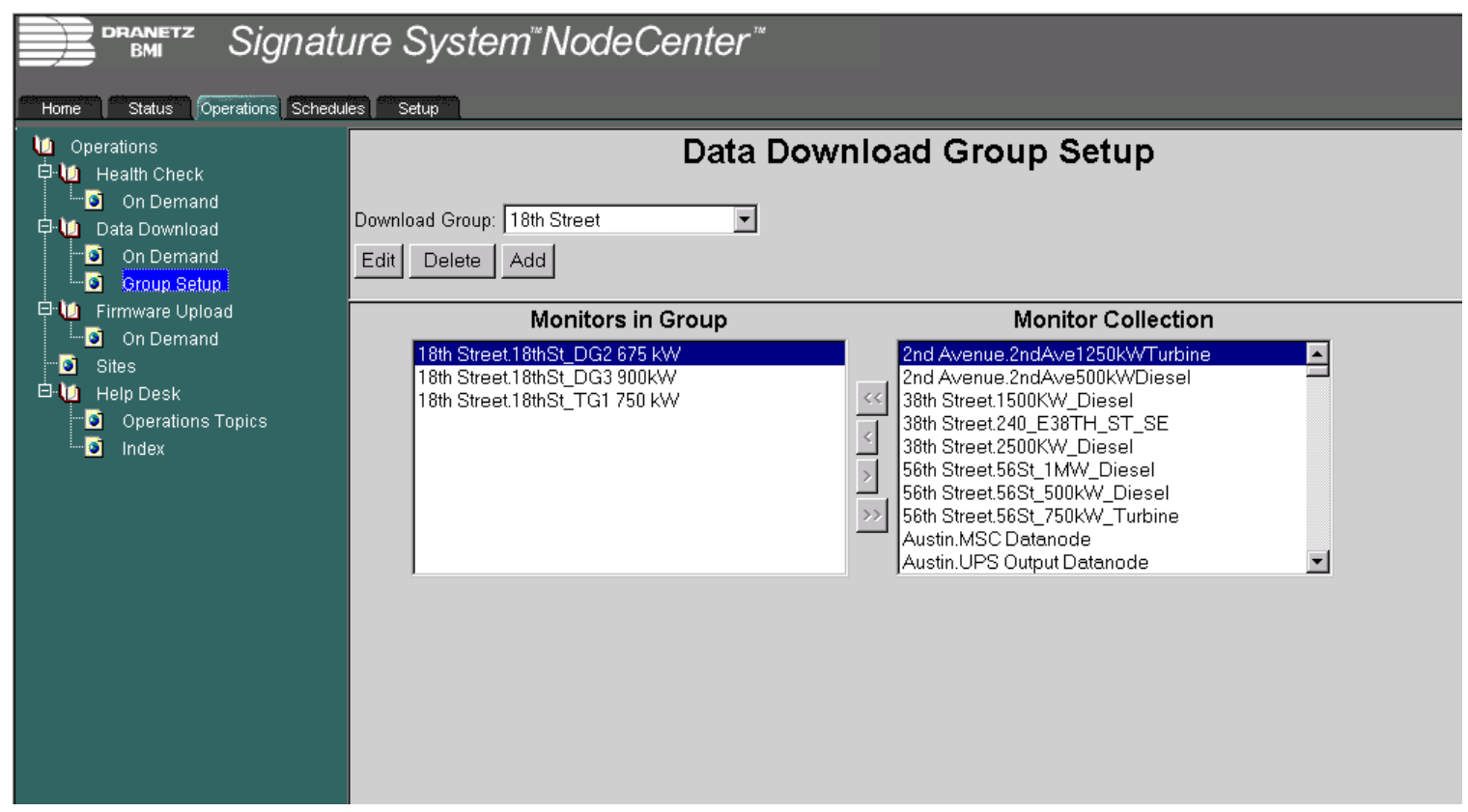

Figure 7. Data Download Group Setup page

Select the Add button. The Data Download Group Setup page displays the message "You are in the process of adding a group" (Figure 8). In the Group Name field, enter the name of the group (e.g., 24 Hour Download). After entering the name, select the Add button. The group is added. 


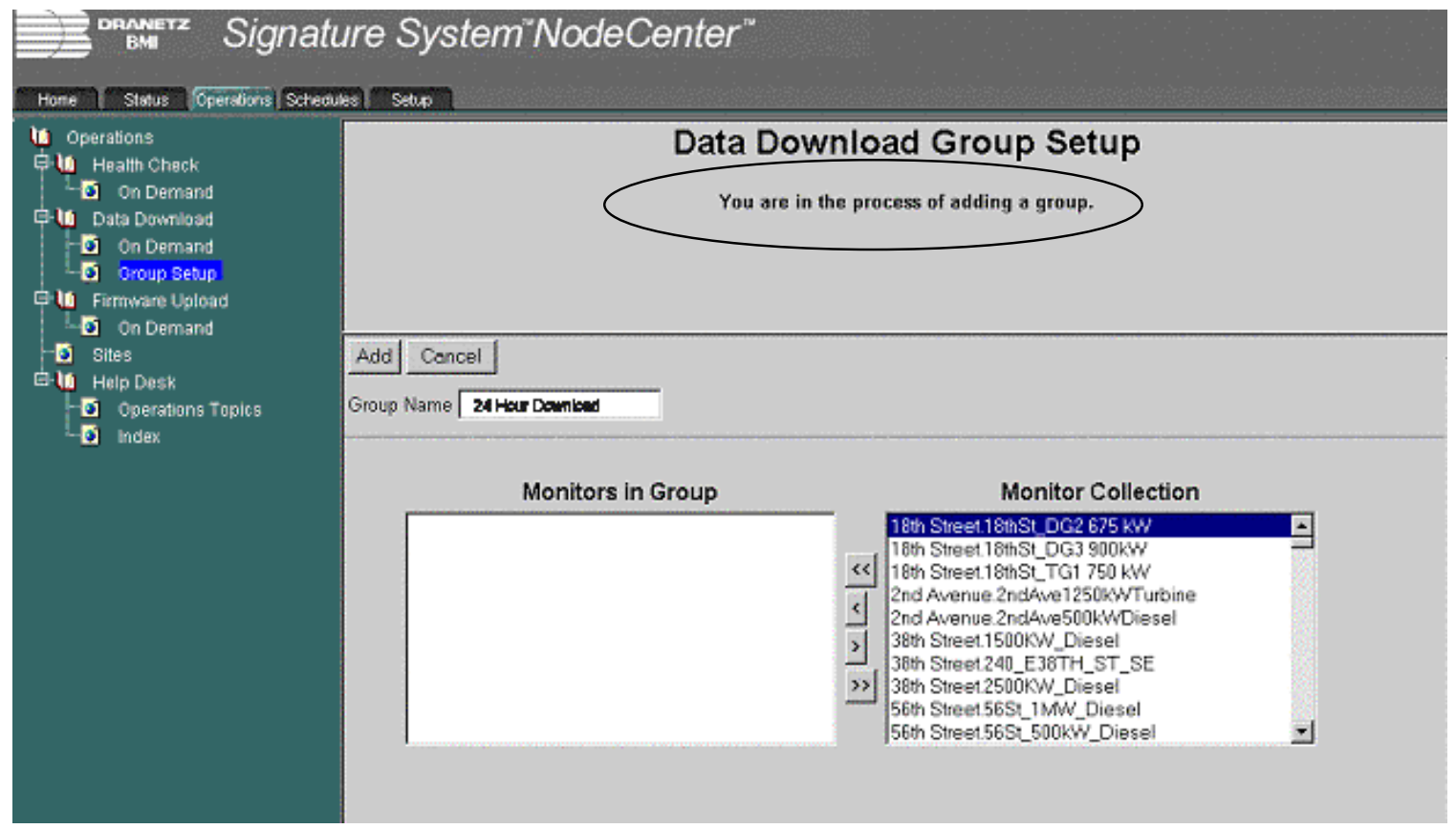

Figure 8. Data Download Group Setup page: adding a new group

\subsection{Adding Monitors to a Group}

As an example, those individual monitors (DataNodes) to be downloaded once every 24 hours should be included in the 24 Hour Download group.

To add monitors (DataNodes) to the download group, select Data Download and then Group Setup from the Operations Tab. This displays the Data Download Group Setup page (Figure 9). Choose the group to which the monitors are to be added by highlighting it in the Group Name drop-down box. Select the Edit button.

The message "You are in the process of editing the group information" is displayed. Highlight the monitor in the monitor collection that is to be part of the group, and use the arrow to move the monitor from Monitor Collection to Monitors in Group. When all the monitors are in the group, select the Update button. 


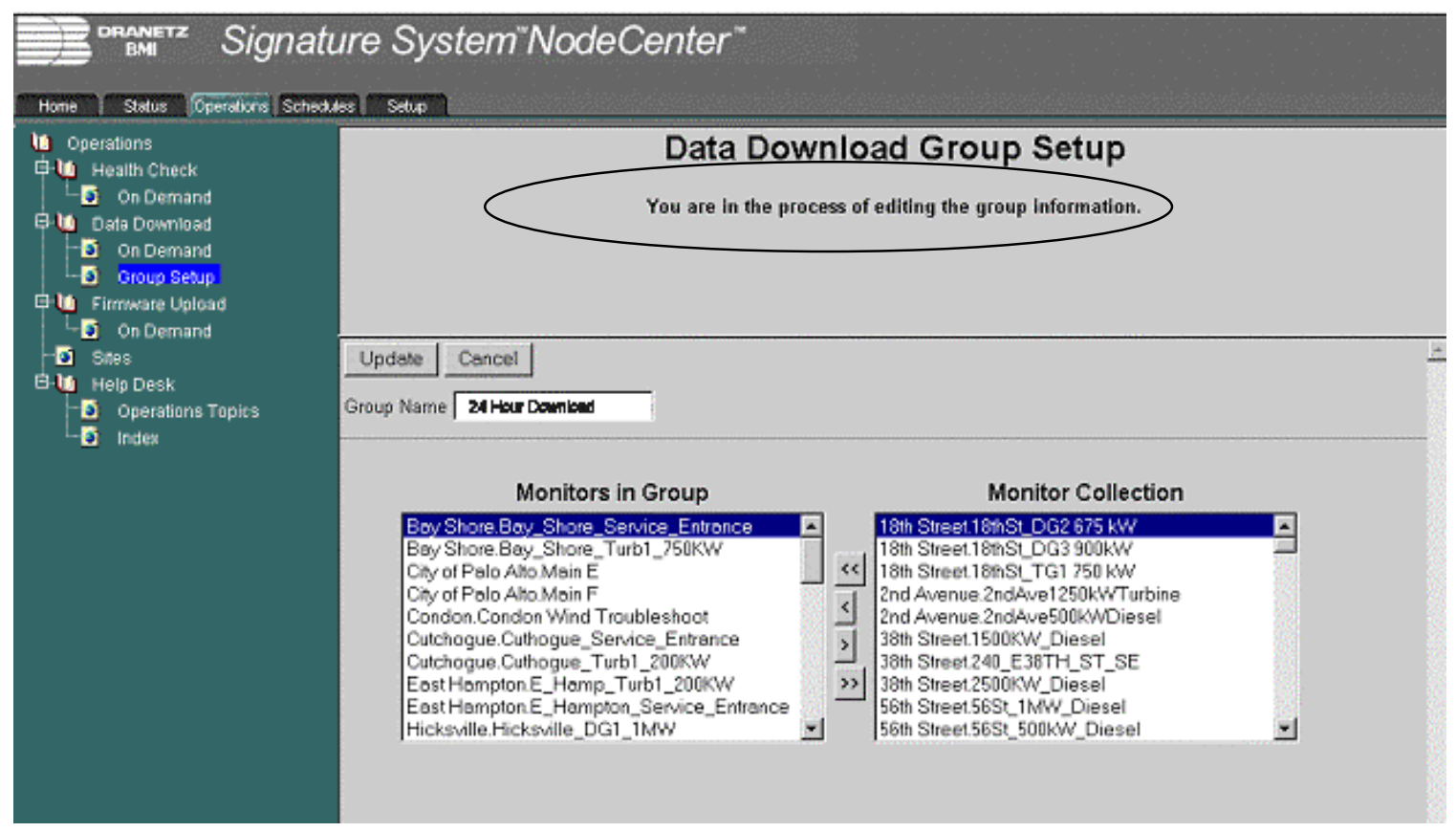

Figure 9. Data Download Group Setup page message

\subsection{Adding a Group to a Schedule}

The group can now be added to the download schedule. From the Schedules tab, select Schedules. The Schedule Setup page is displayed (Figure 10). Select the Add button.

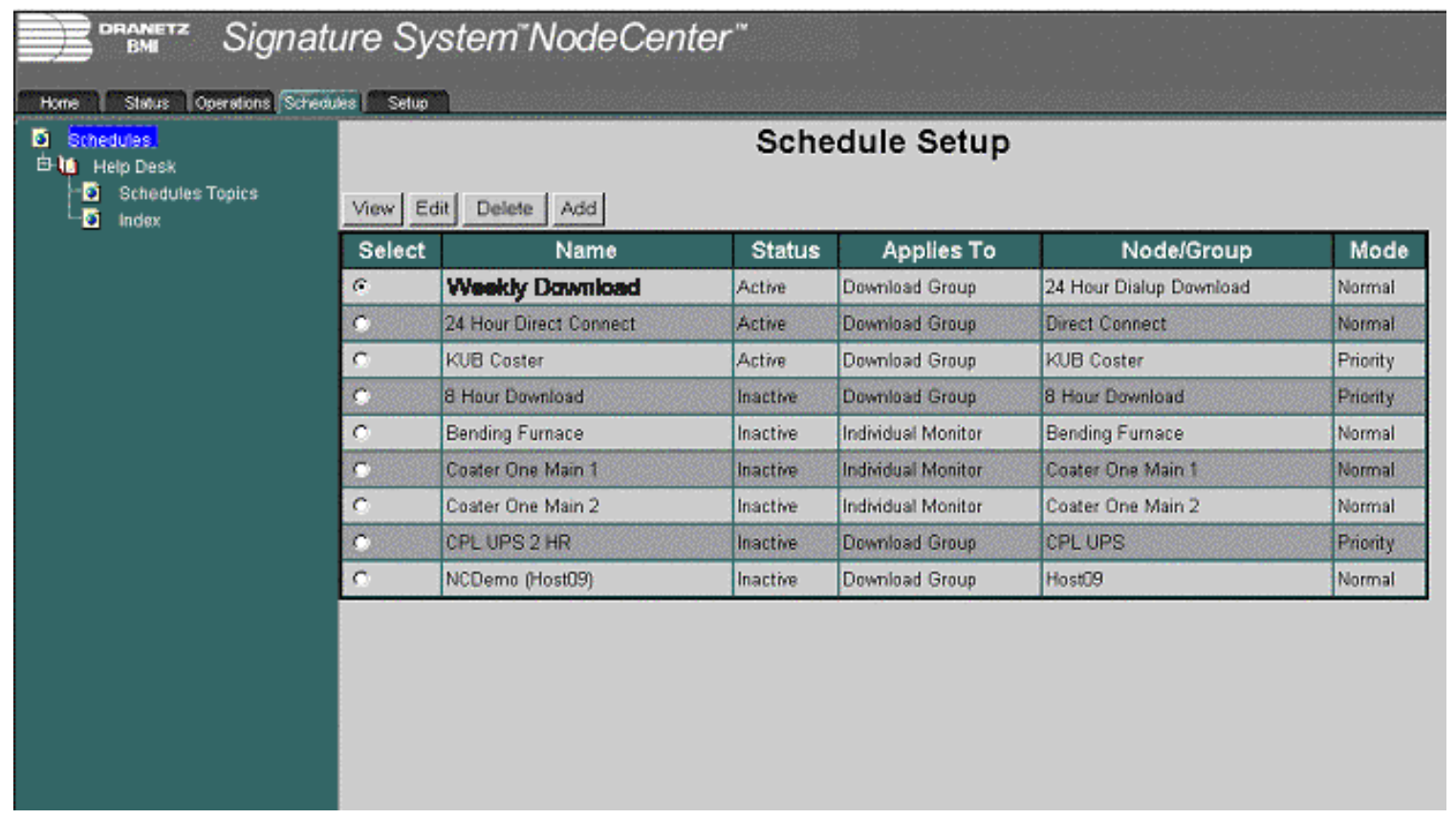

Figure 10. Schedule Setup page 
The Schedule Setup page is displayed with the message "You are in the process of adding a schedule" (Figure 11). Check the Active radio button. Enter the name of the schedule (e.g., 24 Hour Download). In the drop-down box, select either Download Group or Individual Monitor. In this case, Download Group is used. From the Node/Group drop-down box, select the group just created (24 Hour Download group). Select Normal mode (once every 24 hours), and select the days of the week by placing a check mark in the box beside each day that the group is to be downloaded.

Note that a priority mode is available. This will provide hourly downloading options.

Indicate the start time for the schedule to be activated. Note that the time is indicated in Greenwich Mean Time. The offset is displayed beside the Time of Day field. When the information is complete, select the Add button. The schedule is added.

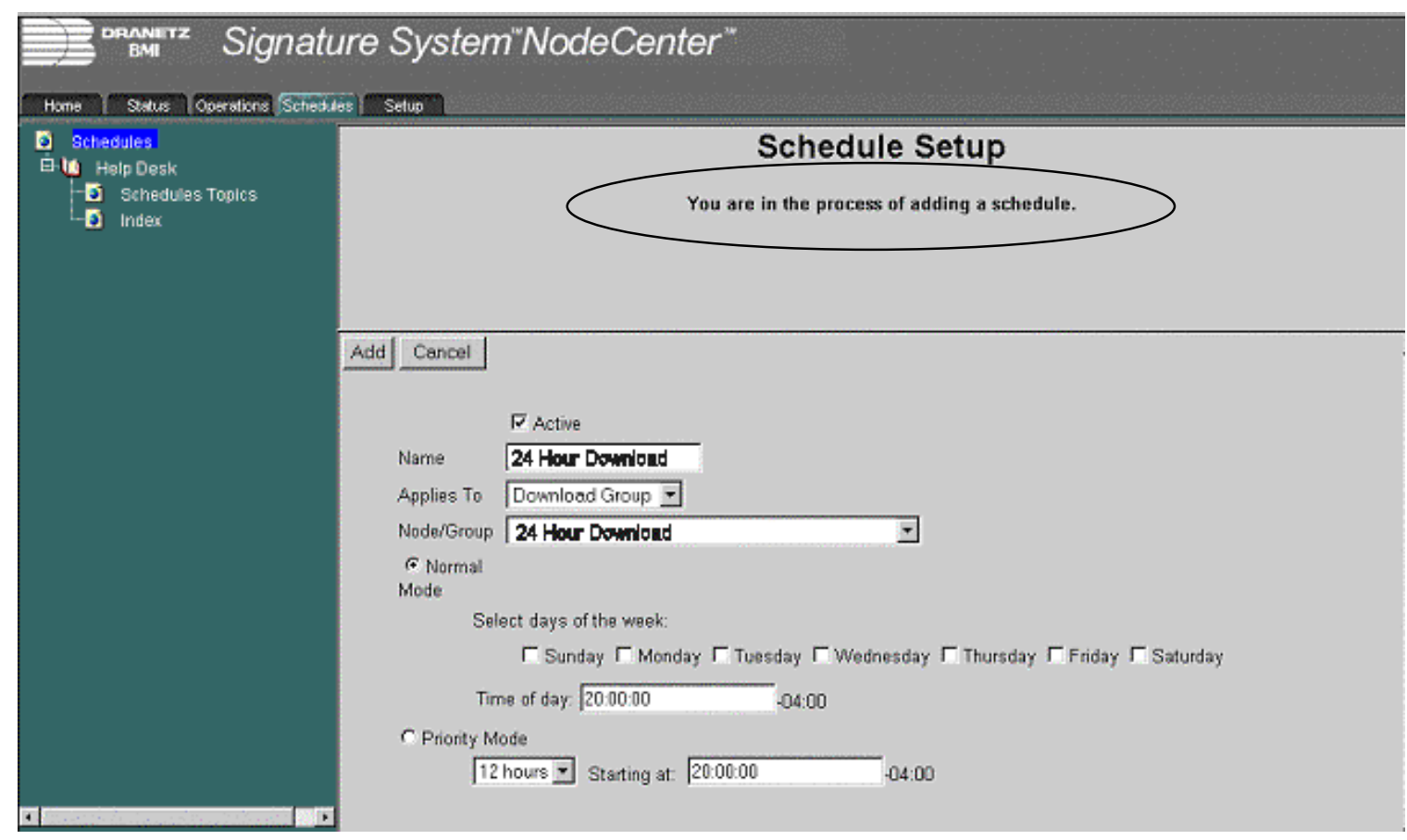

Figure 11. Schedule Setup page: adding a new schedule

In summary:

- A site has been created.

- An InfoNode has been added.

- A health check has been performed.

- A group has been created.

- DataNodes have been added to the group.

- A schedule has been created, and the group has been added to the schedule.

Initially, there could be a great deal of data to download. It is recommended that a manual download be performed for each newly added InfoNode before a scheduled download occurs. 
To perform a manual download, select the Operations tab. Then select Data Download and On Demand from the tree. The Data Download on Demand page is displayed (Figure 12). A group or an individual monitor can be downloaded. In this case, a group download is performed. Select the Groups radio button and, in the drop-down box, highlight the group to be downloaded. (A "read only" group is added with the name of the InfoNode when the InfoNode is initially contacted. This group cannot be altered and contains those DataNodes associated with the InfoNode.)

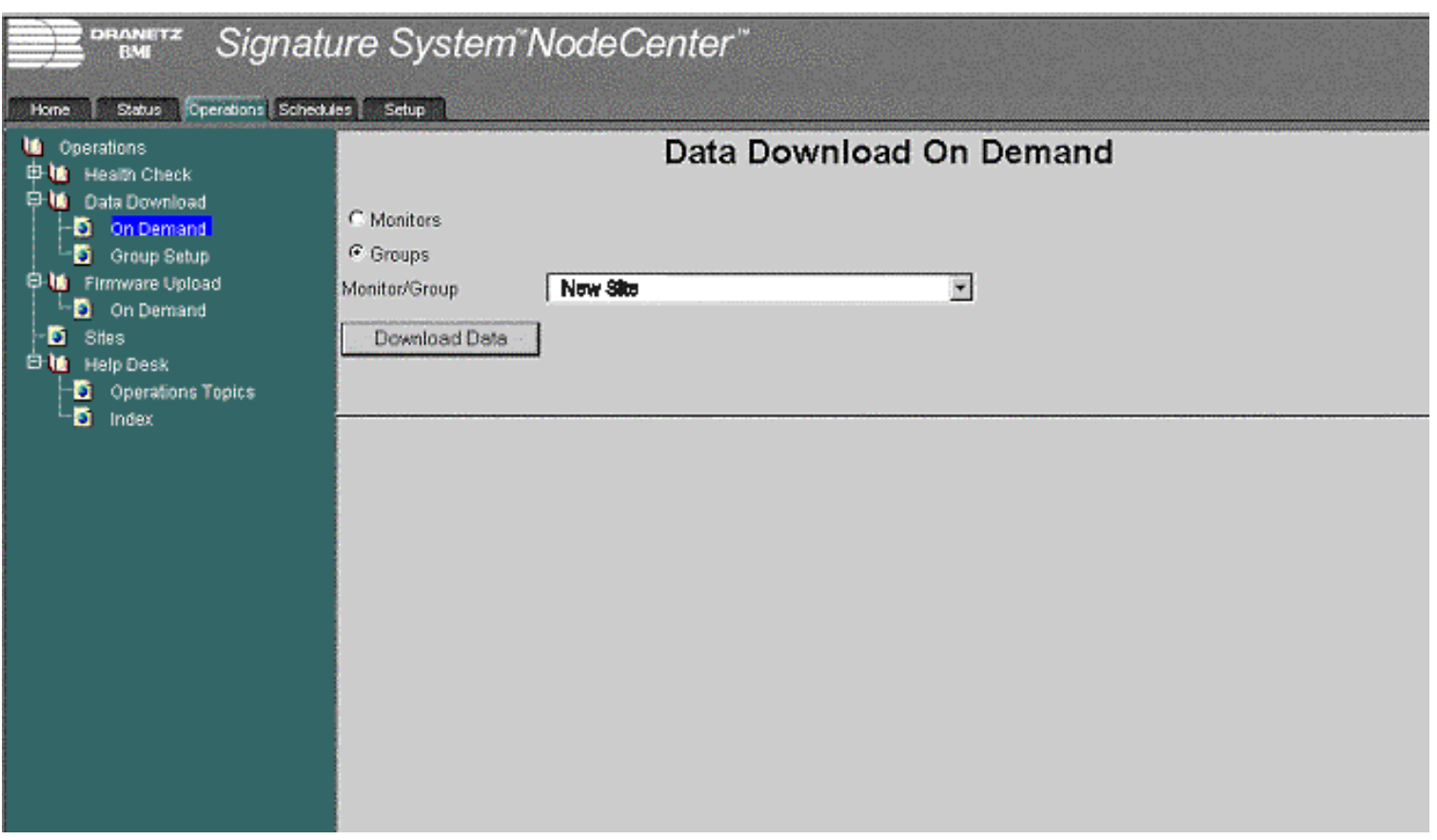

Figure 12. Data Download on Demand page

\subsection{Recommendations}

When downloading instruments, the status logs are useful to assess InfoNodes and DataNodes that need attention. A check of the Instrument Contact log quickly shows if an instrument can be contacted.

Data download logs show detailed information about Datanodes contacted and the amount of data downloaded. The amount of data downloaded can provide clues about the performance of the DataNode. 


\section{Creating a PQView Database}

PQView ${ }^{\circledR}$ databases are created using the Power Quality Data Manager. All data management is performed here. The Power Quality Data Analyzer's function is to create reports.

Open the Power Quality Data Manager by selecting the Manage Power Quality Data button (Figure 13).

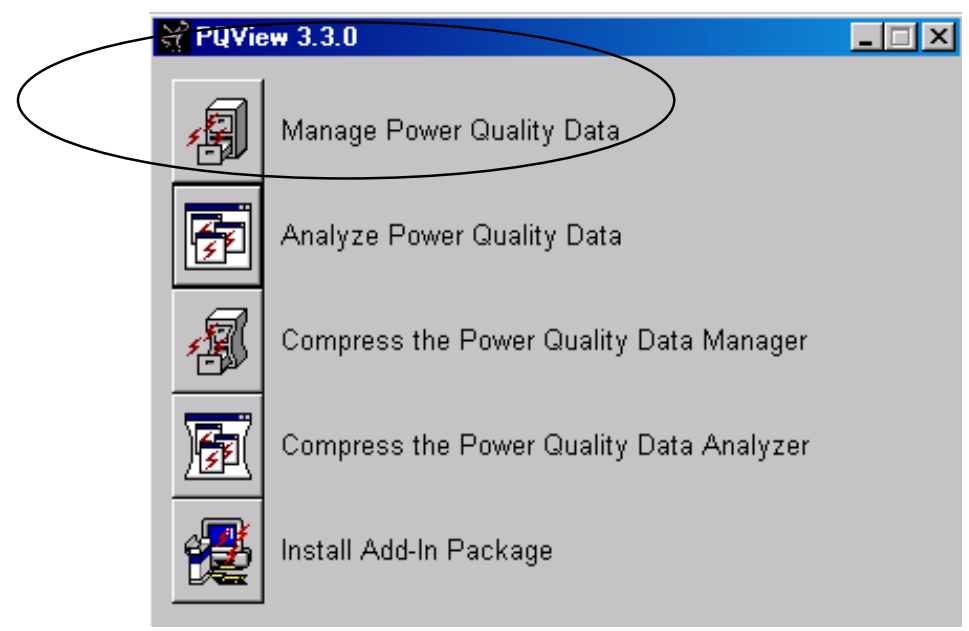

Figure 13. PQView panel

From the menu, select File and then New Power Quality Database (Figure 14).

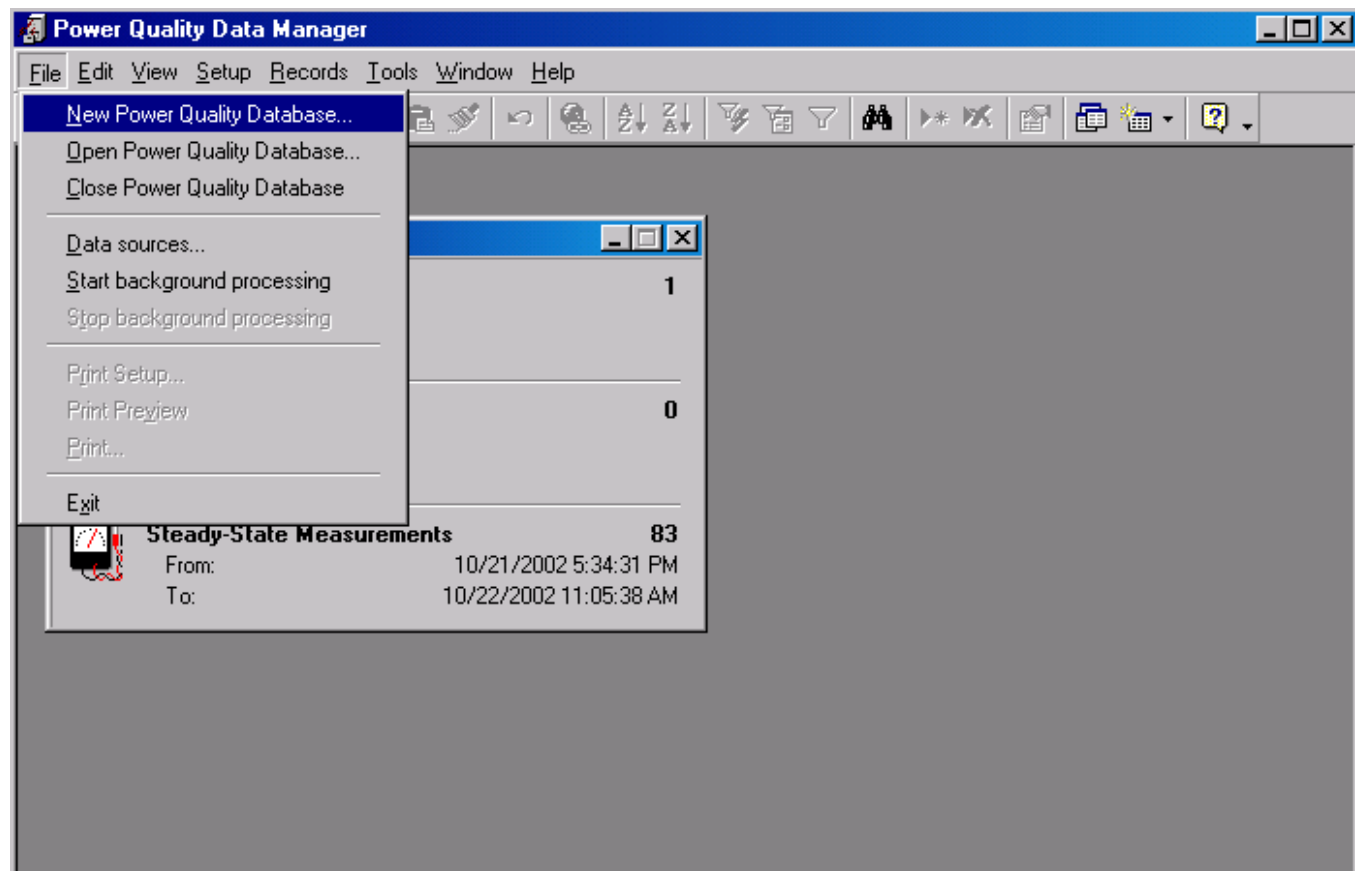

Figure 14. Power Quality Data Manager 
The Select Template Database window is displayed (Figure 15). It is here that the type of template to be used for data import is selected. Select the Normal PQView 3.3 Database by highlighting it and selecting the OK button. This is the latest template, and it contains the most channels.

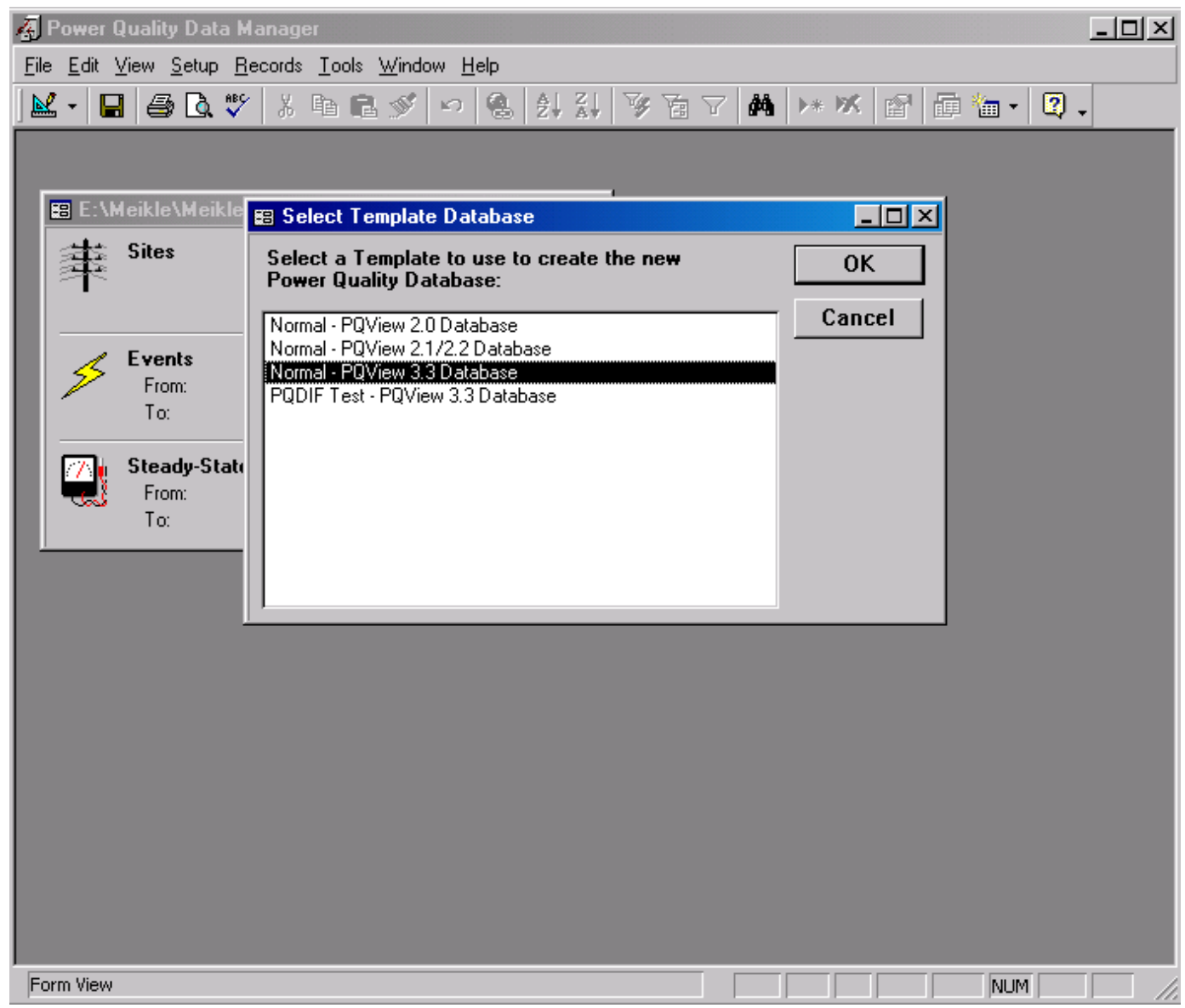

Figure 15. Select Template Database window

The New Power Quality Database window is displayed (Figure 16). Browse to the location where the new PQView database will reside. In the File Name field, enter the name of the database being created. Select the Save button. 


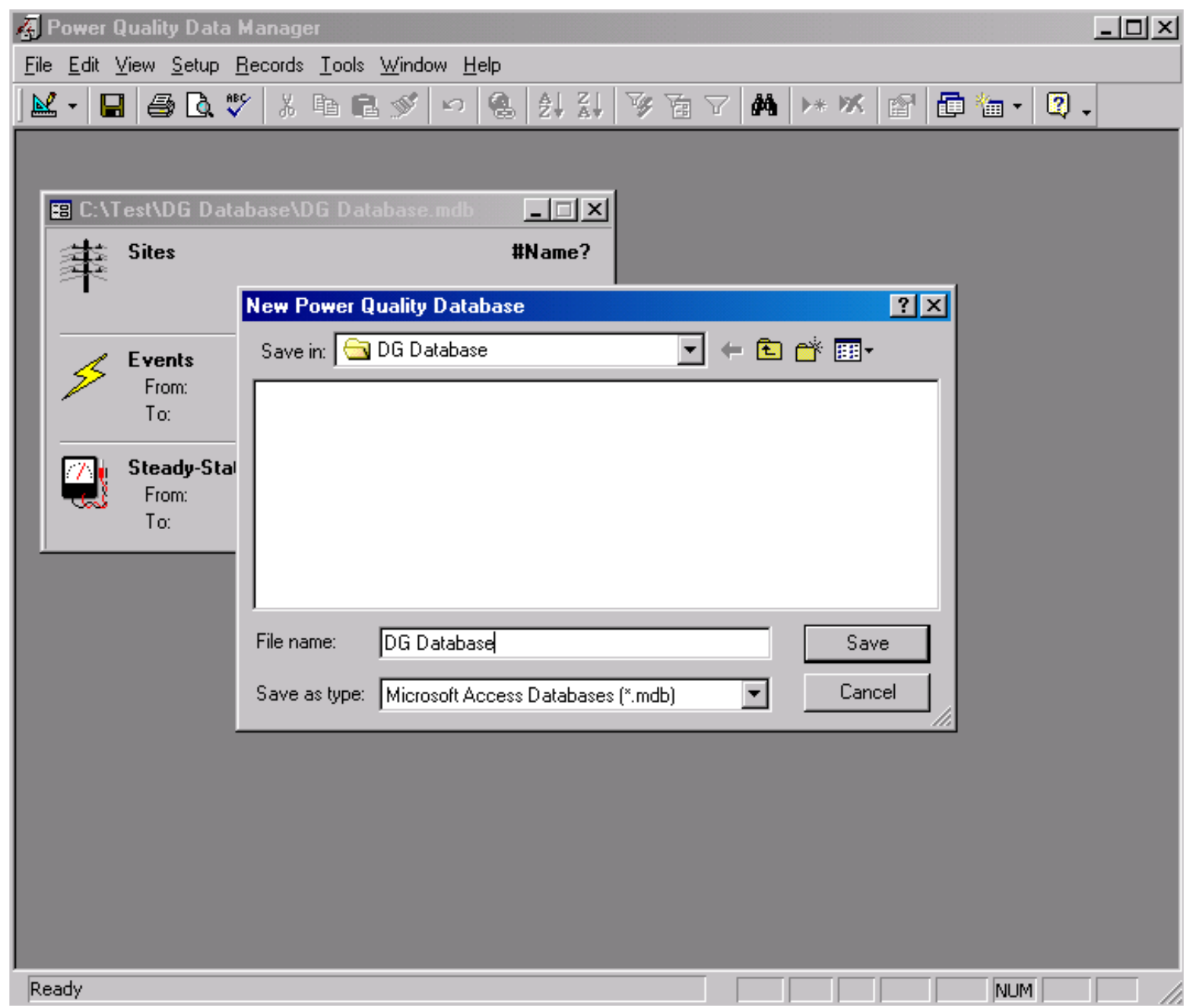

Figure 16. New Power Quality Database window

The newly created database is displayed in the PQView Main window. Note that, at this point, there are no sites, events, or steady-state measurements (Figure 17).

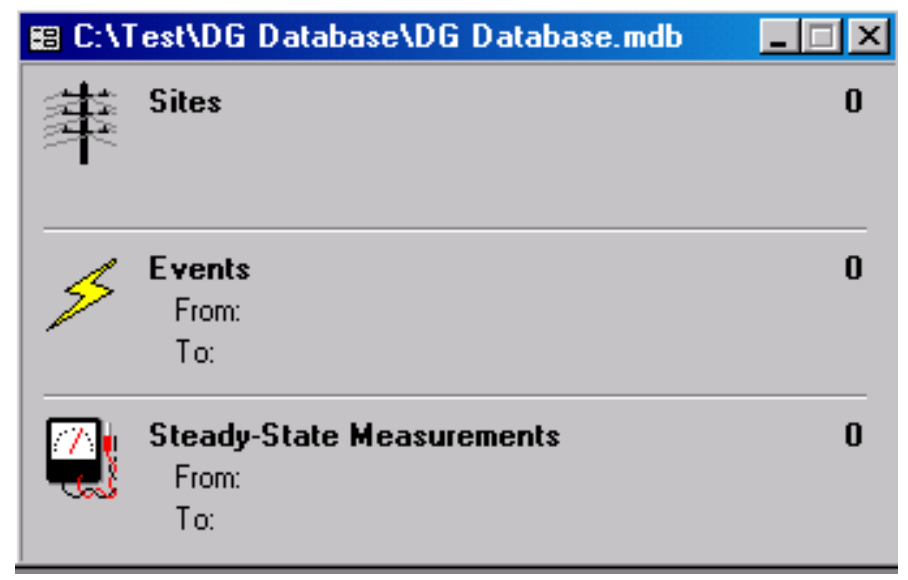

Figure 17. New database 


\subsection{Creating a New Data Source}

To import the sites and their associated measurements into the database, a data source must be created. From the menu, select File and then Data sources (Figure 18).

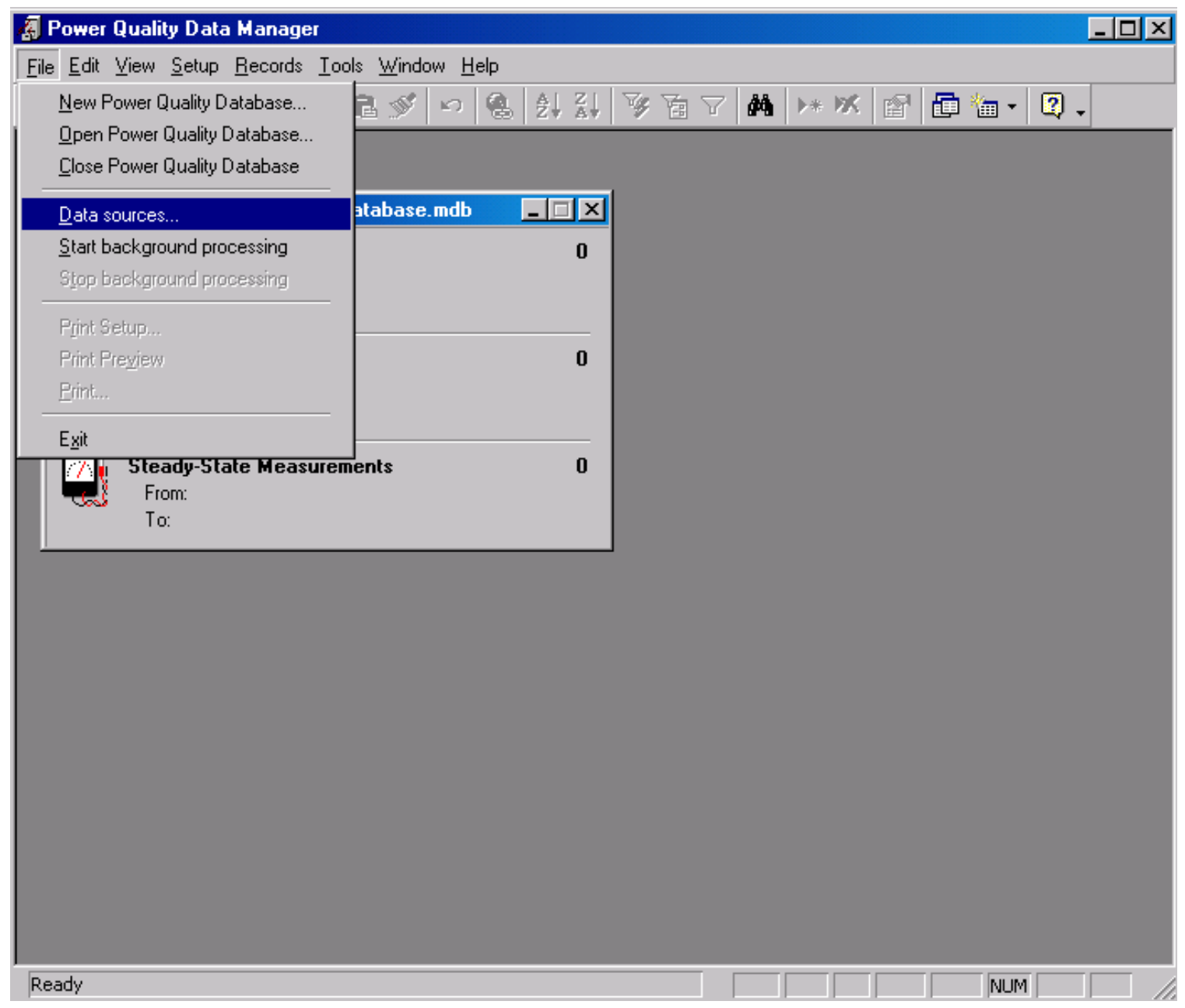

Figure 18. Creating a new data source

The Data Sources window is displayed (Figure 19). Select the New button. 
Use this form to create, configure, enable, import, and delete data sources.

\begin{tabular}{|l|l|l|}
\hline \multicolumn{1}{|c|}{ Last Import Time Close } \\
\hline Active Name & Next Import Time & New... \\
\hline
\end{tabular}

Figure 19. Data Sources window

The Data Source Setup window is displayed (Figure 20). It is here that all information related to importing the data into the database is entered. In the Name field, enter a descriptive name for the data to be imported (e.g., NodeCenter Data). A brief description may also be entered in the Description field. This field, however, is not required.

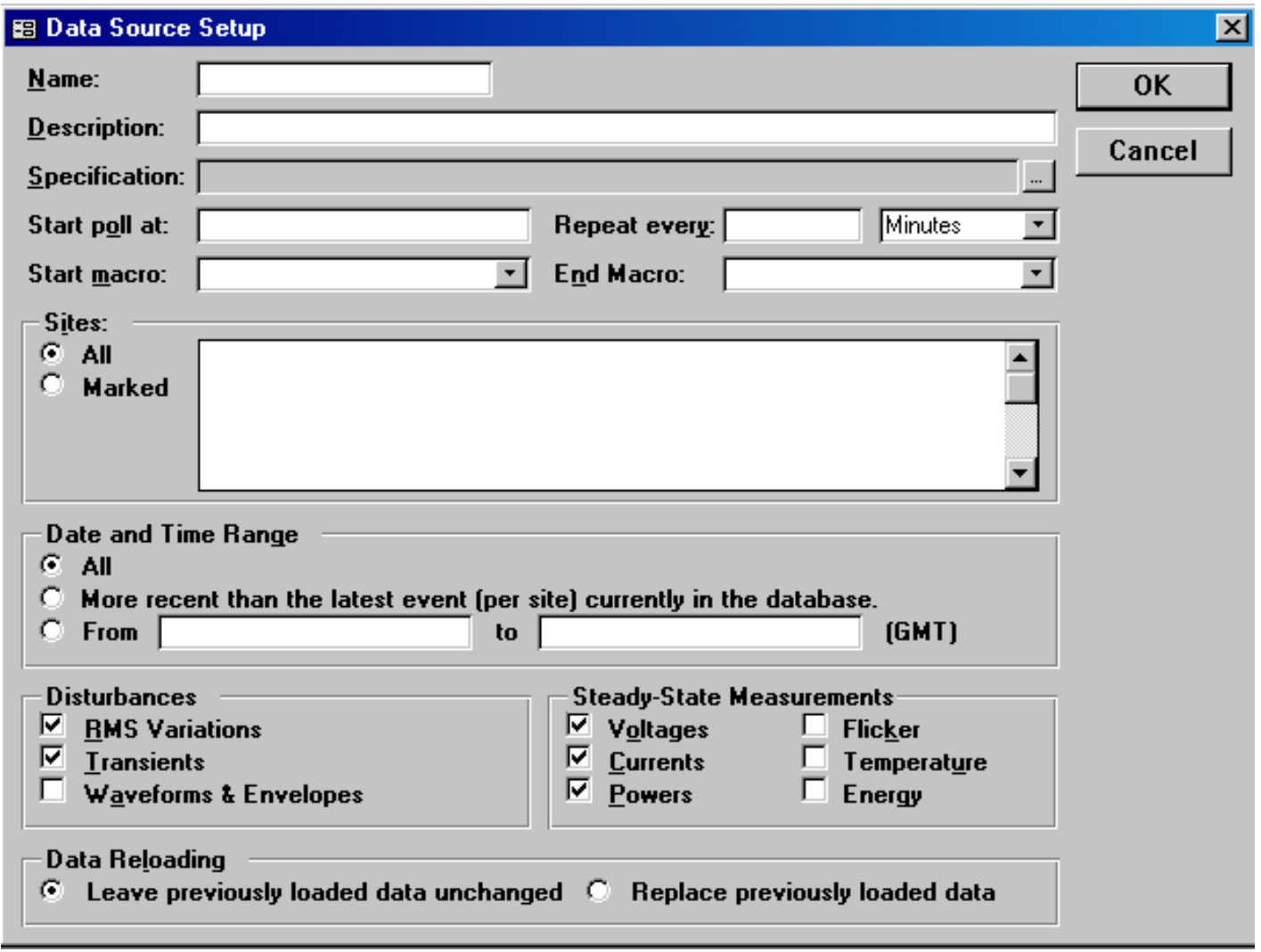

Figure 20. Data Source Setup window 


\subsubsection{Designating the Data Format and Location}

Select the $\cdots$ button next to the Specification field. The Data Store Format window is displayed (Figure 21). Highlight the type of data to be imported into this data source. In this case, highlight NodeCenter Import and select the OK button.

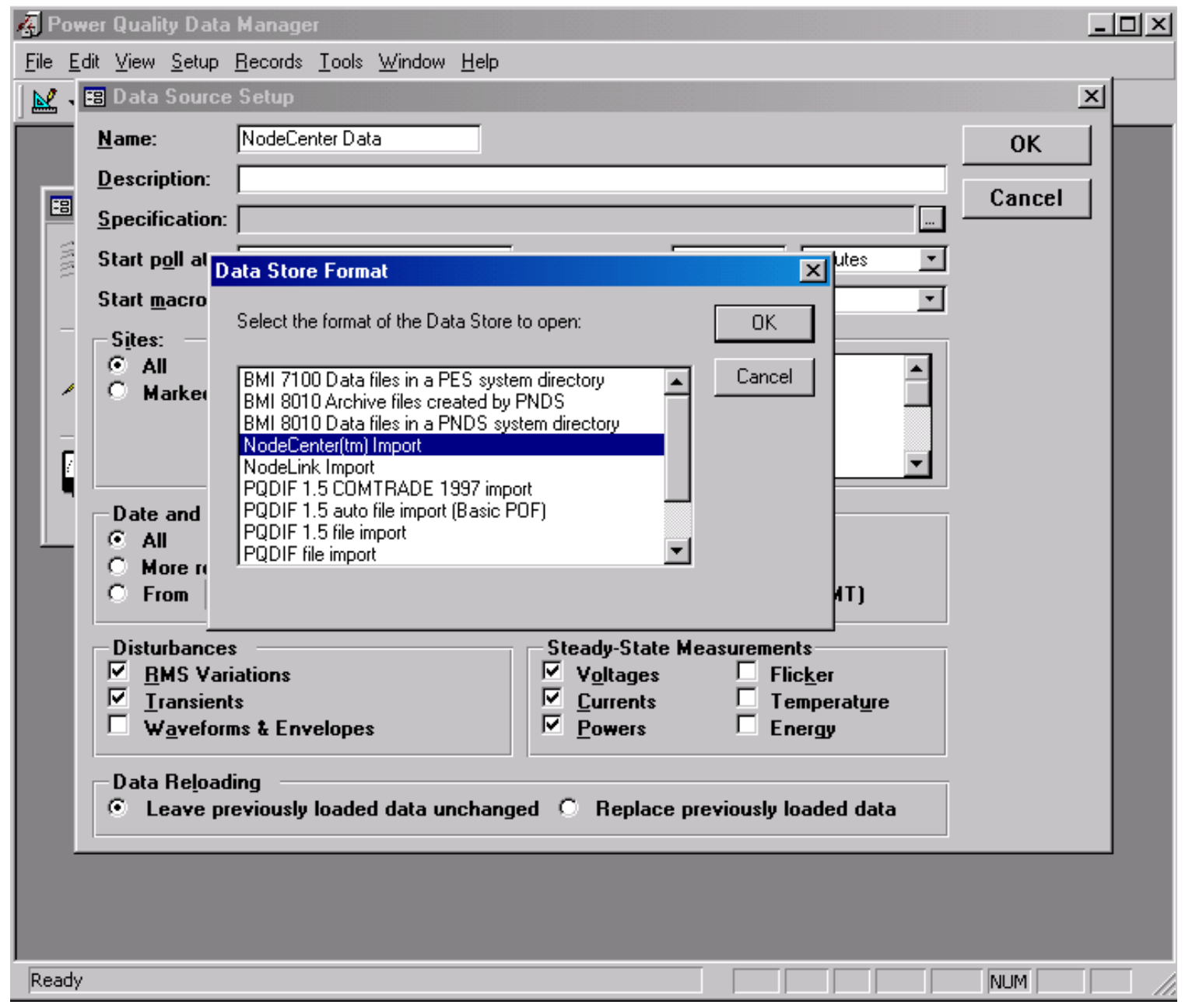

Figure 21. Data Store Format window

It is then necessary to specify the location where the NodeCenter (raw PQDIF data) resides (Figure 22). 


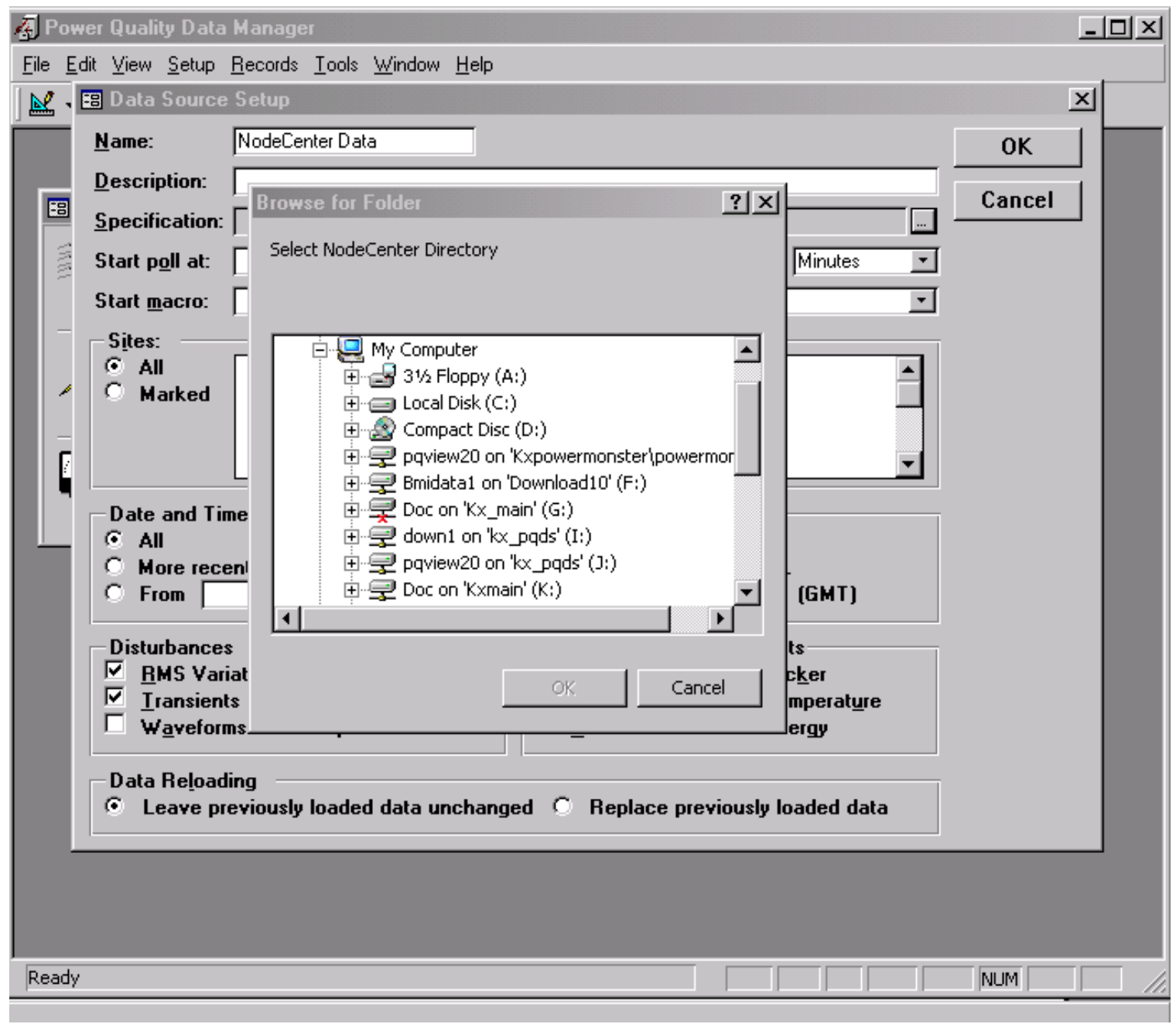

Figure 22. Specifying data location

Browse to the location of the PQDIFPOF folder on the NodeCenter server. Open the folder and select the OK button (Figure 23). 


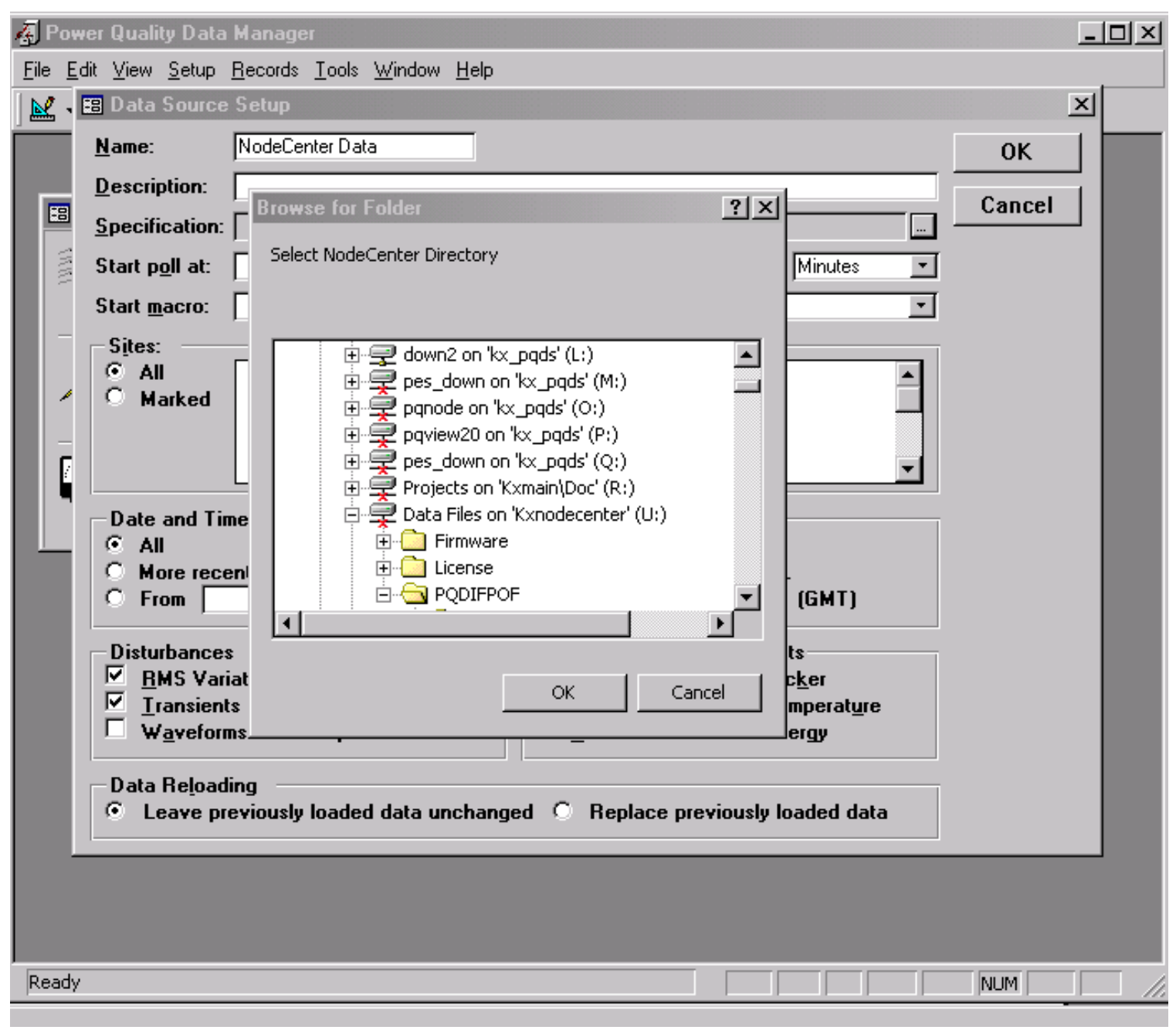

Figure 23. PQDIFPOF folder on the NodeCenter server

\subsubsection{Sites}

A list of all the sites downloaded by NodeCenter is displayed in the Sites section (Figure 24). If specific sites are to be imported, individually select the sites by enabling the checkboxes beside their names. The Marked radio button is automatically enabled. If all sites are to be imported into the database, enable the All radio button. 


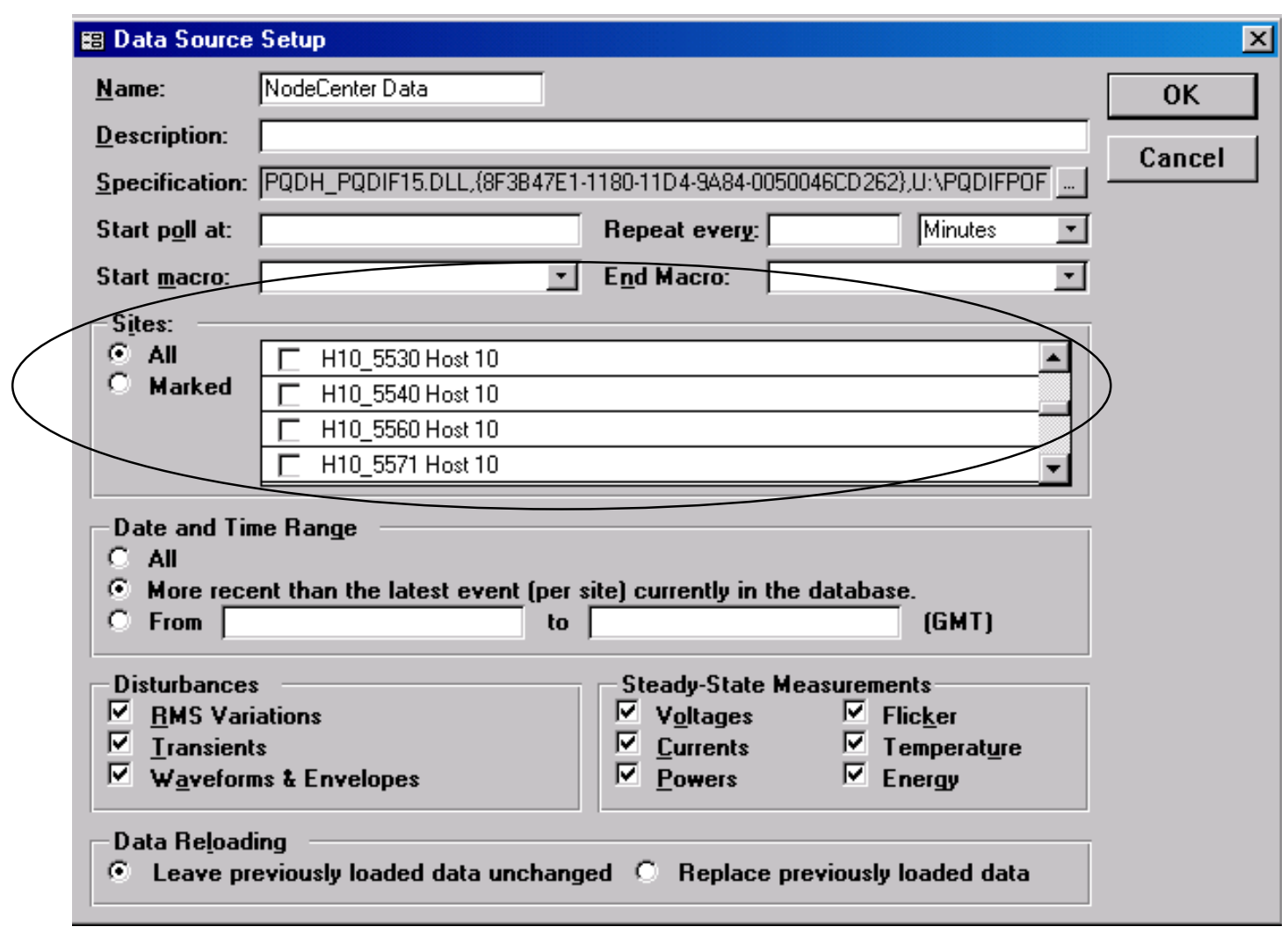

Figure 24. Data Source Setup window: sites

\subsubsection{Automatic Importing}

Data can be automatically imported into PQView. The time for the automatic download to begin is entered into the Start Poll field. Imports may occur as frequently as once every minute. A reasonable interval is once a day. This is entered into the Report Every field. The first box designates the frequency of the import. The second box indicates the unit of time. Completion of the automatic import setup is performed in the main window of PQDM by selecting File and then Start background processing (Figure 25).

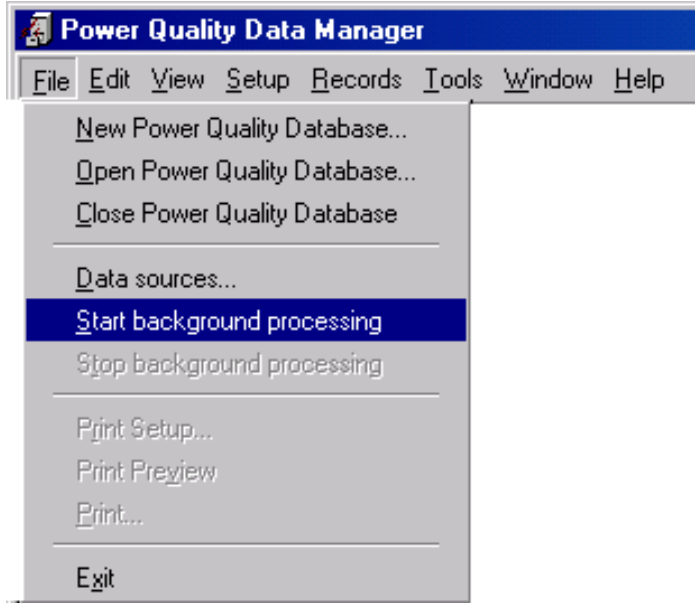

Figure 25. Start Background Processing for automatic downloading 


\subsubsection{End Macro}

Crucial to importing distributed generation data is the Standard End macro. This macro will be explained in detail in the Setting Up the Standard End Macro Section. From the Data Source Setup window, select Standard End Macro in the End Marco drop-down box (Figure 26).

\section{$\begin{array}{llll}\text { Start macro: } & \pm \text { End Macro: Standard End Macrd }\end{array}$}

Figure 26. End Macro: Standard End Macro selected

\subsubsection{Date and Time Range}

For date and time range, there are three options for importing data.

- All

The most common use of this option is a "one time" import.

- More recent than the latest event (per site) currently in the database

This option is chosen when more imports are scheduled. It is the most efficient way to import data.

- From (blank) to (blank) (GMT)

This date and time range option is for specifying a date and time range.

When importing distributed generation data, select the More Recent Than the latest Event (Per Site) Currently in the Database" radio button. Use this option for the initial import of data as well.

\subsubsection{Disturbances and Steady-State Measurements}

Select the options in the Disturbances and Steady-State Measurements boxes that are to be imported into the newly created database.

\subsubsection{Data Reloading}

In the Data Reloading section, enable the Leave Previously Loaded Data Unchanged radio button (Figure 27). This will ensure that importing starts after the last date and that data are not re-imported over and over again.

Data Reloading

c Leave previously loaded data unchanged $C$ Replace previously loaded data

Figure 27. Data Reloading: Leave previously unloaded data unchanged

After all setup selections are made, close the Data Source Setup window by selecting the OK button. Select the Import button from the Data Sources window to initiate an initial import (Figure 28). 


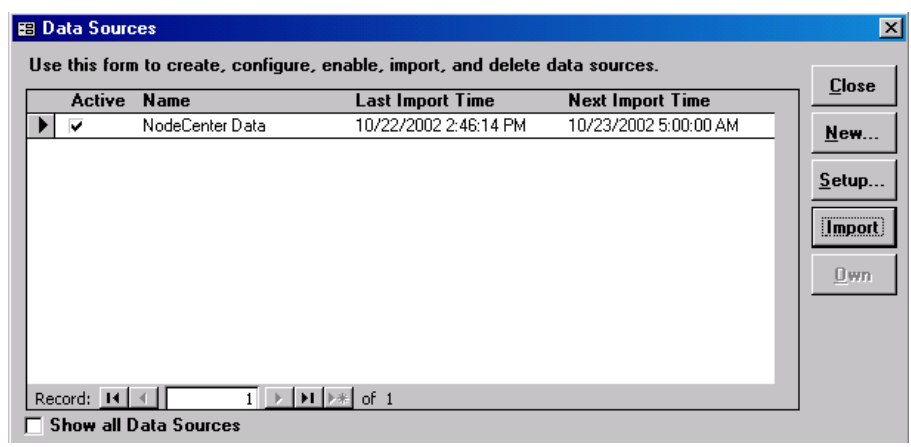

Figure 28. Data Sources window: initiating import

Return to the main Power Quality Data Manager window after the initial data import (Figure 29). Note that Sites now indicates the number of sites for which data has been imported. Also indicated are the number of events and steady-state measurements imported.

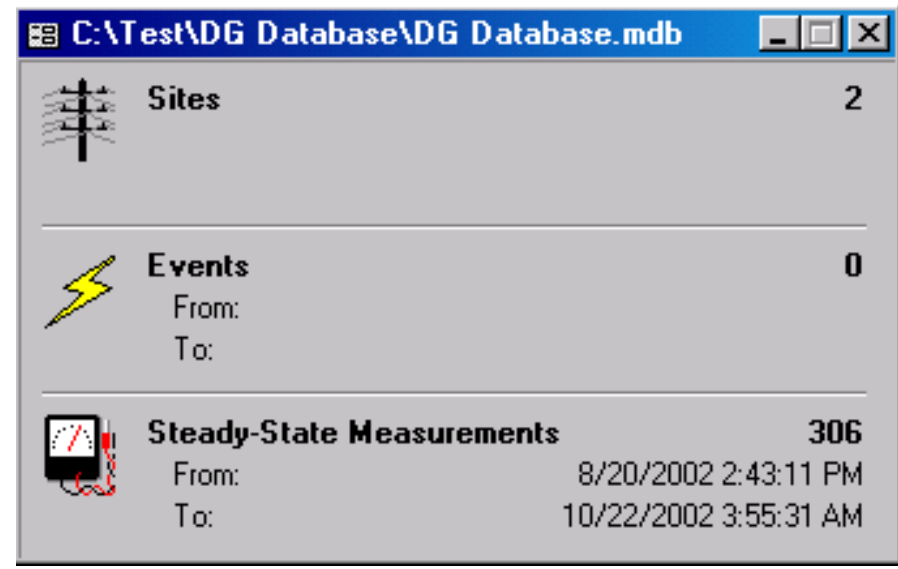

Figure 29. Sites, events, and steady-state measurement count

Site information must now be assigned to each of the sites in the database. Open the Sites window (Figure 30) by double-clicking the Sites icon. 


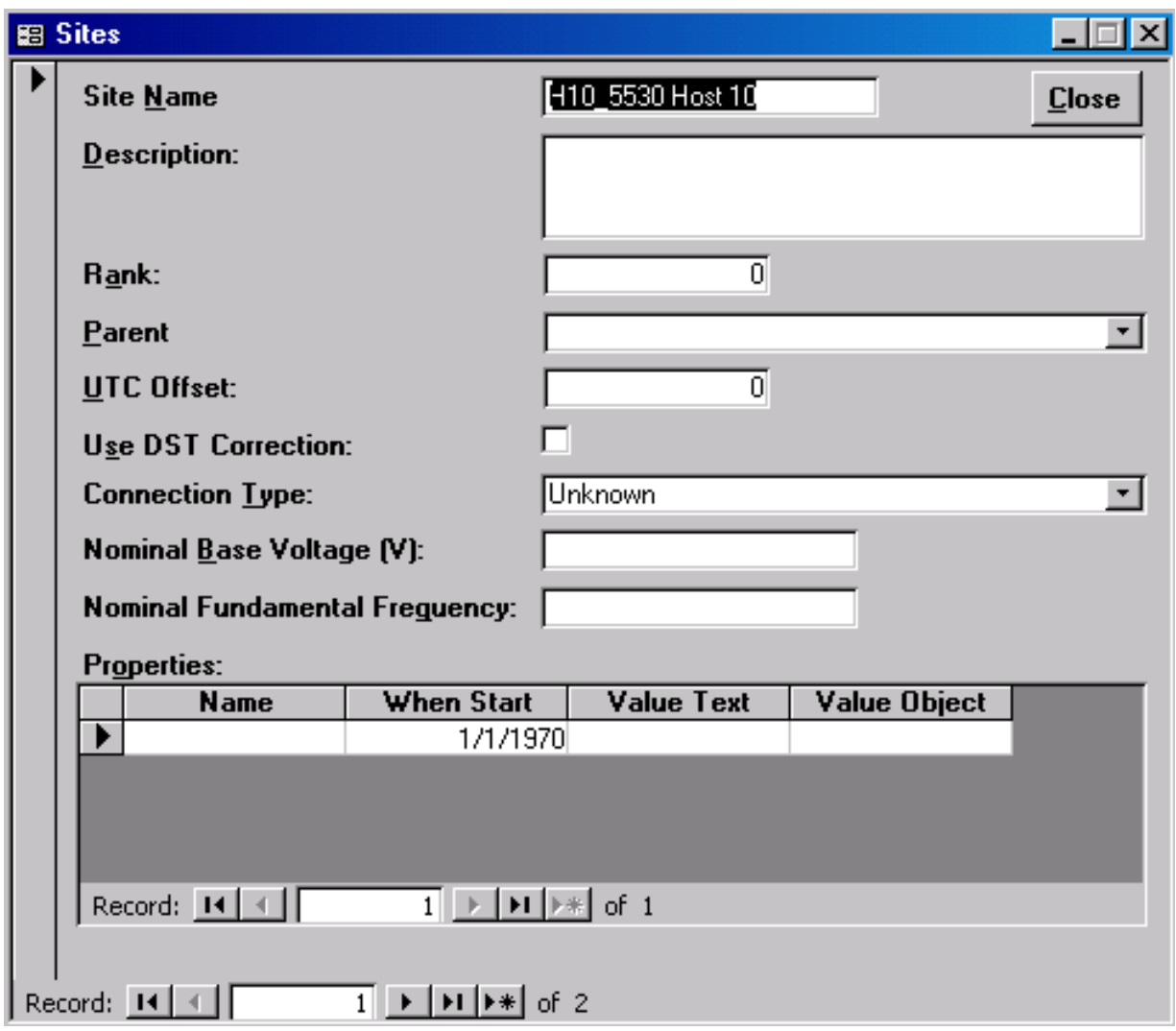

Figure 30. Sites window

Table 1 lists each field in the Sites window and its description.

Table 1. Sites Window Fields

\section{Field}

Site Name

Description

Rank

Parent

UTC Offset

\section{Use DST Correction}

Connection Type

Nominal Base Voltage (V)

Nominal Fundamental

Frequency

Properties
Description

The name of a data-gathering site

Any relevant information

A way of ordering, a sorting rank that overrides the name for displayed values

A reference to the parent site record, used to create a hierarchy for the sites

Number of hours to add to the UTC time to convert it to local time

Checking the box activates the daylight-saving time adjustment

Types of connections

Nominal base voltage

Nominal fundamental frequency

List of properties associated with the site 
It is not necessary to enter information into all of these fields. Fields that should be considered mandatory are UTC Offset, User DST Correction, Connection Type, Nominal Base Voltage, and Nominal Fundamental Frequency.

Properties can be assigned to each site (Figure 31). A common property assignment is PQWebAlias, a necessary property if the data are to be displayed via PQWeb. Properties for filtering data might also be assigned.

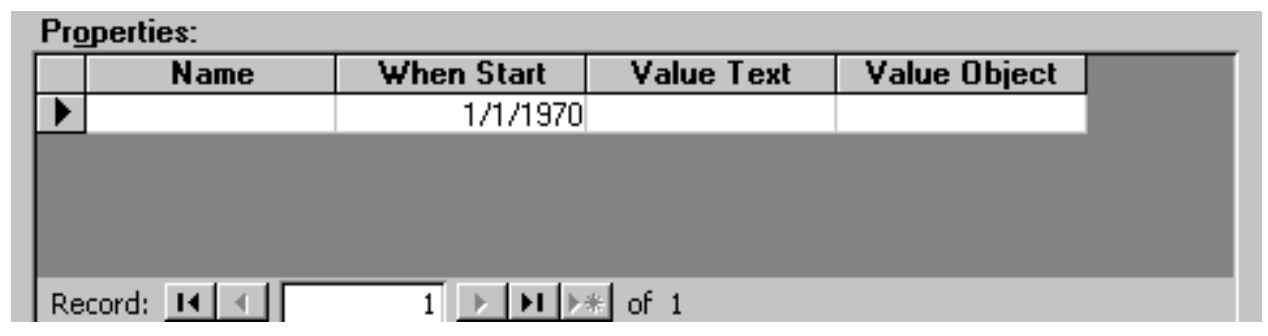

Figure 31. Properties fields

\subsection{Automatic Importing}

To enable automatic importing, select File and then Start Background Processing. For an automatic import to occur, PQDM must be left open on the import machine. Importing will automatically be performed at the designated time.

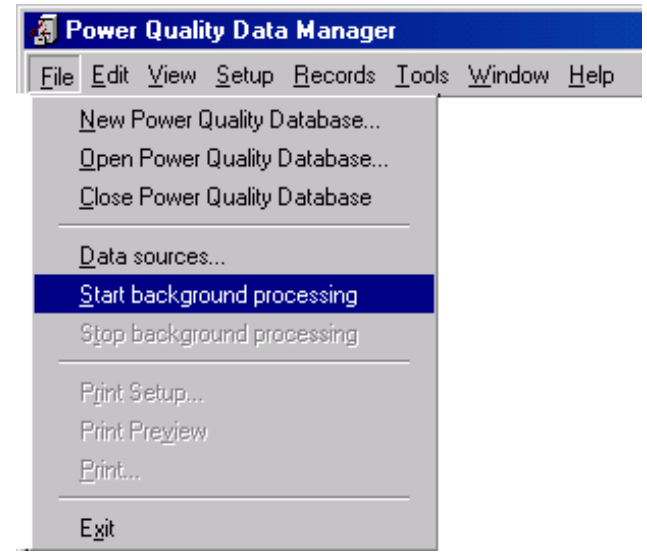

Figure 32. Start Background Processing: automatic importing

\subsection{Setting up the Standard End Macro}

The Standard End Macro lets you specify numerous tasks at the end of a data source import (Figure 33). The Standard End Macro can:

- Delete data

- Create custom queries

- E-mail notifications

- Unpack steady-state measurements

- Control data source imports. 


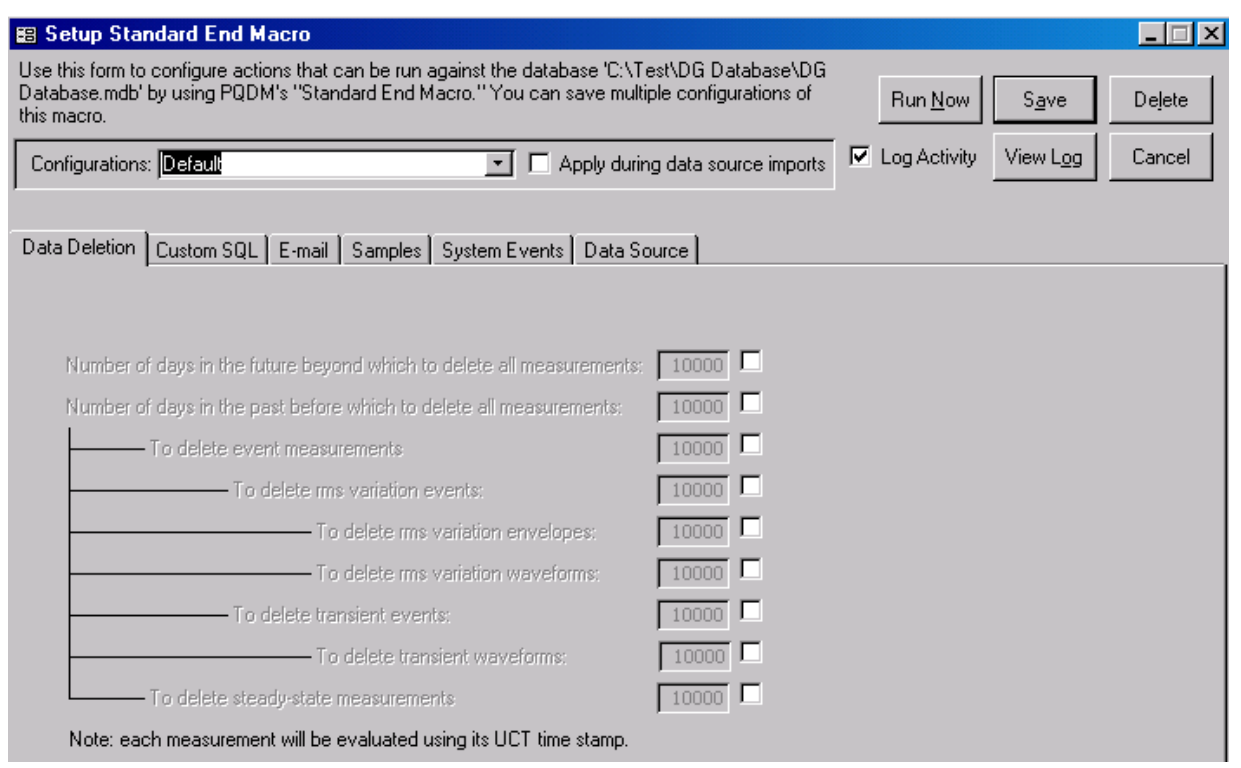

Figure 33. Setup Standard End Macro page

\subsubsection{Deleting Data}

The Data Deletion tab of the Standard End Macro permits automatic deletion of old or bad event data. Future events (or bad data) can be deleted by date and past events by date or type. When deleted by date, an event is evaluated according to its UTC time stamp.

The default date evaluation is 10,000 days (approximately 27 years).

The indenting is a visual hint of the hierarchy of table relationships. For example, deleting "rms variation events" deletes associated "rms variation envelopes" and "rms variation waveforms."

\subsubsection{Custom Queries}

The Custom SQL tab (Figure 34) of the Standard End Macro can accept up to three SQL statements to be executed against the connected database after data have been imported. Running custom queries after data are imported is useful, for example, when an instrument is prone to capturing false measurements. You can construct an SQL statement that deletes the false measurements each time you import from that instrument.

If your database is in Microsoft Access, you can type the name of a query in any of the boxes instead of an actual SQL statement. Queries are stored in PQDM itself (e.g., "C:Program Files $\backslash P Q V i e w 30 \backslash p q d m . m d b ")$. 


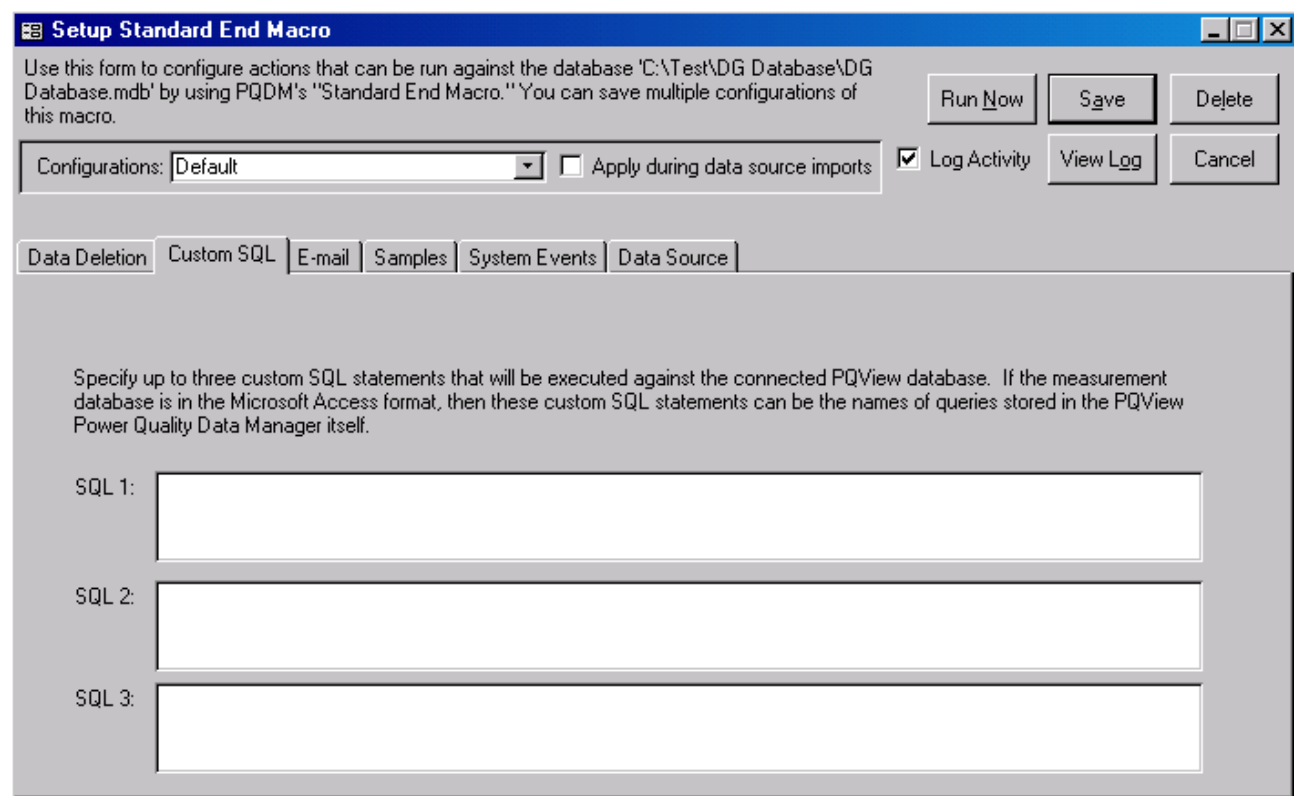

Figure 34. Custom SQL tab

\subsubsection{E-Mail Notifications}

The E-mail tab (Figure 35) of the Standard End Macro replaces the "Sag Mail End Macro." Its only function is to enable e-mail notifications. To view the PQView Notifications tool (Figure 36), select the Configure button.

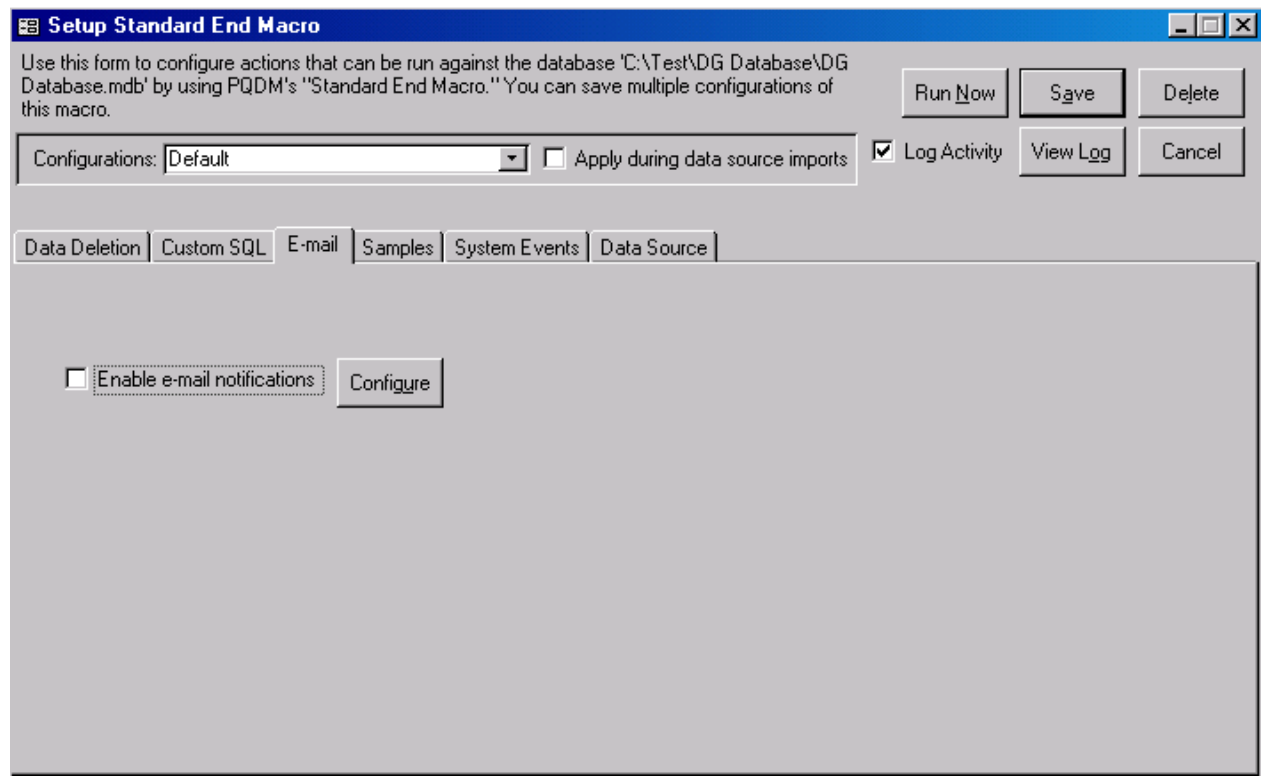

Figure 35. E-mail tab 


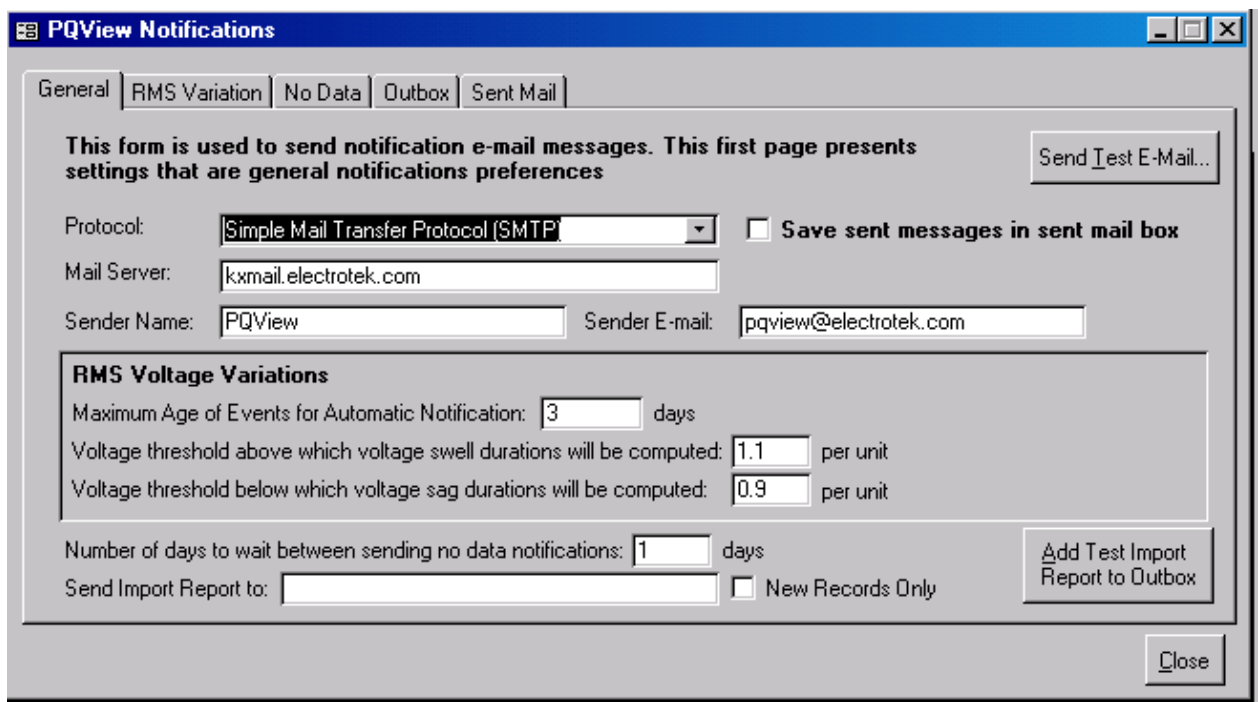

Figure 36. PQView Notifications

\subsubsection{Unpacking Steady-State Measurements}

The Samples tab of the Standard End Macro increases the usability of data inside PQView with other applications. Measurements are normally stored in PQView in a binary format, but with this tab, they can be changed for specific sites and channels. Each steady-state sample can become a record in a table, opening up the data to any program that can read Microsoft Access databases. The Samples tab cannot be set up until the completion of an initial import because the sites are not available until that time.

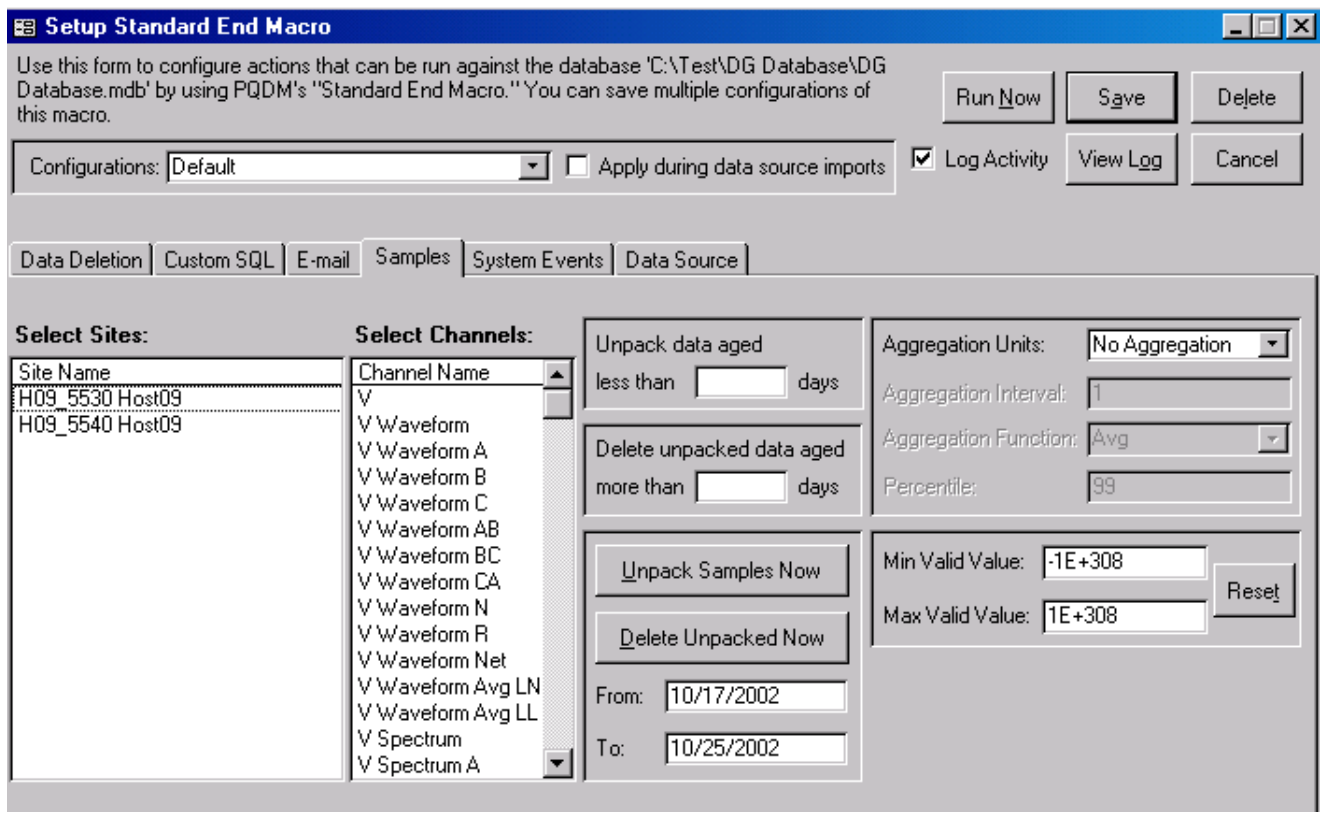

Figure 37. Samples tab

Using this tab, you can automatically or manually unpack steady-state samples. You can also automatically or manually delete previously unpacked samples. In any case, you must first select one or more sites and one or more channels. 
To enable automatic unpacking, type the number of days to be used as the lower threshold for the age of the data to unpack. Previously unpacked data are replaced if found. To maintain a window of unpacked samples online, type the number of days to be used as the upper threshold for the age of the unpacked data to delete.

To manually unpack samples, type a date range in the From and To boxes, and select the Unpack Samples Now button. To manually delete previously unpacked samples, type a date range in the From and To boxes, and then select the Delete Unpacked Now button.

Save your setups by selecting the Save button, and check the Apply During Data Source Imports box to ensure unpacking occurs after the import.

\subsubsection{System Events}

Measurement records and system event records can be automatically correlated (Figure 38).

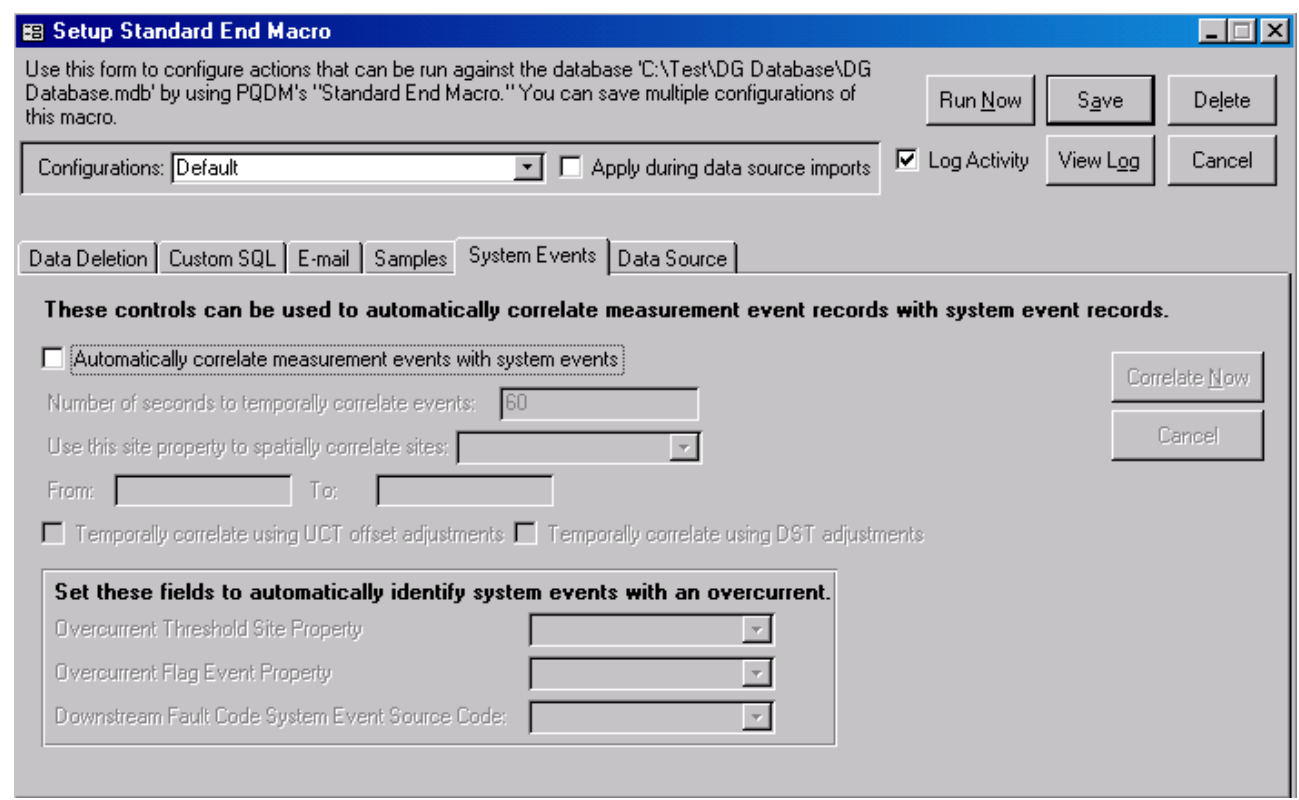

Figure 38. System Events tab

\subsubsection{Controlling Data Source Imports}

The Data Source tab of the Standard End Macro (Figure 39) sets up PQDM to perform these tasks after a specific data source has been imported:

- Compact and repair the connected database

- Open another database to begin its data source imports (daisy-chaining)

- Quit the program.

To access the features of this tab, you must first select a data source. 


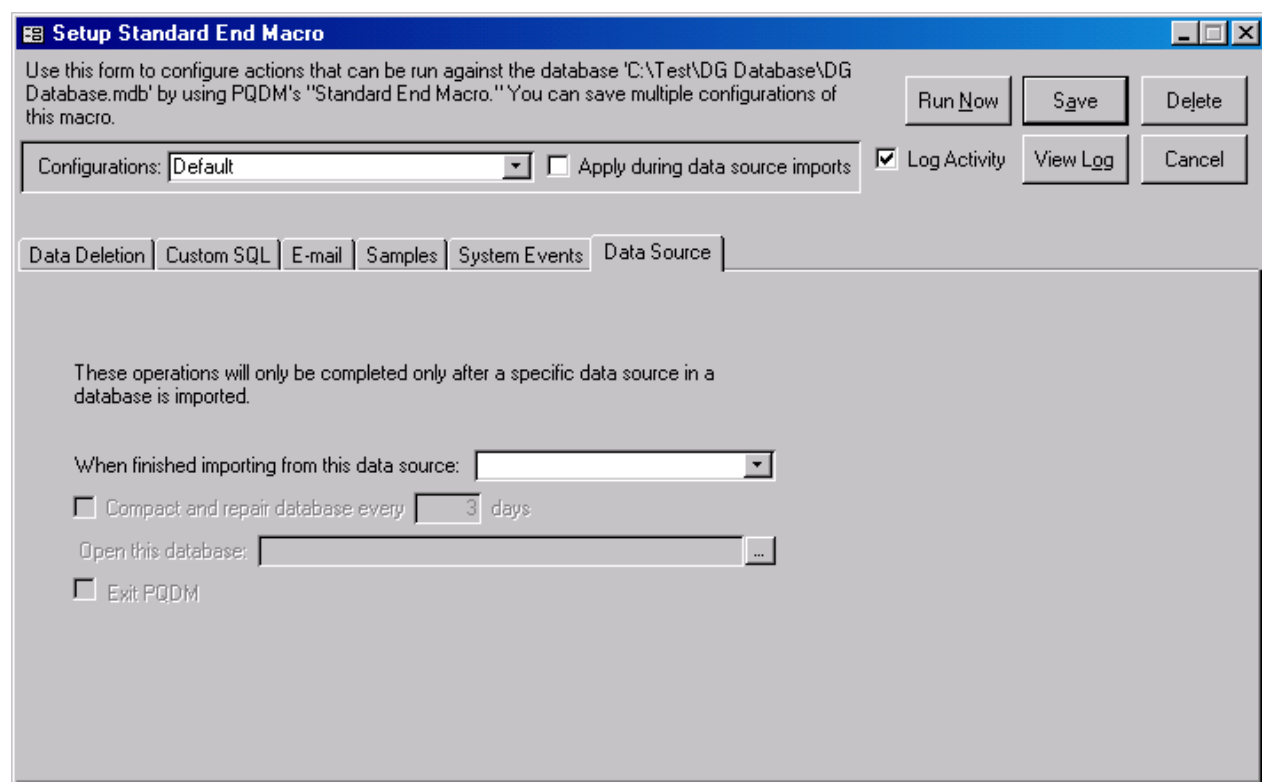

Figure 39. Data Source tab

If a perpetual daisy chain of data source imports is set up, all data sources in the chain must be on the same import schedule (i.e., daily, weekly, etc.). Otherwise, the data source with the longest interval between imports will ultimately control the timing of the imports in the chain.

The example database setup is a Microsoft Access 2000 database. The maximum database is 2 gigabytes. Should a larger database be needed, it is recommended that a SQL database be created. The SQL database can be as large as 1,000 gigabytes. Another advantage of the SQL database is that there is no limitation on the number of users that can access the database at once. 


\section{Using NodeCenter and PQView for Optimum Data Acquisition}

Both NodeCenter and PQView provide detailed information about the data acquisition process and data. After the automated download is complete, review the following status logs and PQView database to ensure that downloads and data acquisition are complete:

- NodeCenter Instrument Contact Status Log

This log provides time-stamped information about the success or failure of contacting InfoNodes.

- NodeCenter Data Download Log

This log provides information about the amount of data downloaded for each

DataNode as well as time-stamped information about download requests and the initiation and completion of data downloaded for specific DataNodes.

- PQView Steady-State Trends

Building steady-state and power trends in the PQView Power Quality Data Analyzer for the data of interest and importing them into Excel spreadsheets provides detailed information.

\subsection{NodeCenter Instrument Contact Status Log}

The NodeCenter Instrument Contact Status Log provides time-stamped information about InfoNode communication. This information includes:

- Initiation - initiation of communications (Figure 40)

\begin{tabular}{|l|l|l|l|}
\hline $\begin{array}{l}\text { 2002-12-09 } \\
09: 18: 15.536 Z\end{array}$ & Host 10 & Host 10 & $\begin{array}{l}\text { Communication session with downloadable instrument Host 10 } \\
\text { initiated. }\end{array}$ \\
\hline
\end{tabular}

Figure 40. Initiation of downloadable instrument

- Termination - termination of contact (Figure 41)

\begin{tabular}{|l|l|l|l|}
\hline $\begin{array}{l}\text { 2002-12-09 } \\
09: 18: 30.497 Z\end{array}$ & Host 10 & Host 10 & $\begin{array}{l}\text { Communication session with downloadable instrument Host 10 } \\
\text { terminated. }\end{array}$ \\
\hline
\end{tabular}

Figure 41. Termination of communication session of downloadable instrument

- Failure - failure to communicate (Figure 42).

\begin{tabular}{|l|l|l|l|}
\hline 2002-12-09 & Host 10 & Host 10 & $\begin{array}{l}\text { Communication session with downloadable instrument Host } 10 \\
\text { failed. }\end{array}$ \\
\hline
\end{tabular}

Figure 42. Communication session failed 
If the Instrument Contact Status Log indicates a communication session with an InfoNode failed, a download should be re-initiated. If this download fails, an attempt should be made to contact the InfoNode directly through either DSL or dial-up to confirm that the InfoNode cannot be contacted by any means. This indicates a communication failure or an InfoNode failure.

\subsection{NodeCenter Data Download Log}

The NodeCenter Data Download Log provides time-stamped information about the data associated with each DataNode. This includes:

- Request for data download (Figure 43)

\begin{tabular}{|l|l|l|l|}
\hline $\begin{array}{l}\text { 2002-12-09 } \\
15: 00: 38.515 Z\end{array}$ & NodeCenter & NodeCenter & $\begin{array}{l}\text { User ELECTROTEKkaren requested data download for download group Host } \\
10 .\end{array}$ \\
\hline
\end{tabular}

Figure 43. Request for download

- Initiation of data download (Figure 44)

\begin{tabular}{|l|l|l|l|}
\hline 2002-12-09 & Host 10 & Host 10 & Data download from downloadable instrument Host 10 started. \\
\hline
\end{tabular}

Figure 44. Initiation of download

- Size and completion of data download (Figure 45)

\begin{tabular}{|l|l|l|l|}
\hline $\begin{array}{l}\text { 2002-12-09 } \\
\text { 15:03:41.214Z }\end{array}$ & Host 10 & Host 10 & Data download of monitor Host 10.H10_5530D finished: no data downloaded. \\
\hline
\end{tabular}

Figure 45. Size of data download and completion of download for specific DataNode

- Completion of InfoNode download (Figure 46).

\begin{tabular}{|l|l|l|l|}
\hline 2002-12-09 & Host 10 & Host 10 & Data download from downloadable instrument Host 10 finished. \\
\hline
\end{tabular}

Figure 46. Notice of InfoNode completion of Infonode download

An entry in the log that no data were downloaded for a particular DataNode (Figure 45) is an indication that all data were downloaded from a previous session or that there is a problem with the DataNode. This can be confirmed by checking the Instrument Health Status Summary NodeCenter (Figure 47).

\begin{tabular}{|l|l|l|l|l|}
\hline Host 10 & H10_5530D & GEKV DataNode & Connection failure & 2002-12-09 15:11:41:135Z \\
\hline
\end{tabular}

Figure 47. Instrument Health Status Summary log entry

The log entry (Figure 47) in the Instrument Health Status Summary log shows there is a "connection failure." To confirm this, the InfoNode can be contacted directly. 
If the size of the data download is less than expected, it is recommended that the InfoNode be contacted directly and that the data for the DataNode in question be viewed directly by building a "smart trend" to see if the trend corresponds to data expectations.

\subsection{Steady-State and Power Trends}

Viewing data in the PQView database is another way to locate possible missing data. GEkV meters continuously monitor Phase A voltage. ADAM modules monitor power. By building a steady-state trend of Phase A data in the Power Quality Data Analyzer of PQView or a power trend spanning a specified date range, data gaps may be easily found. These trends can be exported to Microsoft Excel to view the specific date range of the data gap (Figure 48 through Figure 51).

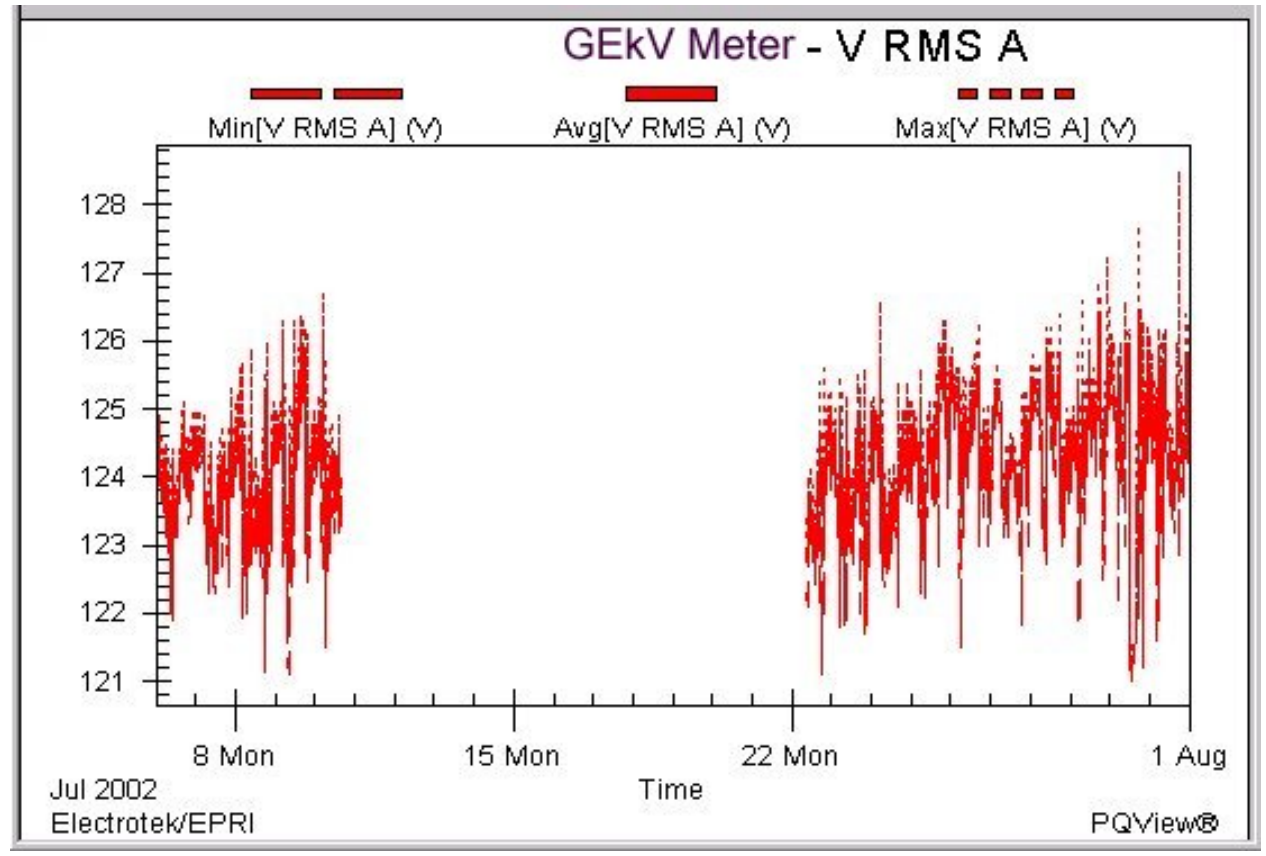

Figure 48. Steady-state trend displaying data gap

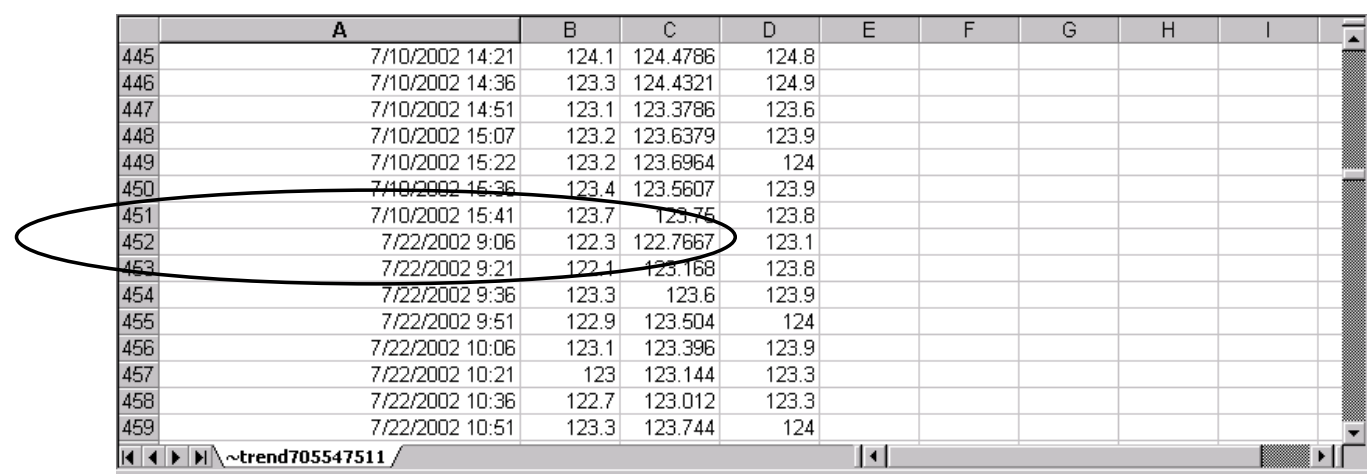

Figure 49. Data points in Microsoft Excel displaying data gap 


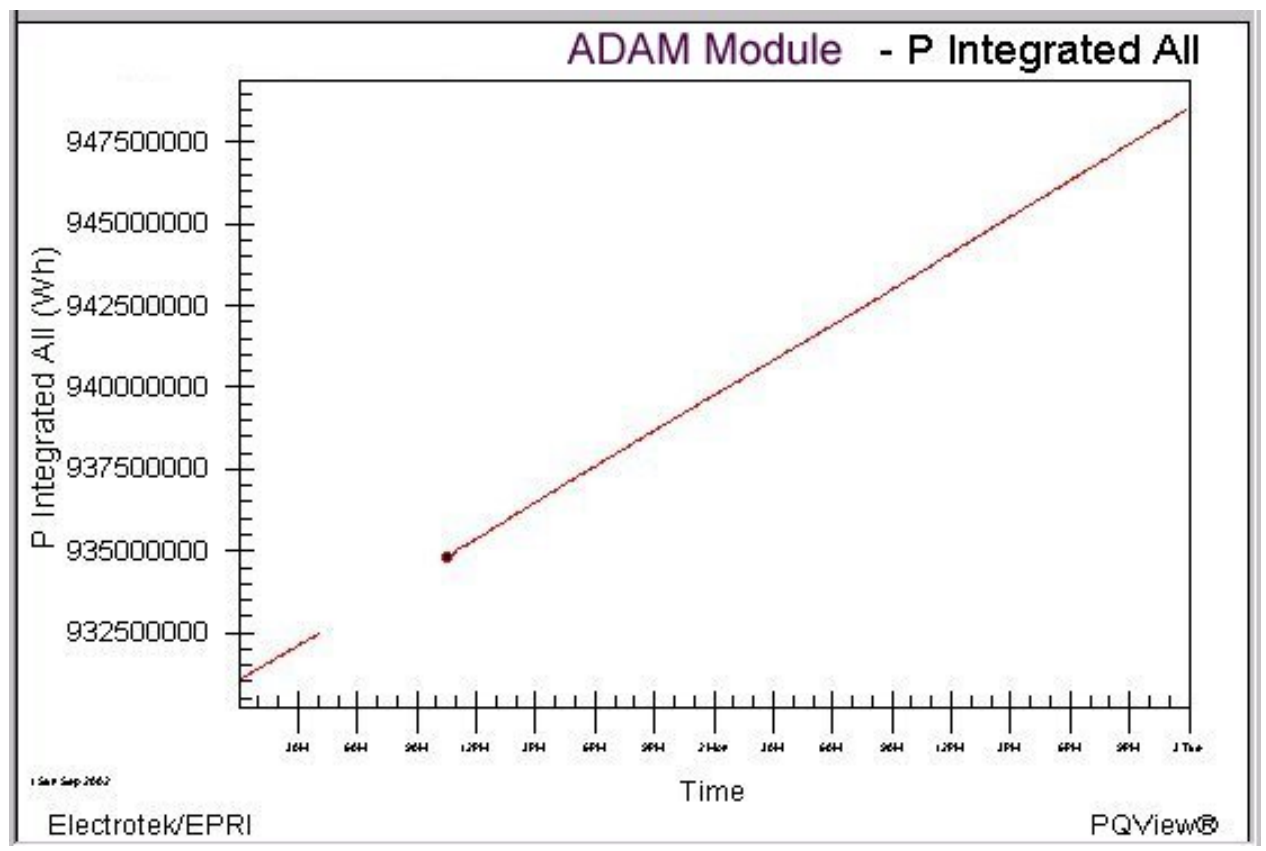

Figure 50. Power trend displaying data gap

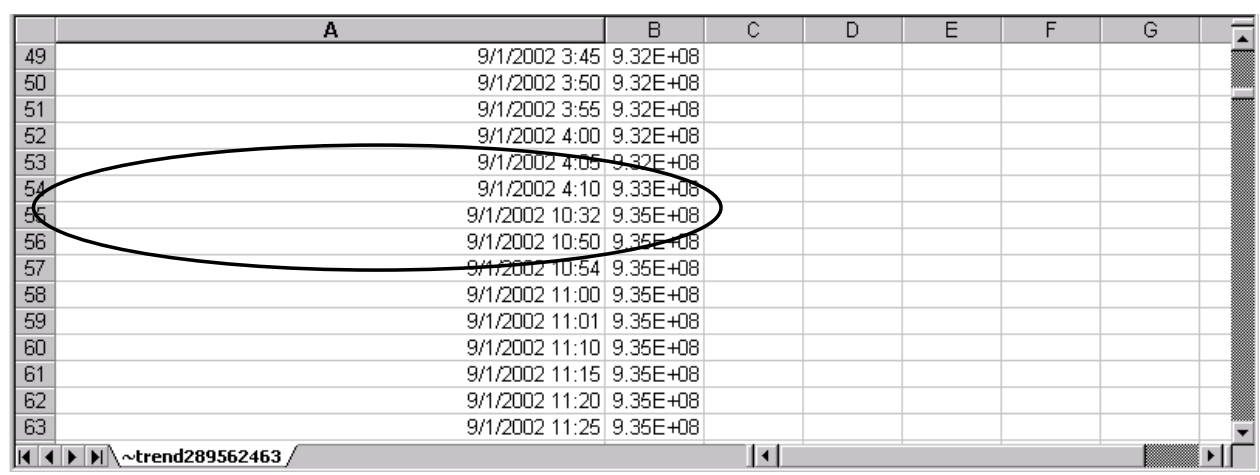

Figure 51. Data points in Microsoft Excel displaying data gap

If there are gaps in any of these trends, there should be an attempt to initiate downloads to ensure that all data have been downloaded from the InfoNode. The InfoNode should be contacted directly to ensure there are no performance issues. 


\section{$4 \quad$ Creating a PQView SQL Database With Microsoft SQL Server 7.0 or Microsoft SQL Server 2000}

By default, PQView 3.0 databases are created using Microsoft Access 2000. Access 2000 database files are limited to $2 \mathrm{~GB}$ and by how many users may access them at once. Microsoft SQL Server increases the file size limit to 1,000 GB and can support more simultaneous database users.

This section will guide the user through the steps of creating a SQL Server database using Microsoft SQL Server 2000. The steps are nearly identical on a computer running SQL Server 7.0. This section will also explain how to create an ODBC Data Source, which must be configured once on each computer that will run the PQView Data Manager or Data Analyzer.

The SQL Server database is created using the SQL Server Enterprise Manager. The enterprise manager provides administrative tools that can:

- Configure all SQL Server options for each registered server

- Create and administer all SQL Server databases, objects, logins, users, and permissions in each registered server

- Define and execute all SQL Server administrative tasks on each registered server

- Design and test SQL statements, batches, and scripts interactively by invoking SQL Query Analyzer.

Creating an SQL Database for use with PQView consists of five steps. These are:

1. Creating the database file

2. Creating the PQView database structure with SQL Query Analyzer

3. Assigning permissions to user accounts used by PQView and PQWeb

4. Bulk-copying data into lookup tables

5. Creating an ODBC data source on each PQView workstation.

\subsection{Creating the Database File}

This task can be completed on the computer running Microsoft SQL Server or on a computer with Enterprise Manager installed that accesses the database server via client access. In either case, the Enterprise Manager session needs to use a login with administrative privileges.

Open Enterprise Manager by selecting Start and then Programs, Microsoft SQL Server, and Enterprise Manager. Expand the tree under Microsoft SQL Servers. From the SQL Server group, select the Server on which you wish to create the database (in this case, Server 1) and highlight Databases (Figure 52). 


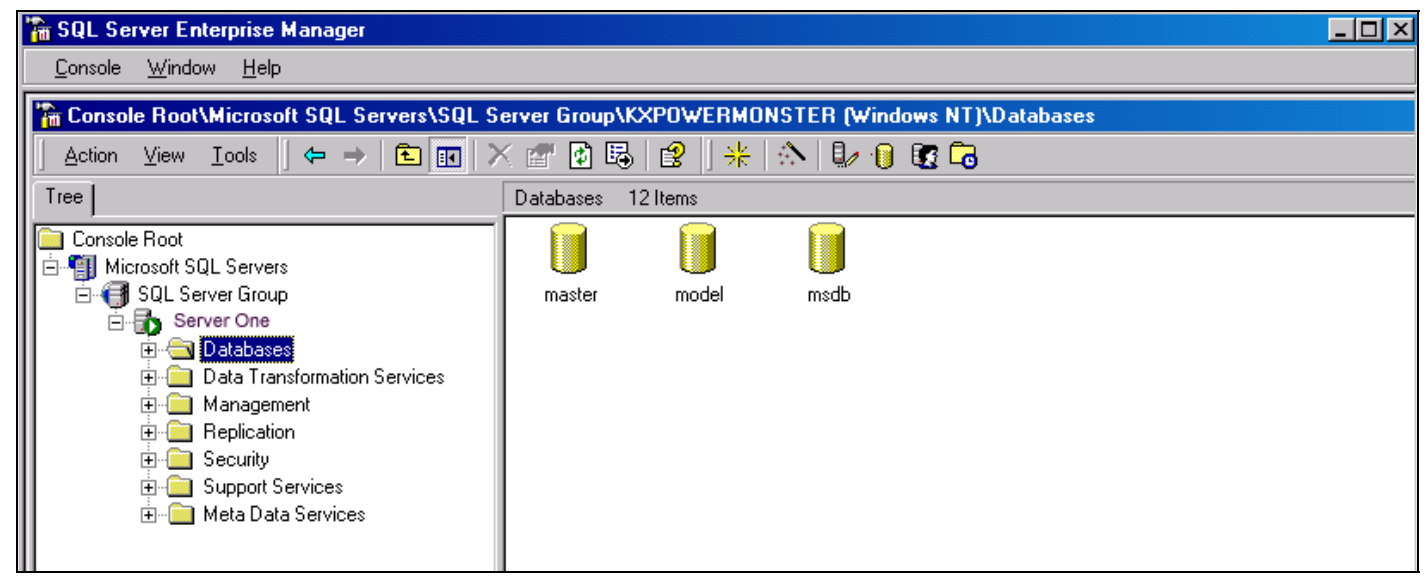

Figure 52. Selecting the server for creating a new database

From the menu, select Action and then New Database (Figure 53).

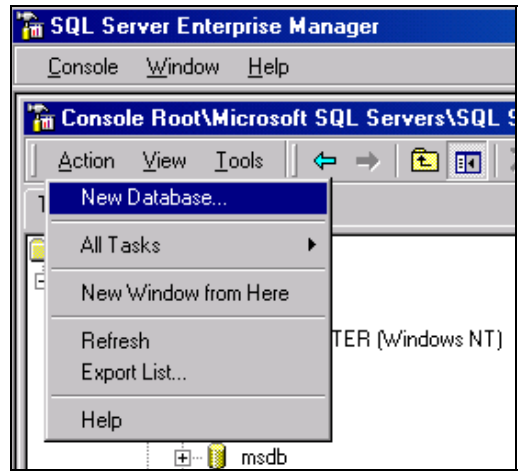

Figure 53. Console Root Menu: Action, New Database

The Data Properties window appears (Figure 54). In the Name field, enter the name of the database you wish to create. 


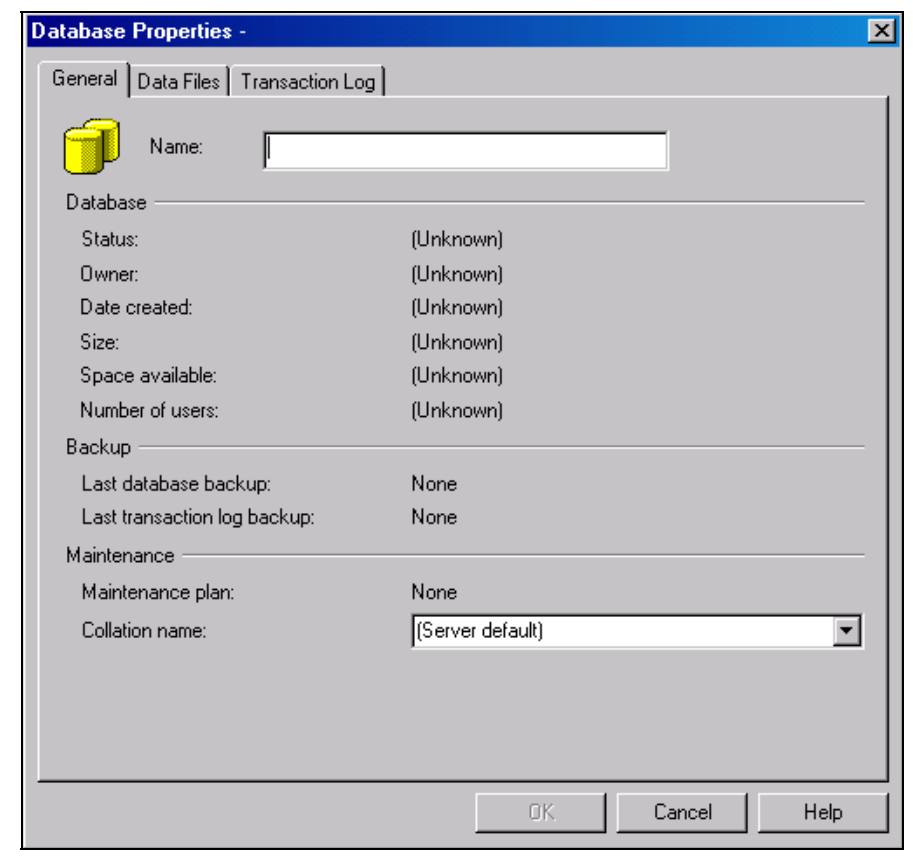

Figure 54. Database Properties window

For example, this database will be named PQVIEW_DEMO_SIGSYS (Figure 55).

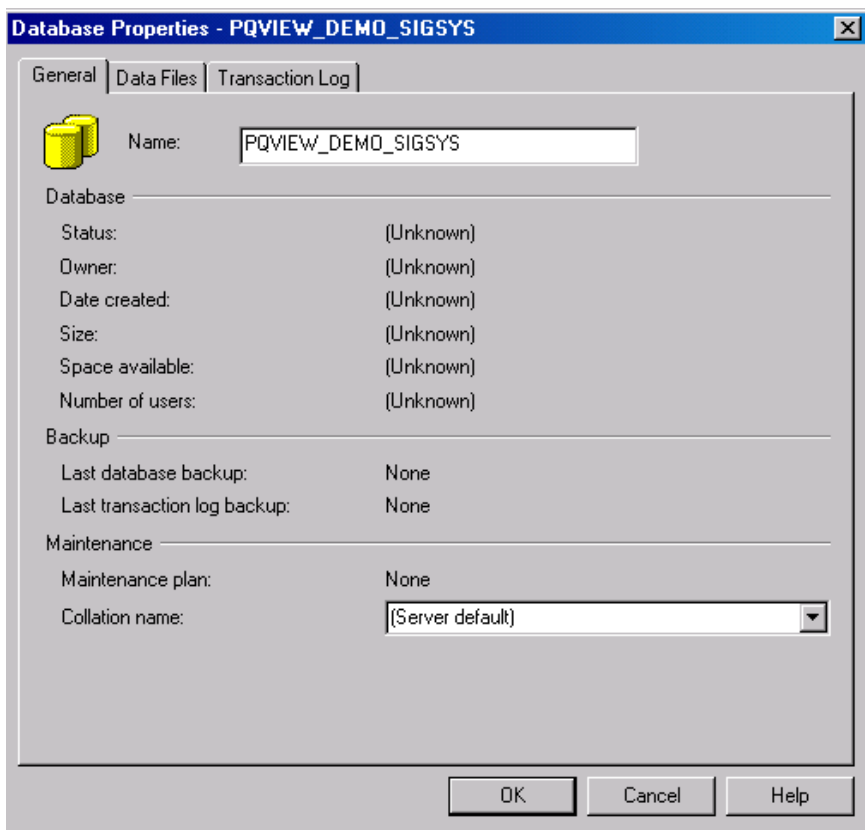

Figure 55. Naming the database

Next, select the Data Files tab. By default, the Automatically Grow File check box and By Percent and Unrestricted File Growth radio buttons are selected (Figure 56). If your database will be smaller than $2 \mathrm{~GB}$, then it is safe to retain these default settings. 
This tab allows you to specify the location of the database file on the server. Note that the default location is usually in the same folder in which SQL Server is installed (under $C: \backslash$ Program Files $\backslash$ ). This probably is not the desired location for the database file because the $\mathrm{C}$ : drive is usually reserved for the operating system and application files. You may instead want to use a folder on a drive reserved for data, such as a D: or an E: drive. The location of the file is best left to the server's database administrator.

If the database will be larger than $2 \mathrm{~GB}$, it is best not to grow it automatically. Specify its full size now. If you run out of file space, you can always expand the database file later. This step may take many minutes to complete if you choose to make a large database. For example, creating a 10-GB database on an unloaded SQL Server computer with two Pentium III 1-GHz microprocessors could take 2 minutes to complete.

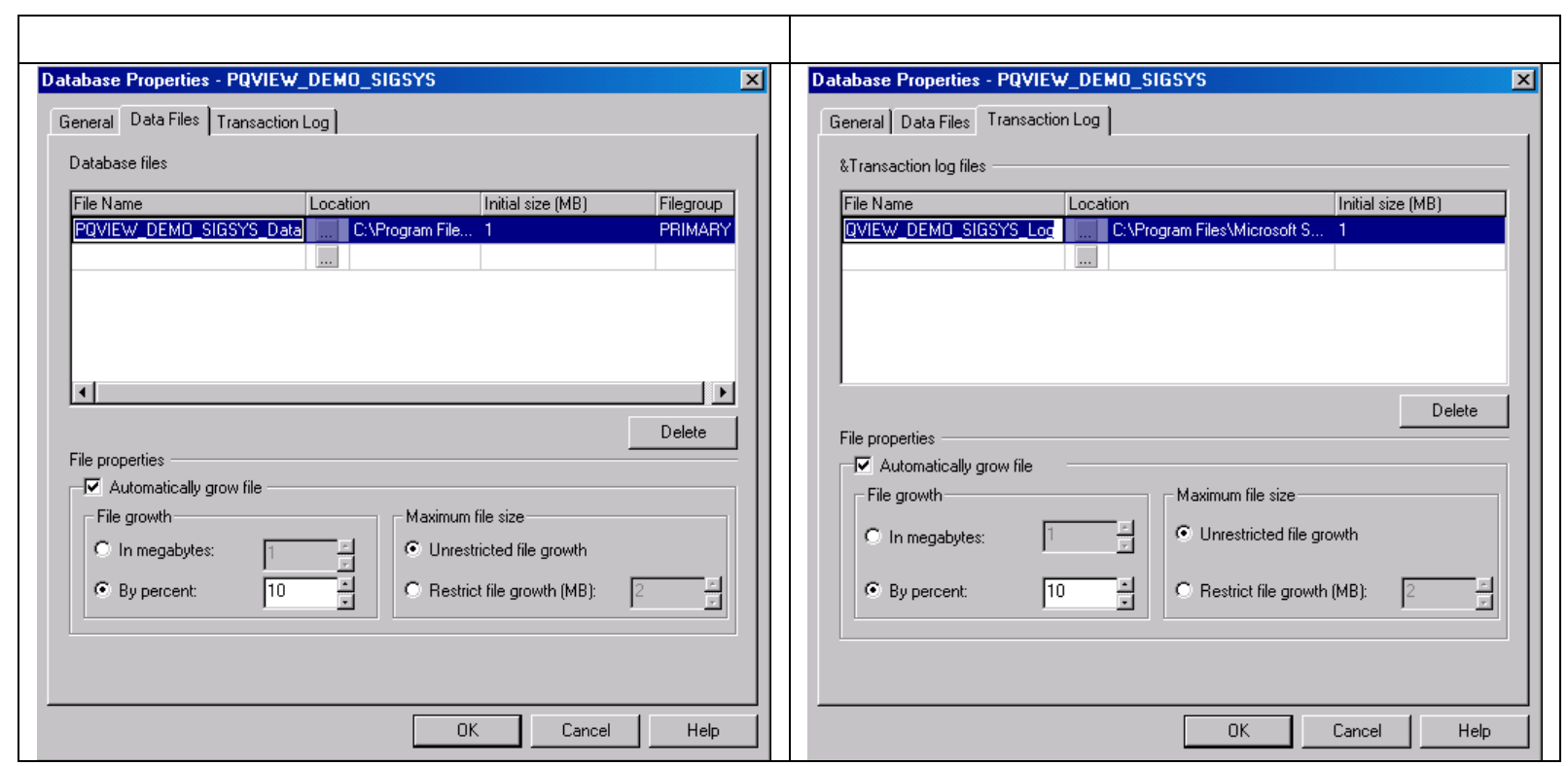

Figure 56. Default settings on Data Files and Transaction Log tabs

Select the Transaction Log tab. Here, maintain the default file properties as well:

Automatically Grow File checkbox enabled, By Percent and Unrestricted File Growth radio buttons selected. Select the OK button.

The database has been created. Now you must populate the database with the PQView tables.

\subsection{Creating the PQView Database Structure With SQL Query Analyzer}

SQL Query Analyzer is used to populate the database with PQView tables (table names, field names, indexes, primary keys, relationships, etc.).

Highlight the database for which you are creating the PQView tables (Figure 57). In this case, it is PQVIEW_DEMO_SIGSYS. 


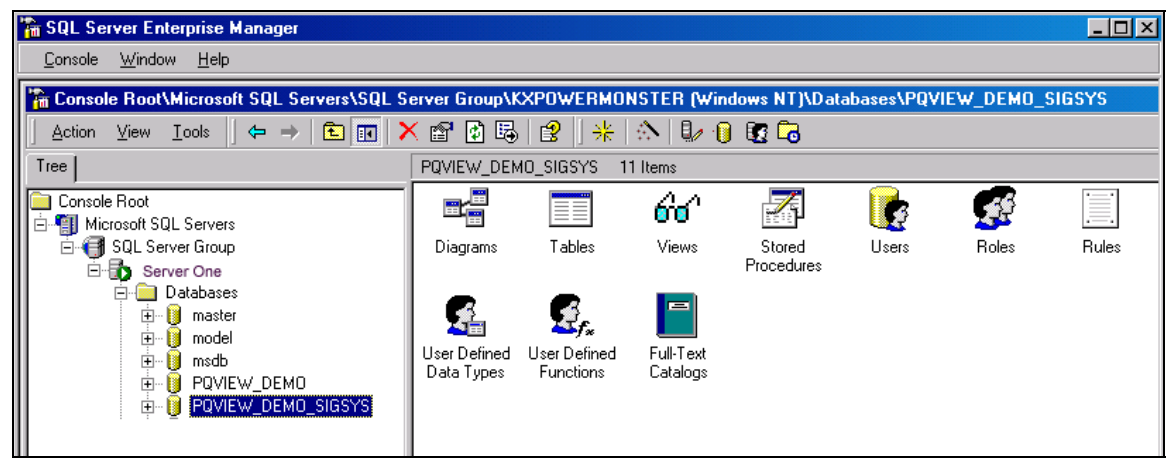

Figure 57. Select the database to be populated with PQView tables

Make sure that the new database (PQVIEW_DEMO_SIGSYS) is selected by highlighting it. From the SQL Query Analyzer menu, select Tools and then SQL Query Analyzer (Figure 58).

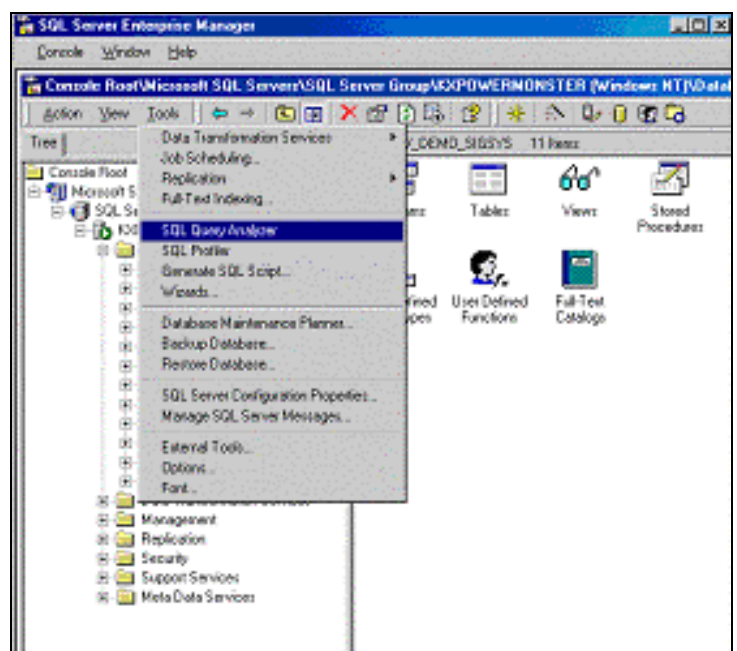

Figure 58. Selecting Tools and SQL Query Analyzer

Now open the pqview33.sql file (Figure 59). This is found either on the PQView CD-ROM or the PQView user group Web site. It may also be found on a computer with PQView 3.0 in c: Iprogram files\pqview30\sql\pqview33.sql (Figure 60). 


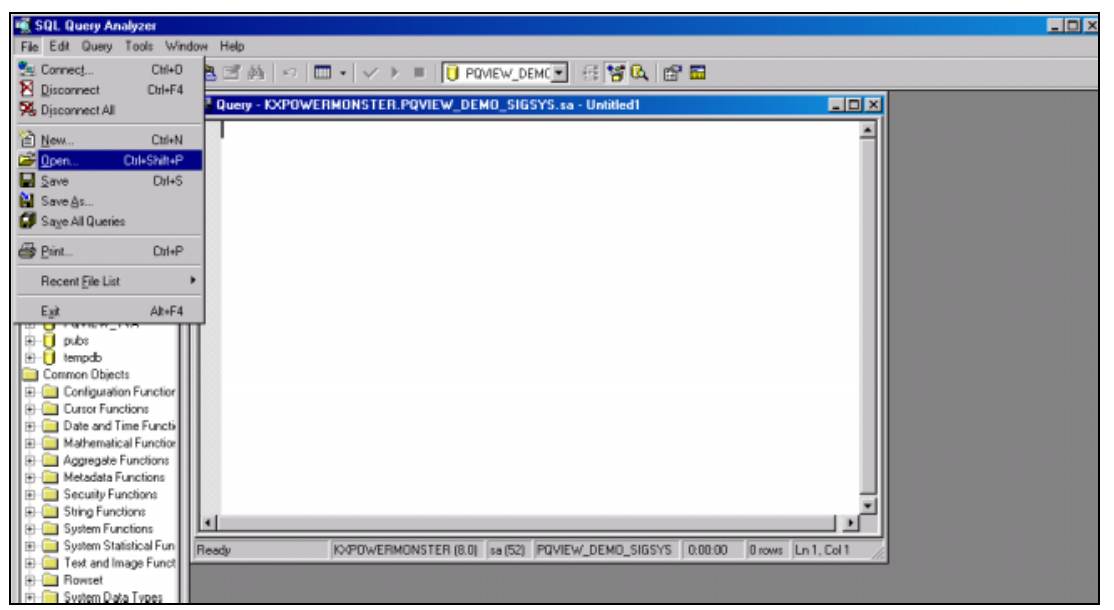

Figure 59. Opening a file in the SQL Query Analyzer

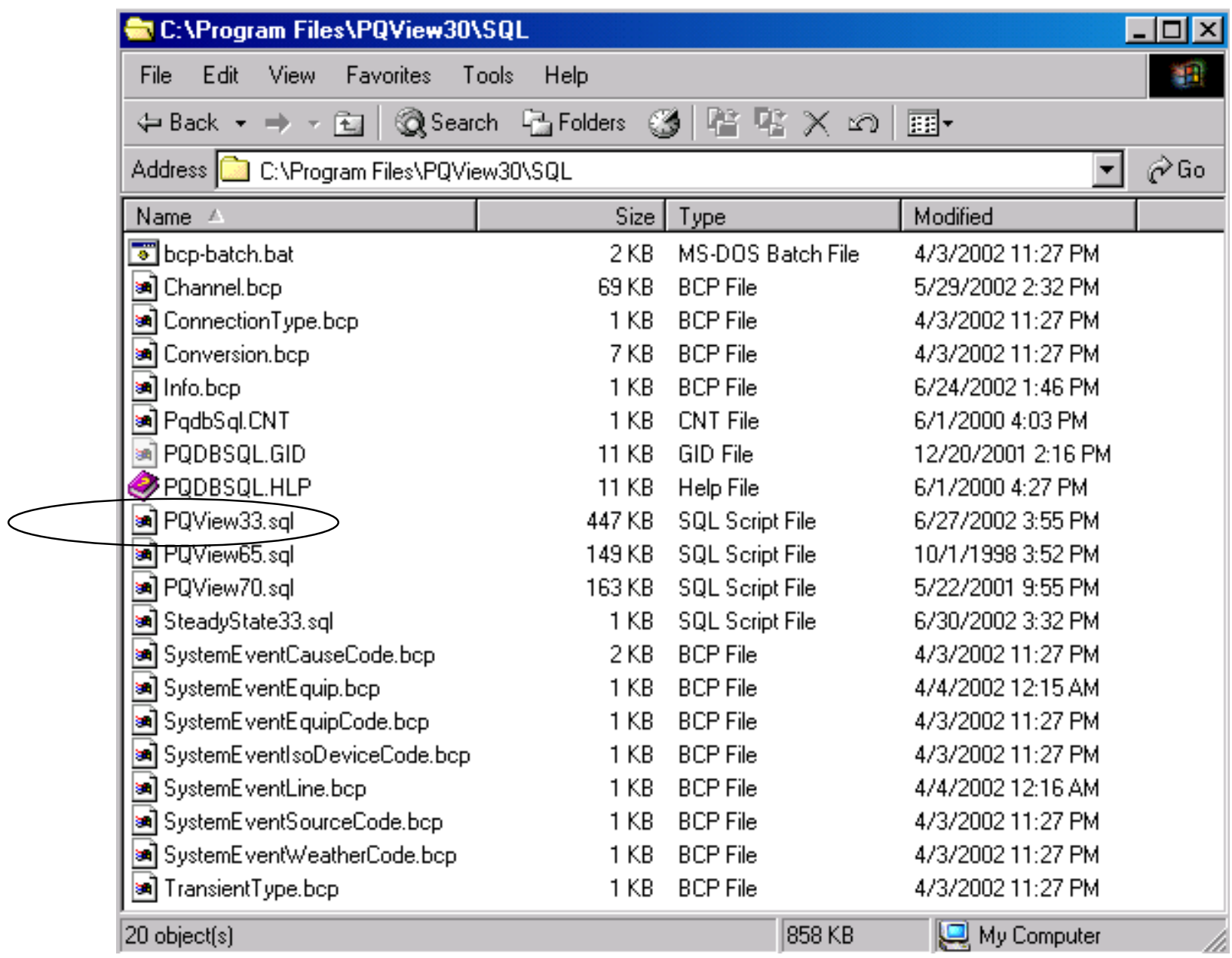

Figure 60. PQView33.sql file located in PQView30ISQL folder

Opening the PQView33.sql file displays the contents in the SQL Analyzer (Figure 61). 


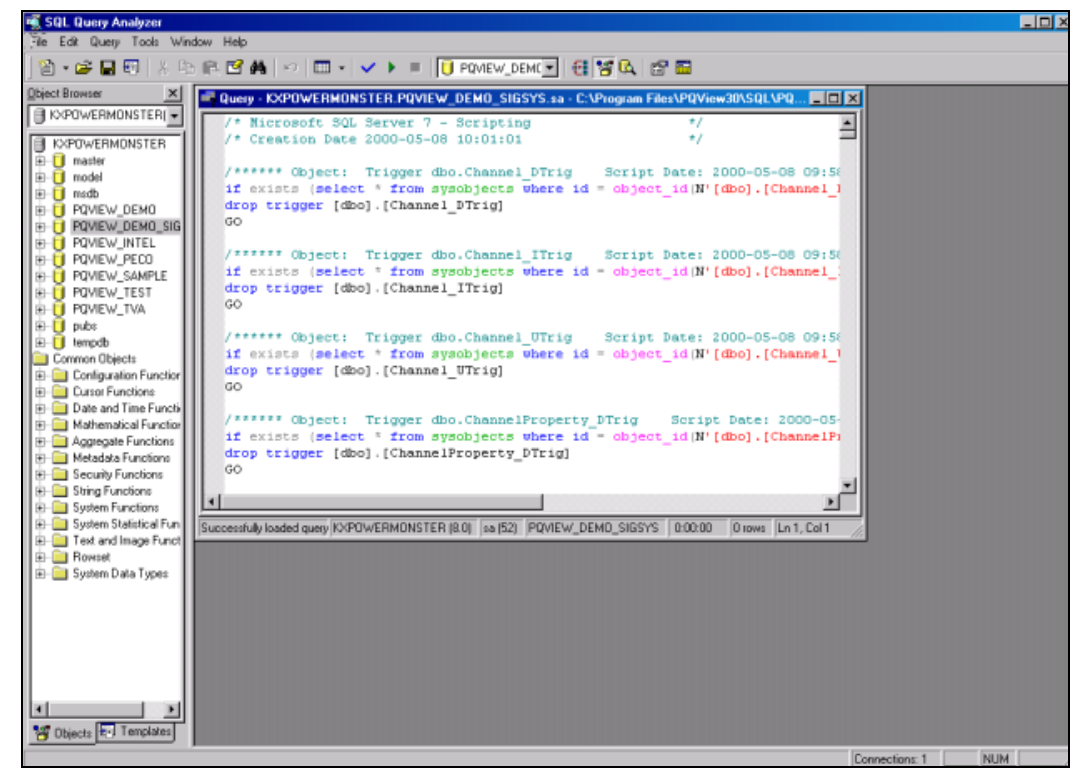

Figure 61. PQView33.sql file contents displayed in the SQL Query Analyzer

To run the script, select the green arrow or F5. If the script is run successfully, you will see "Default bound to column" several times with no error messages (Figure 62). Close the SQL Query Analyzer when this task is completed.

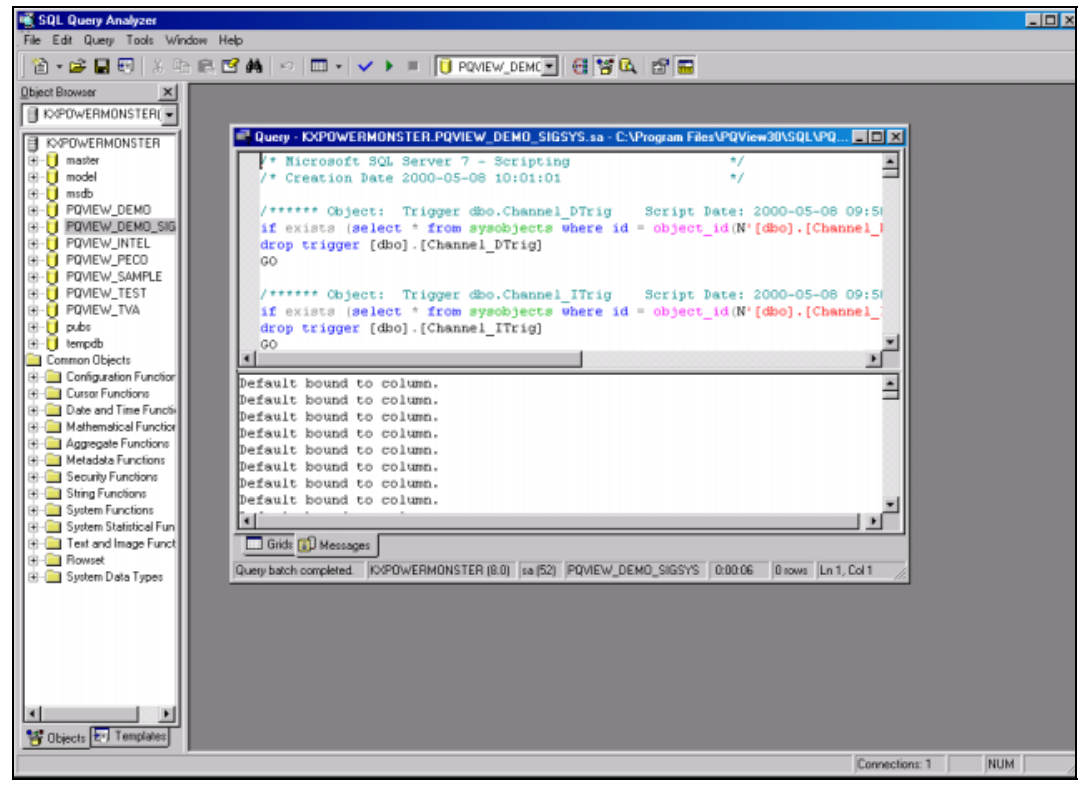

Figure 62. Successfully completed query

Expanding the new database in the tree and highlighting tables displays the tables created by running the script (Figure 63). 


\begin{tabular}{|c|c|c|c|c|c|c|c|c|c|}
\hline \multicolumn{9}{|c|}{ 䈏 SQL Server Enterprise Manager } & - \\
\hline \multicolumn{10}{|c|}{ Console Window $\underline{H}$ elp } \\
\hline \multicolumn{10}{|c|}{ "i. Console RootMicrosoft SQL ServersISQL Server Group KXXPOWERMONSTER (W/indows NT)XDatabasesIPQVIEW_DEMO_SI } \\
\hline Action $\underline{V}$ & lew I & Cools & $\leftrightarrow \Rightarrow$ 田团 & 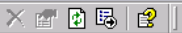 & 尖 & $\therefore$ & 6, 0 & & \\
\hline \multicolumn{4}{|l|}{ Tree } & \multicolumn{6}{|l|}{ Tables 43 ltems } \\
\hline & & & & Name $\Delta$ & & & Jwner & Type & Create Date \\
\hline \multirow{3}{*}{\multicolumn{4}{|c|}{$\begin{array}{c}10 \text { Microsoft SQL Servers } \\
\text { SQL Server Group } \\
\text { B Server One }\end{array}$}} & 国 Channel & & & tho & User & 1/24/2002 12:40:37 PM \\
\hline & & & & 国 ChannelProperty & & & tho & User & 1/24/2002 12:40:37 PM \\
\hline & & & & 图ChannelPropertyvalue & & & tho & User & 1/24/2002 12:40:37 PM \\
\hline \multicolumn{4}{|c|}{ Databases } & 国 ConnectionType & & & sbo & User & 1/24/2002 12:40:37 PM \\
\hline \multirow{2}{*}{\multicolumn{4}{|c|}{ Daster }} & 国 Conversion & & & tho & User & 1/24/2002 12:40:37 PM \\
\hline & & & & 甸Event & & & tbo & User & 1/24/2002 12:40:37 PM \\
\hline \multirow{2}{*}{\multicolumn{4}{|c|}{$\begin{array}{l}\text { TU msdb } \\
\text { tU PQVIEW_DEMO }\end{array}$}} & 囯 EventProperty & & & tbo & User & 1/24/2002 12:40:37 PM \\
\hline \multirow{2}{*}{\multicolumn{4}{|c|}{ OU PQVIEW_DEMO_SIGSYS }} & 面EventPropertyValue & & & tho & User & 1/24/2002 12:40:37 PM \\
\hline & & & & 国 EventTrend & & & abo & User & 1/24/2002 12:40:37 PM \\
\hline \multicolumn{4}{|c|}{$\begin{array}{l}\text { 몹 Diagrams } \\
\text { Tables }\end{array}$} & 囯EventT rigger & & & tho & User & 1/24/2002 12:40:37 PM \\
\hline \multirow{2}{*}{\multicolumn{4}{|c|}{ 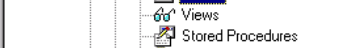 }} & 司IInfo & & & tho & User & 1/24/2002 12:40:37 PM \\
\hline & & & & 国Lock & & & tho & User & 1/24/2002 12:40:37 PM \\
\hline \multirow{2}{*}{\multicolumn{4}{|c|}{ Q Users }} & 国 Notification & & & tho & User & 1/24/2002 12:40:37 PM \\
\hline & & & & 国 RMSVariation & & & tbo & User & 1/24/2002 12:40:37 PM \\
\hline \multirow{2}{*}{\multicolumn{4}{|c|}{ Rules }} & 国 Site & & & ato & User & 1/24/2002 12:40:37 PM \\
\hline & & & & 国 SiteProperty & & & tho & User & 1/24/2002 12:40:37 PM \\
\hline \multirow{2}{*}{\multicolumn{4}{|c|}{$\begin{array}{l}\text { 8. User Defined Data Types } \\
\text { Q. User Defined Functions }\end{array}$}} & 国 SitePropertyValue & & & tho & User & 1/24/2002 12:40:37 PM \\
\hline & & & & 国 SiteSource & & & tho & User & 1/24/2002 12:40:37 PM \\
\hline \multicolumn{4}{|c|}{ 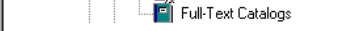 } & 司 Source & & & tbo & User & 1/24/2002 12:40:37 PM \\
\hline
\end{tabular}

Figure 63. Tables added to database using SQL Query Analyzer

You are now ready to give permission to PQView to read and write to these tables and to PQWeb to read these tables.

\subsection{Assigning Permissions to User Accounts Used by PQView and PQWeb} Select Users from the tree by highlighting it. Place your cursor on Users and right-click. This displays the Database User Properties-New User window (Figure 64).

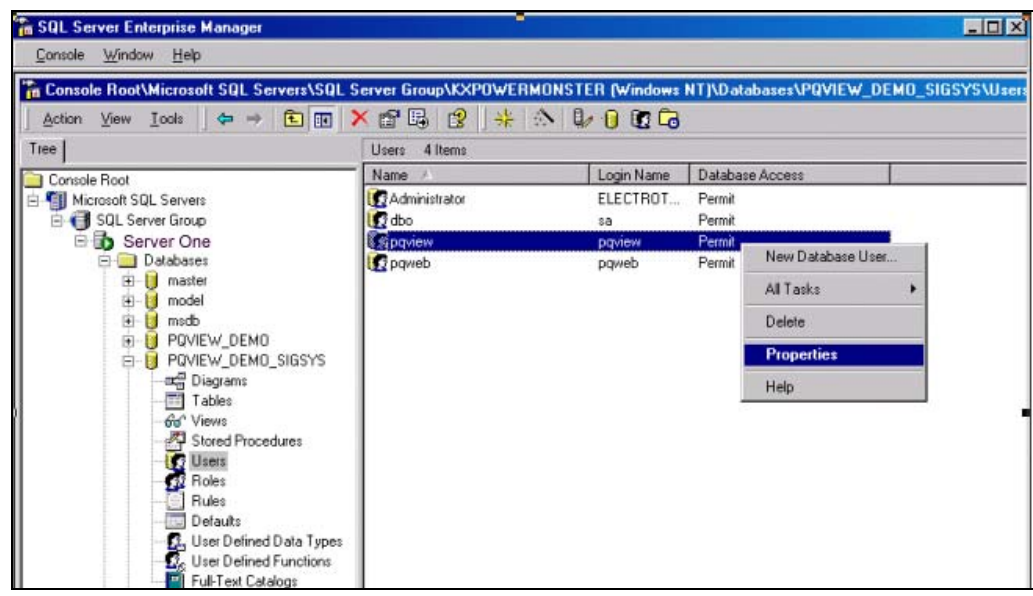

Figure 64. Selecting Users and then Properties

Enter the login name and the user name in the appropriate text boxes (Figure 65). 


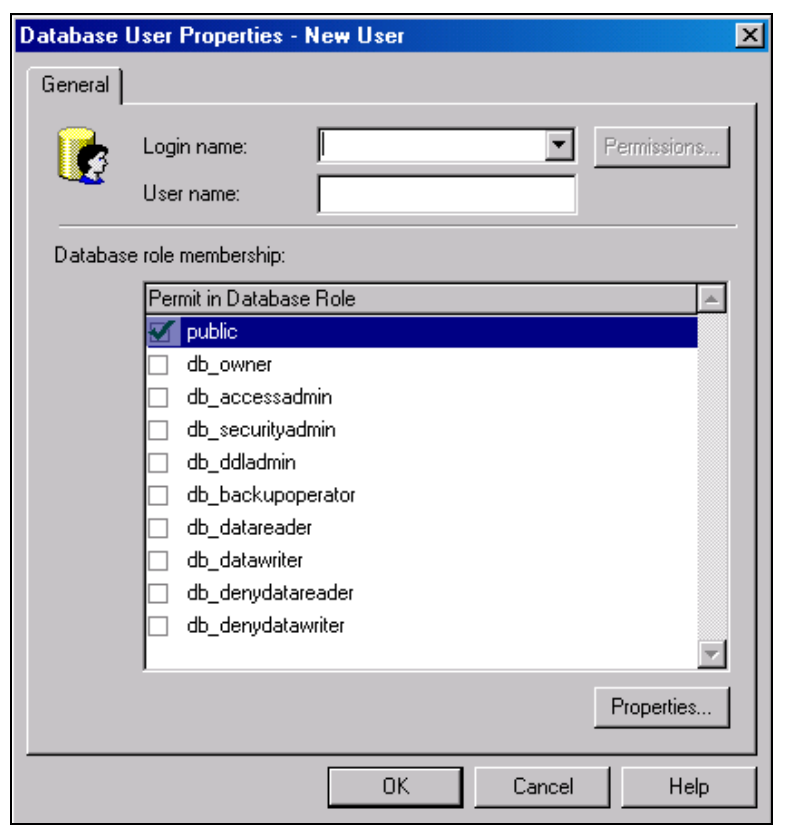

Figure 65. Database User Properties - New User window

The public role is already assigned by default. Select the db_datareader and db_datawriter boxes (Figure 66).

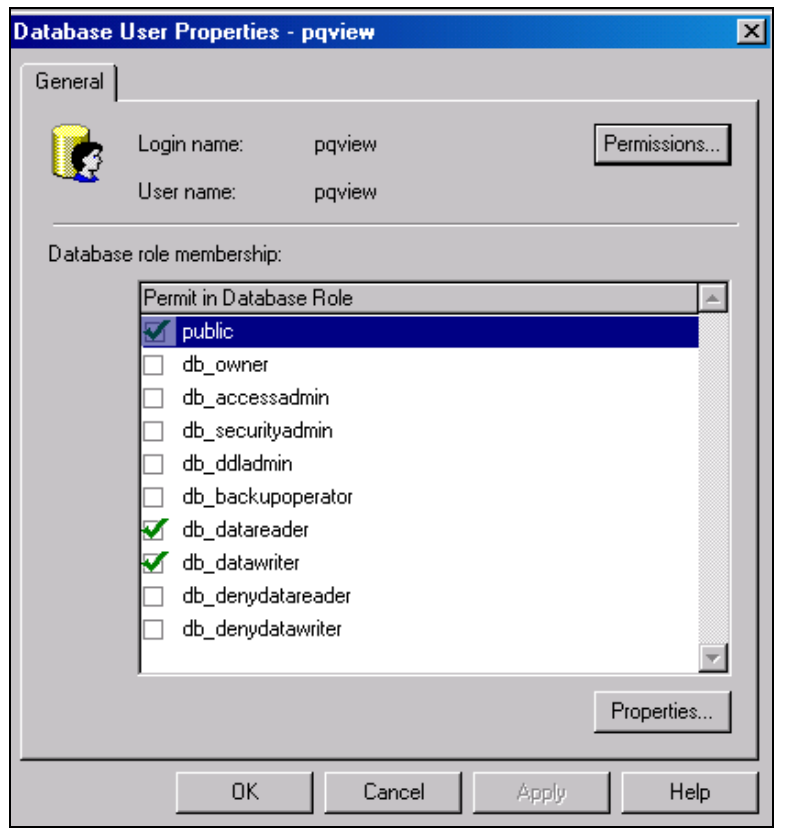

Figure 66. Assigning PQView roles in the Database Users Properties window

Repeat the process for PQWeb. Select only the db_datareader check box. You have now assigned permissions to PQView and to PQWeb. 
You are ready to assign individual table permissions to each account. To assign permissions to the PQView account, highlight the PQView User account and right-click. This displays the Database User Properties - pqview window. Select the Permissions button in the Properties window (Figure 67).

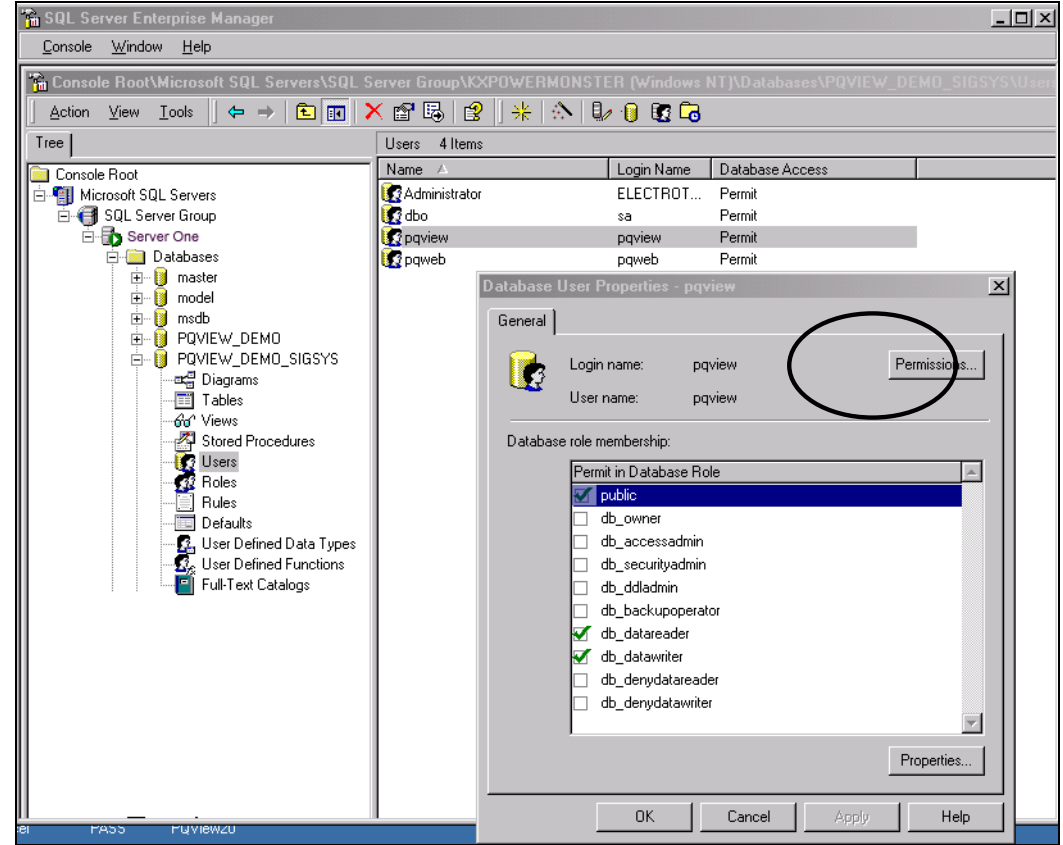

Figure 67. Database User Properties - pqview window

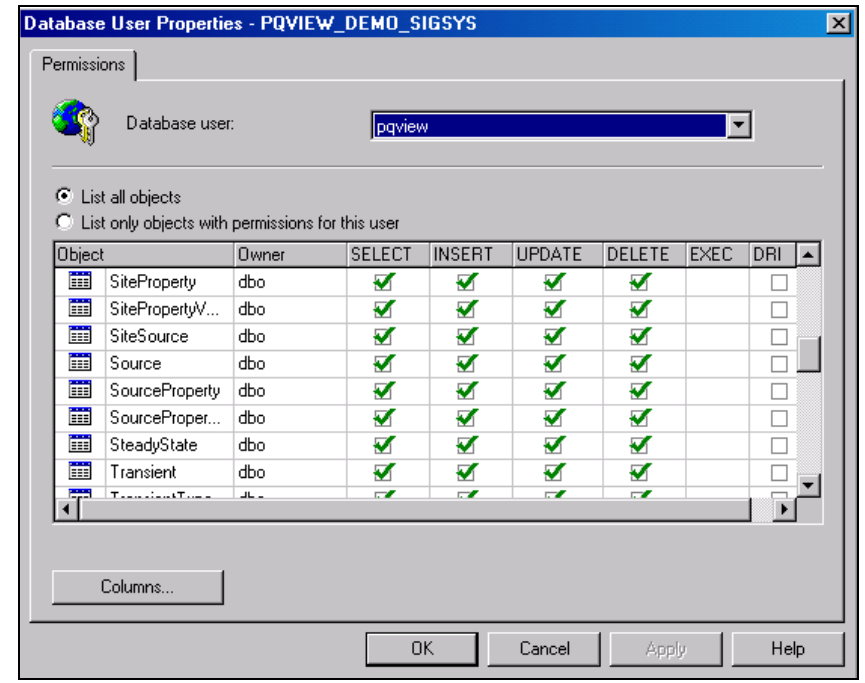

Figure 68. Enabling permissions

On the Permissions tab, assign Select, Insert, Update, and Delete permissions by placing a check in each box (Figure 68). Notice tables are listed other than those PQView tables with which you populated the database. Do not check the boxes associated with those tables. Leave them blank. For a list of tables to which you need to assign permissions, see Table 2. 
After assigning permissions for the PQView tables, select the Apply button. Close the window by selecting the OK button.

Table 2. PQView Tables

\begin{tabular}{|c|c|}
\hline PQView 2.x Tables & PQView 3.0 Tables \\
\hline $\begin{array}{l}\text { Channel } \\
\text { ChanneIProperty } \\
\text { ChanneIPropertyValue } \\
\text { ConnectionType } \\
\text { Conversion } \\
\text { Event } \\
\text { EventProperty } \\
\text { EventPropertyValue } \\
\text { EventTrend } \\
\text { EventTrigger } \\
\text { Info } \\
\text { Lock } \\
\text { Notification } \\
\text { RMSVariation } \\
\text { Site } \\
\text { SiteProperty } \\
\text { SitePropertyValue } \\
\text { SiteSource } \\
\text { Source } \\
\text { SourceProperty } \\
\text { SourcePropertyValue } \\
\text { SteadyState } \\
\text { Transient } \\
\text { TransientType }\end{array}$ & $\begin{array}{l}\text { Channel } \\
\text { ChannelProperty } \\
\text { ChannelPropertyValue } \\
\text { ConnectionType } \\
\text { Conversion } \\
\text { Event } \\
\text { EventProperty } \\
\text { EventPropertyValue } \\
\text { EventTrend } \\
\text { EventTrendValue } \\
\text { EventTrigger } \\
\text { Info } \\
\text { Lock } \\
\text { Notification } \\
\text { RMSVariation } \\
\text { Site } \\
\text { SiteProperty } \\
\text { SitePropertyValue } \\
\text { SiteSource } \\
\text { Source } \\
\text { SourceProperty } \\
\text { SourcePropertyValue } \\
\text { SteadyState } \\
\text { SteadyStateHarmonic } \\
\text { SteadyStateValue } \\
\text { SystemEvent } \\
\text { SystemEventCauseCode } \\
\text { SystemEventEquip } \\
\text { SystemEventEquipCode } \\
\text { SystemEventlsoDeviceCode } \\
\text { SystemEventLine } \\
\text { SystemEventSourceCode } \\
\text { SystemEventWeatherCode } \\
\text { Transient } \\
\text { TransientType }\end{array}$ \\
\hline
\end{tabular}

You are now ready to assign permissions to PQWeb. Repeat the process of opening the Permissions tab in the same manner as for PQView (Figure 69). 


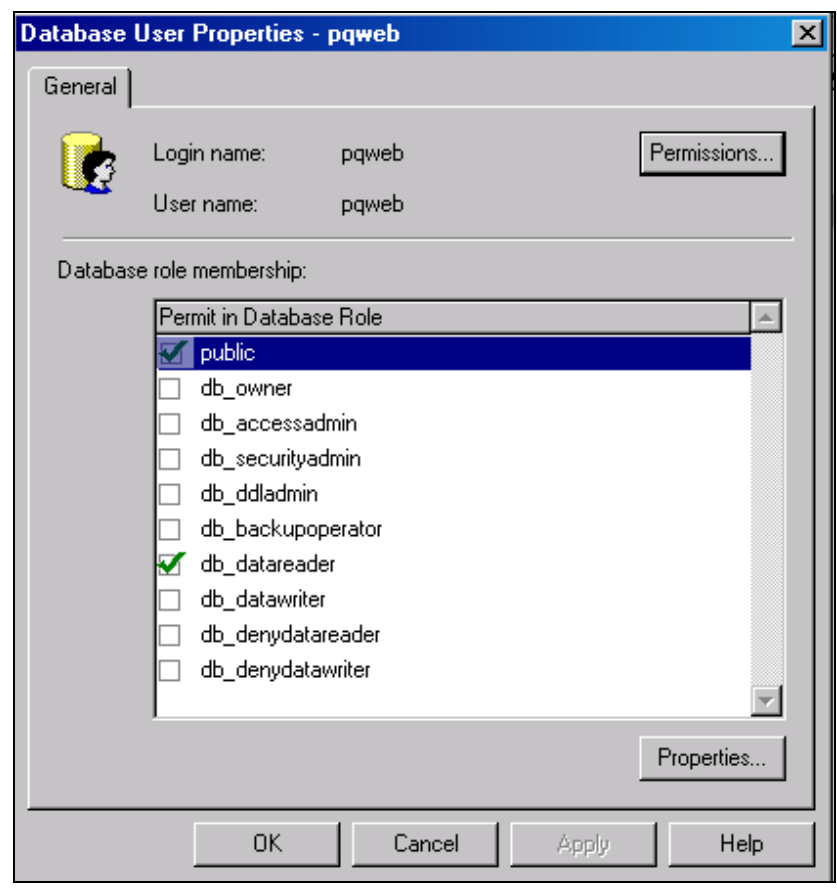

Figure 69. Database User Properties - pqweb

Select the the Permissions button to display the Permissions tab. Enable only Select; leave all the other tables blank (Figure 70).

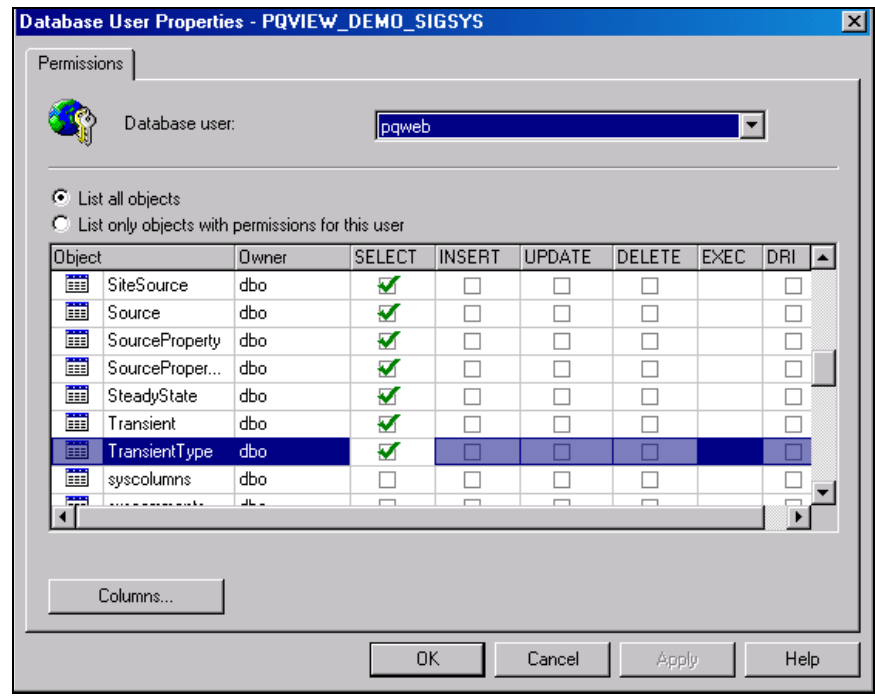

Figure 70. Assigning Select permissions to PQWeb 


\subsection{Bulk-Copying Data into Lookup Tables}

The final step to complete the database is to bulk copy the following data into the appropriate tables: Channel.bcp, ConnectionType.bcp, Conversion.bcp, Info.bcp and transientType.bcp.

Open a DOS prompt, and execute the following commands:

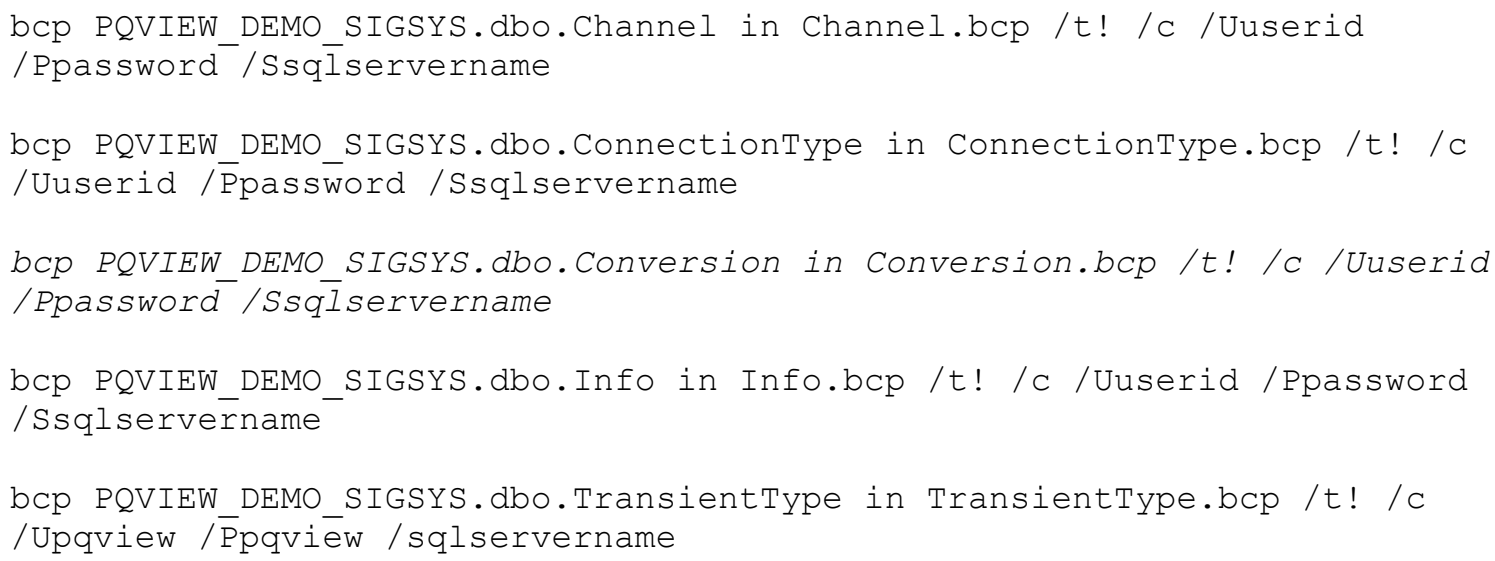

Replace the text in the previous list by using the database name, user name, password, and server name appropriate for your database. The parameters in the command are:

- userID is a valid login for the database with read/write privileges

- password is the password for the login

- sqlservername is the server name upon which the database resides.

Replace the PQVIEW_DEMO_SIGSYS text with the name of your database.

You can also copy these commands into a DOS batch file and run them all at once.

The database is now complete. However, you are not yet done. On each PQView workstation from which you wish to have access to the database, you must create a new ODBC data source.

\subsection{Creating an ODBC Data Source on Each PQView Workstation}

Open Administrative Tools under the Windows Control Panel. Selecting Start, Settings, Control Panel, Administrative Tools, Data Sources (ODBC) displays the ODBC Data Source Administrator window (Figure 71). 


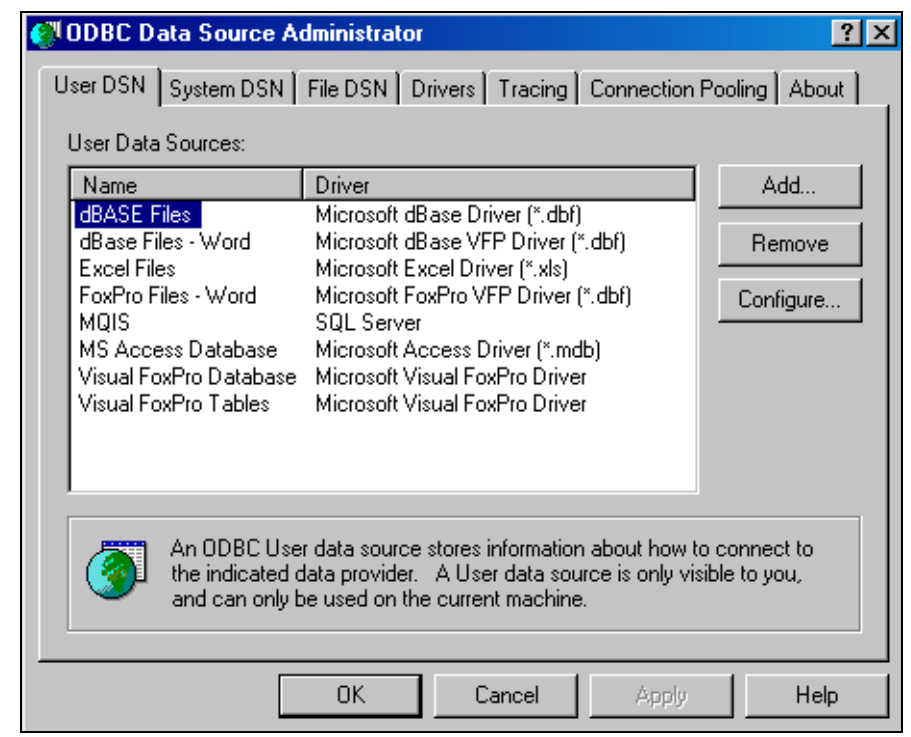

Figure 71. ODBC Data Source Administrator Window

Select the System DSN tab (Figure 72). Highlight the database for which you want to create a new system DSN.

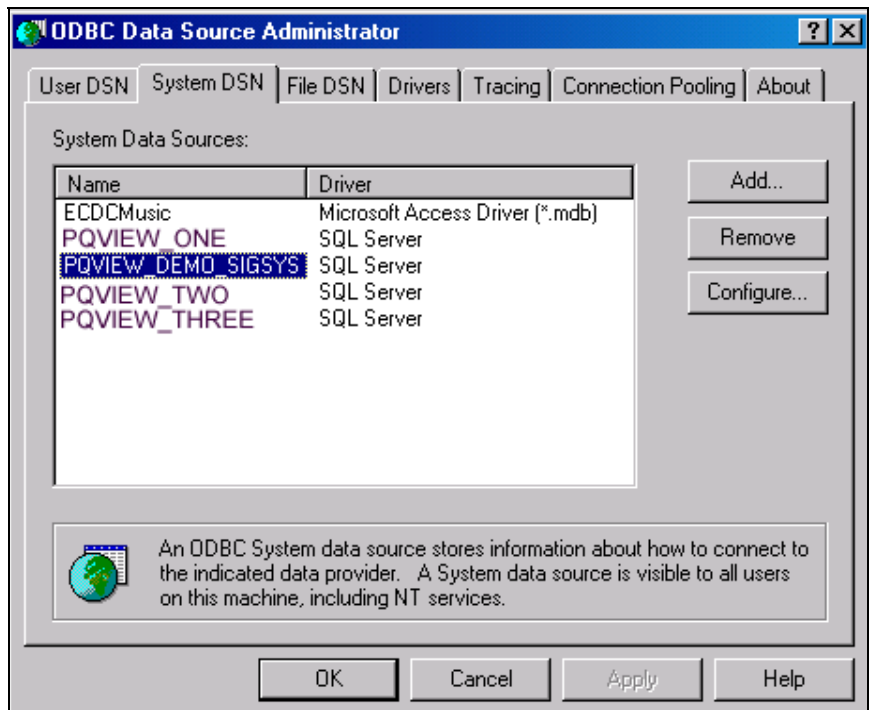

Figure 72. Selecting a database for which to create a system DSN

Select the Add button to add the new System DSN.

Select the SQL Server option by highlighting it, and then select the Finish button (Figure 73). 


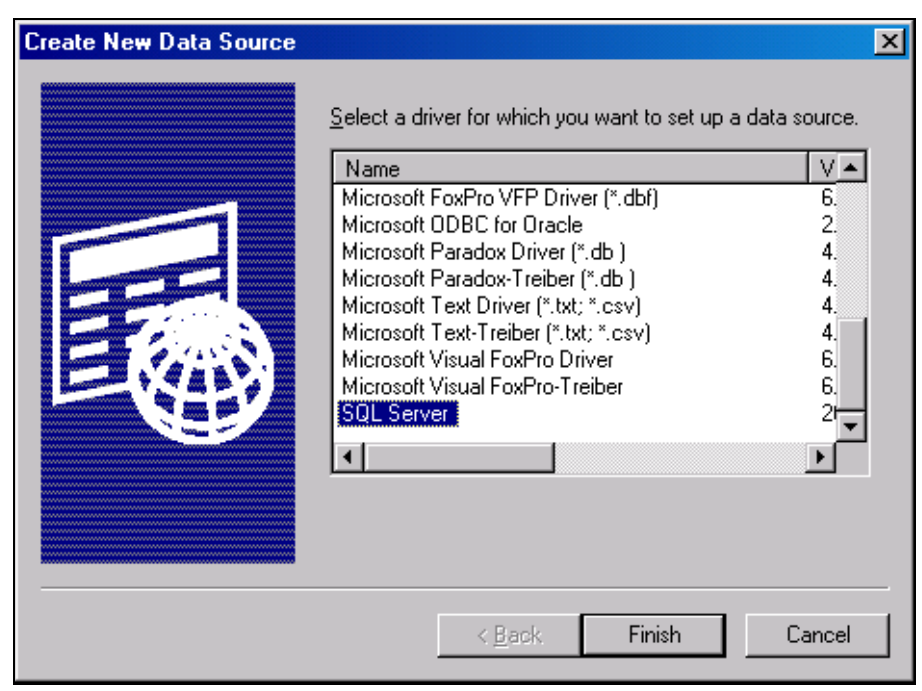

Figure 73. Selecting the SQL Server Option

Fill out the Create a New Data Source to SQL Server form with the appropriate information (Figure 74).

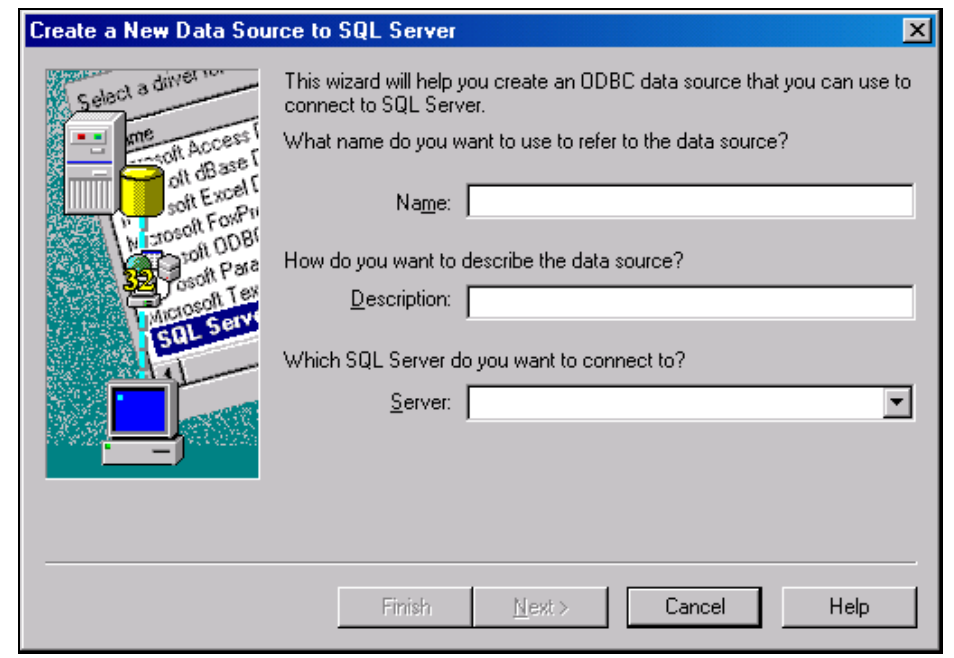

Figure 74. Create a New Data Source to SQL Server window

Supply the name of the database (PQView_DEMO_SIGSYS, in this example), a brief description of the database (this is a demonstration database for Signature System data), and the server on which the SQL database resides (Server One) (Figure 75). Select the Next button to move to the next window. 


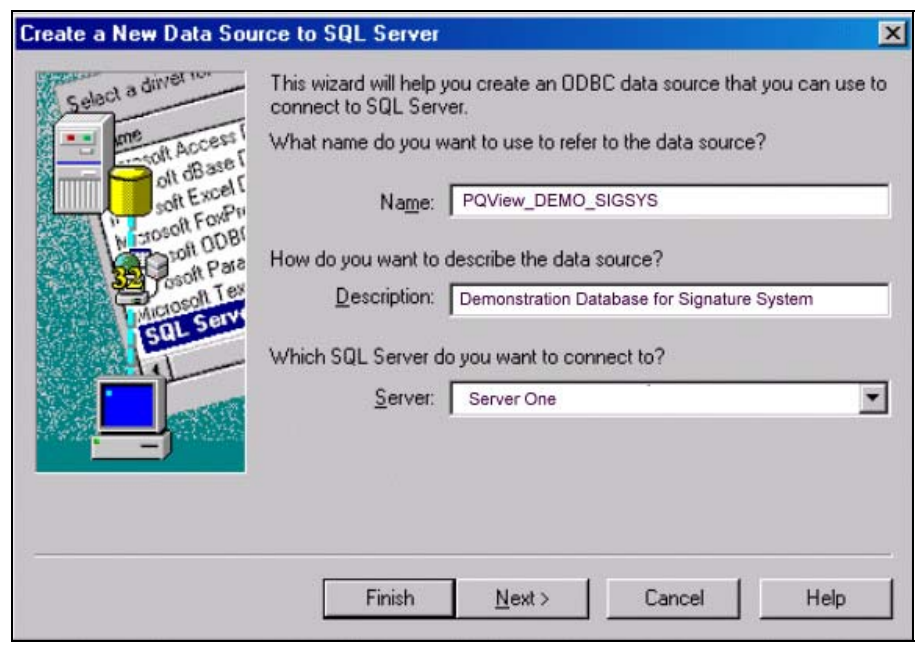

Figure 75. Naming, describing, and assigning a server

Select the "With SQL Server authentication using a login ID and password entered by the user" radio button. Enable the "Connect to SQL Server to obtain default settings for the additional configuration options" check box (Figure 76). Select the Next button.

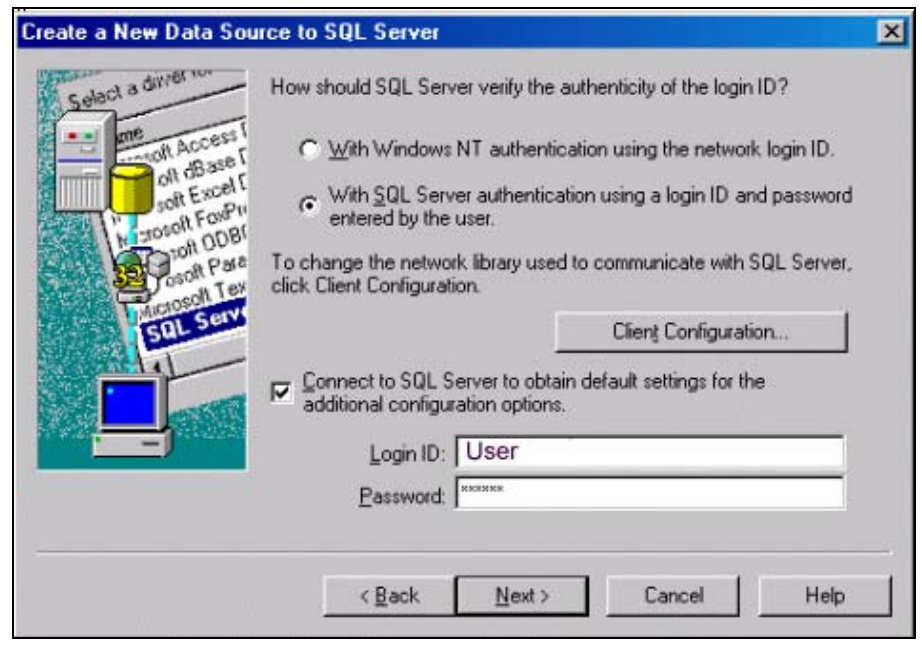

Figure 76. Assigning a User ID and Password

Enable the following check boxes (Figure 77):

- Change the default database to: (Designate the name of the database in the dropdown box.)

- Use ANSI quoted identifiers.

- Use ANSI nulls, paddings and warnings.

Select the Next button. 


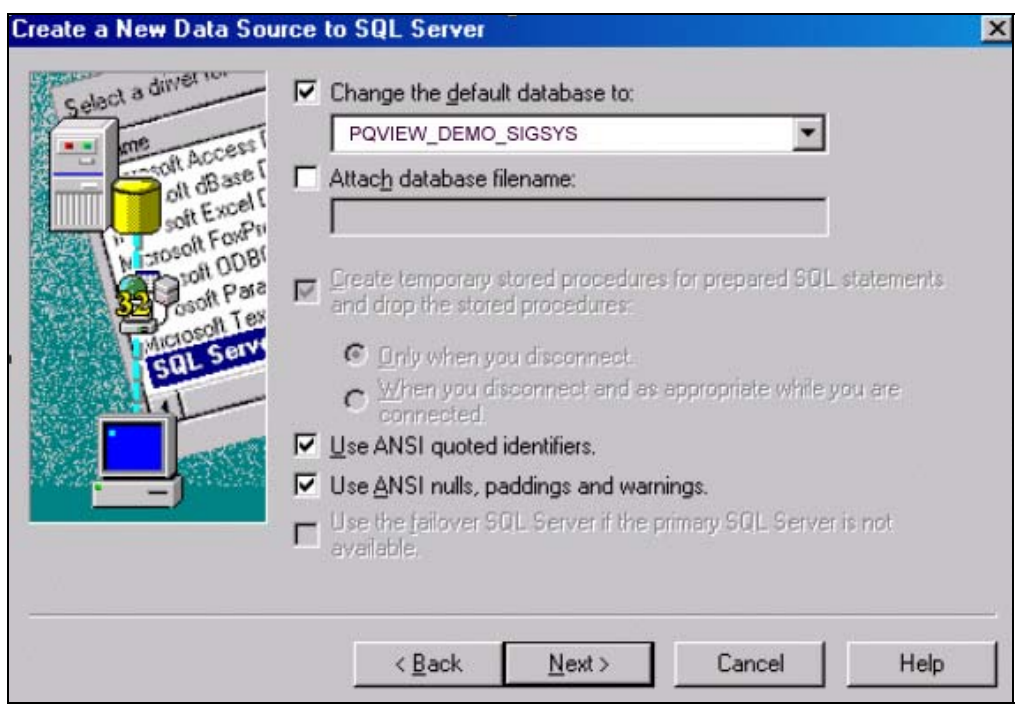

Figure 77. Changing the default database

Enable the "Perform translation for character data" check box (Figure 78).

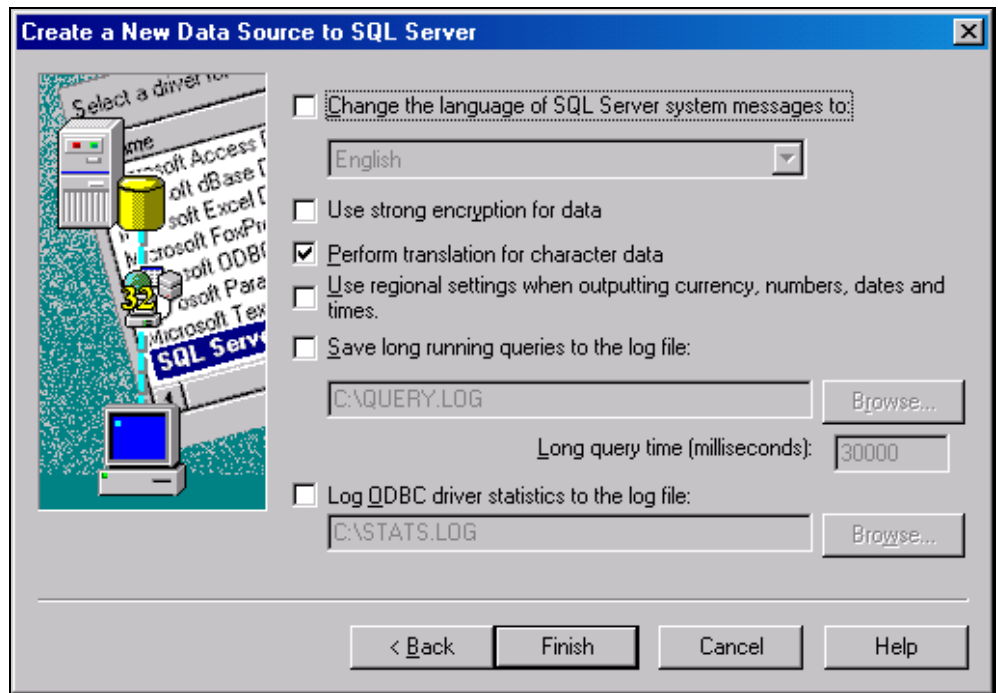

Figure 78. "Perform translation for character data" check box enabled

Select the Finish button to save the new ODBC data source. The configuration of the newly created ODBC data source is displayed (Figure 78). 


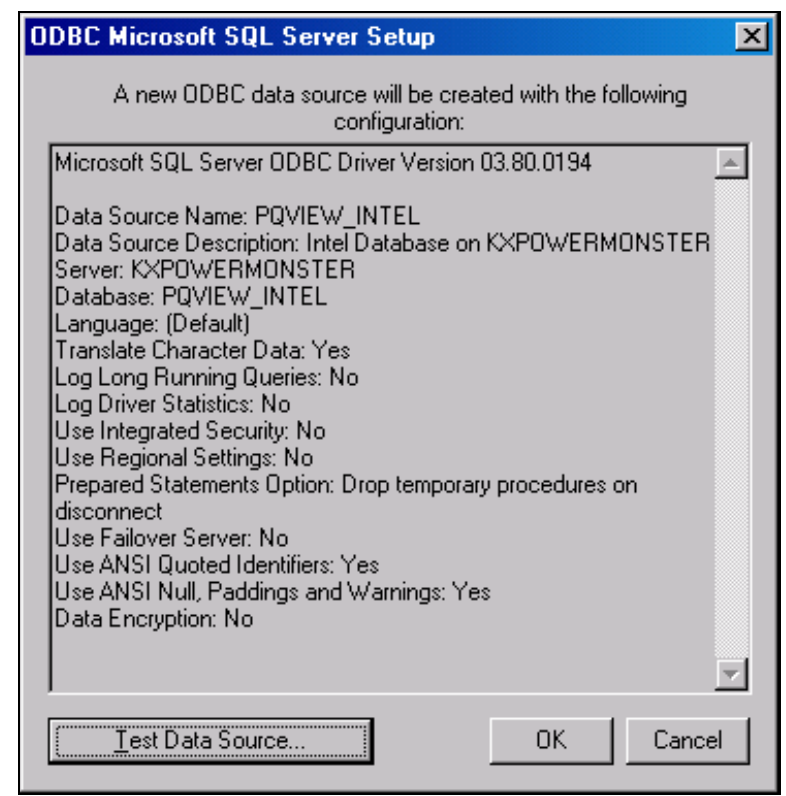

Figure 79. Configuration of new ODBC data source

If you select the Test Data Source button and the test is successful, a message states that connectivity tests were run and the tests were successfully completed (Figure 80).

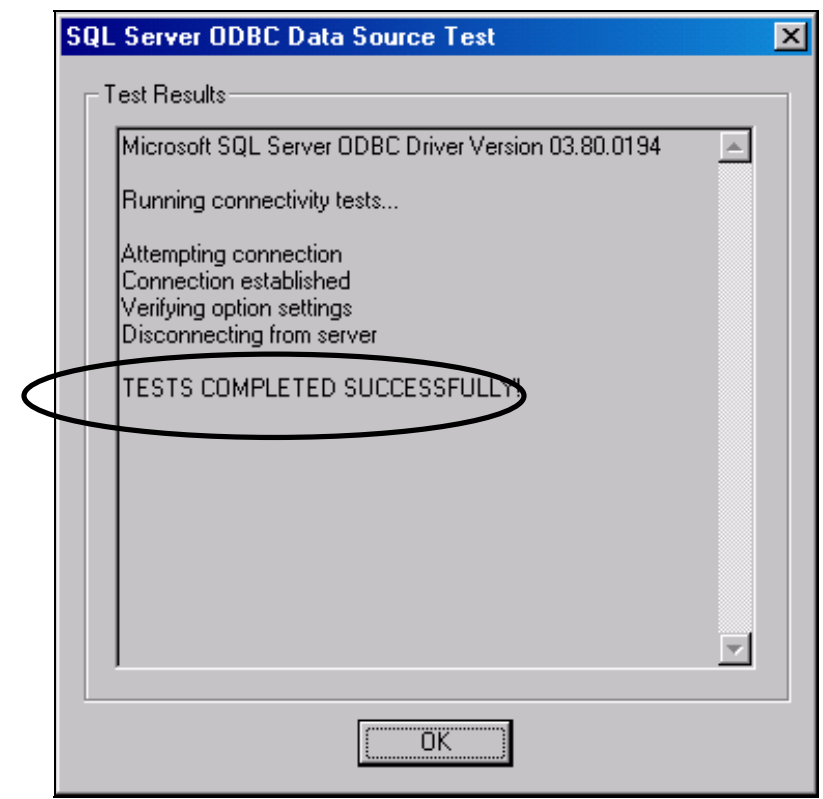

Figure 80. Confirmation of successful ODBC connectivity tests

Selecting the OK button saves the ODBC data source. The database can now be opened in the Power Quality Data Manager and the Power Quality Data Administrator. 
Appendix C: Emergency Load Curtailment Program: Evaluation of a Candidate Facility 
Task 8

C-ii 


\section{Table of Contents}

1 Overview

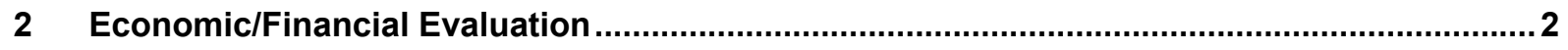

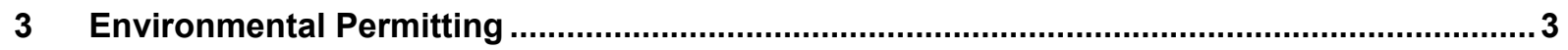

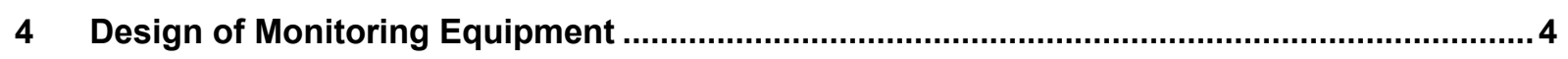

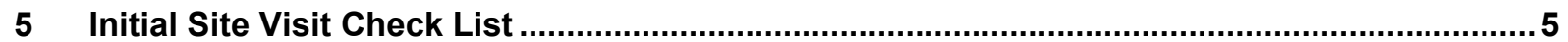

Task 8

C-iii 


\section{Overview}

Before a facility can participate in the Emergency Load Curtailment Program, specific procedures must be performed. These include:

- Economic/financial evaluation

- Environmental permitting

- Design of monitoring equipment

- Equipment procurement, installation, and start-up

- Certification of installed equipment

Some facilities may require additional measures, such as the installation of fuel flow meters or emission reduction technologies. Each of these steps requires that data be collected from the facility. These data are collected through an initial site visit. 


\section{Economic/Financial Evaluation}

This evaluation determines if the facility of interest is a candidate for participation in the curtailment program (i.e., Will the operation of this facility for load curtailment be profitable for both the building owner and the aggregator?). This evaluation usually uses cash flow models. The models require the following facility data:

- Total installed emergency generating capacity

- Curtailable load of the facility

- Physical condition of generators and switchgear

- Operating and maintenance expenses associated with the operation of the emergency generators.

To complete the financial evaluation, additional data may be required from other specialized organizations. Such data include:

- Anticipated expenses for testing, maintenance, and repair of generating and switchgear equipment so it can be used in the load reduction program

- The cost of the aggregator's equipment installation.

Representatives of these organizations will need to visit the facility to obtain this data. 


\section{Environmental Permitting}

To use emergency generators for the load reduction program, a facility should obtain some kind of environmental permit. The information required to obtain this permit includes:

- The type and size of emergency generators

- The type and hourly consumption of fuel

- Diesel/turbine manufacturer's data on NOX, CO, CO2, and PM emissions

- Design parameters of the engine exhaust system.

Very often, emissions are capped not per engine but per facility. Therefore, it is necessary to obtain data on all combustion sources on the premises. These include boilers, hot water heaters, and absorption chillers (using natural gas). The information required for this equipment is similar to what is required for the main generating equipment. In addition, operating schedules and durations of operation of this equipment should be obtained. This is important for calculating annual fuel use and air emissions.

In some cases, fuel consumed by emergency generators during load curtailment must be tracked. This condition often requires the installation of fuel flow meters or fuel level meters on fuel tanks. The preliminary information obtained before a site visit helps determine if the installation of fuel flow meters is necessary. If it is, a detailed evaluation of the fuel handling and supply system will be performed to determine the size and type of flow meters and a suitable place for their installation. 


\section{Design of Monitoring Equipment}

Load reduction program participants are usually required to measure and report on an hourly basis electricity generated by emergency generators and curtailed from the grid. This information can be collected through $\mathrm{GE} \mathrm{kV}$ meters installed on each emergency generator or existing power provider meters on the commercial side. The Signature System ${ }^{\mathrm{TM}}$ InfoNode collects this information. In facilities with more than one generator, an electrical switch is installed to alternate between $\mathrm{kV}$ meters every 10-15 seconds. The information collected on the InfoNode is delivered over the Internet (usually via high-speed connection) to WPT's aggregation center in Knoxville, Tennessee.

If meters are to be installed on each generator, design and equipment specifications for the installations are performed by WPT/Electrotek engineers. The essential information is:

- The location and ability to use existing current transformers and potential transformers on emergency generators

- The location for installation of WPT's aggregation equipment and telephone/DSL jack

- The location of protected power supply, which is necessary for uninterruptible operation of an InfoNode and $\mathrm{kV}$ meters.

An electrical engineer familiar with the installation and operation of $\mathrm{kV}$ meters should collect this information. In some cases, a contractor can perform this evaluation if he has previous experience installing WPT equipment.

If existing KV meters on the commercial side are to be used, the local power provider (the owner of existing the meters) should install a so-called demarcation box, which will make information from the meters available for use by WPT but prevent any access to the electric meters from outside. The demarcation box will provide WPT with totalized signals (KYZ pulses) from existing meters, which can be collected by the InfoNode and sent to the WTP aggregation center. 


\section{$5 \quad$ Initial Site Visit Check List}

The purpose of an initial visit is to gather the necessary data for:

- Economic/financial evaluation

- Environmental permitting

- Design of monitoring equipment

- Equipment procurement, installation, and start-up

- Certification of installed equipment.

This section provides a detailed list of relevant data. Items marked with an asterisk are "niceto-haves" but not required. All others are required.

- Facility Location and Management Information

○ Customer name

- Location

- Facility age and condition

$\circ$ Building equipment and emergency generator management

- Names, positions, and contact information of people responsible for emergency generator operation

- Names, positions, and contact information of people responsible for building equipment (chillers, boilers, heaters) operation

- Sensitivity of the building load to power shortages, availability of smooth transition to emergency generators

- Permit status (facility, emergency generators, other sources of combustion)

- Major building design details

- Emergency generator location

- Indoor temperature and humidity requirements

- Inlet air location (temperature and quality)*

○ Site-specific problems with the emergency generators related to a facility operation

- Noise

- Smoke/fume

- Vibration

- Information about contracting companies that provide services to the facility (company name, manager contact information)

- Emergency generator service company

- Switchgear testing and maintenance company

- Certified electric equipment installation company

- Certified plumbing and mechanical equipment installation company

- Local telephone/DSL installation and service company 
- Load Data

- Historical electric load data (hourly profiles if available), including average winter, average summer, and peak summer loads

- Internal customer loads

- Load factor

- Power factor*

- Essential loads versus non-essential loads

- Curtailable essential and non-essential loads (loads that physically can be transferred to emergency generators)

- Frequency of generator testing under load and no-load conditions (if possible, obtain copies of logs)

- Availability/status of UPS on critical loads

- Hours of battery storage on critical loads or length of time critical loads can go unserved

- Building Electrical Supply System

- Number of connections to utility

- Number, location, and type of commercial $\mathrm{kW}$ meters

- Availability of demarcation box

- Quality and reliability of grid power

- Capacity of client's step-down transformers

- Internal distribution voltage

- Kilowatts of building load connected to generator circuits

- Transformers, switch gear, and equipment

- System make, brand, and serial numbers

- Operational problems

- Equipment required for parallel operation

- Emergency Generators

- On-site emergency generation equipment nameplate data (diesel/combustion turbine, generator)

- Make, model, and serial number

- Age of equipment and installation date (if available)

- Engine horsepower/kilowatts

- Generator electrical characteristics (kilowatts, kilovolt-amperes, power factor)

- Starting system (electric, pneumatic)*

- Access to and availability of current transformers and potential transformers for parallel use for WPT's $\mathrm{kW}$ meters

- Schematic drawings

- Existing current transformers

- Ratios of current transformer and potential transformer

- Output voltage (power transformers if medium voltage) 
○ Place for WPT aggregation equipment

- Whether the generator current transformers feed a central status panel

- Best place for the InfoNode and the GE meters

- Locations of main switchgear and main generator transfer switches

- Best place to install the meters (close to current transformers and/or the generator)

- Available space (wall) to mount one InfoNode and several GE kV meters (one for each generator)

- If the generator does not have current transformers, where they should be installed (generator or transfer switch)

- Resistive load banks (to prevent "wet stacking") and their size

- Availability of protected power supply for WPT aggregating equipment

$\circ$ Emergency generator exhaust/stack information

- Stack material

- Diameter (OD/ID)

- Height above ground level and roof level

- Stack position relative to surrounding buildings

- Access to the stack in case flue gas analysis should be taken

- Fuel used by on-site generation system

- Total capacity of fuel storage tanks

- Documentation and drawings

- Excepts from engine manuals with major technical data

○ Information about fuel consumption (load versus fuel diagram)

- Information about emissions of $\mathrm{NOX}, \mathrm{CO}, \mathrm{CO} 2, \mathrm{PM}$

- One-line electrical drawings (high and low voltage)

- Photographs of the facilities, equipment, stacks, and equipment nameplates*

- General arrangement and sectional drawings*

- Control diagrams*

- Operations and Asset Management

$\circ$ Engine run time during past 5 years (both operation and testing) and engine run $\log \mathrm{s}$

- Status/description of maintenance program (maintenance contractor, scope of annual preventive maintenance)*

○ Maintenance records*

- Records of summary-level operating and maintenance costs for each generator*

O Options for reducing operating costs (combustion air preheating)*

- Frequency of inspections*

- Lube oil system

$\circ$ Frequency of lube oil changes, air filter changes, and results of oil lab analysis

- Lube oil cooler inspection and temperature monitor

- Frequency of bearing inspections (pumps, shaft) and greasing 
- Belts/timing

- Inspection frequency (condition and tension every 250 hours) and replacement of belts (every $8,000 \mathrm{hrs}$ )

○ Frequency of timing check and adjustment

- Air Intake

- Daily inspection and cleaning of main air filter

- Any leakage around air filter

- Filter restriction indicator

- Vibration/noise

○ Vibration sensors and readings

- Changes in noise levels

- Cooling water

- Cooling water temperature and chemistry monitoring

- Type of cooling water treatment (glycol, DI, RO)

- Starting system (daily inspections)

- Electric (loose connections)

- Pneumatic (air/gas reservoir level and lubricant)

- Miscellaneous

○ Fuel filter inspection

- Exhaust backpressure and temperature daily monitoring

- Compression ratio check

- Valve clearance measurement and adjustment every 2,000+ hours

- Crankcase pressure measurement every 2000+ hours

- Engine shutdown system visual inspection (thermocouples, connecting cables, levers)

- Calibration and testing of pressure and temperature switches every 90 days

- Building Equipment and Operations and Maintenance Information

- Boilers and hot water heaters

- Boiler/heater type and capacity

- Burner type and capacity

- Boiler fuel type, tank storage capacity (if separate from the emergency generator fuel supply system)

- Boiler operating logs, including burner firing rates

- Total annual boiler/heater hours of operation

- Type of boiler/combustion controls

- Current boiler operating pressure and flow

- Boiler stack information (see emergency generator stack information)*

- Boiler and burner maintenance records*

- Stack temperatures and flue gas composition*

- Boiler feedwater heaters or combustion air pre-heaters*

- Number of steam traps in plant and condition* 
○ Chillers

- Chiller type and size (kilowatts, tons)

- Refrigerant*

- Operating schedule*

- Suction and discharge pressures*

- Availability of cool storage*

- Other utility supplies

- Cost of water from utility

- Existing water restrictions

- Environmental constraints

- Air emissions limitations

- Noise limitations

- Fuel Handling and Supply System

(only required when fuel meters are to be installed)

- Main fuel tank capacity, geometrical dimensions, and location

- Day tank location, capacity, and geometrical dimensions

- Fuel pumping system design for transport of fuel from main to day tanks

- Fuel pump name plate data (manufacturer, capacity/fuel flow, horsepower/kilowatts, RPMs)

- Piping diagram with pipes dimensions

- Fuel control systems

- Manufacturer, type, and accuracy of the fuel level/amount measurement in main tanks

- Manufacturer, type, and accuracy of the fuel level/amount measurement in day tanks

○ Potential location of flow meters 
Appendix D: Building Economics Model (BEM 9.1) Description and User Manual 
Task 8

D-ii 


\section{Table of Contents}

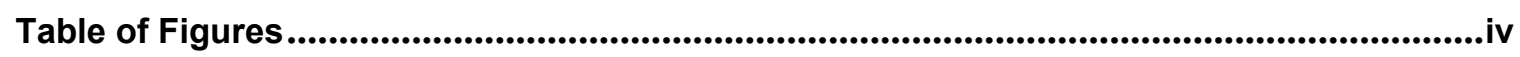

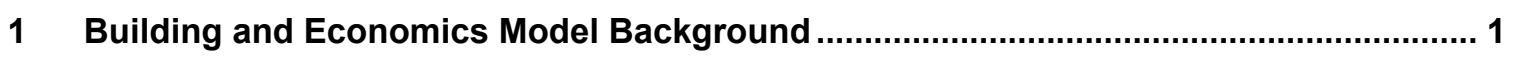

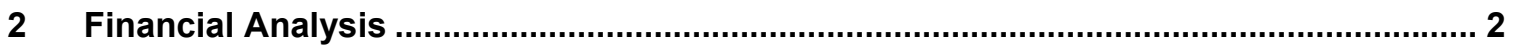

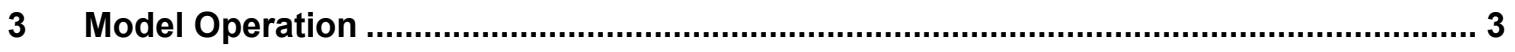

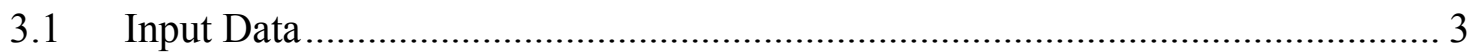

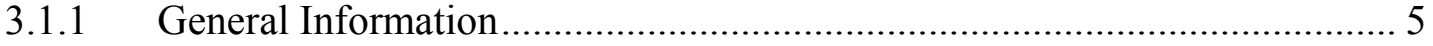

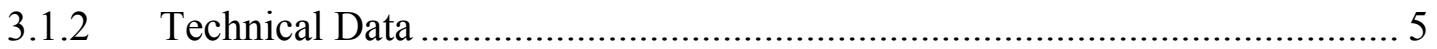

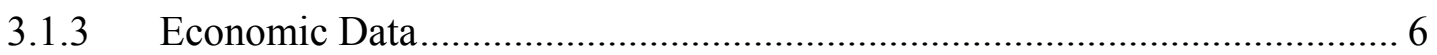

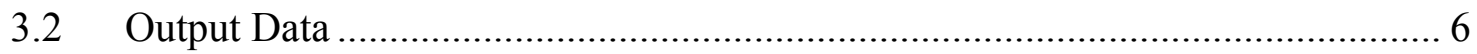

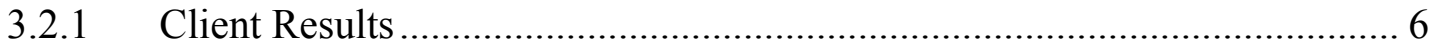

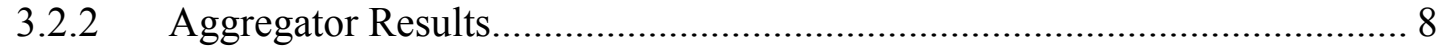

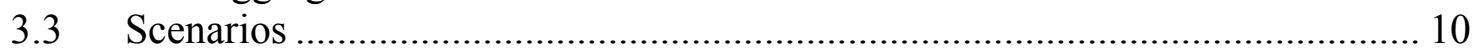




\section{Table of Figures}

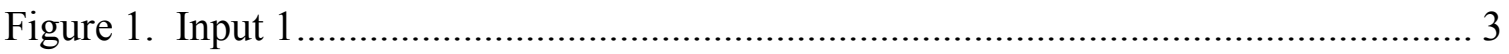

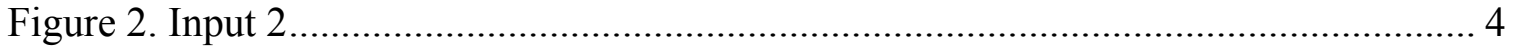

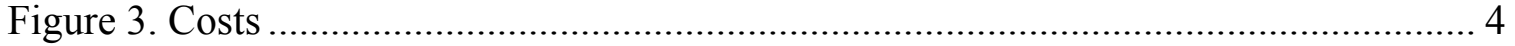

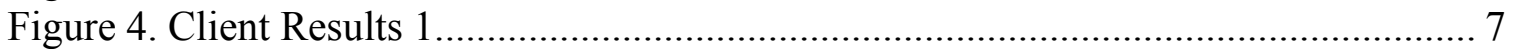

Figure 5. Project Cost, Revenues and Operating Expenses ............................................. 8

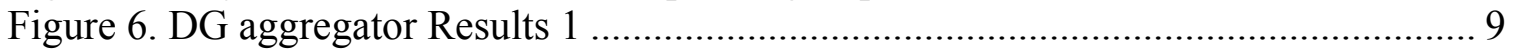

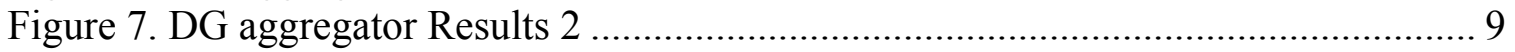




\section{$1 \quad$ Building and Economics Model Background}

Spreadsheet model BEM 9.1 has been developed to examine the financial benefits (or losses) of integrating a new distributed generator into the distributed generation (DG) aggregation system. The spreadsheet is written in Microsoft Excel and is straightforward. It allows users to perform a number of cash flow analyses to determine the best option for the DG incorporated into the system. 


\section{Financial Analysis}

The model provides both the DG owner and the DG with the following project financial indicators on a monthly basis:

- Internal rate of return

- Net present value at the discount rate of $12 \%$

- Payback period.

The model calculates the financial indicators for five evaluation periods: $1,2,3,4$, and 5 years.

Cash flow analysis is based on estimations of the owner's and aggregator's project development costs, monthly operating expenses, and monthly revenues from capacity and electric energy sales and electric energy savings. 


\section{Model Operation}

The model is operated through several screens. Three screens are used to input technical and economic data, and the results of analyses are presented separately for the DG aggregator, DG owner, and partner (if any) of the DG aggregator.

\subsection{Input Data}

Three types of data are input into the model. The first screen, "Input 1" (Figure 1), contains general and technical information. The second screen, "Input 2" (Figure 2), contains economic data. All information can be selected from pop-up menus or directly entered into relevant cells.

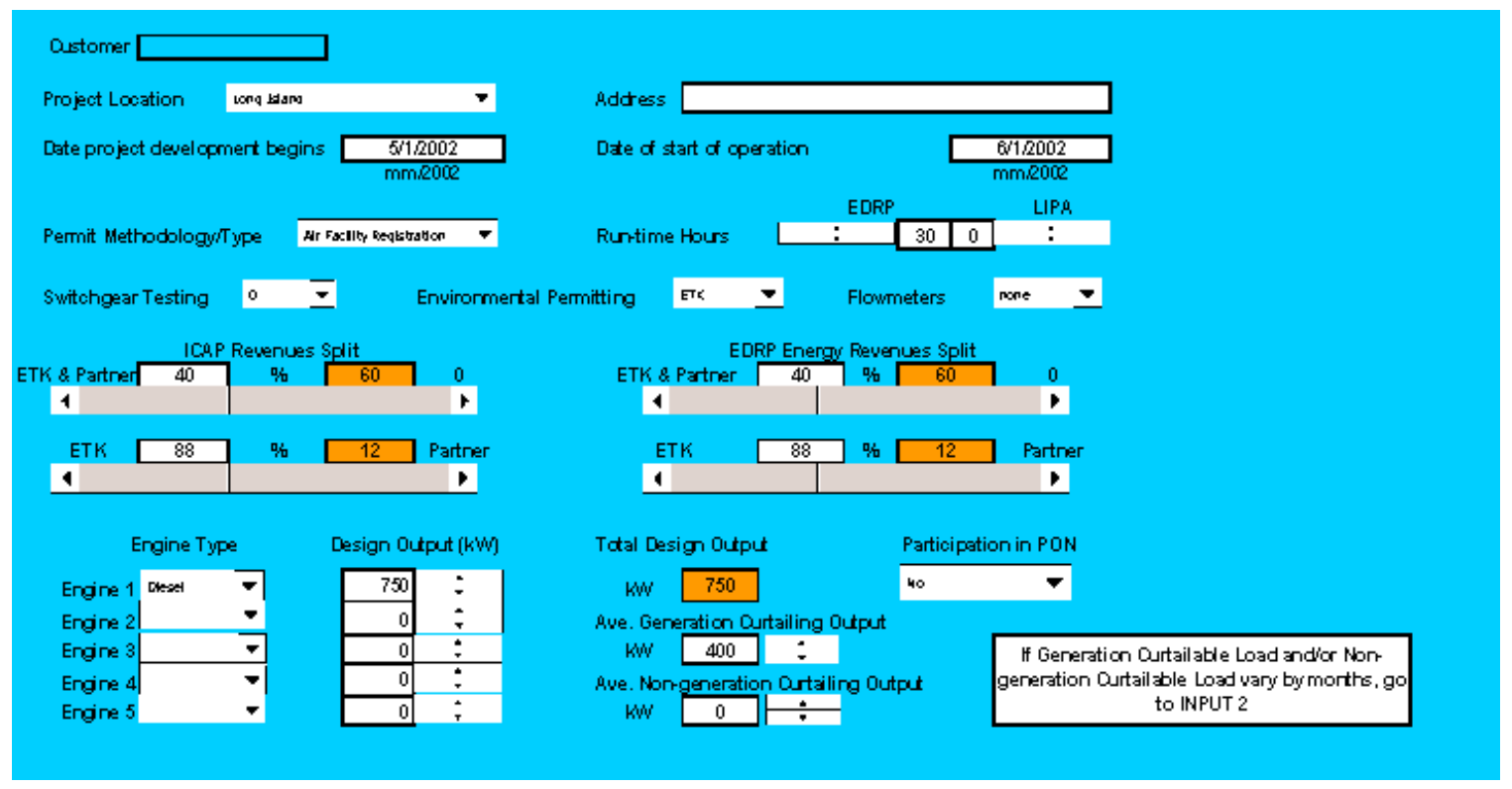

Figure 1. Input 1 


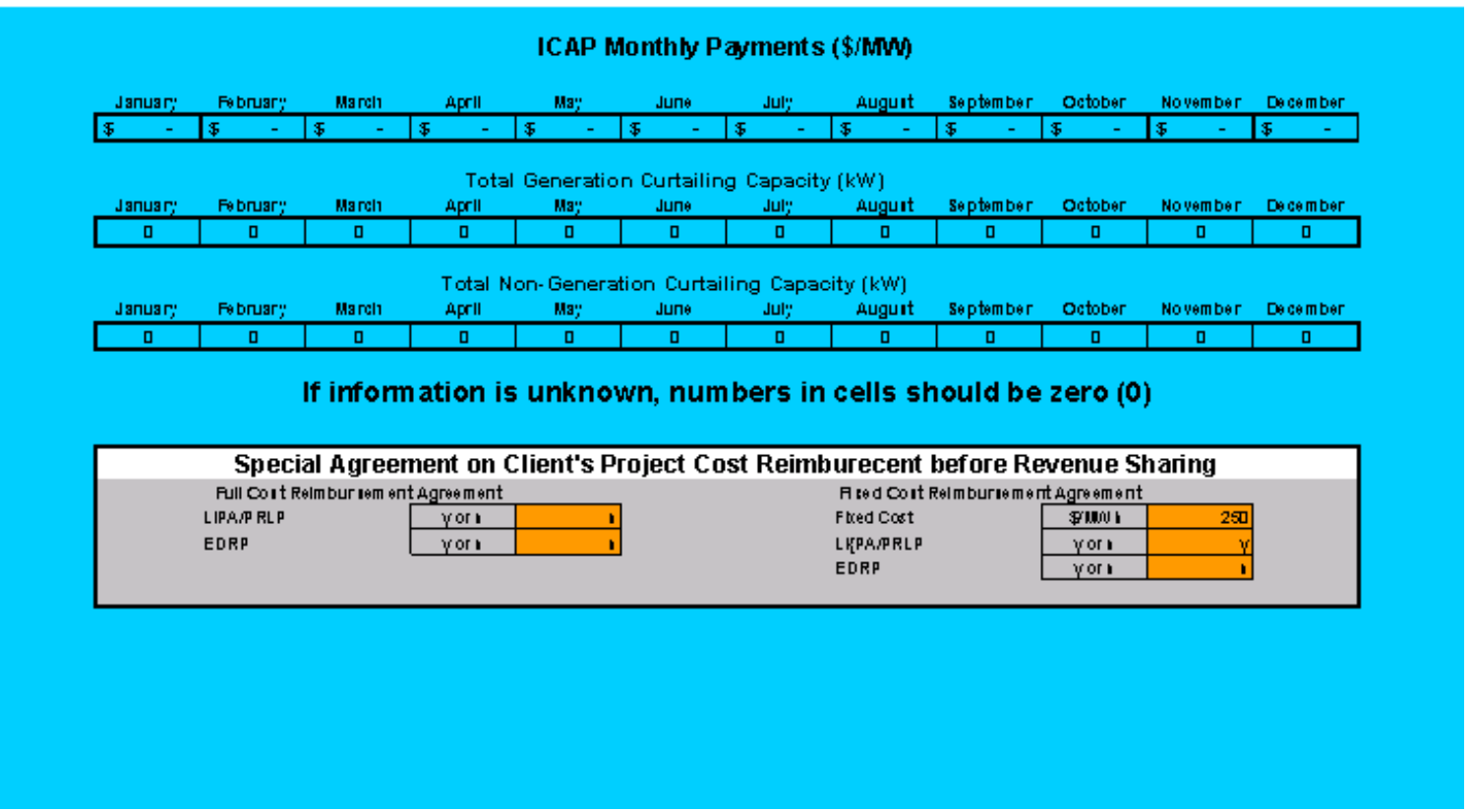

Figure 2. Input 2

Default costing information is presented on the costs screen (Figure 3). This information can be updated in the white fields to the left of the default values.

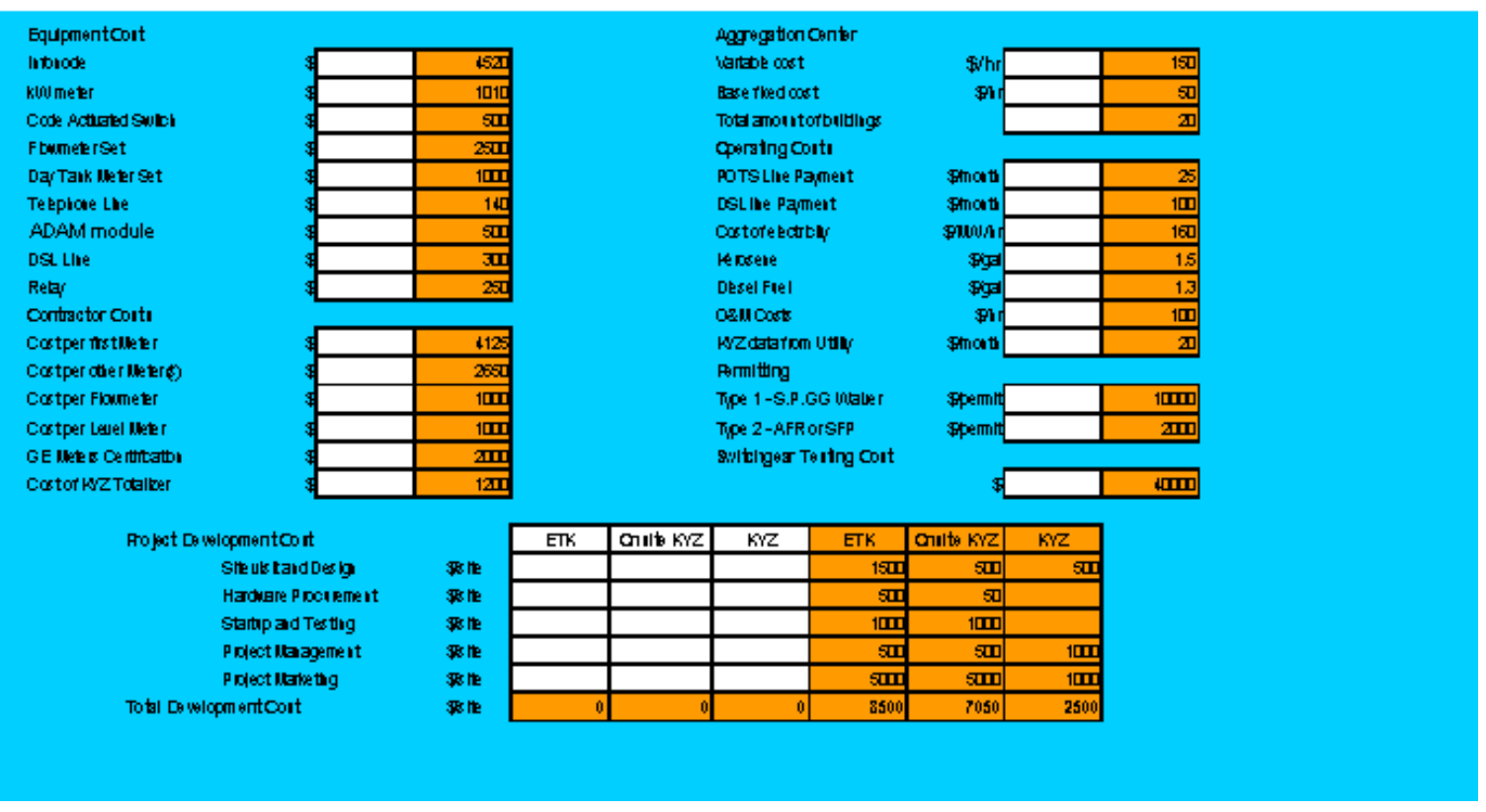

Figure 3. Costs 


\subsubsection{General Information}

General information includes:

- Customer (DG owner) name

- Generator location (Select from Long Island, New York, or Rest of NY State.)

- Facility address

- Data project development begins (format mm/yyyy)

- Data of start of operation after construction (format mm/yyyy)

- Permit methodology/type (Select from air facility registration or state facility permit.)

- Run-time hours (expected hours of operation per year) If the facility is expected to participate in the load reduction programs of the New York Independent System Operator and Long Island Power Authority, these hours should be shown separately.

- Switchgear testing

This shows which party is paying for the switchgear testing if such testing is required. (Select from ETK, owner, or none.)

- Environmental permitting (Select from ETK, owner, or none.)

- Flow meters

These determine if fuel flow meters are required and who is pays for the installation. (Select from ETK, owner, or none.)

\subsubsection{Technical Data}

Technical information can be provided for up to five engines at the same facility. The information required for each of these engines is:

- Engine type

(Select turbine or diesel.)

- Engine design output

- Total engines design output (Updates automatically)

- Average generation curtailing output This is the total building curtailing load in kilowatts. (Select or type the building average curtailing load in kilowatts.) 
- Average non-generation curtailing load

This is the building load that could be curtailed by measures other than running generators. (Select or type the building average non-generation curtailing load in kilowatts.)

\subsubsection{Economic Data}

The input parameters include:

- Capacity revenues split ratios (shares of revenues from capacity sales)

- Ratio of splitting revenues between DG owner and DG aggregator, including aggregator's partner (Type in the percentage for ETK, or select it by moving the bar.)

- Ratio of splitting revenues between DG aggregator and aggregator's partner

(Type in the percentage for ETK, or select it by moving the bar.)

- Electric energy revenues split ratio (share of revenues from electric energy sales)

- Ratio of splitting revenues between DG owner and DG aggregator, including aggregator's partner

(Type in the percentage for ETK, or select it by moving the bar.)

- Ratio of splitting revenues between DG aggregator and aggregator's partner

(Type in the percentage for ETK, or select it by moving the bar.)

- Projection of monthly ICAP payments per megawatt

- Full cost reimbursement agreement

$\circ$ Availability

- Fixed cost $(\$ / M W h)$

\subsection{Output Data}

The results of calculations are presented in three sections: Client Results, Aggregator Results, and Partner Results.

\subsubsection{Client Results}

The client results screen contains two tables. The upper table (Figure 4) presents the following benefits of the DG owner:

- Annual ICAP revenues

The DG owner's share of revenues from capacity sales. It is a reservation payment to the DG owner, who has agreed to operate his generators in response to an activation call. 
- Total annual energy revenues

The DG owner's share of revenues from electric energy sales. In DG projects in which capacity has been sold, the owner of the capacity is obligated to operate the DG in response to an activation call.

- Total annual cost reimbursement

- Savings on electricity payments

For projects in which the owner intends to operate his generator instead of purchasing electricity from the distribution company, energy savings are based on the costs that would have been incurred.

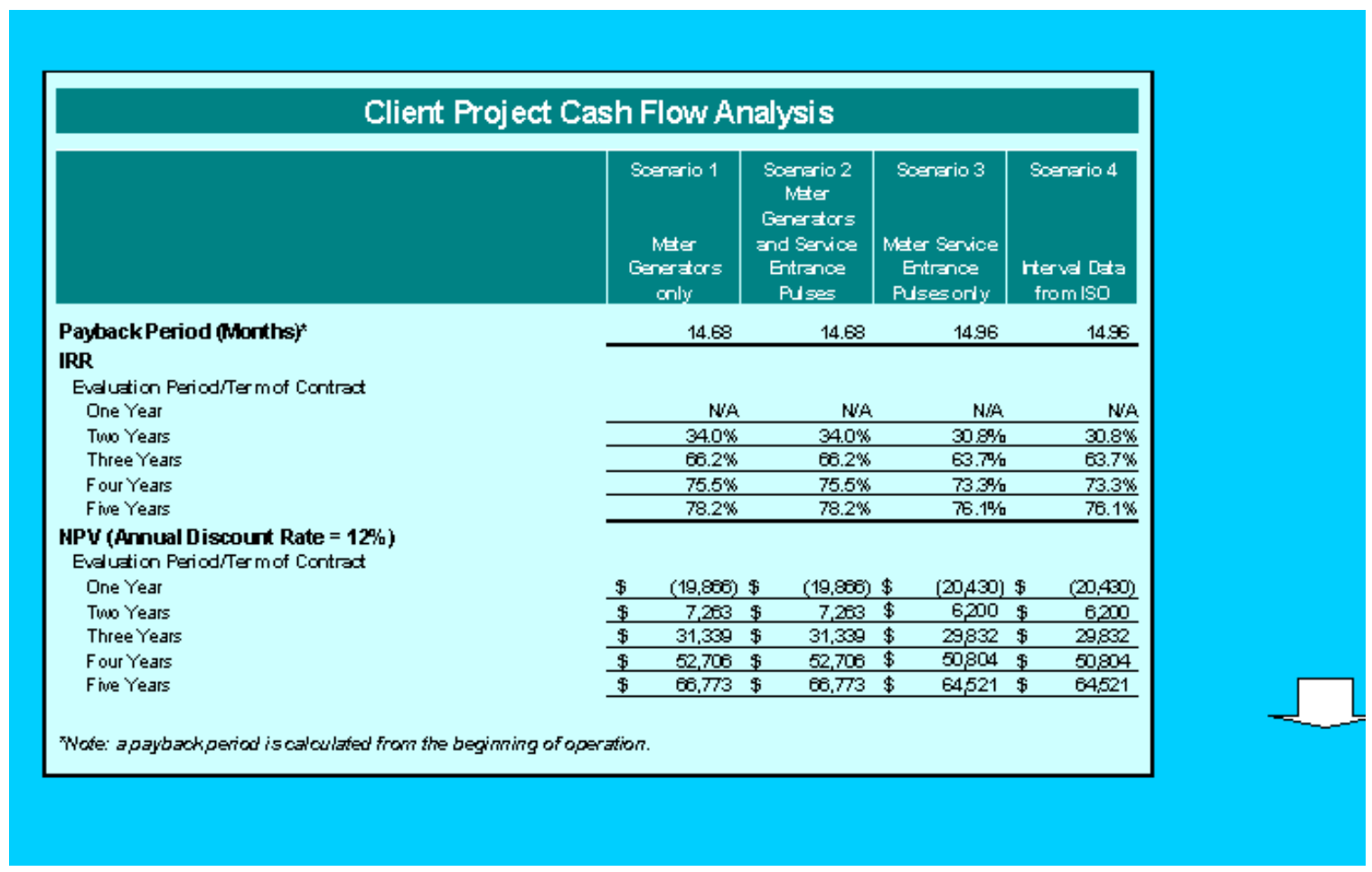

Figure 4. Client Results 1

The lower table on the same screen (Figure 5) presents the following DG owner project costs and operating expenses:

- Project cost

- Equipment cost

- Equipment installation cost

- Project development cost

- Project annual operating expenses

- Fuel cost

○ Non-fuel cost 


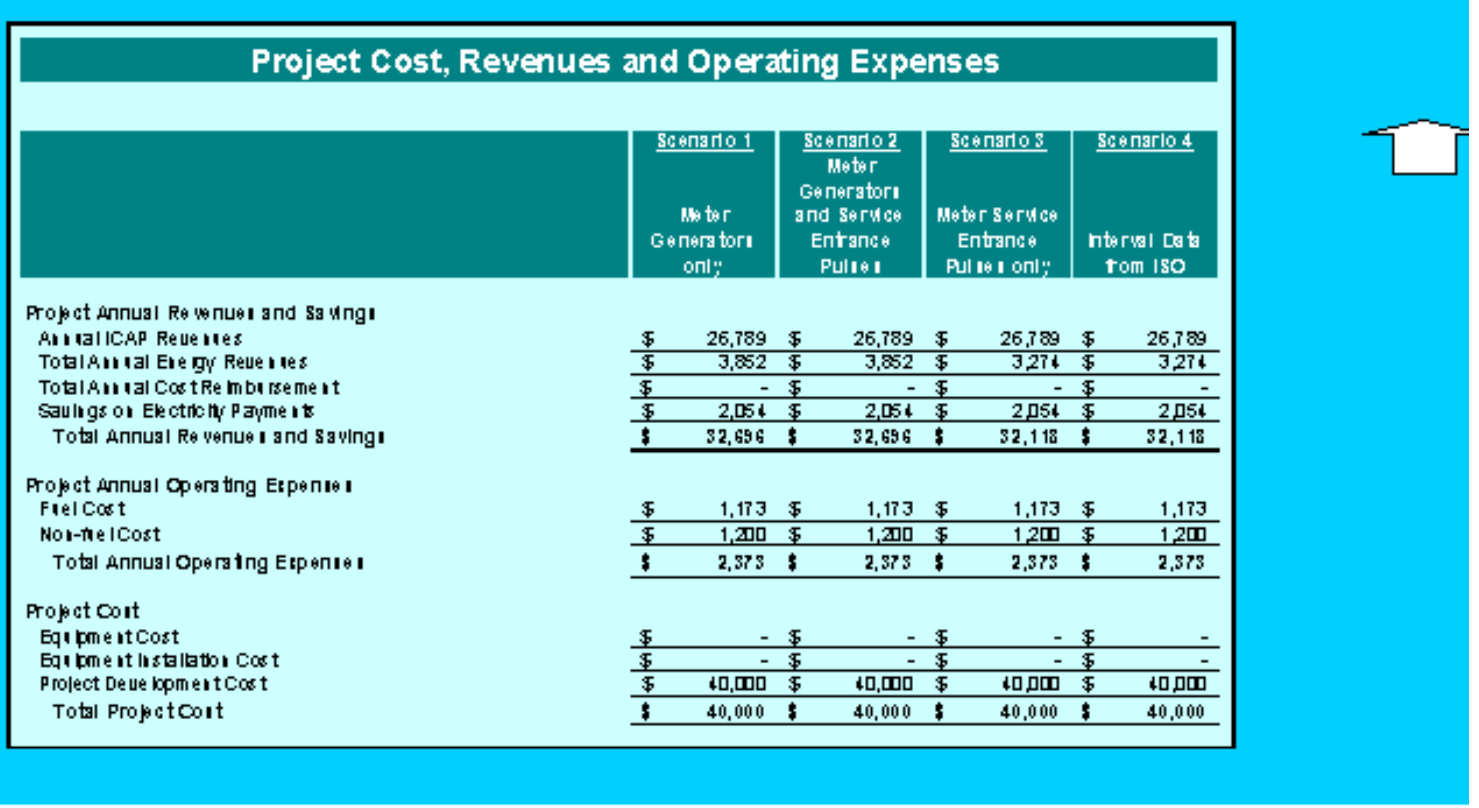

Figure 5. Project Cost, Revenues and Operating Expenses

\subsubsection{Aggregator Results}

The ETK results screen also contains two tables. The upper table (Figure 6) presents the following benefits of the DG aggregator:

- Annual ICAP revenues

These are the DG aggregator's share of revenues from capacity sales.

- Annual energy revenues

These are the DG aggregator's share of revenues from electric energy sales.

The lower table (Figure 7) presents the following DG aggregator's project costs and operating expenses:

- $\quad$ Project cost

$\circ$ Equipment cost

- Equipment installation cost

○ Project development cost

- Project annual operating expenses

- Aggregation and report center

- Buying pulses from LSE

- Telephone line. 


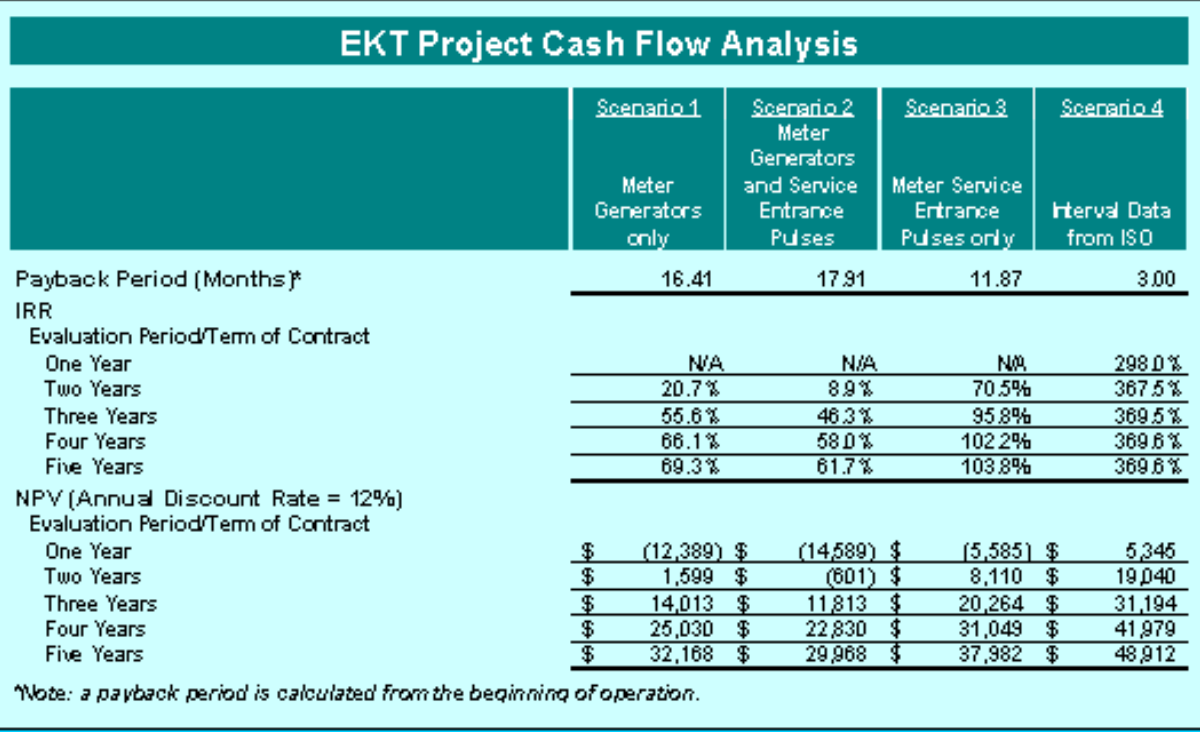

Figure 6. DG aggregator Results 1

\section{ETK Project Cost, Revenues and Operating Expenses}

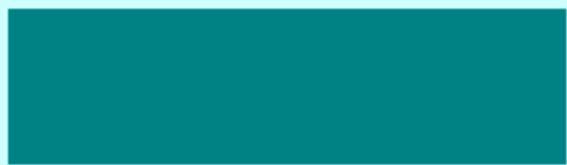

\begin{tabular}{|c|c|}
\hline Scenario 1 & $\frac{\text { Scanario } 2}{\text { Meter }}$ \\
& Generators \\
Meter & and Service \\
Generators & Entrance \\
only & Puses
\end{tabular}

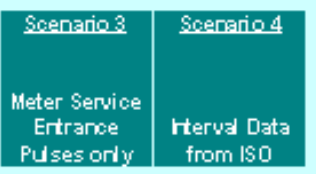

Project Arrual Reverues and Savings Annual ICAP Revenues

Annual Energy Revenues

Tdal Anrual Reverues and Savings

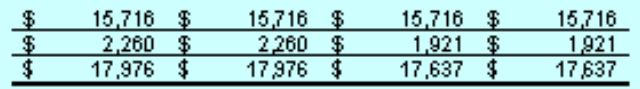

Project Arrual Operating Experses

Aggregation and Report Center

Buying Pulses rom LSE

Telephone line

Tatal Arrual Operating Experses

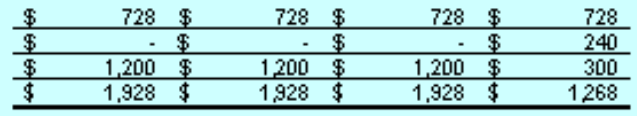

Project Cost

Equipment Cost

Equipment installation Cost

Project Development Cost

Tatal Project Cost

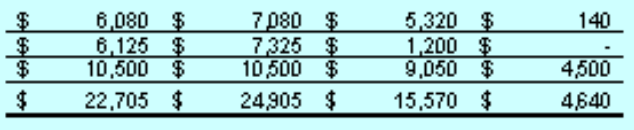

Figure 7. DG aggregator Results 2 
In addition, the partner results screen indicates the following benefits of the partner of the DG aggregator:

- Annual ICAP revenues

These are the DG aggregator partner's share of revenues from capacity sales.

- Annual energy revenues

These are the DG aggregator partner's share of revenues from electric energy sales.

\subsection{Scenarios}

The program is conducting cash flow analyses for four scenarios simultaneously.

The differences among the scenarios are in the scope and design of monitoring equipment to be installed at the generator(s).

\section{Scenario 1}

This scenario includes the installation of a full set of monitoring equipment (electric meters on each generator) on the generation site, an InfoNode for data collection and temporary storage, and a regular telephone line or DSL for data transfer to the KX Data Collection and Management Center.

\section{Scenario 2}

This scenario includes the equipment described in Scenario 1. In addition, it includes equipment for the collection of information about the total building load from commercial service. (This is the most expensive capital investment)

\section{Scenario 3}

This scenario includes only the installation of equipment necessary for the collection of information on building load from commercial power service.

\section{Scenario 4}

This scenario does not include the installation of any equipment on-site. The information about building load is to be purchased at the end of every moth from the electricity

provider. (This is the least expensive capital investment). 
Appendix E: Hunt for Coincident Peak 
Task 8

E-ii 


\section{Table of Contents}

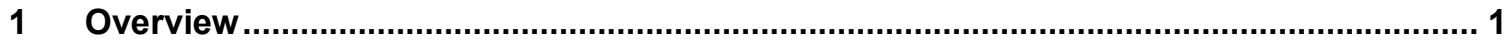

2 Peak-Hunting Advisory Based on Temperature-Humidity Index Analysis...................... 2

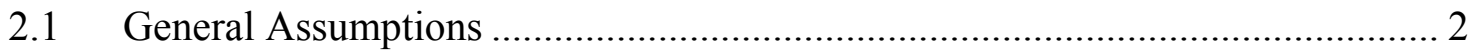

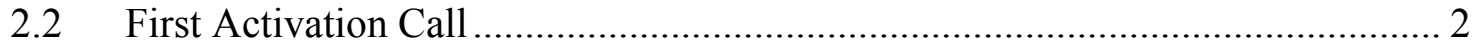

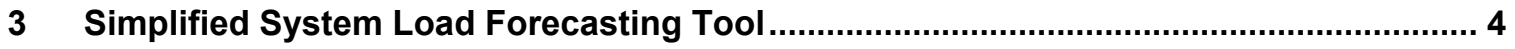

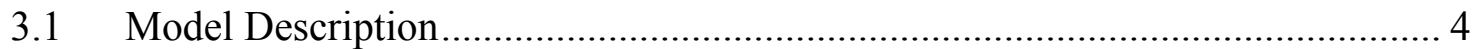

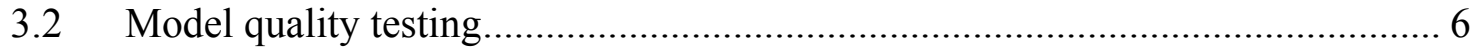




\section{Overview}

The ICAP requirement of an LSE in New York State is based on the collective demand of its aggregated customers (by zone) at the one-hour system peak in the zone. In fact, for summerpeaking zones (all but one in New York State) the coincident peak, by definition, occurs from June through September.

For most cases, the LSE contribution is imputed by estimating its contribution to the system peak based on the collective consumption of its customers relative to the total in each zone.

However, an LSE has the option of measuring its actual demand at the peak hour and having its next year's ICAP requirement determined using that measurement. Therefore, it is acceptable for the generator owner or operator to operate the engines during the LIPA coincident peak. If the owner/operator is successful in this task, then the ICAP requirement for the following year will be zero.

The challenge of this approach is guessing when the hour of system peak will occur. It would be easy to run engines every time the temperature (or temperature-humidity index) is predicted to be higher than at any previous day. But usually, generator owners want to limit the hours of operation for two reasons:

- To minimize the net cost of operation

- To adhere to the New York State Department of Environmental Conservation permit, which limits the hours each engine can operate.

Therefore, a peak-hunting strategy should be developed with the goal of not missing a season coincident peak while not running more than 10 hours per month during the peak-hunting season. This strategy should be able to predict:

- When the first activation should be called at the beginning of the peak season (June through September)

- Each activation thereafter. 


\section{Peak-Hunting Advisory Based on Temperature-Humidity Index Analysis}

To accomplish the major goal (catch the season system coincident peak), the strategy was broken down into several steps, which are described below.

\subsection{General Assumptions}

Several general assumptions were made for future developments of the peak-hunting strategy:

- A system coincident peak usually happens on Monday, Tuesday, Wednesday, or Thursday.

- A peak usually happens during the mid-day hours from 12 p.m. to 6 p.m.

- A system load is well correlated with weather conditions, namely with ambient temperature and humidity. In fact, these correlations are used by the NYISO in its system load prediction tool.

\subsection{First Activation Call}

The first option is to select the time for the first activation call based on the NYPA call. The NYPA has succeeded the past several years. In addition, the Long Island Power Authority peak load reduction program works the same way, and it has also succeeded in hitting the peak.

However, it is difficult to select the first activation call during mild weather. There are dangers of selecting a mild peak point that could be frequently exceeded and missing a mild peak that doesn't get exceeded. To avoid both situations, the following strategy could be used.

To select a first call, it is necessary to know how close the current summer (month) is to average (normal). Each month, the National Oceanic and Atmospheric Administration provides a forecast for the mean temperature of the following month. This means temperature forecast could be compared with the average (20- or 5-year) mean temperature for the month of interest. This will indicate if the month of interest is expected to be cooler or hotter than average.

Next, the historical average peak temperature for the same period is determined and compared with the historical mean temperature, and the deviation of difference between these two temperatures should be determined. This delta (difference) applied to the forecasted mean temperature can provide an indication of the potential peak temperature for the month of interest. For the conservative assumptions, the lower value of the peak temperature deviation could be used as a flag or alert temperature of when the system peak could be expected. Now the LSE operators should watch for available weather forecasts, and as soon as the forecast predicts the flag weather, the decision on running the generators should be made. Several tools and techniques were developed by Electrotek Concepts Inc. to help make such decisions.

\subsubsection{Consequent Activations}

The peak-hunting advisory was developed to support system resource efforts to hunt for the system coincident peak. 
The following criteria form the basis of the program:

- Engines should be operated from 2 p.m. to 6 p.m. on days when the temperaturehumidity index is predicted to be higher than what it was when engines (a) were scheduled to run for the first time in the season or (b) were run the last time.

- Engines will not run at Fridays, Saturdays, and Sundays.

- The forecast for the temperature-humidity index for the day after the target day is lower than for the target day.

The peak-hunting advisory will make a "run" or "do not run" advisory based on the above criteria. 


\section{$3 \quad$ Simplified System Load Forecasting Tool}

An alternative method for predicting the coincident system peak is to compare the forecasted system load with the previous system peak. The NYISO has at its disposal a comprehensive forecast tool that is based on advanced neural network and regression models. This tool is able to predict hourly loads, daily peaks, monthly peaks, and energy demand for all zones of the New York Power Pool for the next 5 days. The results of this forecast are placed on the NYISO Web site and are open to the public. These results contain hourly electric load for each of New York Power Pool zones for the next 5 days. The file is updated every day with new weather forecast data. The accuracy of load prediction is on average in the range of $5 \%$ to $12 \%$ and has a tendency for improvement if weather prediction becomes more accurate. For example, the average accuracy of the 3-days-ahead forecast is in the range of $9 \%$ to $12 \%$, and the 1-day-ahead forecast has usually $5 \%$ to $7 \%$ accuracy. This forecast is used to balance supply and demand through the day-ahead energy market. Unfortunately, the last forecast is usually developed at 8 a.m. of the previous day, and sudden weather condition changes can cause dramatic differences between forecasted and real load values. The New York Power Pool zone load forecasting models are not open to the public and therefore cannot be used for last-moment forecasting in peak-hunting efforts.

An attempt was made to develop a simplified load-forecasting tool. This tool was developed for relatively narrow time and weather conditions spans for the prediction of the combined load for zones $\mathrm{J}$ and $\mathrm{K}$. Zones $\mathrm{J}$ and $\mathrm{K}$ were addressed because:

- The combined load of these two zones represents almost half of the total New York State load

- These two zones are well correlated with each other

- All generators aggregated so far by Electrotek Concepts Inc. are located in these two zones.

\subsection{Model Description}

Because a coincident peak would most likely happen during a hot day when air-conditioning systems are in operation, the algorithm built to forecast combined electric load in zones $\mathbf{J}$ (New York City) and K (Long Island) is for:

- Working days Monday through Thursday

- Each hour between 12 p.m. and 6 p.m.

- Air ambient temperature above $66^{\circ} \mathrm{F}$.

The relatively narrow condition window and lack of resources necessary for the development of a comprehensive model suggest using a simplified linear regression model. 
Historical hourly load data for the K and J zones of the New York Power Pool for May, June, July, and August of 2002 were obtained from the NYISO Web site. Historical weather information for New York City (Central Park) was obtained from the National Oceanic and Atmospheric Administration Web site. A linear regression equation was used to correlate load and weather data. Usually, the system load is well correlated with the temperature-humidity index, which is determined as a complicated function of the dry bulb ambient air temperature and ambient relative humidity. Correlations of system load versus the temperature-humidity index and system load versus ambient air temperature were tested, and the correlation of load versus ambient air temperature was selected as more accurate. To follow typical daily system load patterns, separate equations were developed for each hour from 12 p.m. to 4 p.m. for four business days - Monday, Tuesday, Wednesday, and Thursday - because the preliminary analysis shown that the system load at Friday is usually much lower than for other business days. All equations are presented in Table 1.

Table 1. Load Forecast Equations

\begin{tabular}{cc}
\hline Time & Equation \\
\cline { 2 - 2 } 12 p.m. & $\mathrm{L}=228.76^{*} \mathrm{~T}-6834.5$ \\
1 p.m. & $\mathrm{L}=216.64^{*} \mathrm{~T}-5723.2$ \\
2 p.m. & $\mathrm{L}=237.56^{*} \mathrm{~T}-7347.2$ \\
3 p.m. & $\mathrm{L}=233.37^{*} \mathrm{~T}-7502.5$ \\
4 p.m. & $\mathrm{L}=241.49^{*} \mathrm{~T}-7403.2$ \\
5 p.m. & $\mathrm{L}=245.72 x^{*} \mathrm{~T}-7588.5$ \\
6 p.m. & $\mathrm{L}=251.23^{*} \mathrm{~T}-8051$ \\
\hline
\end{tabular}

On the basis of these equations, a simplified system load prediction tool was built as an Excel spreadsheet model. The input is a set of forecasted dry bulb temperatures for each hour from 12 p.m. to 6 p.m. The output is an hourly combined load for zones J and K. 

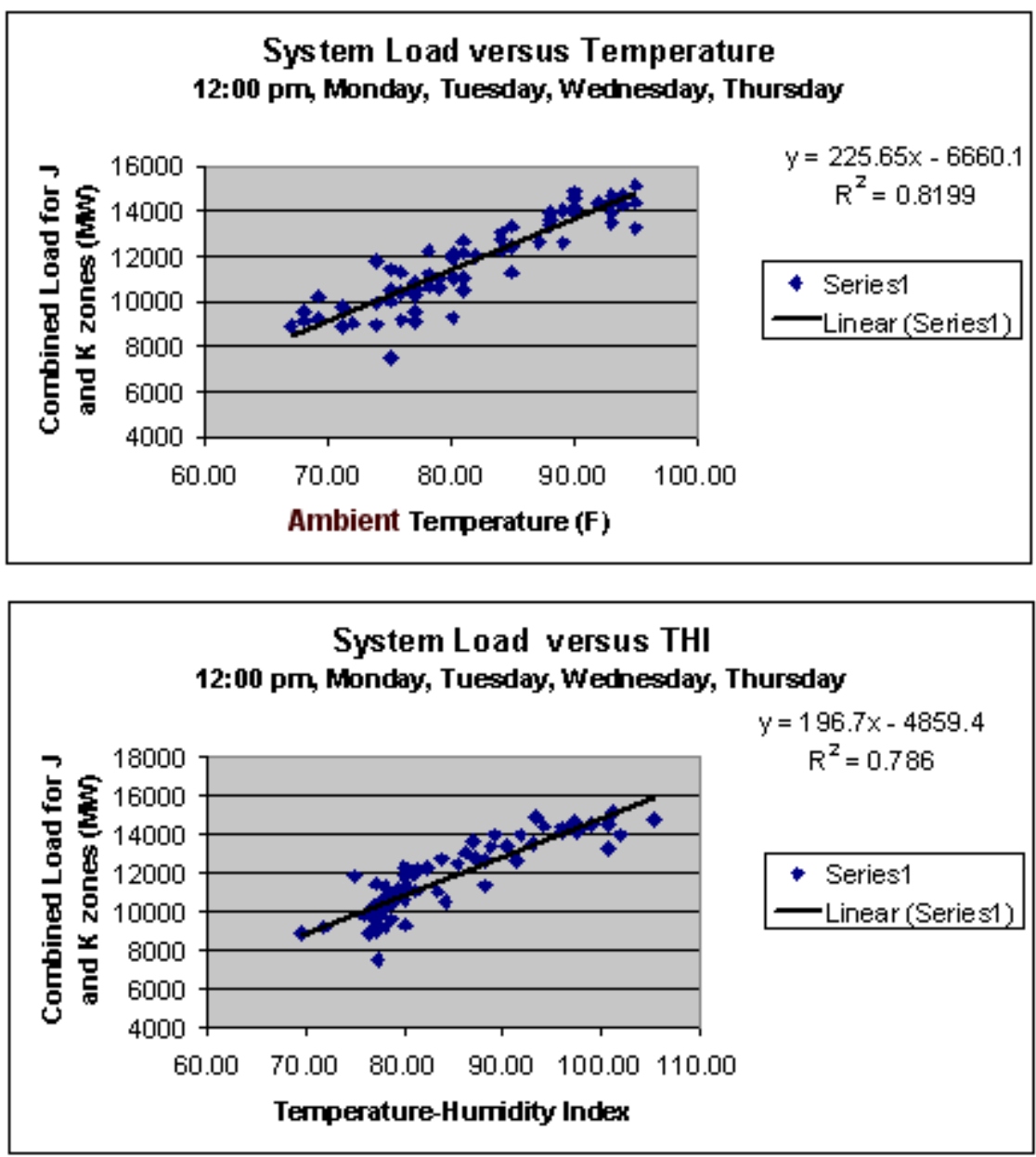

Figure 1. System load correlations

\subsection{Model quality testing}

The model was tested by comparing the forecasted load with forecasts made by the NYISO and real system load values for several hot days during the summer of 2002. Results are presented in Table 2 . 
Table 2. Comparison of Model With NYISO Forecasts

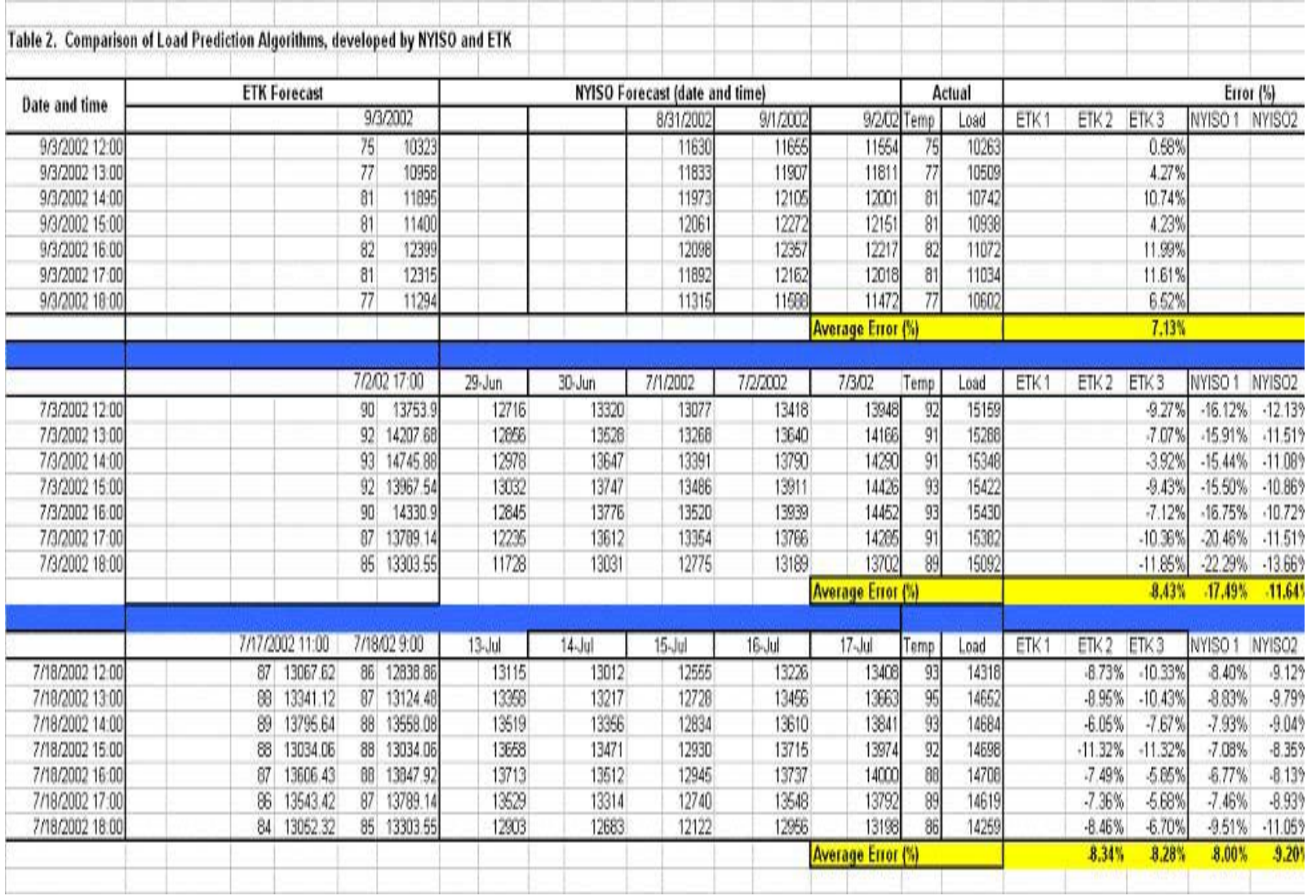

Here, the first section has date and time information for the target day.

The second section contains information about (a) forecasted ambient air dry bulb temperature (taken from the Electrotek Concepts Inc. database on temperature forecast) and (b) combined hourly system load for zones J and K, calculated by the Electrotek Concepts Inc. forecasting tool. The line above the weather and load information shows the time when the weather forecast for the target day was obtained. For example, for July 18, hourly temperatures predicted at 11 a.m. July 17 and at 9 a.m. July 18 were used.

The third section contains information about load forecast developed at 8 a.m. every day for 5 days before the target day. For example, for July 18, these forecasts were prepared from July 13 to July 17.

The next section shows actual dry bulb temperature and the system load for zones $\mathrm{J}$ and $\mathrm{K}$. 
The last section contains error values, calculated as the difference between predicted and actual load values and presented as a percentage of the actual load. Several observations could be made:

- The accuracy of the load forecast for both NYISO and Electrotek Concepts Inc. models is dependent on the accuracy of the algorithm itself and the accuracy of the weather predictions.

- The NYISO forecast becomes more accurate the closer it is made to the target day. Although the accuracy of the forecast made 5 days before the target day is from $10 \%$ to $20+\%$, the average error of the forecast becomes $6 \%$ to $7 \%$ when it is made the day before the target day. Most likely, it is because of the improved weather forecast. When the difference between predicted and actual temperature is within $2^{\circ}$ to $4^{\circ}$, the error of the NYISO forecast is in the range of $4 \%$ to $6 \%$.

- Electrotek Concepts Inc.'s forecast has an average error in the range of 7\% to $8.5 \%$. When the difference between predicted and actual temperatures is within $2^{\circ}$ to $4^{\circ}$ degrees, the error of Electrotek Concepts Inc.'s forecast is in the range of 5\% to 7\%.

The accuracy of the Simplified System Load Forecast Model is less than the accuracy of the NYISO New York Power Pool Load Forecast model but in the range acceptable for the peakhunting activities. 


\section{REPORT DOCUMENTATION PAGE}

Form Approved

OMB NO. 0704-0188

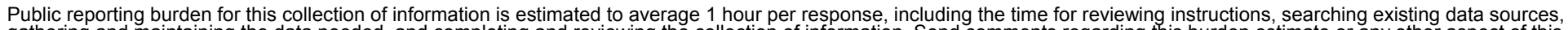

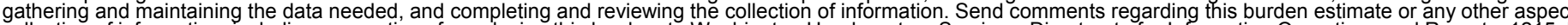

collection of information including suggestions for reducing this burden, to Washington Headquarters Services, Directorate for Information Operations and Rep

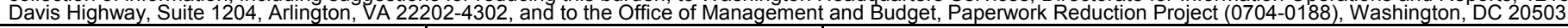
1. AGENCY USE ONLY (Leave blank)
2. REPORT DATE
April 2004
3. REPORT TYPE AND DATES COVERED
Subcontract

4. TITLE AND SUBTITLE

Aggregation of Distributed Generation Assets in New York State: Appendix

5. FUNDING NUMBERS

6. $\mathrm{AUTHOR}(\mathrm{S})$

Electrotek Concepts Inc. and New York State Energy Research and Development

Authority

7. PERFORMING ORGANIZATION NAME(S) AND ADDRESS(ES)

Electrotek Concepts Inc.

8. PERFORMING ORGANIZATION REPORT NUMBER

2111 Wilson Boulevard, Suite 323

Arlington, VA 22201

9. SPONSORING/MONITORING AGENCY NAME(S) AND ADDRESS(ES)

National Renewable Energy Laboratory

1617 Cole Blvd.

Golden, CO 80401-3393

DP04.1001

11. SUPPLEMENTARY NOTES

NREL Technical Monitor: Holly Thomas

12a. DISTRIBUTION/AVAILABILITY STATEMENT

National Technical Information Service

U.S. Department of Commerce

5285 Port Royal Road

Springfield, VA 22161

13. ABSTRACT (Maximum 200 words)

This report appendix describes aspects of a project to demonstrate the technical and economic feasibility of aggregating distributed generating resources in New York State. This project demonstrates a system that allows distributed generation (DG) to participate in competitive markets in much the same way as large central-station power plants. This approach involves aggregating the distributed demand-side resources into a single transaction entity consistent with the requirements of the New York Independent System Operator (NYISO). This single entity then buys or sells capacity and energy (i.e., curtailment) in NYISO markets.

14. SUBJECT TERMS aggregated power; power markets; virtual utility; distributed generation; distributed power; distributed energy; DG; DP; DER; New York; Distribution and Interconnection R\&D; National Renewable Energy Laboratory; NREL

17. SECURITY CLASSIFICATION OF REPORT Unclassified
18. SECURITY CLASSIFICATION OF THIS PAGE Unclassified
19. SECURITY CLASSIFICATION OF ABSTRACT Unclassified
15. NUMBER OF PAGES

16. PRICE CODE

20. LIMITATION OF ABSTRACT

UL 